MARK J GREENING

\title{
FROM ADJUSTMENT TO APPORTIONMENT IN THE GOODS AND SERVICES TAX ACT: A COMPARATIVE ANALYSIS OF THE CHANGE-IN-USE RULES IN AUSTRALIA, CANADA, AND NEW ZEALAND
}

LLM RESEARCH PAPER

THESIS (LAWS 591)

FACULTY OF LAW VICTORIA UNIVERSITY OF WELLINGTON 
MARK J GREENING

\section{FROM ADJUSTMENT TO APPORTIONMENT IN THE GOODS AND SERVICES TAX ACT: A COMPARATIVE ANALYSIS OF THE CHANGE-IN-USE RULES IN AUSTRALIA, CANADA, AND NEW ZEALAND}

LLM RESEARCH PAPER

THESIS (LAWS 591)

FACULTY OF LAW VICTORIA UNIVERSITY OF WELLINGTON 


\section{ABSTRACT}

All countries that have adopted Goods and Services Tax (GST) or Value Added Tax (VAT) employ a 'change-in-use' mechanism to distinguish consumption from the stages of production and distribution. New Zealand's former change-in-use rules were unique. Unlike the 'use' based apportionment approaches employed in Australia, Canada and the United Kingdom, New Zealand employed an adjustment approach that utilised a 'principal purpose' test and deemed supply mechanism. While Canada has also employed an adjustment approach for capital property, the New Zealand rules have operated differently to those in Canada. In response to criticism for being overly complex and confusing, the New Zealand change-in-use rules will adopt a new 'use' based apportionment approach, together with a new mechanism to constrain the number of adjustments, from 1 April 2011 for a number of taxpayers. Applying criteria identified by the Tax Working Group the performance of New Zealand's change-in-use rules are examined, in comparison to those applied in Australia and Canada. In addition, the comparative readability of the change-inuse provisions in all three jurisdictions is examined. The paper concludes that New Zealand should adopt an apportionment approach and that the Goods and Services Tax Act should be rewritten for improved readability.

\section{Word Length}

The text of this paper (excluding abstract, table of contents, footnotes, bibliography and appendices) comprises approximately 50,000 words.

Taxation - Indirect tax - Change-in-use 


\section{CONTENTS}

Introduction 1

A. The Change-in-Use Rules ……............................................................. 1

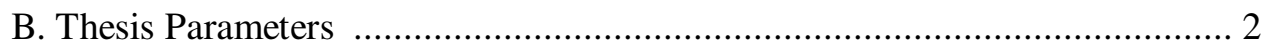

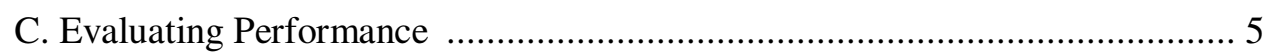

D. The United Kingdom Experience …….....................................................10

E. A Brief Overview of How GST Works in New Zealand ..............................13

$\begin{array}{ll}\text { Chapter } 1 \text { The New Zealand Experience } & 17\end{array}$

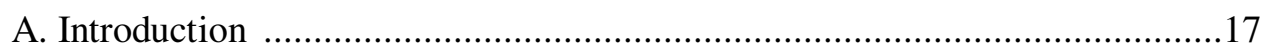

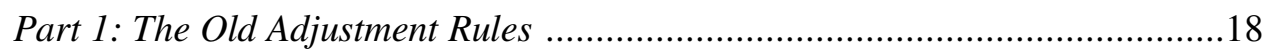

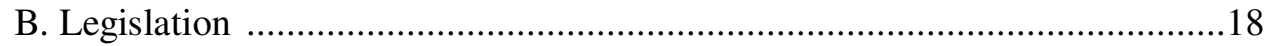

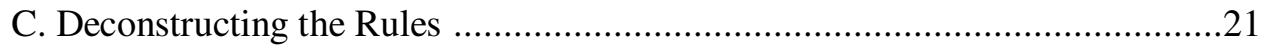

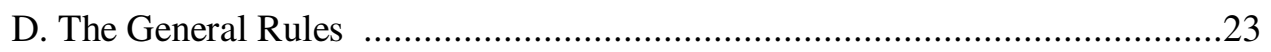

Part 2: Implementation and Operation - Empirical Evidence ............................32

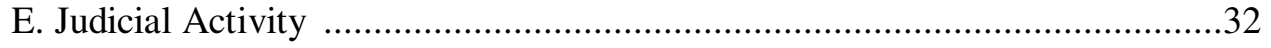

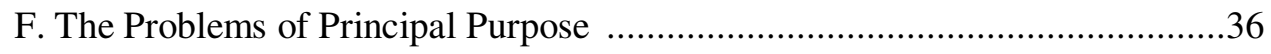

G. The Problems of Calculating Adjustments ...................................................52

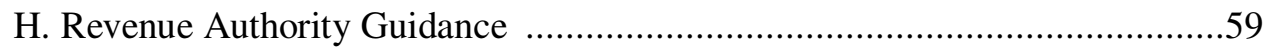

I. The Problem of Compliance: A Chorus of Concerns ....................................61

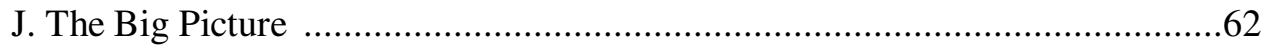

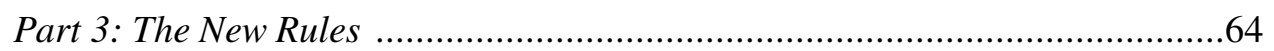

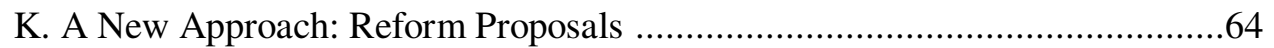

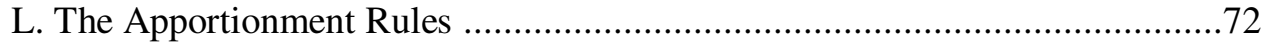

M. Some Comparative Observations of the Two Approaches ...........................78

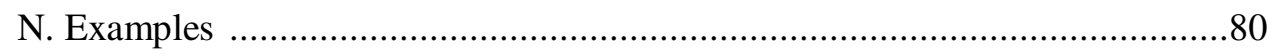

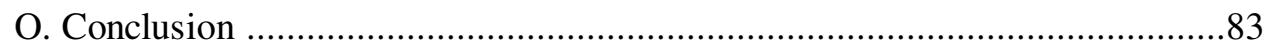

$\begin{array}{lr}\text { Chapter 2 The Australian Experience } & 85\end{array}$

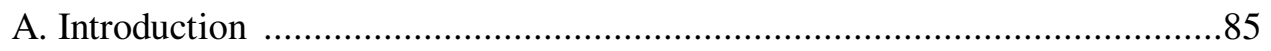




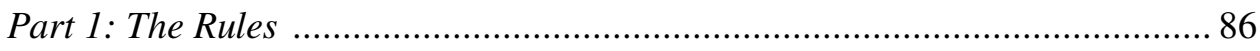

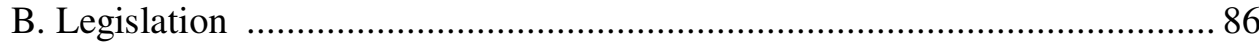

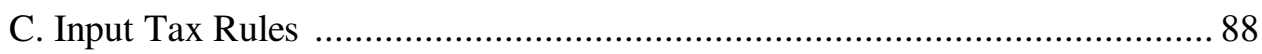

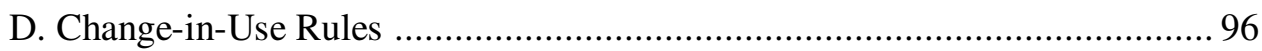

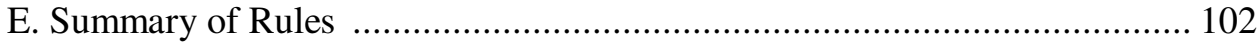

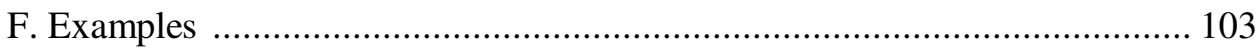

Part 2: Implementation and Operation - Empirical Evidence ........................ 105

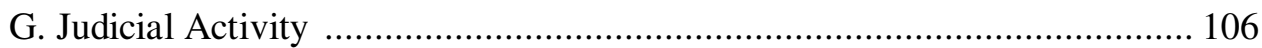

H. Revenue Authority Guidance …........................................................ 110

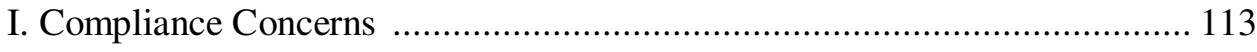

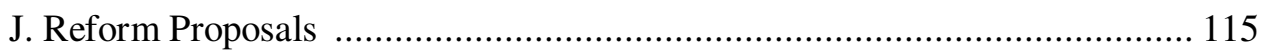

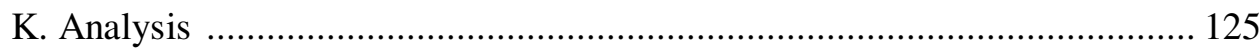

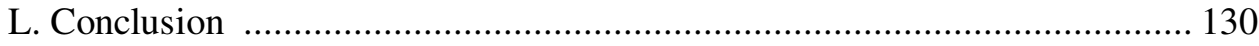

Chapter 3 The Canadian Experience 133

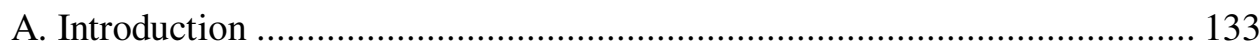

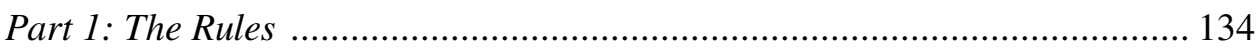

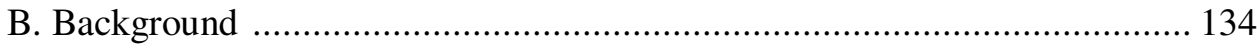

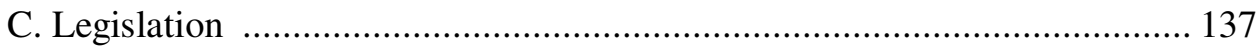

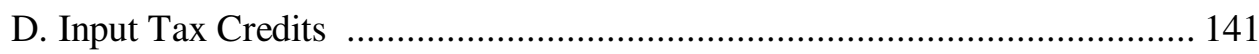

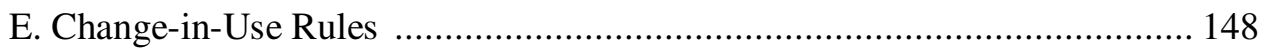

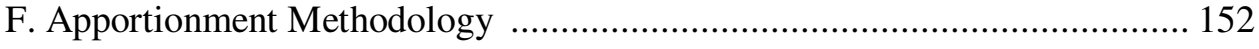

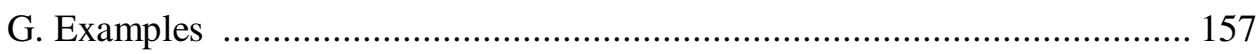

Part 2: Implementation and Operation - Empirical Evidence ....................... 160

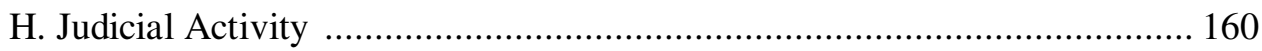

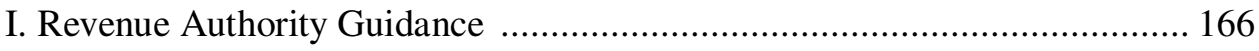

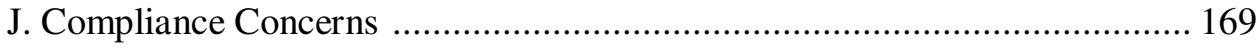

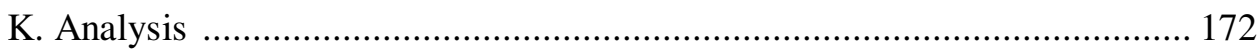

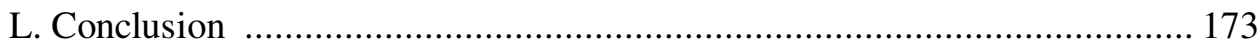




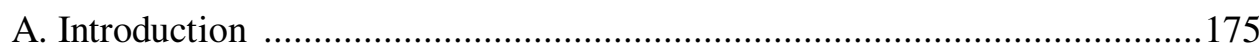

B. Tax Complexity and Legislative Simplification ........................................176

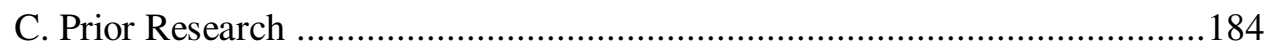

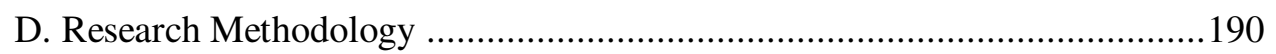

E. Interpretation of Readability Scores …................................................... 195

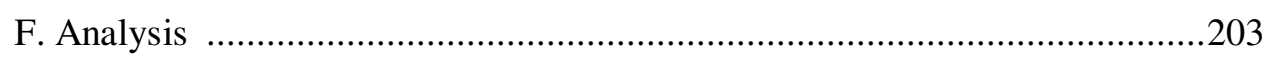

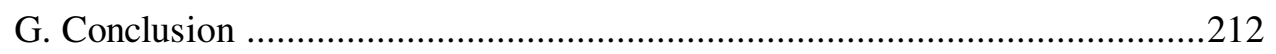

$\begin{array}{lr}\text { Chapter } 5 \text { Conclusions } & 215\end{array}$

A. Evaluating the Performance of the New Zealand Adjustment Approach .....215

B. The Adjustment Approach Experience …….............................................218

C. The Apportionment Approach Experience ..................................................222

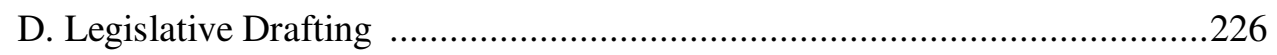

E. Mapping Comparative Complexity …….................................................226

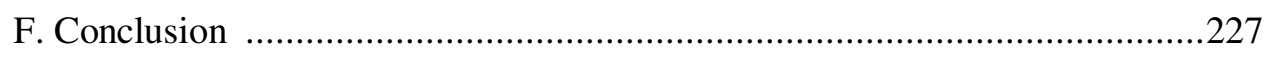

$\begin{array}{lr}\text { Bibliography } & 229\end{array}$

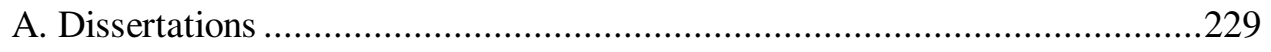

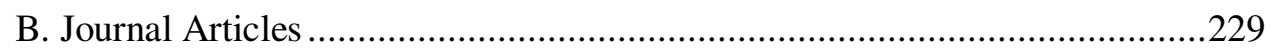

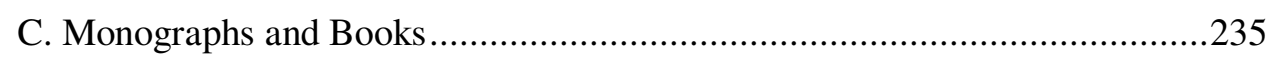

D. Parliamentary and Departmental Material..............................................241

$\begin{array}{lr}\text { Appendix } & 247\end{array}$

A. Goods and Services Tax Act Readability Table ......................................248

Tables

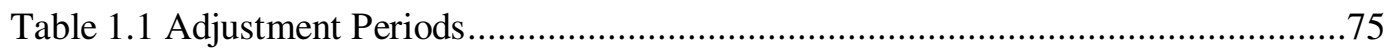

Table 1.2 Application Date for Assets Acquired Before 1 April 2011 ...........................78

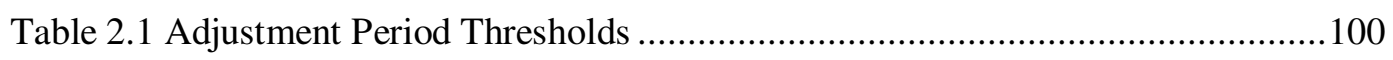

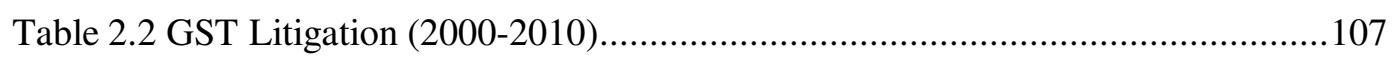

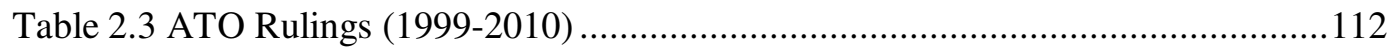


Table 2.4 Input Tax Credit and Adjustment Related Rulings (1999-2009) 112

Table 2.5 Board of Taxation Threshold Proposals ...................................................... 118

Table 2.6 Proposed Changes to Adjustment Thresholds and Periods .......................... 120

Table 2.7 Revised Changes to Proposed Adjustment Thresholds and Periods .............. 121

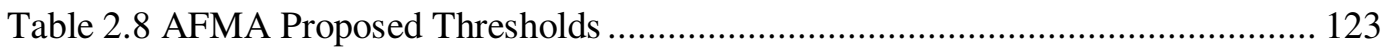

Table 2.9 ABA Proposed Thresholds .................................................................... 124

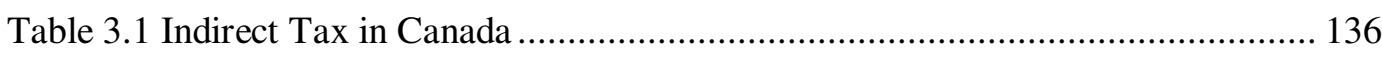

Table 3.2 Canadian Input Tax Credits and Change in Use Rules ............................... 139

Table 3.3 Canadian Capital Property Rules (Division 2, Subdivision D)..................... 140

Table 3.4 Extent of Commercial Activity by Different Entities ................................. 141

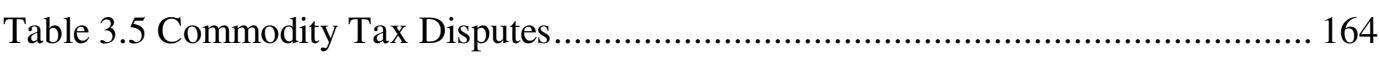

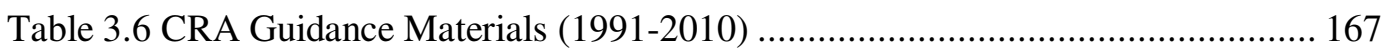

Table 4.1 GST Legislation (Selected Provisions) - Average Readability ..................... 185

Table 4.2 New Zealand Income Tax Legislation (2002) - Average Readability........... 185

Table 4.3 Australian Tax Legislation - Average Readability ..................................... 188

Table 4.4 New Zealand Income Tax Legislation (2004) - Average Readability........... 189

Table 4.5 New Zealand Income Tax Legislation (2007) - Average Readability ........... 189

Table 4.6 2010 Australian Change-in-Use Provisions -Readability ............................. 196

Table 4.7 Comparison of Richardson \& Smith Data Against 2010 Study.................... 197

Table 4.8 2010 New Zealand Change-in-Use Provisions - Readability....................... 200

Table 4.92010 Word97 vs Online Tool - Average Readability of GST Act ................ 201

Table 4.10 2010 Canadian Change-in-Use Provisions - Average Readability .............. 202

Table 4.11 Comparison of Empirical Studies - Average Word FRE and WPS Scores . 204

Table 4.12 Comparison of Change-in-Use Provisions - Average FRE and WPS Scores 205

Table 4.13 Alternative Readability Scores for Change-in-Use Provisions .................... 208

Table 4.14 Structural Complexity for Change-in-Use Provisions............................... 210

Table 5.1 Comparison of De Minimis Rules in Australia, Canada and New Zealand ... 224

Table 5.2 Comparison of Adjustment Thresholds in Australia and New Zealand......... 224 


\section{Figures}

Figure 1.1 The Introduction of the Goods and Services Tax Act 1985..........................19

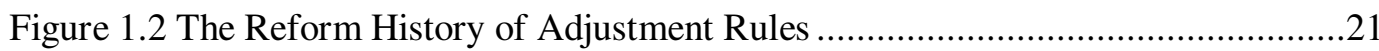

Figure 1.3 Principal Purpose (100 per cent Input tax Credit) .........................................24

Figure 1.4 Adjustment of 100 per cent Input Tax Credits (Clawback and Reversal) .......26

Figure 1.5 Principal Purpose: Used Up Point Model ...................................................27

Figure 1.6 Principal Purpose Tipping Point Model.......................................................27

Figure 1.7 Principal Purpose (More or Less Than Half) …..............................................30

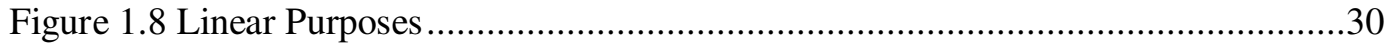

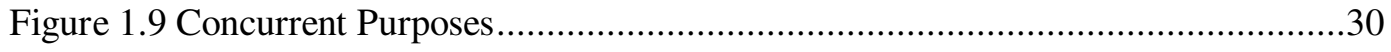

Figure 1.10 Total Cases Citing GST Provisions 1985-2010 (Accumulated).....................33

Figure 1.11 Total Cases Citing GST Provisions 1985-2010 (Courts)..............................33

Figure 1.12 Reported GST Cases 1985-2010 (Accumulated) ........................................33

Figure 1.13 Reported GST Cases 1985-2010 (Courts) …..............................................34

Figure 1.14 Reported Principal Purpose and Adjustment Cases (Accumulated)...............34

Figure 1.15 Reported Principal Purpose and Adjustment Cases (Courts)........................34

Figure 1.16 Timeline of Cases (Principal Purpose and Adjustments) 1985-2010 ............35

Figure 1.17 Official Guidance on Application of Section 21 .....................................60

Figure 1.18 Guidance, Cases, and Legislative Activity Timeline.................................63

Figure 1.19 Comparison of Current and Proposed Rules .............................................

Figure 2.1 Timeline of Legislative Amendments to Apportionment Rules......................87

Figure 2.2 Adjustment Period Distinctions Related to Use ...........................................99

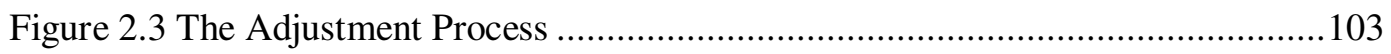

Figure 2.4 Reported GST Cases 2000-2010 (Accumulated) .......................................108

Figure 2.5 Reported GST Cases 2000-2010 (Federal Courts) .....................................109

Figure 2.6 Timeline of Division 11 and Division 129 Cases......................................110

Figure 2.7 Timeline of GST Rulings Discussing Division 11 and Division 129...........113

Figure 3.1 Non-Capital and Capital Property Treatment Flowchart .............................152 
Figure 3.2 Reported GST Cases 1991-2010 (Accumulated) …................................... 161

Figure 3.3 Total Reported GST Cases 1991-2010 (Per Year) ...................................... 161

Figure 3.4 Reported GST Cases 1991-2010 (Per Section) .......................................... 162

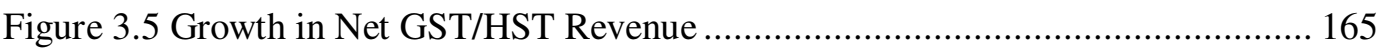

Figure 3.6 CRA Documents for Section 141.1 (1991-2010) ....................................... 167

Figure 3.7 CRA Documents for Section 169 (1991-2010) ......................................... 168

Figure 3.8 CRA Documents for Section 199 (1991-2010) ........................................ 168

Figure 3.9 CRA Documents for Section 200 (1991-2010) ........................................... 168

Figure 3.10 CRA Documents for Section 206 (1991-2010) ....................................... 169

Figure 3.11 CRA Documents for Section 208 (1991-2010) ….................................... 169

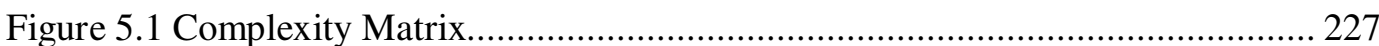




\section{INTRODUCTION *}

“... there is very little published empirical research and analysis of our laws and their administration. It is much easier to rely on intellect and to engage in intuitive reasoning in drawing conclusions, rather than to get out on the ground and try to ascertain what happens in practice and to explore the costs and benefits of legal rules and administration approaches. But empirical analysis is important. It is crucial in any public policy development." $\sim$ Sir Ivor Richardson ${ }^{1}$

\section{A. The Change-in-Use Rules}

Goods and services tax (GST) is a broad based tax on consumption and every business in Australia, Canada, or New Zealand is either involved in its payment or collection (using a credit-offset system). In order that tax is ultimately imposed only on end consumption, GST legislation provides a mechanism to distinguish consumption (use for private purposes) from the stages of production and distribution (use for business purposes). This mechanism (known broadly as the change-in-use rules) plays a crucial role in ensuring tax is collected on private consumption.

In New Zealand, the change-in-use mechanism from the inception of the GST in 1986 to April 2011 has adopted an adjustment approach that utilises a "principal purpose" test for entitlement to input tax credits and a deemed supply mechanism for adjustments (hereafter referred to as an "adjustment approach"). In contrast, Australia has always used an apportionment approach for entitlement to input tax credits that has expressly capped the number of adjustments that can be made. ${ }^{2}$ In Canada, the GST change-in-use mechanism has utilised both the adjustment and apportionment approaches, depending on the nature of the goods or services.

\footnotetext{
I wish to thank and acknowledge the immense contribution of Dr David White for his unwavering guidance and support in the preparation of this thesis. I would also like to thank Prof Adrian Sawyer for his valuable comments on early drafts of Chapter 4 (Removing Drafting Style and Structure from the Policy Debate) and David Sherman for his early guidance on Canadian GST in the formulation of Chapter 3 (The Canadian Experience). Finally, I would like to thank Thomson Reuters Carswell for access to Canadian tax resources during the course of this research. Of course all opinions and mistakes are those of the author.
}

1 ILM Richardson "Launch of Journals by Sir Ivor Richardson" (1995) 1 New Zealand Journal of Taxation Law and Policy 196 at 199.

2 As discussed in Chapter 1 (The New Zealand Experience), New Zealand has embarked on adopting an apportionment approach from 1 April 2011 (subject to transitional measures) that is modelled on the Australian rules. 


\section{B. Thesis Parameters}

\section{Thesis methodology}

In response to Sir Ivor Richardson's call for greater empirical research in the field of taxation, ${ }^{3}$ and Dickson \& White's observations that "there has been little research on GST, particularly of an empirical nature", 4 this thesis has undertaken an empirical approach in determining whether New Zealand should adopt an apportionment approach (rather than an adjustment approach) to account for changes-in-use.

To determine whether New Zealand should abandon an adjustment approach and adopt an apportionment approach, I have employed the criteria identified by the Tax Working Group as important in determining good tax design (ie, efficiency, equity, revenue adequacy, integrity, coherence, and simplicity). ${ }^{5}$ Evidence to support the thesis is obtained from examining and comparing the relative experiences of Australia, Canada, and New Zealand in applying the adjustment or apportionment approaches.

In order to determine the extent to which the respective approaches have fulfilled the tax policy criteria, the thesis has adopted an empirical approach that has examined the administration, legal outcomes, and public reaction to the respective rules as a proxy for efficiency and compliance. Accordingly, the Australian, Canadian, and New Zealand chapters are divided into two parts. The first part provides an overview of the respective rules and the second part examines the empirical evidence of the respective rules application. Concluding observations are then provided.

3 ILM Richardson "Launch of Journals by Sir Ivor Richardson" (1995) 1 New Zealand Journal of Taxation Law and Policy 196 at 199.

4 I Dickson and D White "Value-Added Tax and Excises: Commentary" in Institute for Fiscal Studies (ed) Dimensions of Tax Design: The Mirrlees Review (Institute for Fiscal Studies, Oxford University Press, Oxford, 2010) 387 at 388. Document available at <www.ifs.org.uk/mirrleesreview/dimensions/ch4.pdf> (viewed 20 March 2011).

5 Victoria University of Wellington Tax Working Group A Tax System for New Zealand's Future: Report of the VUW Tax Working Group (Centre for Accounting, Governance and Taxation Research, VUW, Wellington, January 2010). See also C Scott and H Davis The Gist of GST: A Briefing on the Goods and Services Tax (VUW Press, Wellington, 1985) ch 4, and H Davis The New Zealand Goods and Services Tax 1985: An Interpretation, Comparison and Evaluation (VUW, LLM Thesis, 1986). 
The thesis has restricted a comparative analysis of other jurisdictions to Australia and Canada. Australia was selected on the basis of economic and geographic proximity, and the opportunity for harmonisation of GST rules between New Zealand and Australia. ${ }^{6}$ Canada was selected on the basis that it provided not only an additional jurisdictional comparison of an apportionment approach, but that it also provided a unique opportunity to compare the relative success of both approaches operating within a single jurisdiction at the same time.

An examination of the respective jurisdictions also highlighted the differences in drafting styles. This raised an important question about whether drafting style had influenced the respective experiences of the GST change-in-use rules in each jurisdiction. Accordingly, the legislative provisions containing the change-in-use rules in each jurisdiction were measured for readability. Significantly this study also provides, for the first time, an assessment of the readability of the entire New Zealand GST Act (attached as an Appendix to this thesis).

The hypothesis adopted for this thesis when it was started in February 2010 was that New Zealand should adopt an apportionment approach. In a fortunate coincidence, this thesis has received an implied endorsement from the New Zealand Parliament, who in December 2010 enacted legislation that has replaced the adjustment rules, with new rules that adopt the apportionment approach.

From 1 April 2016, New Zealand will have finally abandoned its use of an adjustment mechanism in favour of new apportionment rules, borrowed to a large extent from Australia. For a number of taxpayers who decide not to take advantage of the 5-year transitional period the journey will begin from 1 April 2011. For many taxpayers the changes are well over due.

\section{Thesis structure}

The thesis is divided into five chapters. The first chapter examines the New Zealand experience. The chapter provides an overview of the former adjustment rules and

\footnotetext{
6 This selection has been validated by New Zealand's recent adoption of apportionment rules that are modelled on the Australian apportionment rules located in Division 129 of the GST Act (Aust). See discussion in Chapter 2 (The Australian Experience) of this paper.
} 
examines the empirical evidence of their application and the inherent problems they have attempted to over-come. The chapter also provides an overview of the new apportionment rules and outlines some of the key differences the rules provide in comparison to both the former New Zealand adjustment rules and the Australian apportionment rules, which they are modelled upon.

The second chapter examines the Australian experience. The chapter provides an overview of Australia's apportionment rules and examines whether empirical evidence supports the conclusion that an apportionment approach is a better GST design than New Zealand's former adjustment approach. The chapter also reviews proposed reforms of apparent deficiencies in the Australian rules and whether any reform proposals should be adopted in New Zealand (if they have not been already).

The third chapter examines the Canadian experience. Unlike New Zealand or Australia, Canada has adopted both an apportionment and adjustment approach in its GST change-of-use rules. The chapter provides an overview of the rules for each approach (which are distinct from both the New Zealand and Australian rules) and examines whether the evidence indicates which approach has performed better.

The fourth chapter examines the different drafting styles of the respective jurisdiction. It examines the readability of the respective change-in-use provisions and whether the readability of the provisions has influenced the relative outcomes of each approach.

Finally, the fifth chapter draws the strings together and makes a number of comparative observations and conclusions.

Before jumping straight into an examination of each jurisdiction it is also worthwhile outlining the criteria this thesis is using in its evaluation and how GST worked in New Zealand under the former adjustment rules — and generally elsewhere in the world. 


\section{Evaluating Performance}

How do we judge a good or bad tax rule? According to the Mirrlees Review, ${ }^{7}$ the answer provided by seeing how it stacks up against a check list of desirable properties. The most famous checklist of desirable properties are those described by Adam Smith in $1776 .{ }^{8}$ These four canons of good tax design (equity, certainty, convenience; and economy), ${ }^{9}$ or in some instances reduced to the "essential" three cannons (equity, simplicity, and efficiency), ${ }^{10}$ have been applied in numerous studies to evaluate and compare tax rules. ${ }^{11}$ As Davis acknowledged, "precisely which criteria are adopted and the weighting they are given depends on the question being answered". 12

${ }^{7}$ Institute for Fiscal Studies and Mirrlees J, et al (eds) Tax by Design: Mirrlees Review vol 2, ch 2 (draft) 2 at [2.1.1]. Document available at http://www.ifs.org.uk/mirrleesReview/design_(viewed 20 March 2011). Final publication expected in Spring 2011 by Oxford University Press.

${ }^{8}$ A Smith An Inquiry into the Nature and Causes of the Wealth of Nations (Methuen \& Co Ltd, London, 1776). Document available at http://www.econlib.org/library/Smith/smWN.html (viewed 20 March 2011). An excellent summary of the principles can be found in C Alley and D Bentley "A Remodelling of Adam Smith's Tax Design Principles" (2005) 20 Australian Tax Forum 579 at 586588 and A Sawyer "Regulatory Impact Statements and Accountability: Recent Australasian Experience"(2008) 11 Journal of Australian Taxation 42 at 61-63.

9 In the language of modern economics, Smith's concept of "convenience" is described as the concept of "administrative simplicity" or "compliance" and the concept of "economy" is better know as the concept of "efficiency" or "neutrality".

${ }^{10}$ The modern principle of simplicity is based on Smith's certainty and convenience maxims and seeks to minimise the administrative and compliance costs incurred in raising a given level of tax revenue. The economic literature on tax compliance is substantial. For example: CT Sandford (ed) Tax Compliance Costs Measurement and Policy (Fiscal Publications, Bath, 1995); and C Evans, J Pope and J Hasseldine (eds) Tax Compliance Costs: A Festschrift for Cedric Sandford (Prospect Media Pty Ltd, Sydney, 2001).

${ }^{11}$ A Dixon "Risk-Free Return Method - Out of the Frying Pan and Into the Fire" (2003) 9 New Zealand Journal of Taxation Law and Policy 329; S Ross and P Burgess Income Tax: A Critical Analysis (2nd ed, Sydney, Law Book Company, 1996) 25; M Dirkis “Accidents of History Australia's Residency Rules for Individuals" (1997) 3 New Zealand Journal of Taxation Law and Policy 108; H Davis The New Zealand Goods and Services Tax 1985: An Interpretation, Comparison and Evaluation (VUW, LLM Thesis, 1986) 4; Australian Tax System, Draft White Paper (AGPS, Canberra, 1985) 14; R McLeod Tax Review - Issues Paper (IRD, Wellington, June 2001) 5; and R McLeod Tax Review - Final Report (IRD, Wellington, October 2001) 19. The 2001 Tax Review (across both reports) recognised that good tax design should be guided by five principles: growth (ie, enhancing economic well being), administrative efficiency (ie, reducing cost of imposing tax), fairness (ie, that people should be treated similarly), equity (ie, people should be able to contribute in accordance with their ability to pay), and revenue integrity (ie, continuing to raise sufficient revenue).

${ }^{12}$ H Davis The New Zealand Goods and Services Tax 1985: An Interpretation, Comparison and Evaluation (VUW, LLM Thesis, 1986) 4. 
In 2010, the Tax Working Group identified six principles that should guide the design of a good tax system. ${ }^{13}$ These principles were identified as: efficiency (and growth), equity (and fairness), revenue integrity, revenue adequacy (or fiscal cost), administrative simplicity (or compliance), and coherence. ${ }^{14}$

As this is the most recent New Zealand guidance on good tax design principles, I have selected five of the most appropriate principles, ${ }^{15}$ plus the principles of "visibility" (used by Scott \& Davies in their evaluation of the GST Act), ${ }^{16}$ and "predictability" (identified in the Meade Report), ${ }^{17}$ are used in this study as the criteria for evaluating the performance of the change-in-use rules in Australia, Canada, and New Zealand. The seven criteria are explained below. As the Tax Working Group acknowledged "value judgements are necessary to determine the priorities and respective weighting of these objectives". ${ }^{18}$ However, weighting will also be dependent on the question being asked.

${ }^{13}$ Victoria University of Wellington Tax Working Group A Tax System for New Zealand's Future (Centre for Accounting, Governance and Taxation Research, Victoria University of Wellington, Wellington, January 2010) 15.

${ }^{14}$ Victoria University of Wellington Tax Working Group Second Session Summary (31 July 2009). Document available at http://www.victoria.ac.nz/sacl/cagtr/twg/Publications/SecondSession_Summary.pdf (viewed 20 March 2011).

${ }^{15}$ The principle of revenue adequacy (or fiscal cost) has been excluded on the basis it is a macroeconomic criteria and not appropriate for measuring the performance of legislative rules. The revenue adequacy principle also overlaps with the principles of revenue integrity, administrative simplicity, and efficiency. The principle of revenue adequacy requires that tax reforms are affordable given fiscal constraints and raise sufficient revenue for government spending. A tax reform that places government spending at risk and is outside fiscal constraints does not have revenue adequacy.

${ }^{16} \mathrm{C}$ Scott and H Davies The Gist of GST: A Briefing on the Goods and Services Tax (VUW Press, Wellington, 1985) 28-29. Scott \& Davies identified four criteria to evaluate tax policy design. These were: economic efficiency (or neutrality), equity, administrative simplicity (or compliance) and visibility.

${ }^{17}$ JE Meade The Structure and Reform of Direct Taxation: Report of a Committee chaired by Prof JE Meade (The Institute for Fiscal Studies, George Allen \& Unwin, London, 1978) ch 2, 7. Document available from http://www.ifs.org.uk/docs/meade.pdf (viewed 20 March 2011). The Meade Report outlined six desirable characteristics of a tax system: incentives and economic efficiency; distributional effects; international aspects; simplicity and costs of administration and compliance; flexibility and stability; and transitional problems.

${ }^{18}$ Victoria University of Wellington Tax Working Group A Tax System for New Zealand's Future (Centre for Accounting, Governance and Taxation Research, Victoria University of Wellington, Wellington, January 2010) 56. 


\section{Administrative simplicity and compliance}

The principle of administrative simplicity (also known as administrative efficiency) is concerned with the compliance costs for taxpayers and administration costs for revenue authorities. A tax rule should be simple and inexpensive for taxpayers to comply with and for the revenue authority to administer and enforce. Tax rules that have high litigation activity, require high audit function, or require ongoing recalculation and tracking, would be considered to have high compliance costs.

\section{Efficiency and growth}

Tax policy (and its implementation as statutory rules) should avoid distorting economic decisions or choices in relation to the use or consumption of resources (eg, creating biases towards one form of activity over another) and should not impose heavy costs on taxpayers making decisions. ${ }^{19}$ If a tax rule achieves this outcome it is considered efficient. In this sense, efficiency is synonymous with neutrality. ${ }^{20}$ If a particular approach to the GST change-in-use issue creates uncertainty with individuals avoiding investment or organising their business in a less optimal way, or it requires extensive opinion writing by professional tax advisors and litigation, the approach might be considered inefficient.

\section{Equity and fairness}

Equity is synonymous with fairness and the terms are used inter-changeably. ${ }^{21}$ The concept also includes spatial qualities (ie, immediate and long term). ${ }^{22}$ The 2001 Tax

\footnotetext{
${ }^{19}$ Victoria University of Wellington Tax Working Group A Tax System for New Zealand's Future (Centre for Accounting, Governance and Taxation Research, Victoria University of Wellington, Wellington, January 2010) 15.

${ }^{20}$ H Davis The New Zealand Goods and Services Tax 1985: An Interpretation, Comparison and Evaluation (VUW, LLM Thesis, 1986) 4 at [1.1]. Efficiency or neutrality is the modern economic terminology for Smith's principle of "economy".

${ }^{21}$ Davis suggests they are the same concept and that "equity is fairness". See H Davis The New Zealand Goods and Services Tax 1985: An Interpretation, Comparison and Evaluation (VUW, LLM Thesis, 1986) 5 at [1.2].

${ }^{22}$ Victoria University of Wellington Tax Working Group, A Tax System for New Zealand's Future (Centre for Accounting, Governance and Taxation Research, Victoria University of Wellington, Wellington, January 2010) 15.
} 
Review Issues Paper acknowledged the concepts were inherently subjective and identified four principles of fairness: the ability to pay (ie, vertical equity); even handedness (ie, horizontal equity); user pays (ie, the benefit principle); and transitional fairness (ie, transparency). ${ }^{23}$ The Mirrlees Review also highlighted the need for procedural "transparency" and "fairness" in good tax design. ${ }^{24}$

Horizontal equity requires the equal treatment of equals (ie, taxpayers with the same capacity should contribute the same and have the same tax liabilities). In contrast, vertical equity requires the unequal treatment of unequals (ie, that taxpayers with a greater ability to pay should contribute more and have larger tax liabilities). The benefit principle seeks to align individual benefits from tax expenditure with individual tax liability (or revenue) and focuses on tax-expenditure policy rather than tax-revenue policy. Transparency requires that tax rules should be known before they can be applied. For example, tax reform should not be retrospective or sprung upon taxpayers without prior consultation. Tax rules that are not clearly understood before implementation cannot be considered transparent and therefore would be unfair.Tax rules that treat taxpayers differently or inconsistently are not considered fair. A rule that creates higher compliance costs (ie, litigation costs) than other rules would be inequitable.

\section{Coherence}

The principle of coherence requires a holistic view of the tax system. A tax policy should make sense in the context of the entire tax system and not merely in isolation. The Meade Report observed that "a tax system cannot be simple and easy to understand unless it makes a coherent whole". ${ }^{25}$ For example, a tax rule that does not function consistently with the underlying policy intent of the broader legislation would be considered incoherent.

${ }^{23}$ R McLeod Tax Review - Issues Paper (IRD, Wellington, June 2001) 8.

${ }^{24}$ Institute for Fiscal Studies and Mirrlees J, et al (eds) Tax by Design: Mirrlees Review vol 2, ch 2 (draft) 6-9. A tax system will command respect and be complied with if it delivers outcomes that are perceived as fair. Tax systems that impose unexpected or excessive burdens on taxpayers will be considered unfair. Hence, tax systems that are reliant on self-assessment will require fairness.

${ }^{25}$ JE Meade The Structure and Reform of Direct Taxation: Report of a Committee chaired by Prof JE Meade (The Institute for Fiscal Studies, George Allen \& Unwin, London, 1978) 19. 


\section{Predictability}

According to the Mirrlees Review, ${ }^{26}$ the Meade Report, ${ }^{27}$ proposed a new principle of "predictability" reflecting the "structural aspects of tax rules". According to the Meade Report, "there is a clear need for a certain stability in taxation in order that persons may be in a position to make reasonably far-sighted plans". ${ }^{28}$ A tax rule should be certain and predictable. ${ }^{29}$

\section{Revenue integrity}

According to the Tax Working Group, the tax system should be sustainable over time, minimise opportunities for tax avoidance and arbitrage, and provide a sustainable revenue base for government. The principle of revenue integrity requires that tax rules protect the revenue base. A tax rule that does not achieve these goals does not have revenue integrity.

\section{Visibility}

The principle of visibility is related to the principle of neutrality, ${ }^{30}$ and similar to the concept of transparency (but distinct from the principle of predictability and coherence). According to Scott \& Davis, ${ }^{31}$ visibility requires that the participants are

${ }^{26}$ Institute for Fiscal Studies and Mirrlees J, et al (eds) Tax by Design: The Mirrlees Review vol 2, ch 2 (draft) 2 at [2.1.1]. According to Mirrlees the Meade Report included the principle of "predictability". The concept of "predictability" would appear to be another aspect of "certainty", albeit a procedural one, rather than one directed at determining tax liability. JE Meade The Structure and Reform of Direct Taxation: Report of a Committee chaired by Prof JE Meade (The Institute for Fiscal Studies, George Allen \& Unwin, London, 1978) ch 2, 19. Document available at http://www.ifs.org.uk/docs/meade.pdf (viewed 20 March 2011)

${ }^{27}$ JE Meade The Structure \& Reform of Direct Taxation: Report of a Committee Chaired by Prof JE Meade (The Institute for Fiscal Studies, Allen and Unwin, London and Boston, 1978).

${ }^{28}$ JE Meade The Structure and Reform of Direct Taxation: Report of a Committee chaired by Prof JE Meade (The Institute for Fiscal Studies, George Allen \& Unwin, London, 1978) 21.

${ }^{29}$ This principle has striking similarities to Hayek's principle of predictability in the rule of law: F Hayek Rules and Order: Legislation and Liberty (University of Chicago Press, 1973) vol 1.

${ }^{30} \mathrm{C}$ Scott and H Davies The Gist of GST: A Briefing on the Goods and Services Tax (VUW Press, 1985) 28.

${ }^{31} \mathrm{C}$ Scott and H Davies The Gist of GST: A Briefing on the Goods and Services Tax (VUW Press, 1985) 29-30. 
aware of the tax consequences of their economic decisions. According to Davis, "if the tax system is visible to taxpayers who receive the benefit of government expenditure they will be able to weigh up the costs and benefits". ${ }^{32}$ A similar observation was made in the Meade Report, ${ }^{33}$ which stated that "the taxpayer should, as far as possible, be able to not only see clearly what is to be taxed, but also to understand the purpose which it is intended to serve". Tax rules that are not clearly understood or confusing after implementation cannot be considered visible and therefore would be unfair.

\section{The United Kingdom Experience}

Unfortunately a comparative analysis of the United Kingdom (UK) VAT system could not be included in this thesis due to several reasons. First, the constraint of size, has meant that only a few jurisdictions that adopted an apportionment approach could be examined in sufficient detail from a comparative perspective. Secondly, it would appear that the New Zealand system, has from its outset, intentionally avoided importing elements of the United Kingdom VAT system. Thirdly, the United Kingdom VAT system has been heavily influenced by European directives and is very different from the model first used as a draft GST Act in the New Zealand White paper. ${ }^{34}$ Finally, it would appear that Australia, rather than the United Kingdom, is the model for an apportionment approach in New Zealand. Accordingly, Australia provides a stronger case for comparative examination than the United Kingdom. However, this is not to suggest that the United Kingdom VAT system is not capable of influencing the development of apportionment in New Zealand (or Australia). In fact, submissions on the introduction of the new apportionment rules in New Zealand raised a number of concerns from United Kingdom precedents. For that reason a brief examination of the United Kingdom adjustment rules has been included.

\footnotetext{
${ }^{32}$ H Davis The New Zealand Goods and Services Tax 1985: An Interpretation, Comparison and Evaluation (VUW, LLM Thesis, 1986) 6 at [1.4].

${ }^{33}$ JE Meade The Structure and Reform of Direct Taxation: Report of a Committee chaired by Prof JE Meade (The Institute for Fiscal Studies, George Allen \& Unwin, London, 1978) 19.

${ }^{34}$ EC Directives set the boundaries within which a member state must construct its VAT laws so that VAT legislation of a member state is subordinate to EC Directives.
} 
The United Kingdom VAT apportionment rules are spread throughout the VAT $\mathrm{Act}^{35}$ and subordinate regulations. The United Kingdom Revenue Authority (HMRC) expands on the operation of the apportionment rules through VAT Notices. ${ }^{36}$ In the United Kingdom, VAT is apportioned where goods or services are "used or to be used" partly for taxable (ie, business) purposes and partly for nontaxable (ie, non-business or private) purposes, so that only the part that is directly attributable to the business purpose is counted as input tax. ${ }^{37}$

Generally, VAT is apportioned at the outset, and accounted for in the period in which the VAT became chargeable. ${ }^{38}$ However, the United Kingdom also recognises an alternative treatment known as the Lennartz approach (or mechanism) which is derived from an interpretation of the European Unions's Sixth Directive, which the United Kingdom VAT Act is subject to. ${ }^{39}$ Article 17(2) of the Sixth Directive requires that acquisitions of goods and services be "used for the purposes of ... taxable transactions" before the right to deduct arises. ${ }^{40}$

The Lennartz approach provides that taxpayers may treat the VAT that they incur as fully recoverable from the outset. ${ }^{41}$ This approach derives from Lennartz $v$ Finanznt Munchen $I I I,{ }^{42}$ where the court held that where a taxpayer acquires goods and uses them partly for business purposes and partly for private or non-business purposes

${ }^{35}$ Value Added Tax Act 1994 (UK).

${ }^{36}$ VAT Notices are similar to public rulings.

${ }^{37}$ Value Added Tax Act 1994 (UK), s 24(5) and reg 101(2) Value Added Tax Regulations (1995/2518).

${ }^{38}$ Value Added Tax Act 1994 (UK), Schedule 4 at cl 5(4) Reg 4 Value Added Tax Regulations (1995/2518 and 1997/1086). For goods supplied in the UK, the suppliers tax point; for goods acquired in another EC country the acquisition date; for imported goods outside the EC, the date of importation; and goods removed from customs, the date of removal.

${ }^{39}$ Value Added Tax 2006-07 (Tottel Publishing Ltd, London, 2006) 130 [4.56].

${ }^{40}$ The courts have given the phrase a narrow interpretation so as to require "a direct and immediate link" between the acquisition and taxable supply: Midland Bank Plc v Customs \& Excise Commissioners CJEC Case C-98/98; [2000] STC 501 and Customs \& Excise Commissioners $v$ Southern Primary Housing Ltd 2003 [2004] STC 209 (CA).

${ }^{41}$ A similar entitlement to full input tax credits is available under New Zealand's former "principal purpose" test.

${ }^{42}$ Lennartz v Finanznt Munchen III, CJEC Case C-97/90, [1995] STC 514. 
they have the right to total and immediate input tax credits. In Seeling $v$ Finanzant Starnberg, ${ }^{43}$ the Lennartz approach was extended to construction services. ${ }^{44}$ The taxpayer must then account for output tax on private or non-business use at the end of each subsequent taxable period.

The United Kingdom legislation does not provide any de minimis rules for insignificant adjustments. ${ }^{45}$ The UK legislation also does not directly provide a mechanism that limits the number of adjustments. However, the HMRC, in applying the Lennartz approach to immovable property, calculate output tax credits over a 20year period using a straight-line depreciation method. For movable property (eg, computers) a 5-year period using a straight-line depreciation method is applied. Once the goods have been written off, no further output tax is payable. ${ }^{46}$

The United Kingdom VAT legislation does not prescribe any particular method of apportionment, instead the regulations merely requires that the method adopted must be fair and reasonable (eg, fixed percentage methods, income or revenue methods, expenditure or cost methods, time or space methods, or transaction history methods). ${ }^{47}$ In practice, the HMRC officers will only challenge an apportionment that is completely outside the range of acceptable apportionment methods. ${ }^{48}$

\footnotetext{
${ }^{43}$ Seeling v Finanzant Starnberg, CJEC Case C-269/00, [2003] STC 805. A married couple purchased a holiday bungalow intending to use it 87.5 per cent for business letting and 12.5 per cent for private use and claimed a 100 per cent input tax credit. The court held the taxpayer had the right to treat all VAT as input tax when they purchase capital goods for mixed purposes and allocate the goods wholly to their business: Tolley's Value Added Tax 2007 ( $1^{\text {st }}$ ed, Lexis Nexis Ltd, London, 2007) 740 $[35.7(3)]$.

${ }^{44}$ According to Tolley's, the UK Revenue Authority's attempts to restrict the Lennartz approach “in order to protect the revenue base]" were held to be ultra vires: Charles \& Charles-Tijems $v$ Staatssecretaries van Financien, CJEC, Case C-434/03, [2006] STC 1,429.

45 Tolley's Value Added Tax 2007, (1 ${ }^{\text {st }}$ ed, Lexis Nexis Ltd, London, 2007) 738 at [35.7(2)].

${ }^{46}$ Value Added Tax 2006-07 (Tottel Publishing Ltd, London, 2006) 246 at [13.37].

${ }^{47}$ VAT Notice 706 at [6.6].

${ }^{48}$ Tolley's Value Added Tax 2007, (1 ${ }^{\text {st }}$ ed, Lexis Nexis Ltd, London, 2007) 737 at [35.7(2)]. This is a similar to the approach adopted in Canada.
} 


\section{E. A Brief Overview of How GST Works in New Zealand}

Before examining the respective change-in-use rules it is important to understand how those rules fit within the general framework of a Goods and Services Tax ("GST") in New Zealand. GST is a value added tax ("VAT"). New Zealand's GST system is a broad based indirect consumption tax. ${ }^{49}$ It is recognised internationally for its simplicity and comprehensiveness. ${ }^{50}$

GST is charged on imported goods, as well as any supplies made by a registered person. The current rate of GST is 15 per cent. ${ }^{51}$ Any person carrying on a taxable activity can register for GST. A person can either voluntarily register for GST, or be deemed to be registered if their taxable activity for the year exceeds the specified threshold (currently \$60,000). Figure 5 illustrates how GST generally operates.

A taxable activity is an activity that is carried on continuously or regularly and involves or is intended to involve the supply of goods or services to other persons for consideration. ${ }^{52}$ For a supply to be liable for GST it must be made in New Zealand by a registered person in the course or furtherance of a taxable activity (and not be exempt).

Output and input tax is accounted for using three different methods: payments basis, invoice basis, or hybrid basis. The invoice basis is the default method. ${ }^{53}$

${ }^{49}$ GST is designed to be administratively simple to collect and account for. In the context of fairness and equity, it is difficult for taxpayers to escape paying it.

${ }^{50} \mathrm{C}$ Alley, et al New Zealand Taxation (Brookers Ltd, Wellington, 2009) 888. However, it has become apparent that not all parts of the Goods and Services Tax Act 1985 are as straightforward as initially perceived. The adjustment rules in particular have been the subject of extensive litigation, judicial criticism, and regular review.

${ }^{51}$ Before 1 October 2010 it was 12.5 per cent. When the GST Act was first enacted the rate was 10 per cent.

52 The test for a taxable activity is similar to the business test in the Income Tax Act (ITA) and certainly has used existing ITA case law. But unlike the Income Tax Act business test there is no requirement for the activity to be carried out for profit.

${ }^{53}$ The payments basis can only be used by registered persons whose annual taxable activity does not exceed 2 million. The hybrid basis allows a combination of both: sales (output tax) using the invoice basis, and purchases (input tax) using the payments basis. 
Figure 5: How GST Works (using 15 per cent GST rate)

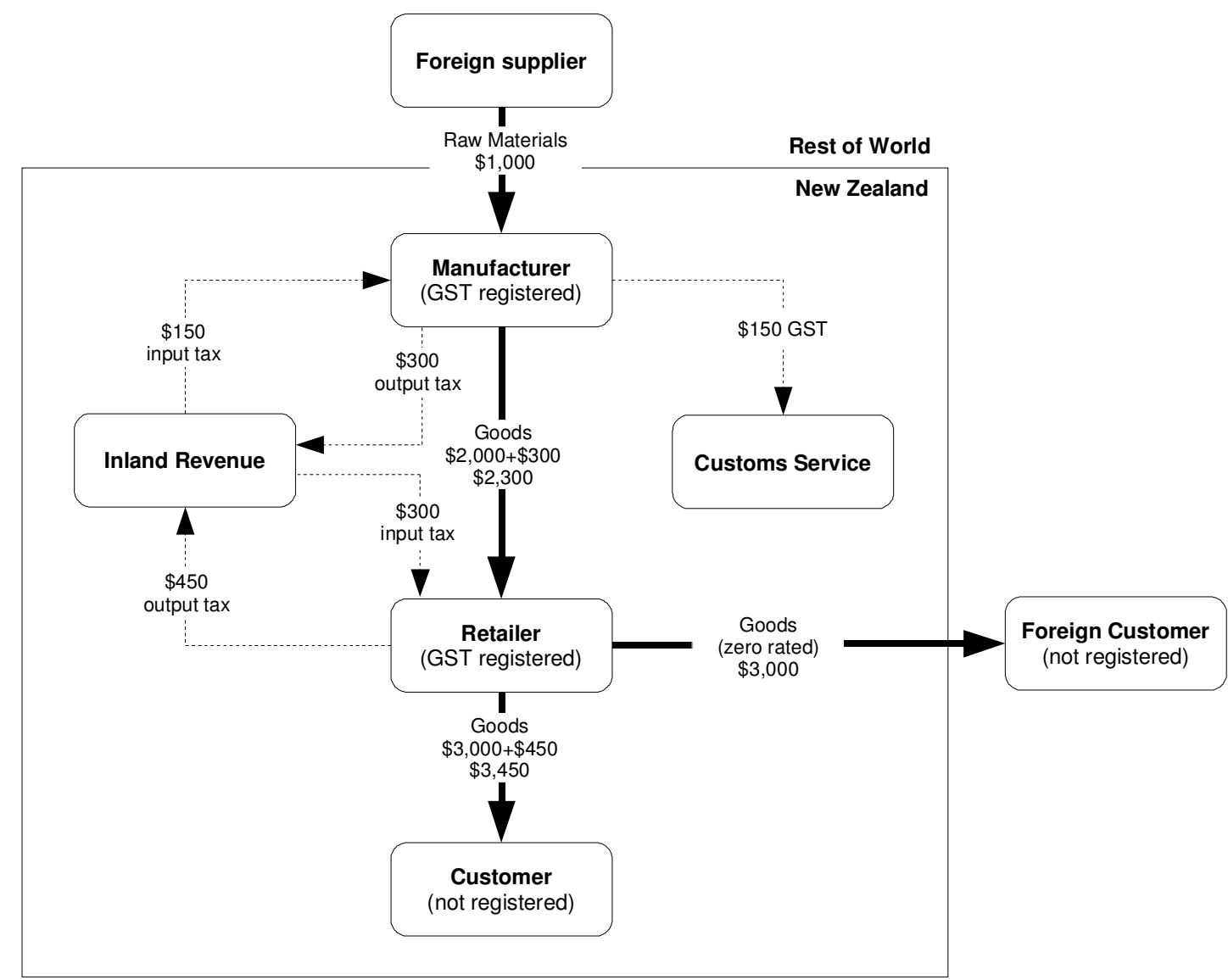

Source: Alley C, et al New Zealand Taxation (Brookers Ltd, 2009) 892 (Fig 19.1).

GST operates on a credit off-set basis (illustrated in Figure 6). ${ }^{54}$ Registered persons both pay (output tax) and claim back (input tax) GST. Registered persons are expected to furnish returns at the end of their taxable period. ${ }^{55}$ The normal taxable period is 2 months. ${ }^{56}$ The amount (if any) payable to IRD at the end of the registered persons taxable period is the difference between input and outpu tax.

GST output tax is charged on the supply of goods and services by a registered person in the course or furtherance of a taxable activity. GST incurred by that registered

${ }^{54}$ This is in contrast to Retail Sales Tax (RST) which has a cumulative effect at each stage of production and distribution. See C Scott and H Davis The Gist of GST: A Briefing on the Goods and Services Tax (VUW Press, Wellington, 1985).

${ }^{55}$ There are three taxable period options: 1-month, 2-months, and 6-months.

${ }^{56}$ As with registration there are thresholds. Anyone can elect to use a 1-month period. Any annual taxable activity exceeding \$24 million must use a 1-month taxable period. If annual taxable activity is less than $\$ 500,000$ the registered person can elect to use a 6-month period. 
person on goods and services that are attributable to making taxable supplies may be claimed as input tax against this output tax. ${ }^{57}$ As discussed above, goods or service acquired for application in the taxable activity may be re-directed to other nonbusiness activities (ie, a change-in-use). In such circumstances a change-in-use mechanism will be required to ensure the registered person is not over or under taxed.

Figure 6: How GST Works: Input and Output Flow (using 15 per cent GST rate)

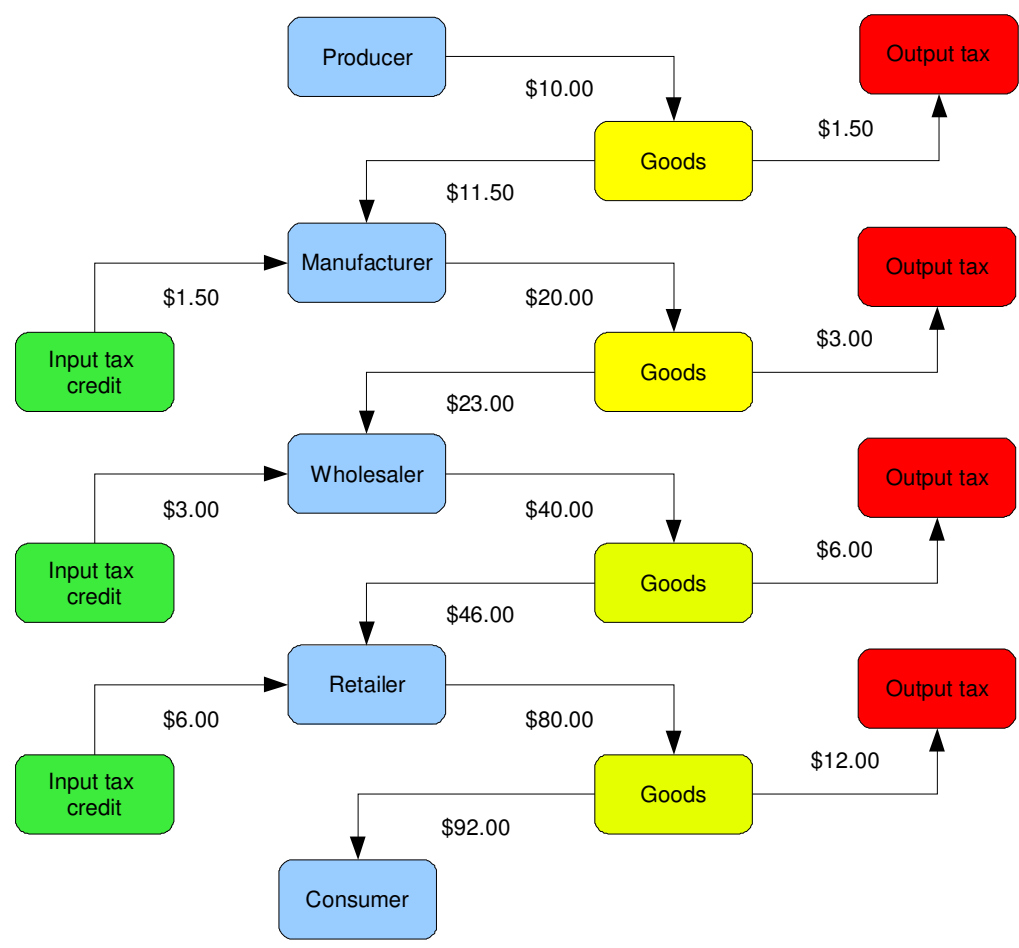

The output tax is the GST collected by the supplier on supplies made and the input tax is the GST paid by the supplier on supplies received.

Source: Deloitte NZSA Educational Tax Course - GST (Continuing Education Paper, March 1994) at [B2].

${ }^{57}$ Before 1 April 2011, attribution was determined by a "principal purpose" test. From 1 April 2011, attribution is determined by "use" (subject to transitional period ending 1 April 2016). 


\section{THE NEW ZEALAND EXPERIENCE}

"The wording governing the question of whether and to what extent the input tax relating to a particular item of expenditure is deductible must be clear enough to withstand word by word dissection by the courts, for this is bound to be an area of conflict between registered persons and the Inland Revenue Department." (emphasis added) ${ }^{1}$

\section{A. Introduction}

New Zealand's GST system is widely considered the international model for VAT\GST systems. ${ }^{2}$ Twenty five years after the introduction and commencement of New Zealand's GST Act, New Zealand will finally replace the former change-in-use rules, which apply an adjustment approach (utilising a "principal purpose" test and deemed supply mechanism), with an apportionment approach (employing a "use" test and value based tracking mechanism). This is a marked and welcome u-turn in policy direction from the 1999 GST Review $^{3}$ and 2008 Issues Paper ${ }^{4}$ — which both expressly declined to implement an apportionment approach.

The new apportionment approach also comes ten years after the adjustment provisions were last revised (in order to incorporate legislative guidance on measurement and calculation methodology), and five years after the Court of

1 Peat Marwick Submissions on the Goods and Services Tax Bill 1985 (25 September 1985) 3 at [1.2] (Finance and Expenditure Committee file number FE/85/307, 262W).

2 Institute for Fiscal Studies (eds) Dimensions of Tax Design: The Mirrlees Review (Institute for Fiscal Studies, Oxford University Press, Oxford, 2010) 388. Document available at <www.ifs.org.uk/mirrleesreview/dimensions/ch4.pdf> (viewed 20 March 2011). See also Krever R and White D (eds) GST in Retrospect and Prospect (Brookers Ltd, Wellington, 2007) viii.

3 B Birch and B English GST: A Review - A Government Discussion Document (Policy Advice Division, IRD, Wellington, March 1999). Document available at <http://taxpolicy.ird.govt.nz/publications/1999-dd-gst-review/overview> (viewed 20 March 2011).

4 Policy Advice Division and Treasury Options for Strengthening GST Neutrality in Business-toBusiness Transactions: An Officials' Issues Paper (IRD, Wellington, June 2008). Document available at <http://taxpolicy.ird.govt.nz/publications/2008-ip-gst-b2b-neutrality/overview> (viewed 20 March 2011). 
Appeal's attempt in CIR v Lundy Family Trust and Behemoth Corp Ltd ${ }^{5}$ to provide clear guidelines on the calculation of adjustments. ${ }^{6}$

The adjustment rules were until 2011 the source of substantial litigation and ongoing uncertainty. The adoption of a new apportionment approach and calculation methodology not only utilises a widely applied adjustment approach that is used by many international jurisdictions, but also better aligns itself to rules (in particular the calculation methodology rules) that are already well established in Australia.

This chapter is divided into three parts. The first part provides a brief overview of the adjustment rules and attempts to provide a conceptual picture of how elements of the rules have developed. Part two examines a number of the issues experienced with the application and interpretation of the former adjustment rules and provides empirical evidence that the rules have a number of ongoing conceptual problems that have not withstood judicial dissection very well. Part three provides a brief overview of the new apportionment rules and concludes that the new rules will provide greater certainty for a far greater number of taxpayers than is currently the case.

\section{Part 1: The Old Adjustment Rules}

\section{B. Legislation}

New Zealand GST law essentially comprises a principal GST $\mathrm{Act}^{7}$ and subordinate legislation (regulations). ${ }^{8}$ The Goods and Services Tax Act 1985 was enacted in October 1985, but did not commence until 1 October 1986. Before its commencement it was subject to three remedial amendment Acts, which probably reflected the speed in which the GST Act was introduced (illustrated in Figure 1.1).

${ }^{5}$ CIR v Lundy Family Trust and Behemoth Corp Ltd (2005) 22 NZTC 19,637 (CA).

${ }^{6}$ It is suggested in the course of this chapter that the new apportionment rules have attempted to rewrite the outcome of the Court of Appeal decision in Lundy and provide a calculation methodology that appears more aligned to the unsuccessful argument advanced by the Commissioner that holding costs (associated with the cost of rental activity and normally factored into rental payments) should be used to determine the value of a change-in-use.

7 Goods and Services Tax Act 1985 (hereafter the "GST Act"). Document available at <www.legislation.co.nz/act/public/1985/0141/latest/DLM81035.html> (viewed 20 March 2011).

8 Goods and Services Tax (Local Authorities Accounting on Payments Basis) Orders (2001, 2005, 2009) and Goods and Services Tax (Grants and Subsidies) Orders (1992, amended in 2003). 
The GST Act was reprinted in 1991 and comprises nine Parts and 100 individual provisions. ${ }^{9}$ In contrast to the Australian GST Act, it contains no diagrams or examples. Numbering of provisions and divisions are consecutive and do not allow room for large expansion without complex numbering. Fortunately, insertions of new provisions have not been extensive. Unlike the Income Tax Act 2007 or the Australian GST Act, defined terms are not highlighted in provisions and the general drafting style is not in plain language. Definitions are also located at the front of the Act in an interpretation provision (rather than the back), while key terms (eg, input tax or supply) are located in separate provisions. In contrast to the Australian GST Act, the general rate of GST is contained within the Act.

Figure 1.1: The Introduction of the Goods and Services Tax Act 1985

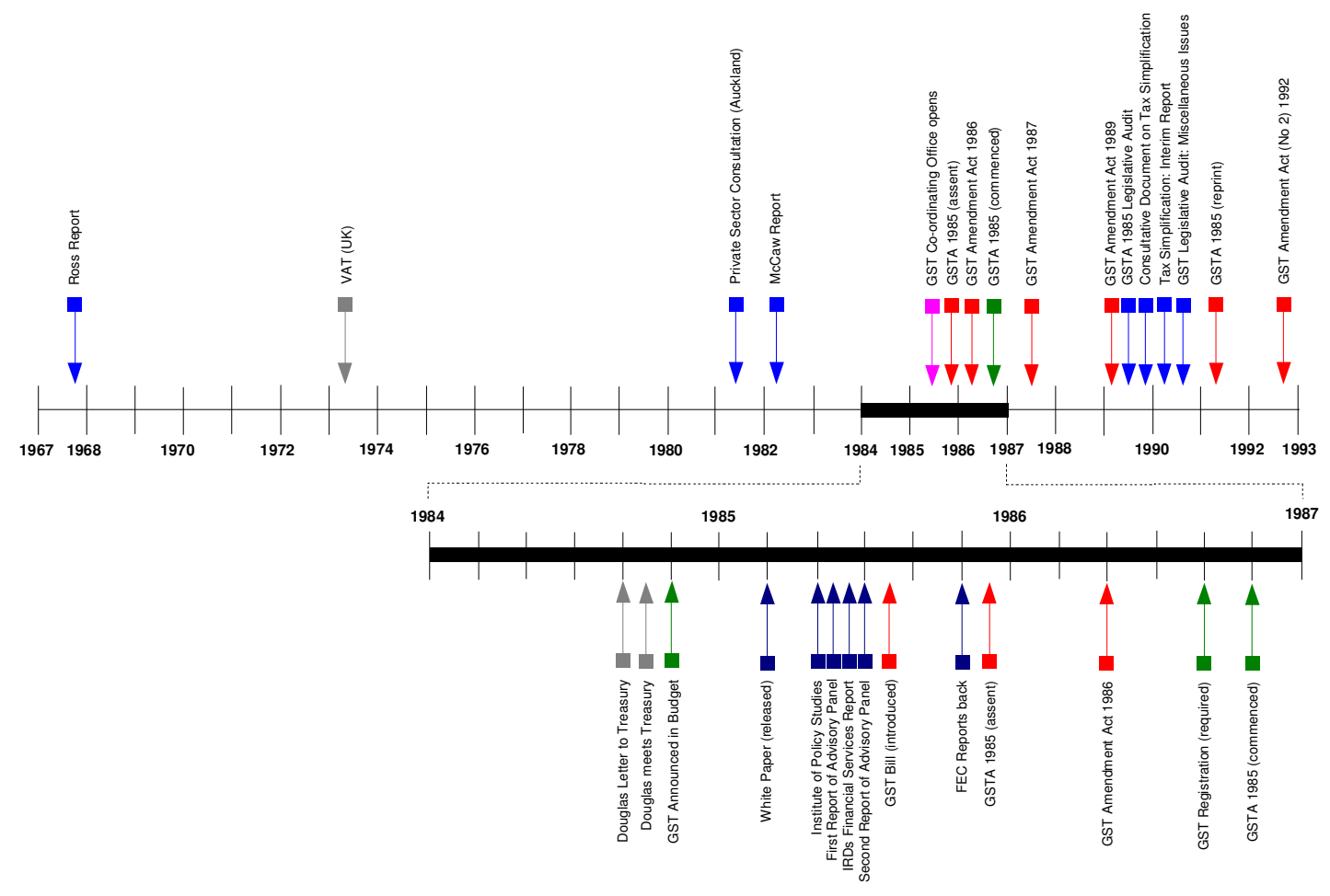

9 The GST Act originally comprised 12 Parts. The 9 active Parts are: Part 1(Interpretation, ss 2 to 7); Part 2 (Imposition, ss 8 to 14); Part 3 (Returns and Payments, ss 15 to 26A); Part 6 (Recovery of Tax, s 42 to 43); Part 7 (Refunds and Relief from Tax, ss 45 to 48A); Part 8 (Registration, 51 to 54); Part 9 (Special Cases, ss 55 to 61A); Part 11 (General Provisions, ss 75 to 79); and Part 12 (Transitional Provisions, ss 84 to 86 ). 
Income tax has been described as a "creature of statute" 10 and GST is no different. Both utilise concepts of time, jurisdiction, and entity (or activity). ${ }^{11}$ The GST Act also appears to directly leverage a number of concepts from income tax law. However, the similarity ends. The language and structure of the GST Act is intentionally different, ${ }^{12}$ a difference that is more pronounced after the rewrite of income tax legislation and final enactment in the Income Tax Act 2007. ${ }^{13}$

Over a period of 25 years the GST Act has been subject to three major reviews. ${ }^{14}$ The adjustment rules have been discussed in all three reviews and have had a number of minor remedial amendments (illustrated in Figure 1.2). While the GST Act has received a reasonable level of reform and remedial legislative activity, the adjustment rules have largely remained untouched since enactment, subject to a revision and codification of the calculation methodology in $2000 .^{15}$

10 J Prebble "Why is Tax Law Incomprehensible?” (1994) British Tax Review 380.

${ }^{11}$ The spatial element of time (ie, taxable periods and periodic adjustments) has had a significant impact on the change-in-use rules.

${ }^{12}$ Given the speed in which the GST Act was drafted, it is hardly surprising that the drafters seem to have leveraged and modified widely known income tax concepts when drafting a new form of indirect tax legislation. For example, the GST Act contains a business test modelled on the income tax concept of business, but modified to make it broader by removing the second limb (ie, the requirement for profit) and renaming it the "taxable activity". Other examples include the adoption of a "purpose" test (considered in CIR v Haenga (1985) 7 NZTC 5,198 and CIR v National Distributors Ltd (1989) 11 NZTC 6,346), which appears in the GST Act as the "principal purpose" test, or the use of the words "to the extent" (considered in CIR v Banks [1978] 2 NZLR 472 (CA)) that enable apportionment. It is little wonder that the early GST cases (eg, Case M53 (1990) 12 NZTC 2,312 (TRA)), referred back to these established income tax cases.

${ }^{13}$ The rewrite of the Income Tax Act (and phased enactment in 2004 and 2007) has adopted a plain language approach to tax legislation. See B Birch and W Creech Rewriting the Income Tax ActObjectives, Process, Guidelines: A Discussion Document (IRD, Wellington, 1994).

${ }^{14}$ D Caygill The Goods and Services Tax Act 1985: Legislative Audit (IRD, Wellington, February 1989); B Birch and B English GST: A Review - A Government Discussion Document (Policy Advice Division, IRD, Wellington, March 1999); and P Dunne GST: Accounting for Land and Other HighValue Assets - A Government Discussion Document (IRD, Wellington, November 2009). Document available at <http://taxpolicy.ird.govt.nz/publications/2009-dd-gst/overview> (viewed 20 March 2011). A more detailed discussion is outlined below (see Part 3 of this Chapter).

${ }^{15}$ Codification of the calculation methodology was enacted by the Taxation (GST and Miscellaneous Provisions) Act 2000 and applied from 10 October 2000. The original s 21 was restructured, effectively moving proviso's to their own subsection. Sections 21 A to 21 I were added, effectively codifying the calculation methodology. All of the case law is in relation to the pre-2000 version of the adjustment rules and there has yet to be a case on the post-2000 versions. 
In December 2010 (with general application from 1 April 2011) the change-in-use rules were "fundamentally changed", shifting from an adjustment approach (utilising a "principal purpose" test and deemed supply mechanism) to an apportionment approach (utilising a "use" test). ${ }^{16}$ This sudden change in direction was brought about by an apparent drive towards reducing compliance costs and broad acknowledgment that the rules (particularly the calculation methodology) were difficult to understand and apply.

Figure 1.2: The Reform History of Adjustment Rules

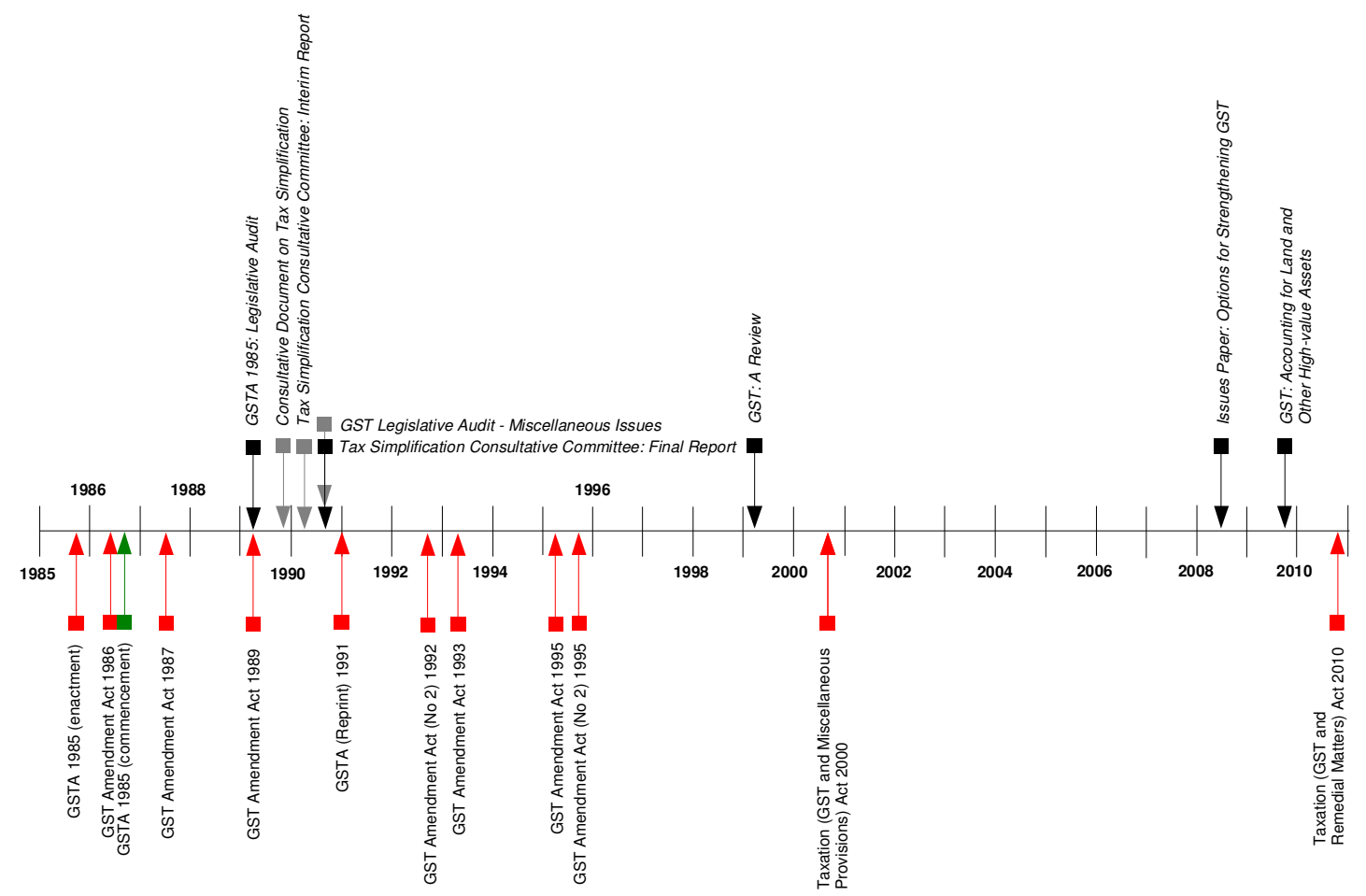

\section{Deconstructing the Rules}

Essentially the New Zealand change-in-use rules can be divided into three periods: (1) the original rules as enacted in 1985 ; (2) the revised rules that codified a number of earlier guidelines in 2000; and (3) the reformed rules (enacted in December 2010) that take affect from 1 April 2011. The first two periods adopted a threshold adjustment mechanism (utilising a "principal purpose" test) that enabled change in use adjustments (utilising a deemed supply mechanism). The third period marks a

\footnotetext{
${ }^{16}$ Taxation (GST and Remedial Matters) Act 2010. Document available at <www.legislation.govt.nz/act/public/2010/0130/latest/DLM3123411.html> (viewed 20 March 2011).
} 
fundamental shift away from a rigid threshold adjustment and deemed supply approach towards the adoption of a new apportionment approach (which would appear to a large extent to have adopted the Australian rules). This later approach utilises a more liberal "use" test that reflects actual use, rather then the application of a broad gateway threshold. Accordingly, a change-in-use is determined by comparing intended (or estimated) use against actual use, rather than a fictional deemed supply created by the existence of another purpose that is not the principal purpose.

An analysis of the rules also has to divide the change-in-use rules into two parts: (1) the gateway tests into the mechanism that entitle the claiming of input or output tax credits (ie, the front-end); and (2) the measurement mechanism that applies the relative financial values to the non-taxable use or deemed supply (ie, the back-end).

Much of the early development and judicial consideration of the change-in-use rules in New Zealand dealt with determining the scope of the change-in-use mechanism (ie the front-end of the rules), with considerably less discussion about how the value of the adjustment should be determined (ie, the back-end of the rules). ${ }^{17}$ Detailed judicial consideration of the calculation methodology did not materialise until the Lundy line of cases, where conflicting methods in determining the value of the input or output tax credits were advanced. Until this line of cases, judicial consideration was very fleeting and generally involved apportionment (eg, 49 per cent or 25 per cent), rather than discussing how a portion would be calculated. ${ }^{18}$ In Australia, judicial consideration of methodology has also been limited. ${ }^{19}$ In Canada, it has had slightly more consideration, but due to the flexibility in choosing a reasonable method of calculation, litigation has again been limited. ${ }^{20}$

\footnotetext{
${ }^{17}$ A large amount of the early New Zealand cases settled on adjustments based on very general apportionment considerations.

${ }^{18}$ During the period where the Courts believed that principal purpose meant "more than half", adjustments for private use could only amount to something less than 50 per cent (eg, 49 per cent) as anything greater would suggest the principal purpose had been abandoned.

${ }^{19}$ American Express Wholesale Currency Services Pty Ltd [2010] FCAFC 122, (2010) 77 ATR 12.

${ }^{20}$ Canada employs a "fair and reasonable" methodology test.
} 


\section{The General Rules}

The adjustment rules are based on the inter-related operation of ss 3A (definition of input tax), 20 (calculation of tax payable), and 21 (adjustments) of the GST Act. The policy objective of the adjustment rules is to ensure that input tax credits reflect the extent of the taxable use of goods and services. ${ }^{21}$ This is achieved by making adjustments to input tax or output tax if the original intended use of the goods and services changes, or if they are acquired for both taxable and non-taxable purposes.

\section{Input tax credits}

The expression "principal purpose" is used in both ss 3A (input tax) and 21 (adjustments). ${ }^{22}$ Unfortunately, the expression is not defined in the GST Act leaving the courts to determine its nature and scope.

Input tax is currently defined in $\mathrm{s} 3 \mathrm{~A} .{ }^{23}$ The definition provides that:

“(1) Input tax, in relation to a registered person, means -

(a) tax charged under section 8(1) on the supply of goods and services made to that person, being goods and services acquired for the principal purpose of making taxable supplies:" (emphasis added)

The "principal purpose" test is a threshold test for entitlement to input tax credits. To obtain an input tax credit, the registered taxpayer has to prove that goods or services

${ }^{21}$ B Birch and B English GST: A Review - A Government Discussion Document (IRD, Wellington, March 1999) at [4.4]. Although this policy was not recognised by IRD until after the Court of Appeal case of CIR v Lundy Family Trust and Behemoth Corp Ltd (2005) 22 NZTC 19,637 (CA). Before Lundy, the IRD considered that the adjustment rules did not necessarily reverse tax credits to the extent of the taxable use (a view advanced by the Commissioner in argument before the Court of Appeal in Lundy).

22 The definition of input tax was initially located in the definitions provisions of s 2(1). However, in 2000, the definition was shifted to its own unique provision. This course of action was recommended in submissions on the GST Bill 1985, but not carried out on enactment. For example, see Peat Marwick Submissions on the Goods and Services Tax Bill 1985 (25 September 1985) 2 at [1.2] (Finance and Expenditure Committee file number FE/85/307, 262W).

${ }^{23}$ Section 3A was inserted by s 85(1) of the Taxation (GST and Miscellaneous Provisions) Act 2000 and applied from 10 October 2000. Prior to the introduction of s 3A, the definition was found in $\mathrm{s} 2(1)$ - the general definitions provision. For the purposes of this paper the key elements of the provision (emphasised above) have remained intact since its introduction in 1985. 
would be "acquired for the principal purpose of making taxable supplies" 24 and not principally for some other non-taxable purpose. ${ }^{25}$ If the acquisition was made principally for making taxable supplies, then the acquisition will be entitled to a full input tax credit. Goods or services not acquired for the principal purpose of making taxable supplies are not entitled to any input tax credits. The input tax credit is not apportioned. Effectively this is an all or nothing approach to input tax credit entitlement (illustrated in Figure 1.3), with the focus of inquiry at the time of acquisition. $^{26}$

Figure 1.3: Principal Purpose (100 per cent Input tax Credit)

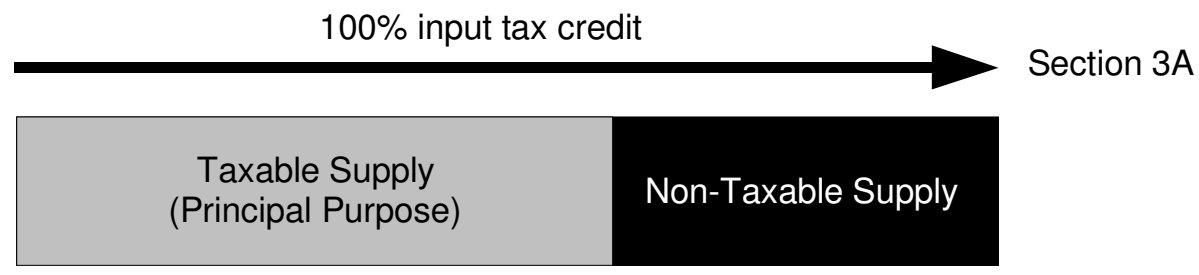

\section{Adjustments}

In most instances goods or services will be acquired for one purpose and the focus of inquiry will be whether they were acquired for making a taxable or non-taxable supply. However, there will be instances where goods or services are initially acquired for mixed purposes or subsequently become used for mixed purposes (eg, acquired for both taxable and non-taxable supplies).

As the input tax rules adopt an all or nothing approach to input tax credit entitlement, it is possible that part of the supply that is used for a non-taxable supply will be included as part of the overall input tax credit entitlement. In such instances adjustment rules are required to ensure the correct amount of input tax is paid (so that the taxpayer is not over-taxed) and equally to ensure the correct amount of tax is

\footnotetext{
${ }^{24}$ Goods and Services Tax Act 1985, s 3A.

${ }^{25}$ The burden of proof is on the registered taxpayer to establish on the balance of probabilities.

${ }^{26}$ Case M53 (1990) 12 NZTC 2,312 (TRA) and cited with approval in CIR v Trustees in the Mangaheia Trust (2009) 24 NZTC 23,711 (HC) and Wairakei Court Ltd v CIR (1999) 19 NZTC 15,202 (HC).
} 
collected in order that the taxpayer has fulfilled their tax obligations (so that the tax base is protected). ${ }^{27}$

To ensure a similar result to an apportionment approach (ie, the clawing back of that part of the full input tax credit not related to making taxable supplies), adjustment rules are required that create a deemed supply of the non-taxable portion of the initial acquisition (illustrated in Figure 1.4). This mechanism is provided for in $\mathrm{s} 21$ (subject to de minimis thresholds) that are designed for changes-in-use. ${ }^{28}$

Section 21(1) as originally enacted stated: ${ }^{29}$

“(1) Subject to section 5(3) of this Act, to the extent that goods and services applied by a registered person for the principal purpose of making taxable supplies are subsequently applied by that registered person for a purpose other than that of making taxable supplies, they shall be deemed to be supplied by that registered person in the course of that taxable activity to the extent that they are so applied:" (emphasis added)

Section 21(1), applies where goods or services used for the principal purpose of making taxable supplies are later applied for a different purpose (eg, non-taxable or exempt). Section 21(1) is used to account for the GST element in the value of personal use of business goods or services (eg, personal use of a business motor vehicle, or goods taken from a corner dairy for personal consumption). Section 21(5), covers the reverse situation - where privately-owned goods or services are

${ }^{27}$ In contrast, an apportionment approach (utilising a use test) will only award input tax credits for the part of the supply that is acquired for taxable supplies. Any part of the supply not related to a taxable purpose will not be awarded input tax credits.

${ }^{28}$ In contrast, a financial de minimis threshold is not specified in the Canadian threshold adjustment rules, which instead apply a 90:10 safe harbour rule (see Chapter 3). The apportionment approach in Australia utilise a safe harbour approach (see Chapter 2).

29 The original s 21 was replaced by s 100(1) of the Taxation (GST and Miscellaneous Provisions) Act 2000 and applied from 10 October 2000. For the purposes of this paper the key elements of the provision (emphasised above) have remained intact since its introduction in 1985. It is interesting to not that prior to the second reading of the GST Bill, many elements of the adjustment rules were to a large extent scattered throughout the GST Act. Clause 23A (subsequently enacted as s 21, was created during the Select Committee phase and brought together "in one clause the various provisions dealing with apportionment" (eg, cls 5(2)(a), 5(2)(b), 9(2), 10(7) and 23(5) of the first reading version of the GST Bill). It was also recommended that "a new de minimis provision be inserted to allow a person engaged in a taxable activity to ignore for apportionment purposes only exempt supplies that did not exceed $\$ 48,000$ and 5 per cent of his total turnover". This subsequently became the first proviso in s 21(1) of the GST Act. 
applied partly for use in a taxable activity (eg, partial business use of a privatelyowned motor vehicle). ${ }^{30}$

Figure 1.4: Adjustment of 100 per cent Input Tax Credits (Clawback and Reversal)

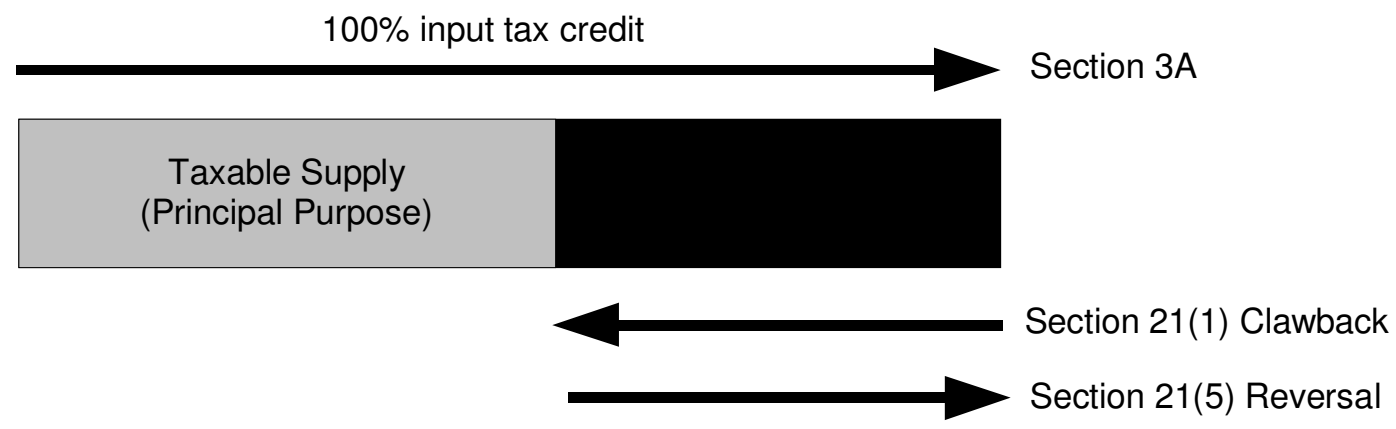

Effectively, the deficiency of a broad brush threshold approach (ie, the "principal purpose" test) to awarding input tax credits, has been overcome by utilising rules designed for changes in subsequent use between taxable and non-taxable purposes, as opposed to apportionment of the initial acquisition.

Unfortunately, the adjustment rules have the potential for output tax credits (adjustments in favour of Inland Revenue) to exceed the total input tax credits initially claimed, as there is nothing expressly provided in the legislation to prevent periodic adjustments continuing indefinitely. While such an approach was rejected by the Court of Appeal (in favour of a "used-up" model, illustrated in Figure 1.5), ${ }^{31}$ it would appear that the principal purpose test does provide a point where the total amount of adjustments (eg, successive output tax credits) could build up to the point where the principal purpose has been abandoned and the taxable activity is no longer the principal purpose (ie, a tipping-point model, illustrated in Figure 1.6). At this tipping point a full adjustment for any outstanding input tax credits would then have to be made. ${ }^{32}$ In contrast, the Court of Appeal resolved the matter slightly differently,

\footnotetext{
${ }^{30}$ Other elements (ie, "subsequently applied" and "to the extent that") are present in the provisions. But due to word restrictions, these elements are not discussed in this paper.

${ }^{31}$ CIR v Lundy Family Trust and Behemoth Corp Ltd (2005) 22 NZTC 19,637 (CA).

${ }^{32}$ This is the obiter reasoning advanced by Judge Barber in Case U13 (1999) 19 NZTC 9,147 (TRA).
} 
on the basis that periodic adjustments and off-one adjustments should produce the same result (ie, an implied financial cap on output adjustments). ${ }^{33}$

Figure 1.5: Principal Purpose: Used Up Point Model

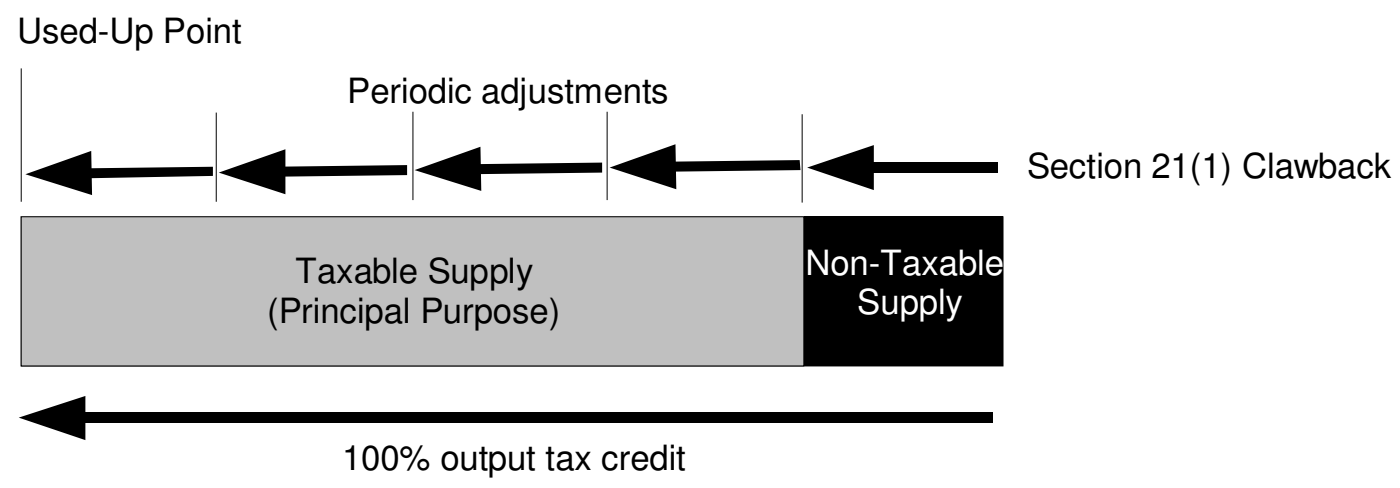

Figure 1.6: Principal Purpose Tipping Point Model

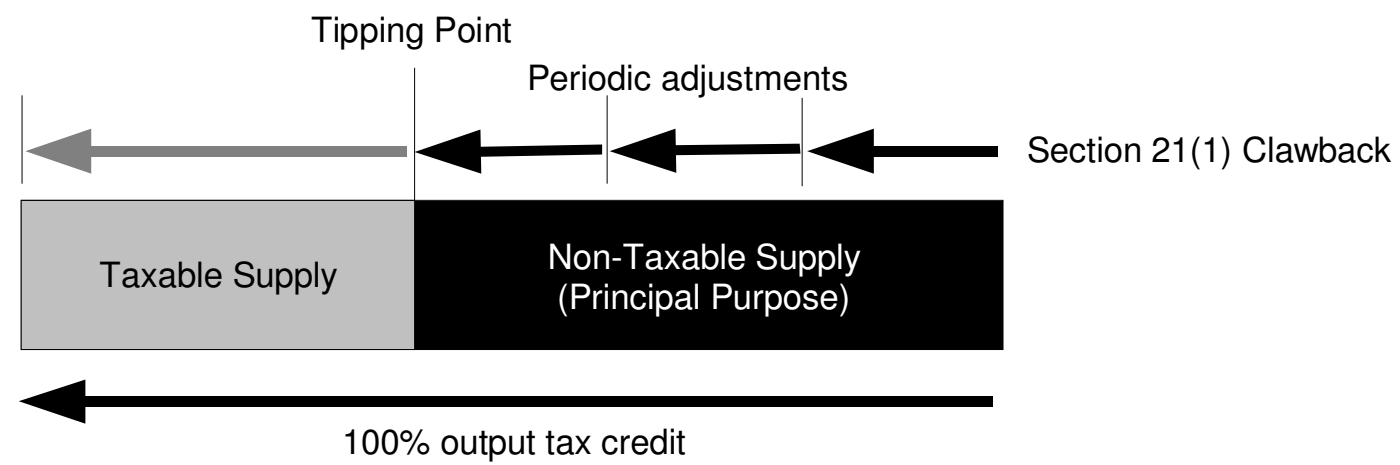

\section{Adjustment exclusion}

A registered person is not required to make output tax adjustments for exempt

supplies that do not exceed the de minimis rule. The de minimis rules are designed to minimise compliance costs by excluding small exempt uses from the operation of the adjustment rules. $^{34}$

The de minimis rule comprises two tests (estimated on a reasonable basis over a 12month period) that must not be breached. The rule provides that a changes-in-use

\footnotetext{
${ }^{33}$ See discussion below in Part 2 of this Chapter.

${ }^{34}$ Goods and Services Tax Act 1985, s 21(1), first proviso. De minimis is the shortened version of the phrase "de minimis non curat lex", meaning that the law does not concern itself with trifles.
} 
below the lesser of either the maximum specified financial value (ie, \$90,000) or specified percentage (ie, 5 per cent), will not activate the adjustment mechanism. ${ }^{35}$ Failing to meet either test will result in the adjustment rules being applied. ${ }^{36}$

\section{Timing of adjustments}

Generally, adjustments will be made according to the taxable periods they are made in. This can result in high administration and tracking costs for changes-in-use for low value supplies. To reduce compliance costs, the rules provide taxpayers the opportunity to elect to make a one-off adjustment (subject to specific conditions), rather than ongoing periodic adjustments. ${ }^{37}$ A one-off adjustment will automatically be available for supplies below $\$ 18,000$ (or above that amount with the agreement of the Commissioner). This option for a one-off adjustment may be taken up only in the first return period in which the goods were acquired or produced.

Supplies above the $\$ 18,000$ threshold (originally $\$ 10,000$ and adjusted for inflation to $\$ 18,000$ in 2000) remain subject to periodic adjustments for an indefinite period. According to Inland Revenue this adjustment requirement is to prevent avoidance opportunities and protect the revenue base. ${ }^{38}$

\section{Calculation of adjustment}

To calculate change-in-use adjustments it is necessary to establish the proportion that goods or services are used in relation to taxable and non-taxable supplies. There are three methods of allocation: direct attribution; the turnover method; or a special

\footnotetext{
${ }^{35}$ Goods and Services Tax Act 1985, s 21(4). The de minimis rule was originally located in the first proviso of s 21(1). In 2000, the threshold was adjusted for inflation from $\$ 48,000$ to $\$ 90,000$.

${ }^{36}$ The new apportionment approach also provides a de minimis threshold approach.

${ }^{37}$ Goods and Services Tax Act 1985, s 21G. Before this provision was enacted in 2000, the Courts had acknowledged that a one-off adjustment was available (for supplies less than $\$ 10,000$ ) under the second proviso in s 21(1): Case N39 (1991) 13 NZTC 3,333 (TRA). The second proviso was inserted by s 18(3) Goods and Services Tax Amendment Act 1986. In 1995, IRD confirmed that a deemed supply occurred in each taxable period in which the goods and services were used for non-taxable purposes (ie, periodic adjustments): Tax Information Bulletin Vol 6:11 (April 1995) 1. Section 21G is to a large extent a codification of judicial interpretation and prior policy.

${ }^{38}$ B Birch and B English GST: A Review - A Government Discussion Document (Policy Advice Division, IRD, Wellington, March 1999) at [4.32].
} 
method. These methods were initially prescribed as policy statements, ${ }^{39}$ but were later codified in the legislation. ${ }^{40}$

Direct attribution involves allocating the cost of goods and services to taxable and non-taxable supplies on the basis of actual use. If the cost of goods and services cannot be directly attributed, the proportion of taxable and non-taxable use can be calculated on a turnover basis. If the direct attribution or turnover methods are not suitable, a registered person may agree with Inland Revenue to use another method of allocation.

\section{Rule refinement}

The principal purpose test has experienced two major refinements. The first was the notion that a principal purpose of a supply did not need to be "more than half" of a taxable supply for it to be entitled to an input tax credit. Something less than a 50 per cent threshold was sufficient, provided it remained the main or fundamental purpose (illustrated in Figure 1.7).

The second refinement was the notion that purposes did not need to be linear, but could be concurrent. In a linear approach, only one purpose can exist at any one time and the taxpayer switches between taxable and non-taxable purposes (illustrated in Figure 1.8). Many of the early cases adopted this approach, although this may have also reflected the nature of the goods and services that were examined. Adopting a concurrent approach acknowledges that non-taxable purposes can exist in parallel to taxable purposes (illustrated in Figure 1.9). This approach acknowledges that some goods and services are capable of different uses at the same time. In both approaches, the court must decide which purpose (taxable or non-taxable) is the principal purpose.

\footnotetext{
${ }^{39}$ See BR Pub 96/11 (expired) in Tax Information Bulletin Vol 8:10 (December 1996) and earlier interpretation statements in Public Information Bulletin 143 (February 1986), Public Information Bulletin 169 (February 1988), Tax Information Bulletin Vol 5:8 (January 1994), Tax Information Bulletin Vol 6:11 (April 1995), Tax Information Bulletin Vol 6:14 (June 1995) and GST Guide -A guide to working with GST (GST 600, December 1997).

${ }^{40}$ The codification was enacted by the Taxation (GST and Miscellaneous Provisions) Act 2000 and applied from 10 October 2000.
} 
Figure 1.7: Principal Purpose (More or Less Than Half)

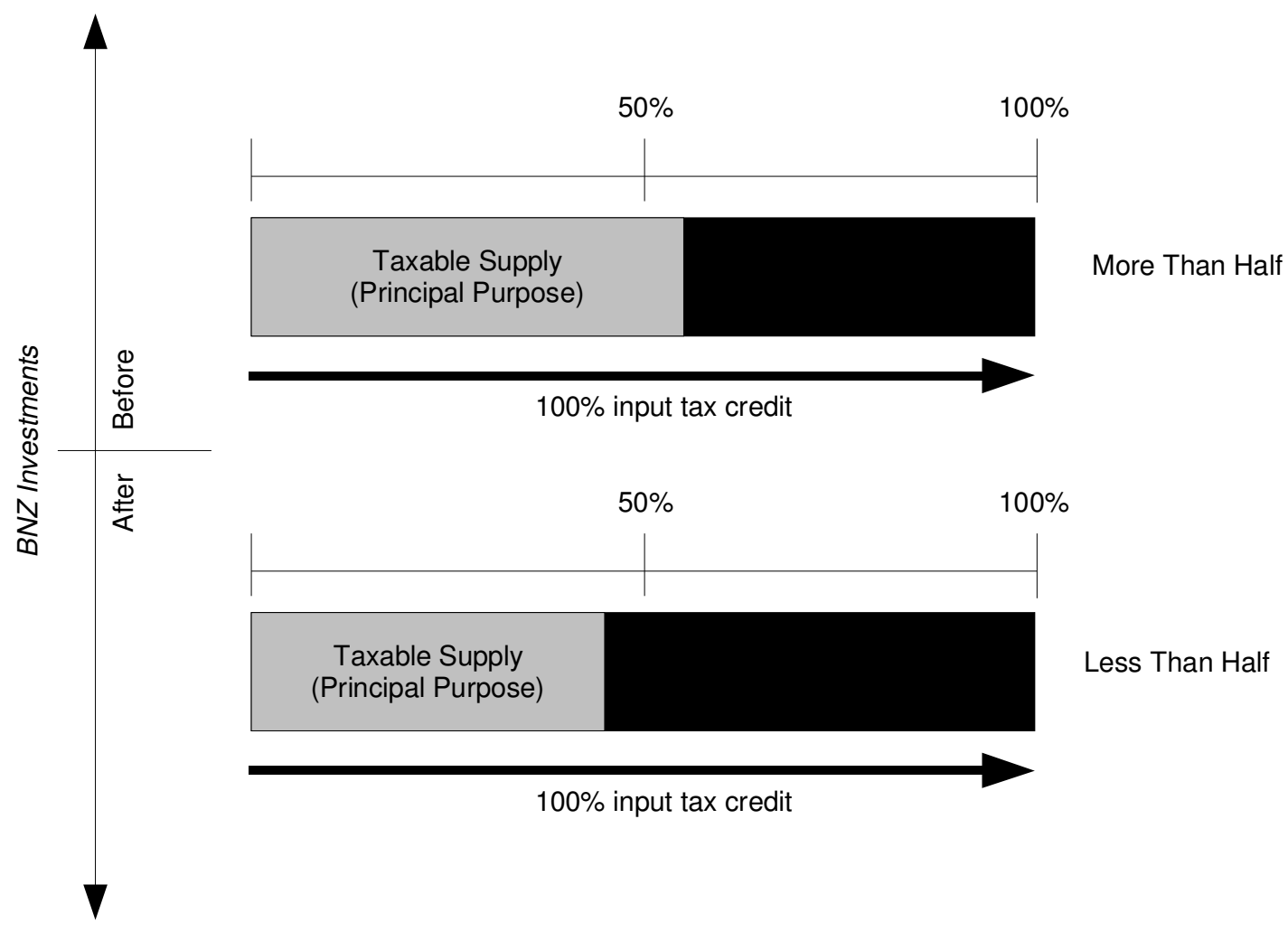

Figure 1.8: Linear Purposes

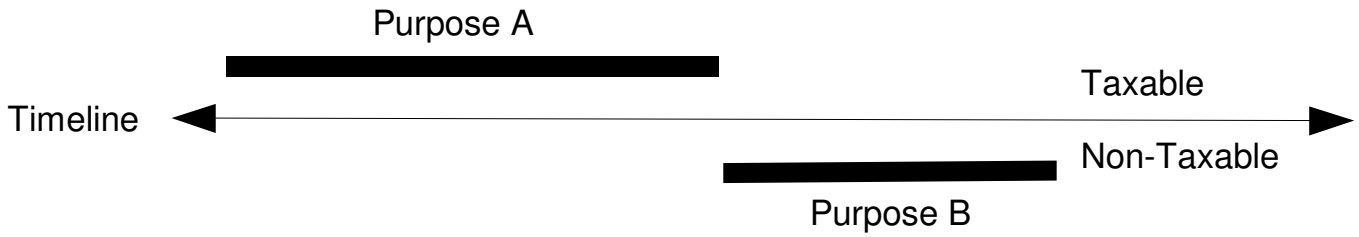

Figure 1.9: Concurrent Purposes

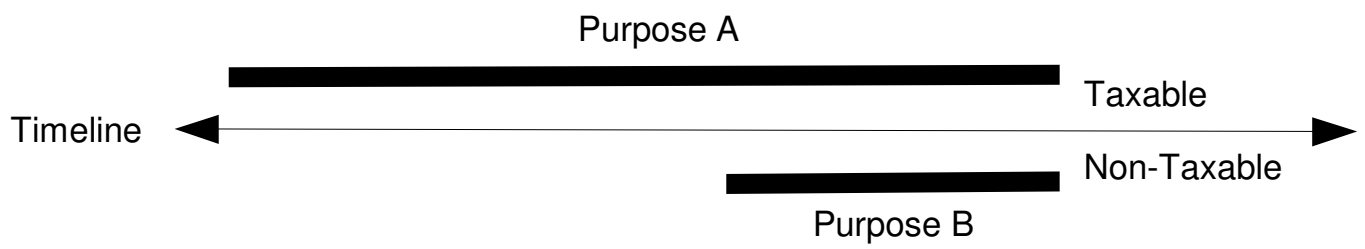

The adjustment rules provide a mechanism that creates a deemed (or fictional) supply in order to make an apportionment between the taxable and non-taxable nature of the supply. The fictional supply is activated when the taxable supply (ie, a good or service acquired for the principal purpose of making taxable supplies) is 
subsequently applied for two or more purposes (one of which is for a non-taxable purpose). Effectively, part of the taxable supply has been applied for a non-taxable purpose. The task before the courts is to identify a non-taxable purpose and to determine the extent of that purpose as a portion of the ongoing taxable purpose (ie, the principal purpose).

In some instances the courts have instead sought to identify the make-up of the taxable supply itself. ${ }^{41}$ However, this ignores the fact that the focus of inquiry is on purpose of the supply, not the supply itself. Rather, the deemed supply (or fiction) results from the identification of a non-taxable purpose. The non-taxable purpose does not result from identifying what does or does not make up a taxable supply (or taxable activity). This misconception appears to be at the heart of the legal services cases, which seek to apply an analysis that was in part, first attempted by Judge Barber in Case S81 (and over-turned in Morris), by suggesting that rental activity (an exempt supply) was part of the normal course of property development (ie, sufficiently tied to property development).

It is submitted that an examination of purpose is separate from an examination of supply, although how the supply is used (or not used), may assist in a determination of purpose. In most cases the courts could have resolved the cases on what should have been (or not been) the taxable supply at the start, rather than utilising the change-in-use mechanism to achieve the same result. Exempt supplies could never have been part of a taxable supply. Often the taxable supply has been identified by the courts as the equivalent taxable activity (eg, the provision of elderly care, or property development) and this equivalence may have added to the general confusion.

\section{Restructuring}

In 2000, the adjustment rules were restructured (and redrafted) into new provisions that made a distinction between input tax adjustments ${ }^{42}$ and output tax adjustments. ${ }^{43}$

\footnotetext{
${ }^{41}$ For example see Case S81 (1996) 17 NZTC 7,505 (TRA).

${ }^{42}$ Goods and Services Tax Act 1985, ss 21E to $21 \mathrm{I}$.
} 
The restructuring also codified prior policy statements on methodology published in Tax Information Bulletins (TIB). ${ }^{44}$ No case law has examined these rules and for the purpose of this thesis they have not been examined in detail due to the constraints of this paper. $^{45}$

\section{Part 2: Implementation and Operation - Empirical Evidence}

The extent of judicial consideration and the amount of litigation of the principal purpose test and the adjustment rules strongly suggests that the adjustment rules have not worked well. The rules have invited substantial judicial interpretation (and appeal) of key elements of the rules. This ongoing interpretation illustrates the underlying complexity inherent in the adjustment approach adopted in New Zealand and the manner in which it has been drafted.

\section{E. Judicial Activity}

Over the last 25 years (from 1985 to 2010), there have been 532 reported cases that have cited or considered GST provisions (illustrated in Figures 1.10 and 1.11). ${ }^{46}$ Of those cases, 349 interpreted a provision of the GST Act according to the headnotes (illustrated in Figures 1.12 and 1.13). ${ }^{47}$ White and Trombitas have reported a similar figure (albeit a slightly lower figure of 335 cases). ${ }^{48}$

${ }^{43}$ Goods and Services Tax Act 1985, ss 21 to 21D.

${ }^{44}$ For example Tax Information Bulletin Vol 5:8 (January 1994) 1.

${ }^{45}$ This thesis is based on the assumption that the restructuring is a codification of existing law and for this reason has avoided adding to the pre-existing complexity of the rues by citing revised adjustment provisions.

46 This figure results from a search for "Goods and Services Tax Act" across the full text of all reported tax cases in Thomson Reuters (New Zealand) Brookers Tax Service Cases database (viewed 20 March 2011).

${ }^{47}$ This figure results from a search for "Goods and Services Tax Act" across the headnote field of all reported tax cases in Thomson Reuters (New Zealand) Brookers Tax Service Cases database (viewed 20 March 2011).

${ }^{48}$ D White and E Trombitas "New Zealand" in Ecker T, Lang M and Lejeune I (eds) The Future of Indirect Taxation: Recent Trends in VAT and GST Systems Around the World - A Global Comparison (2011, forthcoming publication) at [1.5] fn 34. As no date of application is provided it is assumed the estimated figures do not relate to the year ended 2010 (more likely October 2010) which would explain the slight difference. McKenzie recorded 300 GST cases (as at 1 May 2008): A McKenzie GST: A Practical Guide (8th ed, CCH Ltd, Auckland, 2008) viii. 
Figure 1.10: Total Cases Citing GST Provisions 1985-2010 (Accumulated)

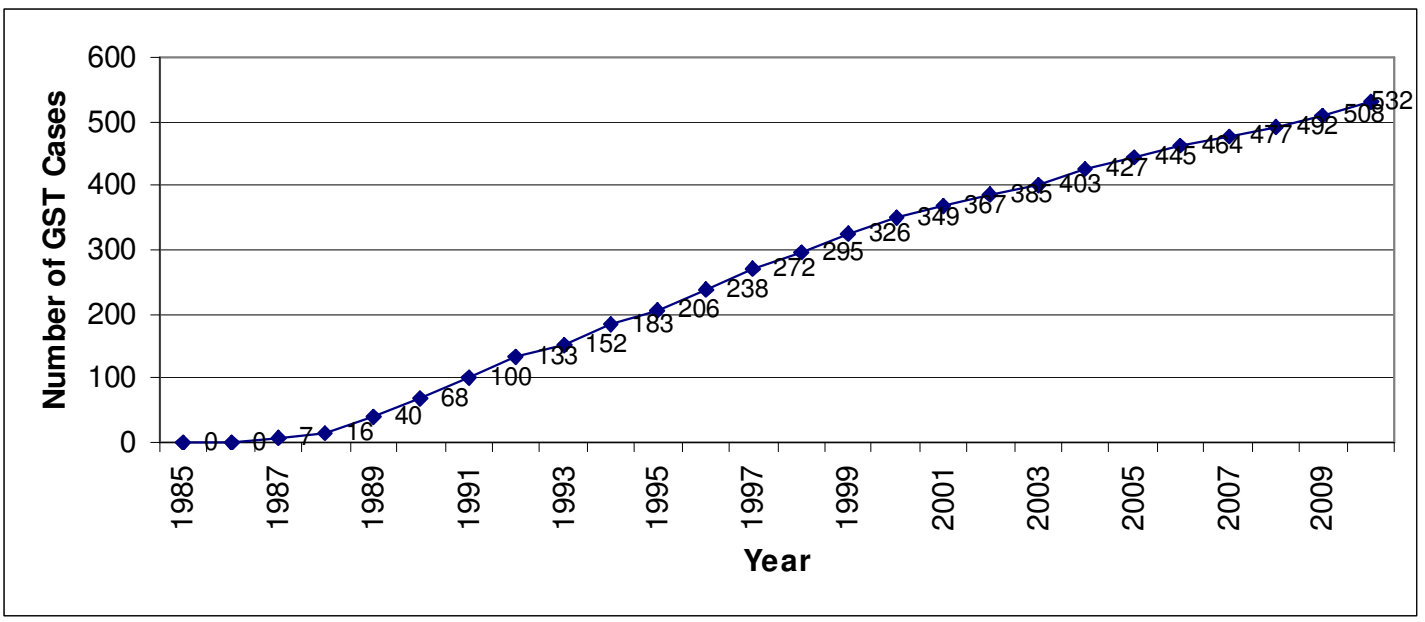

Figure 1.11: Total Cases Citing GST Provisions 1985-2010 (Courts)

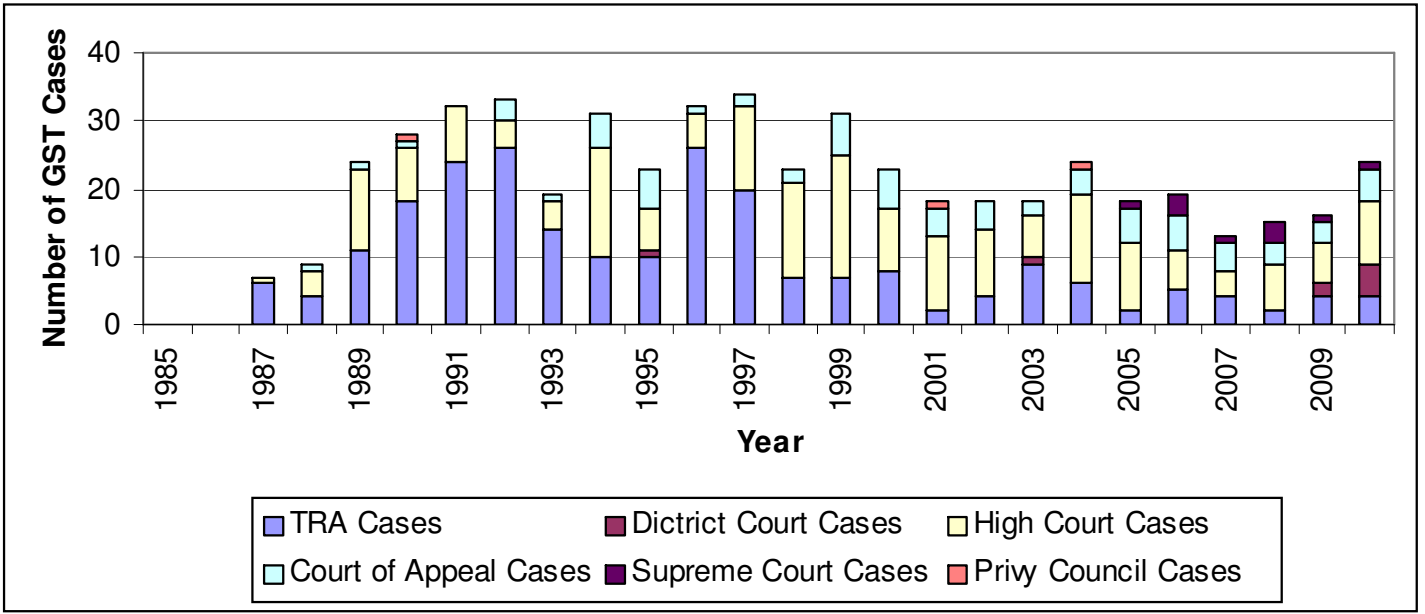

Figure 1.12: Reported GST Cases 1985-2010 (Accumulated)

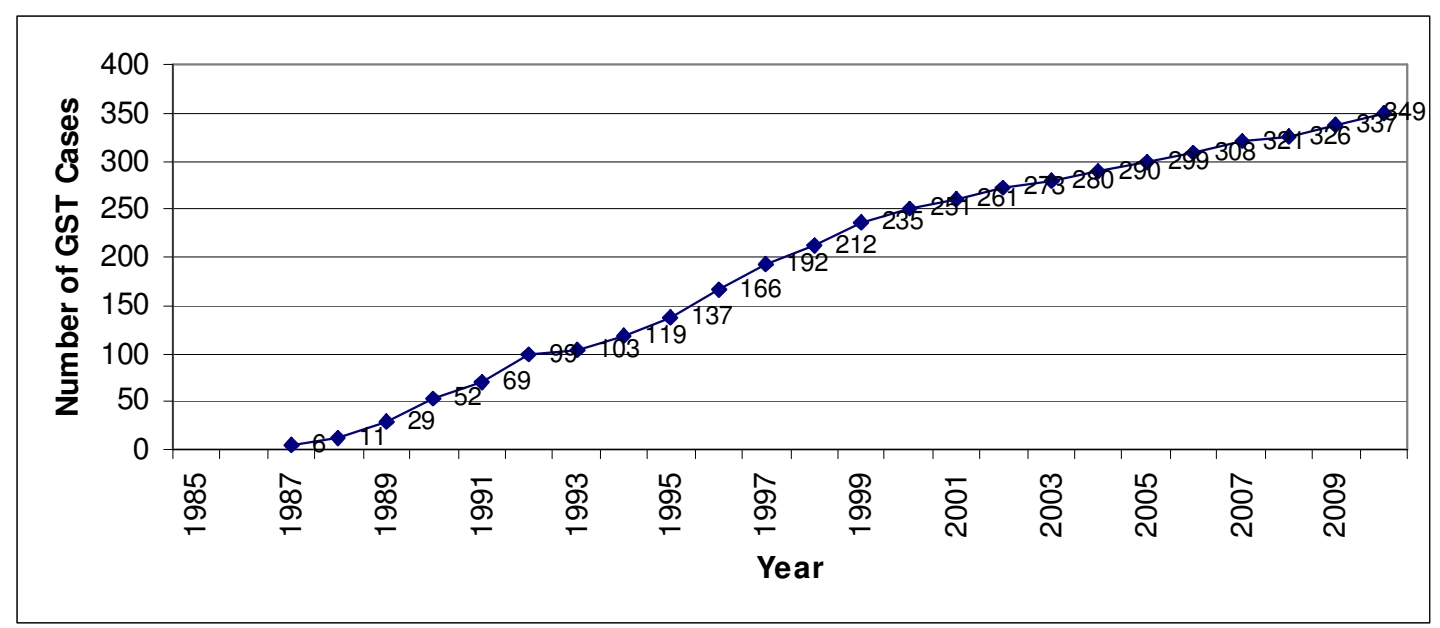


Figure 1.13: Reported GST Cases 1985-2010 (Courts)

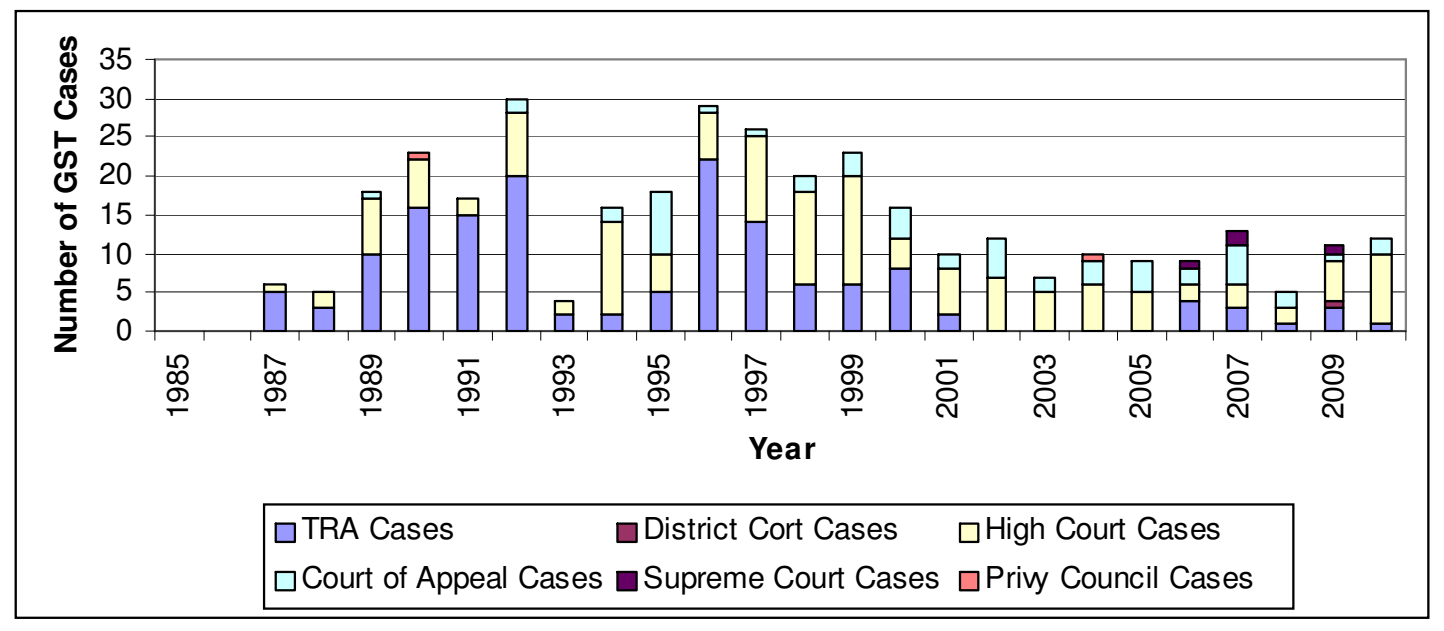

Figure 1.14: Reported Principal Purpose and Adjustment Cases (Accumulated)

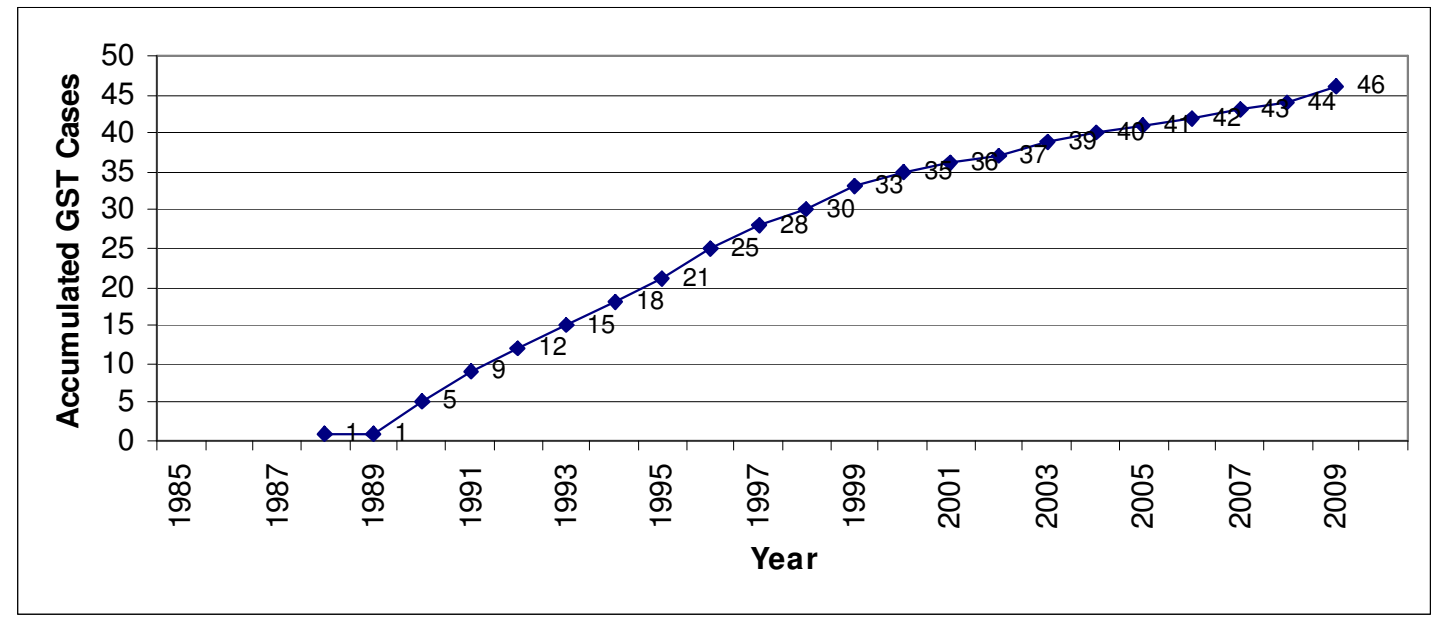

Figure 1.15: Reported Principal Purpose and Adjustment Cases (Courts)

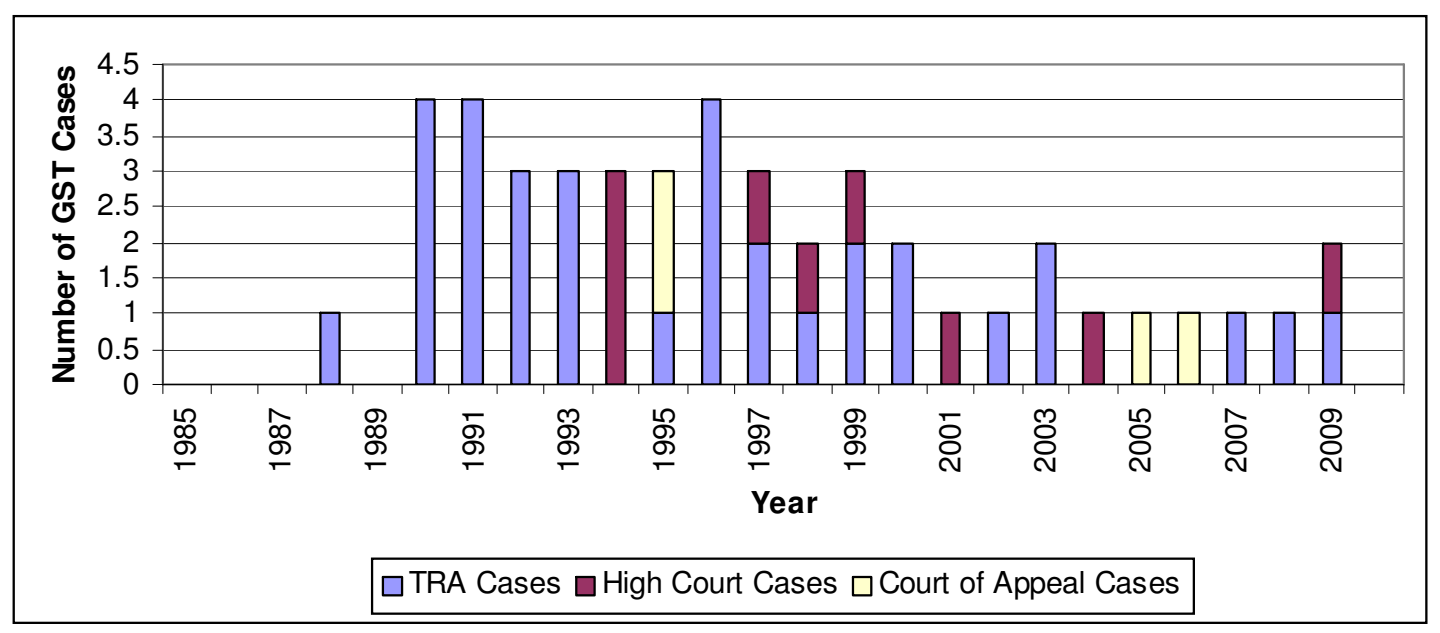


Over the same period there have been 46 cases that are related to resolving changein-use or principal purpose issues (illustrated in Figures 1.14 and 1.15). This figure equates to 13 per cent of recognised GST cases (eg, 46/349). The 46 cases comprise 33 Taxation Review Authority (TRA) cases, nine High Court cases, and four Court of Appeal cases. Figure 1.16 illustrates the sequential development of the respective cases. Interestingly, there have been no cases that have interpreted or applied the revised adjustment rules enacted in 2000.

Figure 1.16: Timeline of Cases (Principal Purpose and Adjustments) 1985-2010

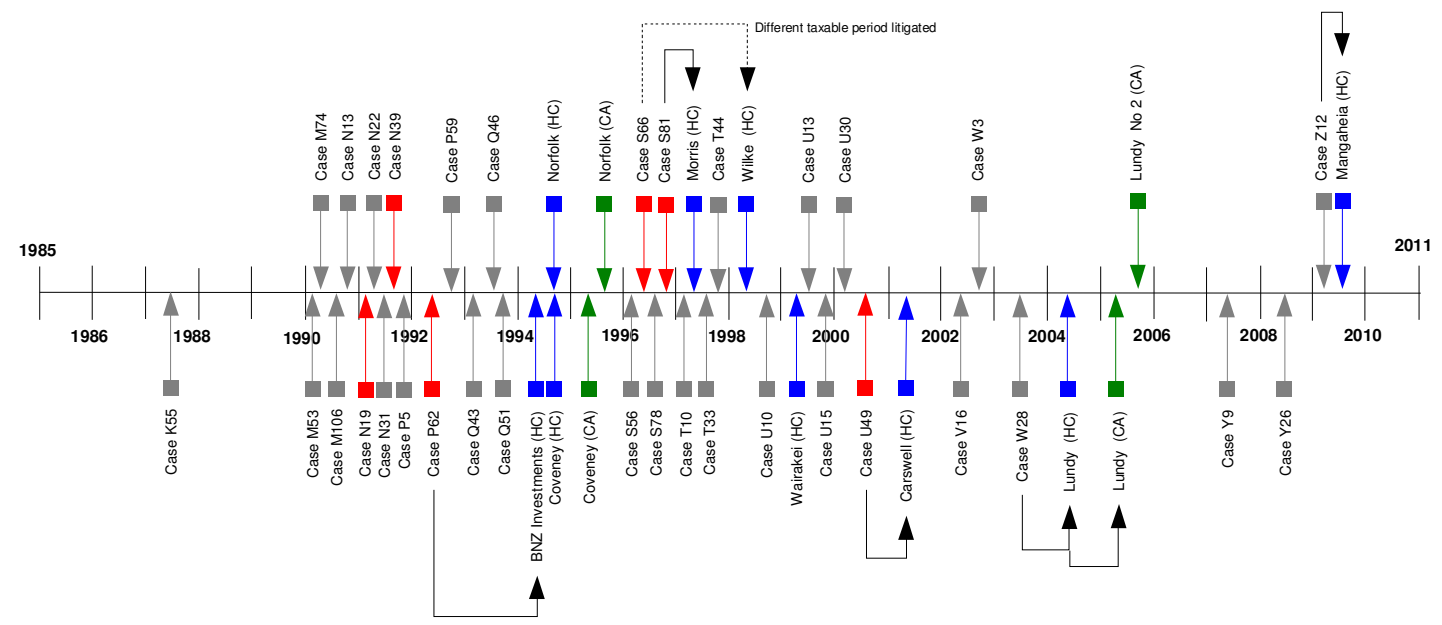

Judicial consideration of the 46 cases can also be mapped into four broad overlapping categories. The first field of categorisation groups cases on the basis of the facts. Generally there are six broad groups of fact situations: (1) the vehicle cases $;^{49}$ (2) the land cases $;{ }^{50}$ (3) the legal services cases $;{ }^{51}$ (4) the dwelling cases; ${ }^{52}$

${ }^{49}$ Case K55 (1998) 10 NZTC 453 (TRA); Case M53 (1990) 12 NZTC 2,312 (TRA); Case M74 (1990) 12 NZTC 2,441 (TRA); Case M106 (1990) 12 NZTC 2,674 (TRA); and Case P5 (1992) 14 NZTC 4,034 (TRA).

${ }^{50}$ Case Q46 (1993) 15 NZTC 5,227 (TRA); Case S66 (1996) 17 NZTC 7,412 (TRA); Wilke v CIR (1998) 18 NZTC 13,923 (HC); Case U15 (1999) 19 NZTC 9,162 (TRA); Wairakei Court Ltd v CIR (1999) 19 NZTC 15,202 (HC); and Case V16 (2002) 20 NZTC 10,182 (TRA).

${ }^{51}$ Case Q43 (1993) 15 NZTC 5,208 (TRA); Case U30 (2000) 19 NZTC 9,286 (TRA); Case W3 (2003) 21 NZTC 11,014 (TRA); Case Z12 (2009) 24 NZTC 14,142 (TRA); CIR v Trustees in the Mangaheia Trust (2009) 24 NZTC 23,711 (HC).

52 Case P59 (1992) 14 NZTC 4,406 (TRA); Case Q51 (1993) 15 NZTC 5,284 (TRA); Norfolk Apartments Ltd v CIR (1995) 17 NZTC 12,003 (HC); Norfolk Apartments Ltd v CIR (1995) 17 NZTC 12,212 (CA); Coveney v CIR [1995] 1 NZLR 90; (1994) 16 NZTC 11,328 (HC); CIR v Coveney (1995) 17 NZTC 12,193 (CA); Case S16 (1995) 17 NZTC 7,123 (TRA); Case S56 (1996) 17 NZTC 
(5) the financial services cases $;^{53}$ and (6) the property development cases. ${ }^{54} \mathrm{~A}$ second field of categorisation between the cases makes a distinction between (1) the private use cases; or (2) exempt supply cases. ${ }^{55}$ A third field of categorisation also exists in respect of input tax adjustments or output tax credit adjustments (although the courts have recognised this is not a significant distinction) ${ }^{56}$ Finally, a fourth field of categorisation of the cases exists between: (1) singular competing purposes (eg, switching between two opposing purposes); and (2) concurrent purposes (eg, two purposes that occur at the same time or overlap).

\section{F. The Problems of Principal Purpose}

The principal purpose test has been a source of extensive and ongoing judicial examination since its unexpected introduction. To a large extent the principal purpose test has been problematic because the concept of "purpose" and "principal" are not defined in the GST Act, but also because the concepts are inherently open to many different interpretations. In the absence of adequate guidance, there has been ample scope for argument and confusion, as the Court of Appeal recognised in Lundy. ${ }^{57}$

7,361 (TRA); Case T10 (1997) 18 NZTC 8,055 (TRA); Case T33 (1997) 18 NZTC 8,228 (TRA); and Case T44 (1998) 18 NZTC 8,295 (TRA).

${ }^{53}$ Case P62 (1992) 14 NZTC 4,427 (TRA) and CIR v BNZ Investment Advisory Services Ltd (1994) 16 NZTC 11,111 (HC).

${ }^{54}$ Case N13 (1990) 13 NZTC 3,105 (TRA); Case N19 (1991) 13 NZTC 3,158 (TRA); Case N22 (1991) 13 NZTC 3,187 (TRA); Case N31 (1991) 13 NZTC 3,277 (TRA) (quantum); Case N39 (1991) 13 NZTC 3,333 (TRA); Case S78 (1996) 17 NZTC 7,488 (TRA); Case S81 (1996) 17 NZTC 7,505 (TRA); CIR v Morris (1997) 18 NZTC 13,385 (HC); Case U13 (1999) 19 NZTC 9,147 (TRA) (quantum); Case U49 (2000) 19 NZTC 9,429 (TRA); CIR v Carswell Investments Ltd (2001) 20 NZTC 17,149 (HC); Case W28 (2003) 21 NZTC 11,289 (TRA); CIR v Lundy Family Trust (2004) 21 NZTC 18,595 (HC); CIR v Lundy Family Trust and Behemoth Corporation Ltd (2005) 22 NZTC 19,637 (CA); CIR v Lundy Family Trust and Behemoth Corporation Ltd No 2 (2006) 22 NZTC 19,738 (CA) (quantum); Case Y9 (2007) 23 NZTC 13,095 (TRA); and Case Y26 (2008) 23 NZTC 13,282 (TRA).

${ }^{55}$ Group one, two, and three relate to questions of private or taxable use, where as group five and six relate to exempt supplies. Group four consists of overlaps between private use (business use) and exempt supplies (residential accommodation).

${ }^{56}$ CIR v Morris (1997) 18 NZTC 13,385 (HC) at [27].

${ }^{57}$ CIR v Lundy Family Trust and Behemoth Corp Ltd (2005) 22 NZTC 19,637 (CA) at 19,647 at [42]. 
The principal purpose test is not defined in the GST Act and Parliament did not explain why it had adopted a "principal purpose" test. However, its appearance is clearly connected to the appearance of the adjustment rules, in an attempt to differentiate between two or more competing purposes — one purpose associated with a taxable activity or supply (ie, the "principal purpose"), and other purposes associated with a non-taxable activity or supply.

When the GST Act was first proposed (White Paper) ${ }^{58}$ it did not contain any adjustment rules. The Advisory Panel (First Report) ${ }^{59}$ observed that adjustment rules were "necessary in order to distinguish between the supply of goods and services for personal reasons and the supply of goods and services for the purpose of the furtherance of a taxable activity." 60 The Minister agreed, but neither the Bill nor the GST Act contained any detailed adjustment guidelines.

The appearance of a "principal purpose" test was a surprise for many who had expected detailed rules and guidance, rather than a conceptual test of "purpose", that had is origins in income tax law. ${ }^{61}$ According to Teixeira, this was "not the type of

${ }^{58} \mathrm{R}$ Douglas Proposals for the Administration of the Goods and Services Tax (Wellington, March 1985) [The White Paper]. See Figure 1.1.

${ }^{59}$ D Brash Report of the Advisory Panel on the Goods and Services Tax (Wellington, June 1985) [First Report]. See Figure 1.1. It is interesting to observe that the language used in the White Paper in regard to the adoption of an adjustment mechanism is couched in terms of a set of apportionment rules. For example, "The draft legislation contains no rules to apportion inputs between taxable supplies and other supplies. In our view such rules are necessary in order to distinguish between the supply of goods and services for personal reasons and the supply of goods and services for the purpose of the furtherance of a taxable activity. Again, apportionment rules are required in order to deal with charities and non-profit organisations and they could, depending upon the policy decisions made by Government, be required in other areas." Nowhere in the White Paper does it refer to a deemed supply mechanism as the basis for apportionment.

${ }^{60}$ D Brash Report of the Advisory Panel on the Goods and Services Tax (Wellington, June 1985) ch "General Comments on the Draft Legislation".

${ }^{61}$ It is evident when reading the GST Act that the drafters drew on income tax concepts and language (present at the time) to provide some degree of certainty. For example, taxable activity draws on the first limb of the income tax concept of business, but does not require an intention for profit (thus making it broader). See Grieve v CIR [1984] 1 NZLR 101 (CA). 
guidance anticipated by many traders, who expected clear rules and apportionment formulae." 62

\section{The meaning of "purpose"}

The expression "principal purpose" comprises two concepts: "purpose" and "principal". Both terms have borrowed extensively from income tax concepts. ${ }^{63}$ The term "purpose" is best described as the objective or ends (ie, the effect which is sought to be achieved or to be done), not the means to an end. It has also been described with approval as "the object or the end which the taxpayer has in mind or view" ${ }^{64}$ In one of the earliest GST cases considering the meaning of principal purpose, Judge Bathgate in Case M53 observed that: ${ }^{65}$

\footnotetext{
“"Purpose' is a fairly common word in tax law. In CIR v Haenga (1985) 7 NZTC 5,198; (1985) 9 TRNZ 41 Richardson J considered the various ways of interpreting the word 'purpose', according to its statutory context and the ways that the dictionary meaning of the object or end in view varies, according to whether it is the immediate or ultimate object, the conscious or unconscious purpose and the objective or subjective purpose that is to be considered. ... The proper interpretation of the word is dependent on its statutory context." (emphasis added)
}

Adding that: ${ }^{66}$

“'Purpose' is not a material thing but is dependent to a large extent upon a state of mind, but it is not the same as 'intent' or 'motive'. The word is commonly used in the tax avoidance field, where 'purpose' is said to mean the effect which is sought to be achieved - the end in

${ }^{62}$ A Teixeira, C Scott, and M Devlin Inside GST: The Development of Goods and Services Tax (VUW Press, Wellington, 1986) 45.

${ }^{63}$ Plimmer v CIR [1958] NZLR 147 (CA); Newton v C of T [1958] AC 450; CIR v Walker [1963] NZLR 339 (CA); CIR v Hunter [1970] NZLR 116 (CA); Mangin v CIR [1971] NZLR; Ashton v CIR [1975] 2 NZLR 717; (1975) 2 NZTC 61,030; Grieve v CIR [1984] 1 NZLR 101; (1984) 6 NZTC 61,682 (CA); CIR v Haenga (1985) 7 NZTC 5,198 (CA); and CIR v National Distributors Ltd [1989] 3 NZLR 661; (1989) 11 NZTC 6,346 (CA).

${ }^{64}$ A discussion of "purpose" can be found in M Keating "The Principal Purpose Test for the GST Input Tax: Is a Wide Interpretation Justified?" 16 New Zealand Journal of Taxation Law and Policy (2010) 85.

${ }^{65}$ Case M53 (1990) 12 NZTC 2,312 (TRA) at 2,316 at [20].

${ }^{66}$ Case M53 (1990) 12 NZTC 2,312 (TRA) at 2,316 at [22]. 
view, and what is done or what is contracted to be done is said to be the purpose of a transaction - Newton v FCT (1958) 11 ATD 442; [1958] AC 450, Mangin v CIR 70 ATC 6001; [1971] NZLR 591 and Ashton v CIR (1975) 2 NZTC 61,030; [1975] 2 NZLR 717; (1975) 1 TRNZ 190.” (emphasis added)

Several years later in CIR v BNZ Investment Advisory Services Ltd, the High Court again sought to import income tax concepts of purpose. Doogue J observed that: ${ }^{67}$

\begin{abstract}
"So far as the word 'purpose' is concerned, there was no real difference between them in their submissions. They relied upon cases such as Plimmer v CIR [1958] NZLR 147; CIR v Hunter [1970] NZLR 116 (CA); CIR v National Distributors Ltd [1989] 3 NZLR 661; (1989) 11 NZTC 6,346 (CA), and CIR v Walker [1963] NZLR 339 (HC \& CA). They were agreed that purpose is the object which the taxpayer has in mind or in view. It is not synonymous with intention or motive. (emphasis added)"
\end{abstract}

This interpretation of "purpose" would subsequently find support as one of several general principles in CIR $v$ Trustees in the Mangaheia Trust (2009) 24 NZTC 23,711 (HC) and Wairakei Court Ltd v CIR (1999) 19 NZTC 15,202 (HC), where Chisholm J held that: ${ }^{68}$
"Purpose is a reference to the object that the taxpayer had in mind or in view. This is not synonymous with intention or motive. Moreover, care must be taken to avoid confusing the means by which the taxpayer achieves its purpose with the purpose itself: $C I R \vee B N Z$ Investment Advisory Services Ltd (1994) 16 NZTC 11,111; Norfolk Apartments Ltd v CIR (1995) 17 NZTC 12,003 (HC) and 12,212 (CA)"

The meaning of "principal": a main or more than half approach?

Early judicial consideration of "principal purpose" does not make any reference to authority, although it did tend to suggest that the expression "principal" should be “more than half". ${ }^{69}$ In Case M53, ${ }^{70}$ Judge Bathgate suggested that a 50:50 approach to mixed use was insufficient to establish a "principal purpose". It was not until Case

\footnotetext{
${ }^{67}$ CIR v BNZ Investment Advisory Services Ltd (1994) 16 NZTC 11,111 (HC) at 11,115.

${ }^{68}$ Wairakei Court Ltd v CIR (1999) 19 NZTC 15,202 (HC) at 15,206 at [20].

${ }^{69}$ Case M53 (1990) 12 NZTC 2,312 (TRA). Subsequently cited with approval in Case M106 (1990) 12 NZTC 2,674, although "principal purpose" was not found for want of evidence.

${ }^{70}$ Case M53 (1990) 12 NZTC 2,312 (TRA).
} 
N13 that two cases were cited as authority: CIR $v$ Mitchell $^{71}$ and General Motors New Zealand Ltd $v$ Taylor. ${ }^{72}$ Unfortunately the cases provide slightly different tests and the court in Case $N 13^{73}$ was left to determine which way it would turn. No doubt in light of Case M53, Judge Bathgate adopted Mitchell's “more than half” approach.

Davison CJ in Taylor ${ }^{74}$ interpreted the word "principally" by asking the question "what was the primary and fundamental purpose ... as opposed to a merely incidental or accessory purpose?". ${ }^{75}$ This was an approach that Davidson CJ observed was consistent with Funk \& Wagnell's New Standard Dictionary definition, which provided that "principally" meant:

"First or highest in rank, character, authority, value or important; most important; leading; chief; as the principal men of a town; principal points of advantage. Being the most worthy or important, as distinguished from what is incidental, appertinent, or accessory; as, a principal obligation, right or estate."

Three years later Davison CJ in Mitchell $^{76}$ again explored the meaning of "principal". ${ }^{77}$ Interestingly, Davison CJ this time drew upon the observations of Lord Morton of Henryton in Fawcett Properties Ltd v Buckingham County Council ${ }^{78}$ (a case not cited in Taylor) where Lord Morton expressed the view that the word "mainly" probably meant "more than half". An interpretation that was supported by the dictionary definition of "mainly" which provided that it meant "for the most part,

${ }^{71}$ CIR v Mitchell (1986) 8 NZTC 5,181 (HC).

${ }^{72}$ General Motors New Zealand Ltd v Taylor (1983) 6 NZTC 61,880 (HC).

${ }^{73}$ Case N13 (1991) 13 NZTC 3,105 (TRA).

${ }^{74}$ General Motors New Zealand Ltd v Taylor (1983) 6 NZTC 61,880 (HC) at 61,885.

${ }^{75}$ This wording would resonate through later High Court judgments with approval.

${ }^{76}$ CIR v Mitchell (1986) 8 NZTC 5,181 (HC).

${ }^{77}$ An appeal from Case E102 (1982) 5 NZTC 59,547 (TRA).

${ }^{78}$ Fawcett Properties Ltd v Buckingham County Council [1961] AC 636 (HL). Subsequently supported in CIR v Mitchell (1986) 8 NZTC 5,181 (HC) and General Motors New Zealand Ltd v Taylor (1983) 6 NZTC 61,880 (HC). 
chiefly, principally" ${ }^{79}$ His Honour concluded that the correct test to apply was "greater than the total of all other uses" (emphasis added). ${ }^{80}$ This test confirmed the "more than half" approach. ${ }^{81}$

The TRA in Case N19, ${ }^{82}$ Case $N 22,{ }^{83}$ Case N39, ${ }^{84}$ and Case P5, ${ }^{85}$ would also apply a "more than half" approach. Notwithstanding these cases, it was Judge Barber in Case $P 5$, who was the first to suggest a preference for something "less than half" - an approach that would later find approval in the High Court. ${ }^{86}$ Until Case P62, ${ }^{87}$ the courts had adopted a "more than half" approach to principal purpose.

\section{As Judge Barber in Case P5 observed: ${ }^{88}$}

"The meaning of the word 'principal' in relation to purpose or use has been dealt with in a number of cases over the past decade, and Judge Bathgate also deals with that aspect in Case M53. It is sufficient to say, for present purposes, that the word 'principal' merely means main. This could be a user of less than $50 \%$."

\footnotetext{
${ }^{79}$ Interestingly, the Commissioner had argued in the TRA that the word "principally" meant "substantially more than half". Yet in BNZ Investment Advisory Services, the Commissioner would argue for the contrary.

${ }^{80}$ CIR v Mitchell (1986) 8 NZTC 5,181, 5,184 at [21]. An appeal from Case E102 (1982) 5 NZTC 59,547 .

${ }^{81}$ Interestingly Judge Barber in Case N39 and Counsel in Case N19 both misinterpreted Davidson CJ when discussing Mitchell. In fact Davidson CJ in Mitchell never used the phrase "a greater use than all other uses", but did use the phrase: "greater than the total of all other uses" (emphasis added). The use of the word "total" indicates that the principal purpose must be greater than 50 per cent, which is greater than the total of all other purposes. It appears that the word "total" is absent from any discussion of what Davidson CJ actually said in Mitchell.

${ }^{82}$ Case N19 (1991) 13 NZTC 3,158 (TRA).

${ }^{83}$ Case N22 (1991) 13 NZTC 3,187 (TRA).

${ }^{84}$ Case N39 (1991) 13 NZTC 3,333 (TRA). Appealed as CIR v Morris [1998] 1 NZLR 344, (1997) 18 NZTC 13,385 (HC).

${ }^{85}$ Case P5 (1992) 14 NZTC 4,034 (TRA).

${ }^{86}$ CIR v BNZ Investments Advisory Services Ltd (1994) 16 NZTC 11,111 (HC). An appeal from Case P62 (1992) 14 NZTC 4,427 (TRA).

${ }^{87}$ Case P62 (1992) 14 NZTC 4,427 (TRA).

${ }^{88}$ Case P5 (1992) 14 NZTC 4,034 (TRA) at 4,037 at [12].
} 
This interpretation was later cited with approval by Judge Willy in Case P62. ${ }^{89}$ Although the High Court in BNZ Investments ${ }^{90}$ would overturn on appeal the decision in Case P62, ${ }^{91}$ Judge Willy's analysis in Case P62 of how the principal purpose should be measured (on something less than 50 per cent), was not challenged. ${ }^{92}$

In BNZ Investments, the taxpayer was a financial planner and offered investment advice to its customers (for a small fee amounting to 2 per cent of total business income), as well as implementing that advice (and receiving a larger commission). Generally, 90 per cent of their time was spent on investment advice and 10 per cent on implementation. While both activities were of a financial nature and therefore exempt supplies, ${ }^{93}$ the provision of advice was excluded from the financial services exemption. ${ }^{94}$ Thus, only the implementation of advice was an exempt activity.

Accordingly, the taxpayer argued that the supply of advice (not implementation) was the principal purpose and was entitled to claim a full input tax credit. The CIR argued to the contrary although conceded that the taxpayer might be entitled to a 10 per cent adjustment. The TRA found for the taxpayer and allowed an adjustment of 10 per cent for the exempt activity.

The High Court (overturning the result in the TRA) held that the advice was merely a "means to an end" (not the end or ultimate purpose) and provided little income to the business. The main method of earning income was by earning commissions on investments placed with financial institutions. Doogue J observed that:

\footnotetext{
"With all respect to the TRA, it, like the taxpayer, has confused the means by which the taxpayer achieved its purpose with its purpose. Its purpose was not the provision of almost free advice to its customers but the making of an income from the investments made by those
}

${ }^{89}$ Case P62 (1992) 14 NZTC 4,427 (TRA) at 4,446 at [83].

${ }^{90}$ CIR v BNZ Investment Advisory Services Ltd (1994) 16 NZTC 11,111 (HC).

${ }^{91}$ Case P62 (1992) 14 NZTC 4,427 (TRA).

${ }^{92}$ M Keating “The Principal Purpose Test for the GST Input Tax: Is a Wide Interpretation Justified?" (2010) 16 New Zealand Journal of Taxation Law and Policy 85 at 91.

${ }^{93}$ Goods and Services Tax Act 1985, s 3(1).

${ }^{94}$ Goods and Services Tax Act 1985, s 3(19). 
customers: that is, the GST-exempt activity. The error is understandable when the taxpayer, to achieve its income, had to invest so much time and trouble in the investment advice aspect of its business."

The essential difference between the TRA and High Court in determining which purpose (advice or implementation) was the principal purpose was the High Court's focus on the revenue generated, rather than effort (or time) spent. Doogue J justified this approach on the basis that here was no suggestion that the taxpayer was carrying on business for a purpose other than achieving a profit. Had the taxpayer charged realistic fees (that were not loss making) or demonstrated that revenue was not central to their on-going existence, the focus and result may well have been different.

Within a year the court again returned to the meaning of the word "principal" in Case $S 81^{95}$ which was successfully appealed in CIR v Morris. ${ }^{96}$ In Morris, Giles J did not refer directly to Taylor ${ }^{97}$ or Mitchell, ${ }^{98}$ but did cite with approval Doogue J's analysis of those cases in BNZ Investments - where Doogue J concluded that "the word "principal" should be interpreted as main or primary or fundamental purpose". 99

The significance of the Morris case is the judicial recognition of two lines of competing cases (those supporting a more than half approach, and those that supported something less) and the explicit decision to follow the "less than half" test. While BNZ Investments is cited as the authority for this principal purpose test, Morris is when it became the undisputed authority.

${ }^{95}$ Case S81 (1996) 17 NZTC 7,505 (Judge Barber).

${ }^{96}$ CIR v Morris (1997) 18 NZTC 13,385 (HC). An appeal from Case S81 (1996) 17 NZTC 7,505 (TRA).

${ }^{97}$ General Motors New Zealand Ltd v Taylor (1983) 6 NZTC 61,880 (HC) at 61,885.

${ }^{98}$ CIR v Mitchell (1986) 8 NZTC 5,181 (HC) at 5,183.

${ }^{99}$ CIR v BNZ Investments Advisory Services Ltd (1994) 16 NZTC 11,111 (HC) at 11,115 at [17]. Unfortunately, Mitchell suggests that that the word "mainly" probably means "more than half, which leaves us in a some what circular argument. What is probably needed is for the Courts to come out and state that mainly does not mean "more than half", instead of circling the meaning of the expression by using different words that were also prescribed by the very same Judge. The association of the word "primary" as suggesting a main or fundamental test, rather than a more-than-half test, is also an interesting one in light of the contrasting interpretation in Canada, where "primary purpose" is interpreted as a "more than half" test. 
The test outlined in BNZ Investments ${ }^{100}$ has since been approved by the High Court in Norfolk Apartments Ltd v CIR, ${ }^{101}$, Wairakei Court Ltd v CIR, ${ }^{102}$ and CIR v Trustees in the Mangaheia Trust. ${ }^{103}$ It appears the courts, with approval from commentators ${ }^{104}$, have moved towards adopting the Taylor ${ }^{105}$ interpretation of "principal purpose" and moved way from the "more than half" approach in Mitchell. ${ }^{106}$ This was a shift in thinking that was certainly open for subsequent High Courts to entertain.

As Keating observes, a shift from a "more than half" approach to a "fundamental purpose" approach avoids the need for the court to weigh up a single purpose against combined alternatives - which could be unduly arduous. The court "must simply determine which is the most significant of all competing purposes". ${ }^{107}$ However, the proposed removal of the "principal purpose" test, and adoption of a use apportionment based test, could well throw the courts back to more detailed measurement process.

An alternative approach to principal purpose: the sufficient nexus test

Despite the general principles outlined in Wairakei Court Ltd $v$ CIR, the High Court in CIR v Trustees in the Mangaheia Trust sought to apply a "nexus" test to determine the "principal purpose", first used in Case Q43 (1993) 15 NZTC 5,208 (TRA) and subsequently in Case U30 (2000) 19 NZTC 9,286 (TRA) and Case W3 (2003) 21 NZTC 11,014 (TRA).

${ }^{100}$ CIR v BNZ Investment Advisory Services Ltd (1994) 16 NZTC 11,111 (HC).

${ }^{101}$ Norfolk Apartments Ltd v CIR (1995) 17 NZTC 12,003 (HC).

${ }^{102}$ Wairakei Court Ltd v CIR (1999) 19 NZTC 15,202 (HC).

${ }^{103}$ CIR v Trustees in the Mangaheia Trust (2009) 24 NZTC 23,711 (HC).

${ }^{104}$ M Keating "The Principal Purpose Test for the GST Input Tax: Is a Wide Interpretation Justified?" (2010) 16 New Zealand Journal of Taxation Law and Policy 85. See also Deloitte NZSA Educational Tax Course - GST (Continuing Education Paper, March 1994).

${ }^{105}$ General Motors New Zealand Ltd v Taylor (1983) 6 NZTC 61,880 (HC).

${ }^{106}$ CIR v Mitchell (1986) 8 NZTC 5,181 (HC).

${ }^{107}$ M Keating “The Principal Purpose Test for the GST Input Tax: Is a Wide Interpretation Justified?” (2010) 16 New Zealand Journal of Taxation Law and Policy 85, 91. 
According to Gendall J: ${ }^{108}$

"These decisions demonstrate one way of approaching the factual inquiry required under s $3 \mathrm{~A}(1)(\mathrm{a})$. To establish whether the services were required for the "principal purpose" of making taxable supplies may be to ask whether there is sufficient nexus between the services acquired and the making of the taxable supplies. It is inherent in a "sufficient nexus" approach that the purpose must be the principal purpose - if the principal purpose was something other than the making of taxable supplies then the conclusion should be there was insufficient nexus." (emphasis added)

Some commentators have expressed concerns about this High Court decision. According to Keating: ${ }^{109}$

“... Gendall J's decision (and the reasoning in Case T30) is both bad policy and contrary to the clear wording of the legislation. Furthermore, the reasoning in that decision even appears to be at odds with the income tax treatment of similar administrative expenses."

However, a similar use of "nexus" or being "tied" to the taxable activity was also applied in Wairakei Court Ltd $v$ CIR to determine the principal purpose. ${ }^{110}$ The fact the courts have been drawn to devise other tests to determine the "principal" purpose illustrates the general difficulty in identifying and applying such a test.

Is "principal" the immediate or ultimate purpose? - a blurring of the lines

In Wairakei Court Ltd $v$ CIR the High Court was called upon to determine the temporal scope of the principal purpose test. ${ }^{111}$ The facts were similar to $C I R v$ Norfolk Apartments Ltd. ${ }^{112}$ The taxpayer had expanded their rest home business and

${ }^{108}$ CIR v Trustees in the Mangaheia Trust (2009) 24 NZTC 23,711 (HC) at [27].

${ }^{109}$ M Keating “The Principal Purpose Test for the GST Input Tax: Is a Wide Interpretation Justified?" (2010) 16 New Zealand Journal of Taxation Law and Policy 85, 100.

${ }^{110}$ Wairakei Court Ltd v CIR (1999) 19 NZTC 15,202 (HC) at 15,208 at [31].

${ }^{111}$ An examination prophetically mentioned in the quote above from Judge Bathgate in Case M53 (1990) 12 NZTC 2,312 (TRA) at [20].

112 Norfolk Apartments Ltd v CIR (1995) 17 NZTC 12,003 (HC), (1995) 17 NZTC 12,212 (CA). There a taxpayer claimed input tax credits on the purchase of land used for the construction of a GST-exempt retirement village. Residents purchased a licence to occupy a particular unit and an ancillary right to use common areas (eg, corridors, stairwells, parking areas, the grounds and recreation areas). The taxpayer argued that there were two purposes and two supplies as part of an overall package to residents: an exempt supply of apartments (eg, dwellings), and a taxable supply of common areas and 
acquired additional land to expand the existing complex as well as construct several self-contained studio units and six stand-alone villas. Occupation of the units and villas were granted under a licence to occupy. Importantly, the provision of care was a compulsory component of the licence. The Commissioner rejected the taxpayer's claim for full input tax credit on the basis the principal purpose of the supply of the studio units and villas was not immediately for elderly care, but for occupation and accommodation.

The court rejected the Commissioner's argument and concluded that the dispute had essentially resulted from the Commissioner's inability to make a proper distinction between "the objector's object and the means by which it has set out to achieve that object". ${ }^{113}$ The court held that when determining the principal purpose it was necessary to make an overall evaluation of "all relevant purposes", ${ }^{114}$ and purposes that could not be fulfilled until some future time should not be automatically ruled out. Chisholm J observed that: ${ }^{115}$

“... In some cases it may be possible to achieve the principal purpose within the taxation period under consideration while in other cases achievement of the principal purpose may be much more distant in time. Each case will depend on its own facts."

The High Court determined that the licences to occupy the studios and villas were "factually and legally tied to the provision of care to the elderly" which was a

the facilities by way of a lease. The dwellings took up one-third of the land, the remainder being for common use. Both the High Court and Court of Appeal rejected the taxpayer's claim. The Courts held that the taxpayer's principal purpose in acquiring and developing the land was to be able to provide accommodation in dwellings situated within a retirement village. That was an exempt supply and therefore no input tax deduction was available. The High Court considered the supply of common areas was an ancillary or incidental purpose. The Court of Appeal observed that (at [14]):"Norfolk may now wish to say that its principal purpose was to provide a package for the residents of the retirement village but commonsense suggests that what must have been uppermost in the minds of the [taxpayer] was the supply of the apartments (the dwellings), for without them the project would simply not exist." The Court while unable to accept that there were two purposes observed that even if there had been two purposes the common areas were legally considered part of the building (as appurtenances to the building) so that they formed one exempt supply.

${ }^{113}$ Wairakei Court Ltd v CIR (1999) 19 NZTC 15,202 (HC) at 15,208 at [31].

114 This observation would appear to contradict Keating's conclusion that a principal purpose test avoids the need to consider every purpose — a point Keating considers an advantage of the principal purpose test.

${ }^{115}$ Wairakei Court Ltd v CIR (1999) 19 NZTC 15,202 (HC) at 15,207 at [27]. 
taxable activity. ${ }^{116}$ The licences to occupy constitute nothing more than a legal mechanism that made it possible to deliver residential care to the occupants of the studio units.

\section{Principal purpose and the other purpose: the one purpose model}

The High Court in CIR v Carswell Investments $\operatorname{Ltd}^{117}$ was invited to entertain an argument that there could only be one purpose, which effectively challenged the reasoning in Morris that it was possible to have two different concurrent purposes. In Morris, Giles J had held that: ${ }^{118}$

“s 21(1) requires a purpose which need not be the 'principal purpose' ... [but rather] a new purpose that is separate and distinct from the principal purpose."

It was argued that s 21(1) drew a distinction between a "principal purpose of making taxable supplies" on the one hand, and "a (subsequent) purpose other than that of making taxable supplies" on the other. Accordingly, the subsequent purpose had to be a new and different purpose, which displaced the earlier principal one. A principal and a subsequent purpose could not co-exist. ${ }^{119}$

This interpretation was rejected by the High Court. Panckhurst J observed that the very concept of deeming a supply presupposed that the principal purpose subsisted, which meant that there had to be two purposes co-existing. ${ }^{120}$ This interpretation was

\footnotetext{
116 The different outcome in Norfolk and Wairakei can be explained on the basis of the taxpayer's taxable activity. In Norfolk, the activity was classified as providing dwellings (an exempt non-taxable activity), whereas in Wairakei it was elderly care (a taxable activity). Had the taxpayer in Norfolk been providing "retirement care", the result might have been different, although the Court of Appeal's recognition that the common areas formed part of the building (an appurtenances to the dwellings) as a single exempt supply, would suggest not.

${ }^{117}$ CIR v Carswell Investments Ltd (2001) 20 NZTC 17,149 (HC).

${ }^{118}$ CIR v Morris (1997) 18 NZTC 13,385 (HC) at 13,395 at [45].

119 The word "subsequently" was inserted into s 21(1) by s 6(1)(b) of the Goods and Services Tax Amendment Act 1987 and the reason for its late insertion is unknown. It is interesting to note that Willy J in Case Q51 (1993) 15 NZTC 5,284 (TRA) at 5,291 at [49] observed that "subsequent was the opposite of contemporaneous". See also Case P59 (1992) 14 NZTC 4,406 (TRA). It is submitted that such an interpretation would appear to suggest that s 21 cannot apply to apportion mixed uses that have dual purposes at the time of acquisition because they are contemporaneous and have not changed.

${ }^{120}$ CIR v Carswell Investments Ltd (2001) 20 NZTC 17,149 (HC) at [33].
} 
reconfirmed in Lundy (HC). ${ }^{121}$ However, had it been accepted, it would have prevented any model of multiple concurrent purposes, which proved troublesome for the courts to apply, ${ }^{122}$ when attempting to then determine the level of apportionment between them. If the principal purpose test had also remained a more than 50 per cent test, such an interpretation would have provided a very simple model to apply, that would have had very low compliance costs (and avoided any need for de minimis rules).

Under a one-purpose model, an adjustment would only occur if the principal purpose had been abandoned and would provide a one-off full output tax credit adjustment. This would effectively have removed any mismatching or disconnect between input and output tax credits or indefinite adjustments. ${ }^{123}$

\section{Concurrent purposes - the multiple purpose model}

Despite a number of High Court cases providing guidance, the courts continued to struggle with the operation of the rules and identification of the issues. In Case $W 28,{ }^{124}$ (a property development case that was ultimately decided on the question of valuation methodology in the Court of Appeal decision in Lundy), ${ }^{125}$ Willy J held that Morris $^{126}$ and Carswell ${ }^{127}$ were authority for the proposition that it was possible to have two concurrent principal purposes, which was an interpretation rejected by the High Court as wrong and not supported by either Morris or Carswell. ${ }^{128}$

${ }^{121}$ CIR v Lundy Family Trust (2004) 21 NZTC 18,595 (HC).

${ }^{122}$ For example, see CIR v Lundy Family Trust (2004) 21 NZTC 18,595 (HC).

${ }^{123}$ Effectively this is the change-in-use adjustment model applied in Canada and might explain the low litigation activity the Canadian rules have experienced.

${ }^{124}$ Case W28 (2003) 21 NZTC 11,289 (TRA) at 11,300 at [23].

${ }^{125}$ CIR v Lundy Family Trust and Behemoth Corp Ltd (2005) 22 NZTC 19,637 (CA).

${ }^{126}$ CIR v Morris (1997) 18 NZTC 13,385 (HC).

${ }^{127}$ CIR v Carswell Investments Ltd (2001) 20 NZTC 17,149 (HC).

${ }^{128}$ The Carswell case was a failed attempt to distinguish Morris on the basis that the rental activity was part of the principal purpose and not a separate purpose (ie, the rental activity facilitated security while the properties were marketed for sale, not to derive rents). In essence this was a similar line of argument advanced by Judge Barber in Case $S 81$ who suggest rental activity was part of property 
On appeal in CIR v Lundy Family Trust, ${ }^{129}$ the High Court acknowledged that there were multiple purposes (eg, property development for sale and letting), but found that while "the principal purpose and subsequent purpose co-exist" there could only be one principal purpose at anyone time and this was the purchase of the properties for ultimate sale. The letting supply was a lesser purpose. According to Chisholm J, the real issue was not whether there could be two principal purposes, but the extent to which the properties were applied for the non-taxable purpose of letting.

The High Court (and subsequently the Court of Appeal) ${ }^{130}$ were also unable to accept the Commissioner's argument that the principal purpose of property development had been subsequently displaced by a new principal purpose of letting. Chisholm J considered the argument unsustainable. ${ }^{131}$ The letting was a non-taxable purpose that was deemed to have been supplied by operation of the adjustment rules themselves. The rules themselves imply that the non-taxable supply is the lesser purpose and the amount of displacement is determined by their "extent".

Chisholm J's reasoning would appear to be somewhat circular in logic and does not address the question whether the principal purpose had been abandoned - which is at the heart of Commissioner's argument. ${ }^{132}$ Surely the Commissioner's argument could have been simply addressed by the facts themselves. The fact the apartments remained for sale at all times, suggests that the principal purpose had not been abandoned or displaced. Had the court not accepted the properties were for sale at all times, it is likely the result might have been different.

development (which was an approach and overturned in Morris). Panckhurst $\mathbf{J}$ rejected the argument as it was not supported by the facts. The rental activity was not incidental, but substantial, both in income and duration of the tenancies. Interestingly the Court gave little consideration to the rental activity being an exempt supply when determining the existence of another purpose as it had in Morris.

${ }^{129}$ CIR v Lundy Family Trust (2004) 21 NZTC 18,595 (HC).

${ }^{130}$ CIR v Lundy Family Trust and Behemoth Corporation Ltd (2005) 22 NZTC 19,637 (CA).

${ }^{131}$ CIR v Lundy Family Trust (2004) 21 NZTC 18,595 (HC) at 18,603 at [31].

132 There is nothing in the legislation suggesting that a non-taxable supply cannot be a principal purpose. On the contrary, the principal purpose test operates on the basis of disallowing input tax credits where a non-taxable supply is the principal purpose. 
As Galzebrook J observed: ${ }^{133}$

\begin{abstract}
"In this case, the taxpayers' principal purpose of the sale of the properties in the course of their taxable activities subsisted. The properties were therefore at all times being used for that taxable purpose. They were part of the taxpayers' trading stock and, indeed, remained on the market at all times. At the same time, they were let for residential purposes, but on a temporary basis."
\end{abstract}

Glazebrook J's judgement also suggests that the question of determining the principal purpose is not restricted to examining the evidence or the taxpayer's mind only during the relevant taxable period (where the Court of Appeal recognised that in terms of both time and space the properties were 100 per cent dedicated to both purposes), but over the lifetime of the activity. ${ }^{134}$ In contrast, the measurement of any change-in-use is often framed within the context of the taxable period.

\title{
Subjective or objective test
}

It is also worthwhile noting that in tandem with the court's difficulty in applying the "principal purpose" test, they have had equal difficulty deciding on whether the test should be determined objectively, subjectively, or a combination of both ${ }^{135}$ (or in some instances, if the facts allowed, not at all). ${ }^{136}$ As Chisholm $\mathrm{J}$ observed in Wairakei Court Ltd v CIR there had: ${ }^{137}$

${ }^{133}$ CIR v Lundy Family Trust and Behemoth Corporation Ltd (2005) 22 NZTC 19,637 (CA) at 19,647 at [41].

${ }^{134}$ This broader approach to identifying the principal purpose is consistent with earlier cases.

${ }^{135}$ An objective test was applied in: CIR v Carswell Investments Ltd (2001) 20 NZTC 17,149 (HC) (citing Morris); CIR v Morris (1997) 18 NZTC 13,385 (HC) (citing Case M106); Case U13 (1999) 19 NZTC 9,147 (TRA) (citing Case M106); Case P5 (1992) 14 NZTC 4,034 (TRA); Case M106 (1990) 12 NZTC 2,674 (TRA); Case N13 (1991) 13 NZTC 3,105 (TRA) (citing Case M106); and Case Q43 (1993) 15 NZTC 5,208 (TRA) (citing Case M106). A combination test was applied in: Wairakei Court Ltd v CIR (1999) 19 NZTC 15,202 (HC) (citing Case P62); Case Z12 (2009) 24 NZTC 14,142 (TRA) (citing Wairakei); Case S56 (1996) 17 NZTC 7,361 (TRA); Case Q51 (1993) 15 NZTC 5,284 (TRA); Case P62 (1992) 14 NZTC 4,427 (TRA); Case N13 (1991) 13 NZTC 3,105 (TRA); Case N22 (1991) 13 NZTC 3,187 (TRA) (where Judge Bathgate stated "No matter how 'purpose' is to be interpreted, in either an objective or subjective sense, the purpose of applying A and B to obtain rental returns, albeit for a net loss, was undoubtedly an object or end the objector had in view when it let those properties"), Case M53 (1990) 12 NZTC 2,312 (TRA); Case U30 (2000) 19 NZTC 9,286 (TRA); and Case W3 (2003) 21 NZTC 11,014 (TRA).

${ }^{136}$ Several cases have declined to entertain a decision on whether a subjective, objective or combination test is required. These cases were: Coveney v CIR (1994) 16 NZTC 11,328 (HC) at [55] (where Fraser 
“... been some divergence in judicial opinion about whether the principal purpose should be evaluated objectively, subjectively or by reference to a combination of those factors".

At present it would appear that there are essentially two lines of thinking, best summed up by Case M106 (approved by the High Court in Wairakei) and Case P62 (approved by the High Court in Carswell and Morris). In Case M106 Judge Bathgate observed that: ${ }^{138}$

“... the word 'purpose' in the operation of the Act, and in the particular parts mentioned, is to be given an objective meaning. It is to be determined objectively, from the activities of the taxpayer in relation to the supply of goods and services and the acquisition of goods and services relative to that supply."

According to Giles $\mathrm{J}$ in Morris, a subjective test was unworkable. The practical efficiency of the GST regime required a straightforward approach to purpose which was deduced from the objective facts, not on some idiosyncratic basis. However, some courts consider that such an approach does not rule out considering subjective considerations as well. The most recent word on the issue was expressed by Chisholm $\mathrm{J}$ in Wairakei Court Ltd $v$ CIR (who agreed with the opinion of Willy $\mathrm{J}$ in Case P62) who observed that the proper approach: ${ }^{139}$

\footnotetext{
"was to consider all evidence relevant to the stated intention and the manner in which that intention had been carried through ... it will usually be necessary to consider both subjective and objective indicators when determining the principal purpose".
}

J stated "I do not see any point in conducting an analysis into the subjective and objective approaches"); CIR v BNZ Investment Advisory Services Ltd (1994) 16 NZTC 11,111 (HC) at [19] (where Doogue J stated "I do not find it helpful to traverse this area of the argument as in the context of this case it does not seem to me important whether an objective, subjective or some other intermediate position should be taken."); and Case T44 (1998) 18 NZTC 8,295 at [20] (where Judge Barber stated "It does not matter in this case whether one applies a subjective, objective (the usual test), or mixed test to ascertaining the "principal purpose" as there is no evidentiary conflict in that regard.").

${ }^{137}$ Wairakei Court Ltd v CIR (1999) 19 NZTC 15,202 (HC) at 15,206 at [21].

${ }^{138}$ Case M106 (1990) 12 NZTC 2,674 (TRA) at 2,678-2,679.

${ }^{139}$ Wairakei Court Ltd v CIR (1999) 19 NZTC 15,202 (HC) at 15,206 at [21]. 
The fact the courts have oscillated between whether subjective considerations should be included (or not) has added to the level of uncertainty surrounding the correct application of the principal purpose test. ${ }^{140}$

\section{G. The Problems of Calculating Adjustments}

\section{The Court of Appeal's last word}

\section{The Court of Appeal in CIR v Lundy Family Trust and Behemoth Corp Ltd ${ }^{141}$}

highlighted (and attempted to resolve) a number of ongoing inconsistencies and ambiguities that existed in the adjustment rules in the unanimous judgment of the court delivered by Glazebrook J. These problems included: a lack of connection between adjustments and the initial input tax credits received; the appropriate application of a one-off adjustment; and the degree of apportionment and method for valuing the adjustment. The fact these problems existed almost 20 years after the enactment of the rules and several years after BNZ Investments, ${ }^{142}$ Morris, ${ }^{143}$ and Carswell, ${ }^{144}$ illustrates the ongoing and inherent complexity of the adjustment rules. ${ }^{145}$ For all the protagonists (ie, taxpayers, tax advisors, the revenue authority, and judiciary), the rules remained difficult to understand, hard to apply, and appeared to be divorced from the underlying policy intent.

\footnotetext{
${ }^{140}$ In the author's view it is implicit in an objective test that subjective considerations are taken into account and that there is no distinction between a mixed or objective approach. Clearly the test (whether subjective or objective) will be determined by the statutory language. In those income tax cases where a subjective test was applied the statutory language used subjective words (eg, "intention"). In the former GST provisions (ss 3A and 21) the word "purpose" has been used instead of "intention". It will be interesting to observe whether this debate is re-opened by the statutory language of the new apportionment test which has used the expression "intended use" which would tend to suggest the import of a subjective test. In contrast, the equivalent Australian rules have used more objective terminology (eg, "estimated use"). The Australian terminology is to be preferred if an objective test is intended.

${ }^{141}$ CIR v Lundy Family Trust and Behemoth Corp Ltd (2005) 22 NZTC 19,637 (CA).

${ }^{142}$ CIR v BNZ Investment Advisory Services Ltd (1994) 16 NZTC 11,111 (HC).

${ }^{143}$ CIR v Morris [1998] 1 NZLR 344, (1997) 18 NZTC 13,385 (HC).

${ }^{144}$ CIR v Carswell Investments Ltd (2001) 20 NZTC 17,149 (HC).

145 This remains a concern for some taxpayers who might still be subject to these rules after 1 April 2011.
} 
As in Morris, the facts in Lundy concerned a property development that had acquired input tax credits on the acquisition of the properties, but had subsequently stalled and as an interim measure to keep the project financially afloat, a number of properties were leased, pending sale. ${ }^{146}$ At all material times the properties were actively marketed and available for sale. Although early judicial consideration in the TRA and High Court examined the proper application of the principal purpose test, by the time the case arrived at the Court of Appeal the dispute had centred on the correct methodology to be applied for determining the adjustment.

The CIR argued that the holding costs (eg, interest, rates, insurance, depreciation, and maintenance costs), of the apartments reflected the true value of the supply and had to be included in the adjustment calculation. The taxpayers argued that they had followed the IRD's policy statement example. ${ }^{147}$ They argued the cost of the rental supply was reflected in depreciation, and not the interest, rates, insurance and maintenance, which all related to the property development activity.

\section{Mirror provisions}

The courts have long acknowledged that s 21(1) and (5) were mirror provisions that provided for the receipt and payment of input tax and output tax credits, respectively. ${ }^{148}$ However, while the provisions may have mirrored one another operationally (ie, enabling the receipt or payment of credits by the taxpayer), it remained unclear whether they also mirrored one another financially, so that the total amount of output tax credits that had to be paid (or returned to the revenue authority), were constrained by the initial input tax credits claimed. ${ }^{149}$

\footnotetext{
${ }^{146}$ As a number of prior cases suggest, this is a common strategy with property developers and continues to be a common strategy in New Zealand and in other jurisdictions.

${ }^{147}$ Tax Information Bulletin Vol 5:8 (January 1994) p 1. The policy statement was subsequently codified in 2000. Document available at <www.ird.govt.nz/resources/1/9/194616004bbe4243b4bdf4bc87554a30/tib5-08.pdf> (viewed 20 March 2011).

${ }^{148}$ For example, Case U13 (1999) 19 NZTC 9,147 (TRA). Clause 23A of the GST Bill (which became s 21 of GST Act) was effectively the drawing together of like minded provisions.

149 A process described by the High Court as "reversing" the operation of the adjustments.
} 
The periodic nature of GST and the lack of relationship between the initial input tax credit and the adjustment had the potential for adjustments to be open-ended. A major weakness of an adjustment mechanism that utilises deemed supplies, is the opportunity for unlimited adjustments, especially where the mechanism does not expressly provide in the statutory language for some form of financial cap. The added complexity of ongoing periodic adjustments, where a deemed supply for a new input or output tax credit might arise over the lifetime of the taxable activity, also adds to the confusion. As Keating observes, "it was theoretically possible that adjustments made period-by-period could accumulate over time to more than the original GST portion paid". ${ }^{150}$

Deemed supply mechanisms are artificial and fictional by nature and require an equally artificial and fictional mechanism to constrain them. Without a cap on the financial amount, or the time in which a series of adjustments can be made, there is substantial room for the process to get very messy. ${ }^{151}$ As Judge Barber observed in Case U13: ${ }^{152}$

“... it does concern me that, perhaps, if the apartment were to have been let for long enough (which I understand it was not), the accumulated deemed output of one ninth of rental during the relevant two-monthly GST periods would eventually exceed the total inputs initially taken by the objector when building the apartments. That is not an issue I need to address for the present, but one might have thought that when the initial input has been fully recovered by the respondent, then the deeming procedure of s 21(1) has been completed (and the original principal purpose of making taxable supplies changed or abandoned) and any letting thereafter would be regarded as an exempt activity under s 14(c). However, there may be problems in achieving that equitable outcome in terms of the wording of the Act." (emphasis added)

However, the Court of Appeal in Lundy ${ }^{153}$ rejected such a possibility and in the absence of specific rules examined the overall scheme of the Act to reach an answer.

\footnotetext{
${ }^{150}$ M Keating “Calculation GST Adjustments - The Way Forward?” (2006) 2 New Zealand Tax Planning Report 9 at 11.

${ }^{151}$ In the Australian apportionment rules, the ongoing adjustment process is capped by time, rather than amount (eg, the initial input tax claim).

${ }^{152}$ Case U13 (1999) 19 NZTC 9,147 (TRA) at 9,159 at [37].

${ }^{153}$ CIR v Lundy Family Trust and Behemoth Corp Ltd (2005) 22 NZTC 19,637 (CA).
} 
The Court of Appeal concluded that the adjustment provisions were capped financially, based on a conclusion that one-off and periodic adjustments achieve the same result "of reversing the earlier input tax credit". ${ }^{154}$ Glazebrook J held that "any period adjustments cannot exceed the costs (or lower market value)". However, this did not mean there was financial matching. While the value of the reversal could not exceed the cost, there was the potential for the value to fall below the cost. This was because the value had to be determined on the basis of the "lesser" of cost or market value. Effectively, any reversal could never exceed the initial input tax credits (contrary to the Commissioner's argument that it could).

The court also observed that had there been a total change of use of the whole of the goods (or services) "the deemed supply will be of the whole of the goods (or services) at the lesser of cost or market value". ${ }^{155}$ As discussed above, this approach appears to ignore the argument advanced in Case U13 that the principal purpose may well have been abandoned well before being used up or totally changing. The failure of the Court of Appeal to explore this line of reasoning might suggest that it did not find favour with the court. However, it might also be explained on the basis that such an argument was not advanced.

This analysis also highlights the consequences of different interpretations of the principal purpose test and whether it should adopt a "more" or "less than half" approach. If the principal purpose test is a "more than half" test, then the reasoning from Case U13 would suggest that the principal purpose would be abandoned much earlier than if the test was a "less than half" test. It is also interesting to observe that, while a "less than half" test might provide the court with an easier task in awarding input tax credit entitlement, it also provides a much more difficult task when it comes to measuring subsequent adjustments.

\section{Determining the quantum}

The GST Act provides that the value of a supply is calculated on the lesser of either cost or market value. The court focused on the cost of the deemed supply. Inherent in

\footnotetext{
${ }^{154}$ CIR v Lundy Family Trust and Behemoth Corp Ltd (2005) 22 NZTC 19,637 (CA) at 19,648 at [48].

${ }^{155}$ CIR v Lundy Family Trust and Behemoth Corp Ltd (2005) 22 NZTC 19,637 (CA) at 19,647 at [40].
} 
the valuation process is determining the supply. The court determined that what was being applied (for the purpose of residential letting) was the properties themselves. Thus it was the properties that were the deemed supply and not the exempt activity (eg residential letting). The rental activity was the other purpose, not the supply.

The court also rejected the use of the rent as a means of determining market value. This was because such an adjustment "would have the effect of a GST charge on what is an exempt supply, which would not accord with the scheme of the legislation". 156

This additional reason for not using rent as a basis of value might appear perplexing as the adjustment rules do not appear to make a distinction between private and exempt activities, but rather between taxable and non-taxable purposes. However, this confuses the identification of different purposes with a determination of value the latter being tied to a supply, and the former tied to the taxable and non-taxable purposes.

The Court of Appeal found that the cost of the buildings was their acquisition cost. Consistent with the notion that the rental activity was not the deemed supply the court rejected the notion that holding costs could be used to determine cost. The court also accepted that the land on which the buildings were located were also to be included in the calculation. This was because the land and the buildings were both applied to the residential letting and the buildings were effectively no more used up in that process than the land. In the absence of any guidance, the court accepted depreciation of the cost of the buildings and land was a reasonable method to determine the value of the apportionment - depreciation being a measurement of value over time.

"To the extent" - a rough and ready approach to apportionment

In the absence of any guidance for allocating the adjustments between various periods, the court was left to adopt what it considered reasonable. Glazebrook J

\footnotetext{
${ }^{156}$ CIR v Lundy Family Trust and Behemoth Corp Ltd (2005) 22 NZTC 19,637 (CA) at 19,646 at [38]. Interestingly, the new apportionment rules appear to use market value rental in quantifying the adjustment amount (see Part 3 of this Chapter).
} 
observed that "any reasonable method appears to be allowed by the statute". ${ }^{157}$ Some commentators have suggested this was a "rough and ready" approach to apportionment. ${ }^{158}$ The court itself recognised this point, but considered that such an approach was a reasonable method and within the scope of the legislation.

The court recognised that concurrent purposes provided "conceptual difficulties because it is not possible to separate out the use of the properties on any time or space basis". ${ }^{159}$ During the period in question the property was dedicated 100 per cent to both purposes. In the absence of any other means of apportionment, the court concluded that a division between the value of the land (the principal purpose) and the value of the property (the other purpose) provided a reasonable allocation method for an apportionment. This was also what the taxpayers had done.

The court also recognised that service costs relating to the properties (ie, rates and insurance) also related equally to both purposes. The court rejected a 50:50 apportionment as it did not recognise that the principal purpose remained the sale of the properties and that the service costs would have been incurred whether the properties were let or not. The court was of the opinion that an apportionment of 75 per cent (principal purpose) and 25 per cent (other purpose) recognised this potential difference in use.

The fact the courts have had to resort to a potential alternative use (that did not actually happen, but might have) illustrates the difficulty the courts face with apportioning concurrent purposes. In contrast, an apportionment approach (based on use) avoids consideration of overlapping or concurrent purposes and instead focuses on the actual (or intended) activities.

The apportionment approach adopted by the Court of Appeal appears to acknowledge that different methods of apportionment can be applied for different

\footnotetext{
${ }^{157}$ CIR v Lundy Family Trust and Behemoth Corp Ltd (2005) 22 NZTC 19,637 (CA) at 19,647 at [42].

${ }^{158}$ M Smith "GST and Real Property Transactions in New Zealand: Some Interpretative Issues" in Krever R and White D (eds) GST in Retrospect and Prospect (Brookers Ltd, Wellington, 2007) 277 at 284.

${ }^{159}$ CIR v Lundy Family Trust and Behemoth Corp Ltd (2005) 22 NZTC 19,637 (CA) at 19,647 at [43].
} 
elements of the deemed supply (eg, land or property, versus service costs). This approach has continued in the new apportionment rules (eg, the method of working out the extent of intended taxable use will depend on the nature of the goods and services in question). ${ }^{160}$

The reasoning in Lundy ${ }^{161}$ would also appear to be at odds with Morris, ${ }^{162}$ which used the rental activity to measure the value of the deemed supply. However, in Morris the taxpayer was unable to provide information about the cost of building the two apartments and could not discharge their onus of proof to show that the Commissioner should have used a cost method for fixing the value of the deemed supply.

\section{IRD's continued confusion}

Despite the Court of Appeal's pronouncement of the law, the adjustment rules have continued to be misunderstood. According to IRD the main problems with the adjustment rules are: ${ }^{163}$

(1) The adjustment does not relate to the original input tax credit:

"This approach of taxing the "self supply" of goods and services ignores the original input tax deduction claimed by the GST-registered person as the change-in-use adjustments do not relate to the amount of the deduction claimed on acquisition. This is because the use of goods and services for a non-principal purpose is deemed to be a supply which is separate from the purchase transaction."

(2) There is no limit on the number of adjustments that can be made:

"Another aspect of the GST rules is that there is no statutory limit on the maximum number of adjustments that have to be made, so the number of adjustments required can be excessive relative to the amounts involved."

\footnotetext{
${ }^{160}$ Tax Information Bulletin Vol 21:1 (February 2011) 34.

${ }^{161}$ CIR v Lundy Family Trust and Behemoth Corp Ltd (2005) 22 NZTC 19,637 (CA).

${ }^{162}$ CIR v Morris [1998] 1 NZLR 344, (1997) 18 NZTC 13,385 (HC).

${ }^{163}$ Tax Information Bulletin Vol 23:1 (February 2011) 33. Document available at: <www.ird.govt.nz/resources/e/f/efe82b8045b25b4f9dbabf7747109566/tib-vol23-no1.pdf> (viewed 20 March 2011).
} 
(3) The amount of output tax can exceed the original input tax claim:
"In addition, since change-in-use adjustments do not relate to the amount of the initial input tax deduction, the value of adjustments that a person is required to make can potentially amount to more than the original GST paid on the purchase. Conversely the value of the deduction received by means of change-in-use adjustments can sometimes exceed the amount of GST originally paid."

While the point 2 quote is correct, the point 1 and 3 quotations are confused. The Court of Appeal in Lundy ${ }^{164}$ clearly stated that the output tax credit cannot exceed the original input tax claim. It cannot "potentially amount to more than the original GST paid", but it can amount to less if market value is lower than cost (hence they do not match).

The court also found that the deemed supply was not the letting activity, but a portion of the property and land. For this reason, the property and land were apportioned according to the respective purposes, together with associated service costs. In this respect (ie, determining the value of the apportionment) the deemed supply is not separate from the purchase transaction. However, the act of deeming a supply is conceptually separate, and results from the purpose of the supply.

\section{H. Revenue Authority Guidance}

It is apparent that there has been very little guidance provided on the adjustment rules (illustrated in Figure 1.17). The guidance provided after the introduction of the GST Act was merely a restatement of the legislative provisions and failed to examine how the specific tests applied in common commercial transactions. The poor guidance provided often led to disputes and differing judicial interpretations. It was not until the improving judicial clarification of the rules (eg, BNZ Investments to Morris) that a flurry of revenue authority guidance appeared between 1994 and 1998.

${ }^{164}$ CIR v Lundy Family Trust and Behemoth Corp Ltd (2005) 22 NZTC 19,637 (CA). 


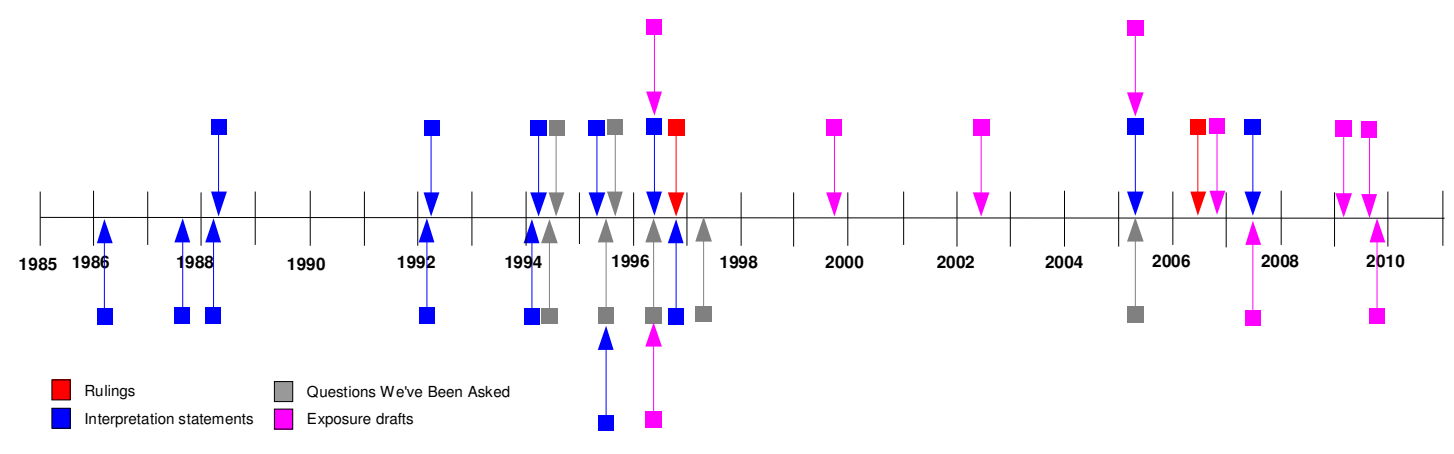

The introduction of the Binding Rulings regime in 1995 did provide the opportunity for taxpayers to benefit from increased certainty. Yet after the enactment of the Binding Rulings regime, there were still very few public rulings published, with most guidance remaining in the form of exposure drafts that are now unlikely to be finalised in light of recent reforms. ${ }^{165}$ It would also appear that IRD have been withdrawing from binding themselves to interpretations, with subsequent re-releases of rulings appearing as (non-binding) interpretation statements.

This trend would appear to suggest the IRD are not confident that they are correctly interpreting the rules, or do not have confidence that the interpretation provided by the judiciary (on which a ruling would be based) is correct and will hold up to subsequent scrutiny after the ruling is released. Either way the IRD appear unable to provide any certainty for taxpayers. Of course, there is another explanation for a deferral of any binding ruling or the general absence of adequate guidance since the enactment of the adjustment rules — inadequate resourcing allocated to providing adequate guidance. ${ }^{166}$ It remains to be seen if the new apportionment approach will be supported by substantially more guidance than provided to the former rules.

\footnotetext{
${ }^{165}$ Recent trends appear to suggest that IRD are withdrawing from binding themselves to interpretations, with recent re-releases of ruling topics appearing as (non-binding) interpretation statements.

${ }^{166}$ Dr David White estimates that that the Policy Advice Division (PAD) GST team was for a large period merely one to two people. See D White "Twenty Years of GST: The Best Path Forward" (2007) 13 New Zealand Journal of Taxation Law and Policy 357 at 358 (fn 9). This is an interesting resource allocation given the amount of revenue the GST Act is responsible for, although more recently the GST team has expanded to four people (subject to resources being distracted by other projects). The fact GST already accounted for approximately 26 per cent of total revenue under a GST rate of 12.5 percent (which has since increased to 15 per cent), would suggest it deserves more attention. Whether the Rulings team is equally under resourced is unknown, but the limited output
} 


\section{The Problem of Compliance: A Chorus of Concerns}

Apart from judicial consideration of the adjustment rules there has been very little detailed examination of the rules. ${ }^{167}$ However, what has been written has not been complimentary. According to Pallot \& Fenwick, ${ }^{168}$ the change-in-use rules are "without a doubt the most practically and technically difficult area in any GST system" and an area of law that will "provide on-going challenges in New Zealand (as undoubtedly in other jurisdictions) for the private sector, tax practitioners and policy makers".

In 1994, Deloitte observed that the adjustment provisions were "lengthy, complex and difficult to interpret; but when one wrestles through them to their conclusion, they combine to produce the apportionment rules". ${ }^{169}$ In 1999, the GST Review acknowledged that the "the legislation does not clearly specify how the calculations are to be made, which creates high compliance costs", ${ }^{170}$ and that the "adjustment approach used in New Zealand is difficult to apply in some circumstances and has resulted in considerable litigation". ${ }^{171}$

In 2010, during submissions on the new apportionment rules the New Zealand Institute of Chartered Accountants (NZICA) were of the opinion that the former

would suggest it is. The lessons of history would suggest that the Rulings team will also need more attention if guidance is to improve above what was delivered in the mid-1990s.

${ }^{167}$ Keating's two articles appear to be the only academic contribution to examining New Zealand's change-in-use rules: M Keating “The Principal Purpose Test for the GST Input Tax: Is a Wide Interpretation Justified?" 16 New Zealand Journal of Taxation Law and Policy (2010) 85 and M Keating "Calculation GST Adjustments - The Way Forward?" (2006) 2 New Zealand Tax Planning Report 9. In part this is a reflection of a general lack of qualified authors to negotiate the topic and limited academic resources, rather than any lack of concern. For statistics on the paucity of research and publications on New Zealand GST in general from 1986 to 2007, see D White "Twenty Years of GST: The Best Path Forward" (2007) 13 New Zealand Journal of Taxation Law and Policy 357 at 365-371.

${ }^{168}$ M Pallot and H Fenwick "Recent GST Reforms and Proposals in New Zealand" (2000) 10 Revenue Law Journal 88 at 94.

${ }^{169}$ Deloitte NZSA Educational Tax Course - GST (Continuing Education Paper, March 1994) D7.2.

${ }^{170}$ B Birch and B English GST: A Review - A Government Discussion Document (Policy Advice Division, IRD, Wellington, March 1999) at [4.6].

${ }^{171}$ B Birch and B English GST: A Review - A Government Discussion Document (Policy Advice Division, IRD, Wellington, March 1999) at [4.10]. 
change-in-use rules were "cumbersome" $" 172$ and the Corporate Taxpayers Group also observed that "the current change-in-use provisions are overly complex and confusing". ${ }^{173}$ Prophetically, submissions on the original GST Bill preceding its enactment, also raised concerns about the adoption of an adjustment mechanism and the drafting of the provisions. One observation is the opening quote to this chapter. Submissions highlighted the fact that the drafting did not "adequately express the draftsman's intent" and that the adoption of a "principal purpose" test would not withstand dissection by the courts and would be "bound to be an area of conflict between registered persons and the Inland Revenue Department." 174

The regular and ongoing chorus of concerns with the operation of the adjustment rules is compelling. It is little wonder that the adjustment rules have finally been abandoned. What is surprising is how long it took to abandon them and adopt an apportionment approach.

\section{J. The Big Picture}

Bringing together Figures 1.2, 1.16 and 1.17 presents an interesting snapshot of activity in New Zealand over the last 25 years (illustrated in Figure 1.18). ${ }^{175}$

\footnotetext{
172 NZICA Submissions on the Taxation (GST and Remedial Matters) Bill (10 September 2010) 5. Document available at <www.parliament.nz/NR/rdonlyres/85113B1E-46F9-40E1-84B497B8FA15C81F/159160/49SCFE_EVI_00DBHOH_BILL10121_1_A68095_NewZealandIn.pdf> (viewed on 20 March 2011).

${ }^{173}$ Corporate Taxpayers Group Submissions on the Taxation (GST and Remedial Matters) Bill (9 September 2010) at [4.6]. Document available at <www.parliament.nz/NR/rdonlyres/9792EC0761A5-4E8E-9022D7816E51CB91/159146/49SCFE_EVI_00DBHOH_BILL10121_1_A67981_CorporateTax.pdf> (viewed on 20 March 2011).

${ }^{174}$ Peat Marwick Submissions on the Goods and Services Tax Bill 1985 (25 September 1985) 3 at [1.2] (FE/85/307, 262W).

${ }^{175}$ Note that all the case law and guidance is related to the period before the legislative codifications introduced by the Taxation (GST and Miscellaneous Provisions) Act 2000.
} 
Figure 1.18: Guidance, Cases, and Legislative Activity Timeline
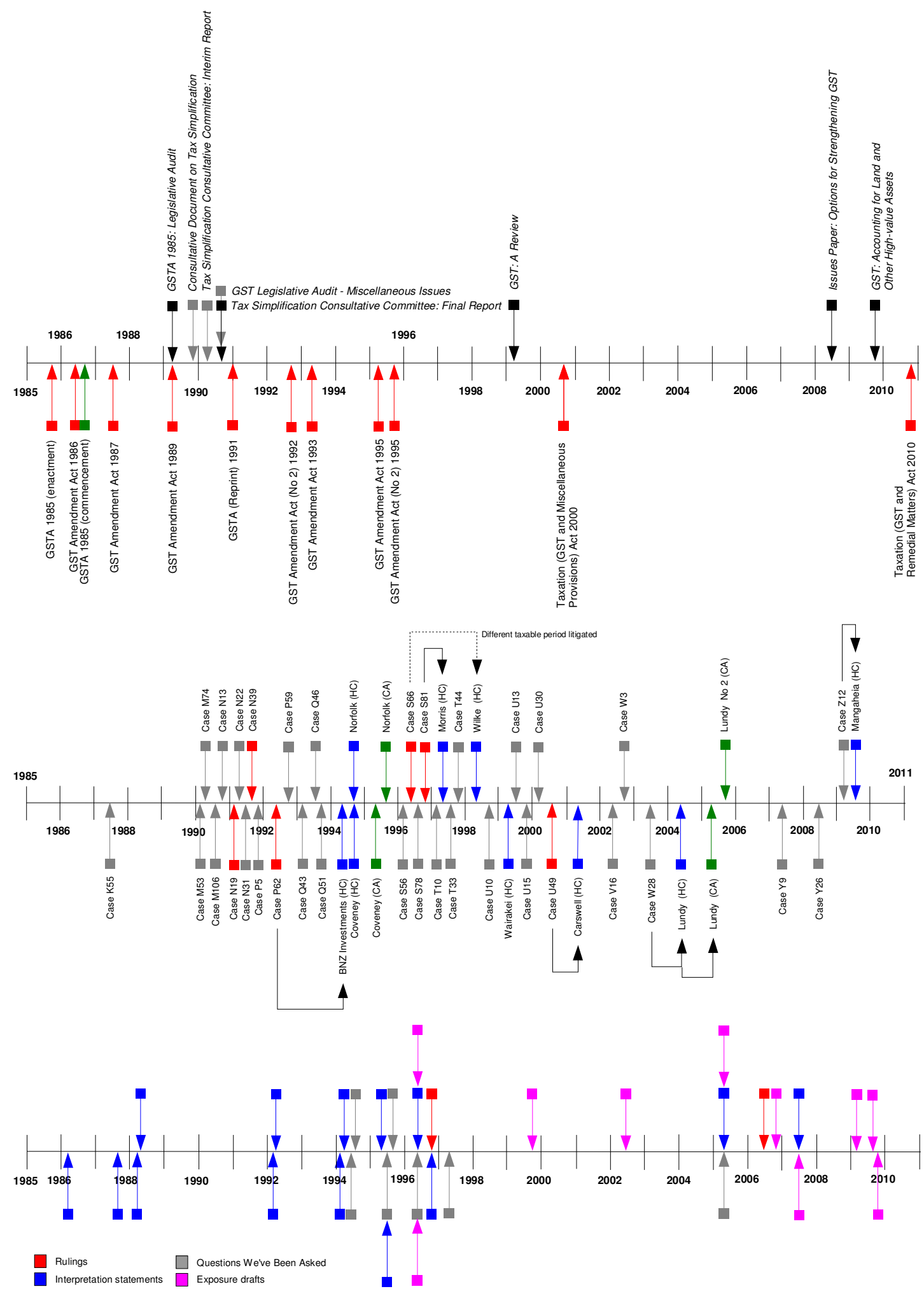


\section{Part 3: The New Rules}

Since embarking on this thesis, Parliament has introduced and enacted the repeal of the adjustment rules and replaced them with a new apportionment approach that has borrowed heavily from the Australian apportionment rules (although not as heavily in legislative expression).

\section{K. A New Approach: Reform Proposals}

\section{The first legislative audit}

There have been three reviews of the adjustment rules since s 21 was first introduced in 1985. The first review of the Goods and Services Tax Act 1985 began in August 1987 (and was later published in February 1989), barely a year after the Act had come into force on 1 October $1986 .{ }^{176}$ By the time the review was published in February $1989,{ }^{177}$ there had already been judicial consideration of the principal purpose test and the application of s $21 .{ }^{178}$ In the meantime IRD had published very little detailed guidance on the application of s 21 or the interpretation of "principal purpose". ${ }^{179}$ The approach taken by the audit exercise was to focus on the issues raised in submissions rather than carry out a comprehensive review, as this was not feasible due to a limited number of staff. ${ }^{180}$

\footnotetext{
176 The purpose of the audit review was to consider any administrative problems in operation and not to consider the well-established fundamental policy structure of the Act.

${ }^{177}$ D Caygill The Goods and Services Tax Act 1985: Legislative Audit (IRD, Wellington, February 1989). Hereafter referred to as the "1989 Review".

${ }^{178}$ Case K55 (1988) 10 NZTC 453 (TRA).

${ }^{179}$ For example, two short summaries with little detail in Public Information Bulletin 162 (April 1987) and Public Information Bulletin 143 (February 1986). Detailed guidance on the application of the principal purpose would not be published until Tax Information Bulletin Vol 5:8 (January 1994) 1.

${ }^{180}$ A constant theme running through much of IRD's activity (or inactivity) with regard to GST (and in particular adjustments) has been a general lack of resources to conduct exhaustive reviews or provide sufficient support for taxpayers and advisors. The GST Act itself was designed and implemented with limited resources and extraordinarily tight time frames. The frugal nature of its birth appears to have continued through the course of its entire life.
} 
Despite the short time frame and limited resources, 120 issues were identified as requiring corrective action or further consideration. ${ }^{181}$ As the Minister of Revenue, David Caygill observed "a large number of submissions commented on the adjustments made for private, exempt, or taxable use of goods and services in terms of section $21 " .{ }^{182}$ Due to the limited resources available to the IRD at the time, the 120 issues were divided into 5 categories ${ }^{183}$ and prioritised for action. However, despite s 21 being categorised as a key issue, the report deferred consideration of $\mathrm{s}$ 21 to a second report.

The second report was subsequently published in September $1990,{ }^{184}$ but due to the complexity of the issue, the GST adjustments topic was again deferred to the Tax Simplification Consultative Committee reports published in March 1990 (Interim Report) ${ }^{185}$ and September 1990 (Final Report). ${ }^{186}$ The Final Report acknowledged that small businesses held concerns about the high compliance costs of calculating private use adjustments and proposed several changes aimed at reducing compliance costs. ${ }^{187}$

${ }^{181}$ D Caygill The Goods and Services Tax Act 1985: Legislative Audit (IRD, Wellington, February 1989).

${ }^{182}$ D Caygill The Goods and Services Tax Act 1985: Legislative Audit (IRD, Wellington, February 1989) i.

${ }^{183}$ The five categories comprised: (1) key policy issues; (2) interpretation problems; (3) industry problems; (4) lesser policy issues; and (5) minor issues. Key issues comprised eight topics including "section 21 private use adjustments".

${ }^{184}$ D Caygill GST Legislative Audit - Miscellaneous Issues (IRD, Wellington, September 1990).

${ }^{185}$ D Caygill Tax Simplification Interim Report of the Consultative Committee (IRD, Wellington, March 1990).

${ }^{186}$ D Caygill Tax Simplification Final Report of the Consultative Committee (IRD, Wellington, September 1990). At the time these reports were being published the government was already committed to reducing compliance costs in another report. See D Caygill Consultative Document on Tax Simplification (IRD, Wellington, December 1989).

${ }^{187}$ To reduce compliance costs the Final Report recommended increasing the threshold for capital assets subject to one-off adjustments from $\$ 10,000$ to $\$ 40,000$, thus reducing the number of assets that required ongoing adjustments for private use. Unfortunately it appears this recommendation was never enacted. However, in 2000 (10 years later) the threshold was increased to $\$ 18,000$ (on the basis of inflation). The Interim Report had recommended that GST registered persons be given the option of making private use adjustments at the end of the income year. This recommendation was abandoned in the Final Report in favour of using the private use calculation in income tax returns for the relevant GST period (thus reducing compliance costs and avoiding interest calculations). 
Ten years later a second review, entitled GST: A Review (published in March 1999), ${ }^{188}$ provided a much broader review of the Goods and Services Tax Act 1985. ${ }^{189}$ Chapter 4 of the 1999 Review is explicitly directed at compliance issues for change-in- use adjustments. ${ }^{190}$ Chapter 5 explored other issues more concerned with wording and technical drafting. ${ }^{191}$ However, unlike the first review in 1989, there is little explanation of concerns or problems with the adjustment rules. Rather, the 1999 Review proposes several policy changes around thresholds ${ }^{192}$, one-off adjustments, and codifying the existing IRD methodology for the allocation of adjustments (eg, direct attribution, turn-over, or special method). ${ }^{193}$ These changes were subsequently enacted in 2000. No changes to the inclusion of "principal purpose" in the changeof-use rules were advanced.

To its credit, the 1999 Review also explored the apportionment approach adopted in Canada and the UK. ${ }^{194}$ However, the report concluded the apportionment approach

${ }^{188}$ B Birch and B English GST: A Review - A Government Discussion Document (Policy Advice Division, IRD, Wellington, March 1999). Hereafter referred to as the "1999 Review".

${ }^{189}$ The 1999 Review acknowledges that it was the first review of the Goods and Services Tax Act 1985 to be conducted under the Government's generic tax policy process. See B Birch and B English GST: A Review - A Government Discussion Document (Policy Advice Division, IRD, Wellington, March 1999) 3.

${ }^{190}$ Chapter 4 and 5 resided in Part 2 of the 1999 Review (entitled "Working with GST"). Chapter 4 comprised 10 pages (pp 27-36) of a 116 page report, a little under 10 per cent. In contrast, Part 3 of the Review (entitled "Maintaining the Revenue Base") comprised 25 pages (pp 41-66).

${ }^{191}$ Chapter 5 comprised four pages (pp 37-40). The two chapters together comprised 10 per cent of the report. The vast majority of the two chapters addresses allocation issues. This would appear to suggest that the confusion surrounding "principal purpose" was reasonably settled (or not considered a significant issue).

192 The minimum threshold for an adjustment to be made (involving an exempt supply) increased from $\$ 48,000$ to $\$ 90,000$. The one-off adjustment for non-taxable to taxable use was increased from $\$ 10,000$ to $\$ 18,000$.

${ }^{193}$ See BR Pub 96/11 (expired) in Tax Information Bulletin Vol 8:10 (December 1996) and earlier interpretation statements in Public Information Bulletin 143 (February 1986), Information Bulletin 169 (February 1988), Tax Information Bulletin Vol 5:8 (January 1994), Tax Information Bulletin Vol 6:11 (April 1995), Tax Information Bulletin Vol 6:14 (June 1995) and GST Guide - A guide to working with GST (GST 600, December 1997).

${ }^{194}$ B Birch and B English GST: A Review - A Government Discussion Document (Policy Advice Division, IRD, Wellington, March 1999) 29 at [4.8-4.9]. Unfortunately the exploration is rather brief. Understandably, no explicit reference is made of the rules applied in Australia. While GST in 
used in both jurisdictions had considerable complexities, especially with the treatment of tax credits on disposal. Furthermore the apportionment approach was considered inconsistent with the GST Acts underlying principle that GST was borne by the final consumer. The report concluded that this key principle should be retained, but that the compliance costs of the existing rules had to be reduced. ${ }^{195}$

\section{The third legislative audit}

Twenty years after the first review, two further reports were released. The first was a 2008 Issues Paper $^{196}$ in which officials explored the adjustment rules applied in other jurisdictions, ${ }^{197}$ among other things. The second was a 2009 discussion document, ${ }^{198}$ in which the government proposed major reform in response to feedback on the 2008 Issues Paper — replacing the existing adjustment rules with a cost-based apportionment approach. ${ }^{199}$ The 2009 reform proposal finally acknowledged that New Zealand's current approach was "complex and confusing". 200

\section{New legislation}

On 5 August 2010, the Taxation (GST and Remedial Matters) Bill 2010 was tabled in Parliament and received its first reading on 19 August 2010, before being directed

Australia was unveiled in August 1998, it was not enacted until 8 July 1999 (and commenced from 1 July 2000), several months after the 1999 Review was published.

${ }^{195}$ B Birch and B English GST: A Review - A Government Discussion Document (Policy Advice Division, IRD, Wellington, March 1999) 29 at [4.11].

${ }^{196}$ Policy Advice Division and Treasury Options for Strengthening GST Neutrality in Business-toBusiness Transactions: An Officials' Issues Paper (IRD, Wellington, June 2008). Officials received 23 submissions and in light of these submissions considered there was scope for reform of the change-in-use rules and recommended publishing a discussion document outlining reform proposals.

197 This time the jurisdictions examined included Australia.

${ }^{198}$ P Dunne GST: Accounting for Land and Other High-Value Assets - A Government Discussion Document (IRD, Wellington, November 2009).

199 The inference in the 2009 Reform proposal is that the feedback comes from the Issues Paper published in June 2008. However, serious concerns with s 21 have been present since the First Review published in 1989.

${ }^{200}$ P Dunne GST: Accounting for Land and Other High-Value Assets - A Government Discussion Document (IRD, Wellington, November 2009) 21. 
to the Finance and Expenditure Committee for consideration. ${ }^{201}$ The Bill (amongst other GST reforms), proposed the repeal of the adjustment rules and the adoption of a use-based apportionment approach together with a new mechanism (modelled on the Australian rules) for capping the number of adjustments. The Bill was reported back from the Finance and Expenditure Committee (FEC) on 15 November 2010, ${ }^{202}$ received its second reading on 24 November 2010, and was passed by the House on 9 December 2010. On 20 December 2010, the Bill was enacted as the Taxation (GST and Remedial Matters) Act 2010, which applies from 1 April 2011 (or from 1 April 2016 under transitional measures).

During the first reading of the Bill the Minister of Revenue acknowledged that while New Zealand's GST system was praised internationally for "its simplicity, its efficiency, and its transparency", over the passage of time some parts of the GST system (ie, the adjustment rules) had lacked clarity and had become "cause for concern". According to the Minister the "purpose of these measures is to clarify those parts of the GST rules where taxpayers have been experiencing difficulty in accounting for GST or interpreting the legislation". ${ }^{203}$ The Minister also acknowledged that the new apportionment rules would make it easier to understand the change-in-use rules, reduce compliance costs, and "simplify the requirements for many GST-registered businesses". 204

\footnotetext{
${ }^{201}$ Submissions on the Bill closed on 9 September 2010. Document available at: <www.parliament.nz/en-NZ/PB/Legislation/Bills/1/e/c/00DBHOH_BILL10121_1-Taxation-GSTand-Remedial-Matters-Bill.htm> (viewed 20 March 2011).
}

202 According to the Tax Policy Report, PAD 2010/255 (7 October 2010), the Finance and Expenditure Committee (FEC) received 16 submissions and according to the Officials Report to the FEC (15 November 2010), heard six submissions on the Bill. The Officials Report on the Bill responded to a number of submissions on the change-in-use rules and appears to indicate that the change-in-use rules took nearly a quarter of the FEC's attention (ie, comprised 22 pages of discussion in a 110 page document).

${ }^{203}$ Dunne P "Taxation (GST and Remedial Matters) Bill - First Reading” (19 August 2010) 665 NZPD 13,277. Document available at <www.parliament.nz/enNZ/PB/Debates/Debates/6/5/e/49HansD_20100818_00001365-Taxation-GST-and-Remedial-MattersBill-First.htm> (viewed 20 March 2011).

${ }^{204}$ Dunne P "Taxation (GST and Remedial Matters) Bill - Second Reading” (24 November 2010) 669 NZPD 15,769. Document available at <www.parliament.nz/enNZ/PB/Debates/Debates/1/1/0/49HansD_20101124_00001004-Taxation-GST-and-RemedialMatters-Bill-Second.htm> (viewed 20 March 2011). 
The emphasis in Hansard on the compliance costs savings of the new apportionment rules is repeated in IRD's summary of the new rules, where it states: ${ }^{205}$

"Overall, the new rules are intended to reduce compliance costs for businesses by being simpler and requiring fewer adjustments."

\section{What is driving reform?}

Both the 1999 GST Review and the 2008 Issues Paper declined to adopt an apportionment approach. The 1999 GST Review conclude that while the apportionment approach may appear to be simpler and more accurate in determining input tax credits, it had considerable complexities. ${ }^{206}$ It acknowledged that the current adjustment approach also imposed high compliance costs, but expressed a preference to keep these rules and to focus on reducing the cost of complying with them. Nine years later, private sector submissions on the 2008 Issues Paper noted that the adjustment rules were "complex and confusing" and the concepts behind imposing GST on mixed use and changes-in-use were not sufficiently transparent and could result in ongoing costs due to the indefinite nature of adjustments. ${ }^{207}$

Underlying the 2009 reform proposals is a strong concern for providing simplicity, improving compliance and reducing compliance costs. Throughout the report, references to "conceptual simplicity", "transparency", and reducing "uncertainty" are regularly made. ${ }^{208}$ The report also explicitly acknowledged that the Australian approach was perceived as simpler. ${ }^{209}$ The focus on transparency appears to be in

\footnotetext{
${ }^{205}$ Tax Information Bulletin Vol 23:2 (February 2011) 33.

206 The 1999 report provided two examples. First, apportionment required prediction of future use. Second, it had complex rules for determining value on disposal. See B Birch and B English GST: A Review - A Government Discussion Document (Policy Advice Division, IRD, Wellington, March 1999) 29 at [4.10].

${ }^{207}$ M Pallot Tax Policy Report to Minister of Revenue, PAD2009/192 (8 October 2009) 3 at [7].

${ }^{208}$ A principal reason for not adopting the Issues Paper proposals to modify the existing rules, was concern that it would not simplify the rules, but rather complicate them further. See P Dunne GST: Accounting for Land and Other High-Value Assets - A Government Discussion Document (IRD, Wellington, November 2009) 22 at [7.7].

${ }^{209}$ P Dunne GST: Accounting for Land and Other High-Value Assets - A Government Discussion Document (IRD, Wellington, November 2009) 22 at [7.7].
} 
direct response to the criticism made by the Court of Appeal in Lundy. ${ }^{210}$ Certainly, the timing of the reform (after the Court of Appeal's judgment) would appear to indicate this.

Similar themes appear throughout several reports to the Minister, which acknowledged that the reform proposals were "more intuitive", provided "greater consistency" for land transactions, and brought the rules "into line with the approach taken in Australia", 211 adding: ${ }^{212}$

"Owing to the clear link between the initial input tax adjustments an the change-in-use adjustments, the proposed rules will be easier to understand and follow than the current rules. ... and will reduce compliance costs"

Generally the reforms appear to focus more on simplicity and compliance than revenue. ${ }^{213}$ There has been no cost-benefit analysis undertaken for implementing the proposed reform and Inland Revenue has acknowledged that it did not have sufficient information on the fiscal impact of reforming the rules. ${ }^{214}$ However, the reform proposals were considered to be "revenue neutral", offering "solutions to neutrality concerns" and not having any "significant" revenue impact. ${ }^{215}$ This would

${ }^{210}$ CIR v Lundy Family Trust and Behemoth Corp Ltd (2005) 22 NZTC 19,637 (CA). The reform proposal directly attributes the Court of Appeal's concerns in terms of "transparency" and "tax and compliance costs": P Dunne GST: Accounting for Land and Other High-Value Assets - A Government Discussion Document (IRD, Wellington, November 2009) 21.

${ }^{211}$ M Pallot Tax Policy Report to Minister of Revenue, PAD2009/202 (20 October 2009) 3 at [2]. Obtained under Official Information Act 1982. Request made to Manager, Policy Advice Division, Inland Revenue Department.

${ }^{212}$ M Pallot Cabinet Paper: GST Issues for the July 1010 Bill PAD 2010/137 (21 June 2010) 2 at [7]. Obtained under Official Information Act 1982. Request made to Manager, Policy Advice Division, Inland Revenue Department.

${ }^{213}$ Clearly there have been revenue concerns in relation to a minority of taxpayers using adjustments to circumvent second hand goods restrictions: P Dunne GST: Accounting for Land and Other HighValue Assets - A Government Discussion Document (IRD, Wellington, November 2009) 32 at [7.49]. This concern will be removed with the adoption of the new apportionment approach.

${ }^{214}$ M Pallot Tax Policy Report to Minister of Revenue, PAD2009/192 (8 October 2009) 3-4 at [10]. Obtained under Official Information Act 1982. Request made to Manager, Policy Advice Division, Inland Revenue Department.

${ }^{215}$ M Pallot Cabinet Paper: GST Issues for the July 1010 Bill PAD 2010/137 (21 June 2010) 1. Obtained under Official Information Act 1982. Request made to Manager, Policy Advice Division, Inland Revenue Department. 
suggest that the administrative costs to the IRD are not a principal driver for these reforms. This is confirmed by Inland Revenue's concern that financial service providers may suffer increased compliance costs if they were required to apply the new apportionment rules. Accordingly, officials supported transitional rules that would enable the preservation of existing agreements. ${ }^{216}$

Little argument is made for justifying the changes on the basis of equity, efficiency, or administrative costs. ${ }^{217}$ Although officials do make several references to underlying revenue concerns and providing options that address "the tax base risks". ${ }^{218}$ Much of the reform is about providing an accurate mechanism to ensure input tax credits correspond to taxable use in the first instance. ${ }^{219}$ At first glance, it is hard to see where compliance costs have been reduced. Both the adjustment approach and the apportionment approach require taxpayers to track their use of goods and services to determine if there has been a change of use.

Furthermore, the apportionment approach could provide the IRD a revenue windfall. At present non-taxable use is accounted for at the end of the GST period (eg, 2 months after the good or service has been acquired). The apportionment approach brings this forward to the time the taxpayer receives the goods or services (eg, the taxpayer now has to predict non-taxable use). ${ }^{220}$ However, the former adjustment approach potentially remitted adjustments more regularly (ie, 2-monthly), whereas

${ }^{216}$ M Pallot Cabinet Paper: Officials Report to the FEC PAD 2010/255 (7 October 2010) 2 at [4]. Obtained under Official Information Act 1982. Request made to Manager, Policy Advice Division, Inland Revenue Department.

${ }^{217}$ Interestingly, no mention is made of harmonising our rules with Australia, although the implication of adopting the Australian approach would result in greater trans-Tasman harmonisation.

${ }^{218}$ P Dunne GST: Accounting for Land and Other High-Value Assets - A Government Discussion Document (IRD, Wellington, November 2009) 2.

${ }^{219}$ Effectively, this addresses judicial concerns raised by the Court of Appeal in CIR v Lundy Family Trust and Behemoth Corporation Ltd (2005) 22 NZTC 19,637 (CA), over the complexity of the existing valuation methodologies.

${ }^{220}$ Alternatively, taxpayers could claim that they do not forecast any non-taxable use, and wait for the next adjustment period. It's unclear how taxpayers will be incentivised to provide fair and reasonable estimates. Guidance in Tax Information Bulletin Vol 23:1 (February 2011) 34, on the application of fair and reasonable estimates is silent on the issue of penalties and one is left to assume not taking a fair and reasonable estimate will probably fall under the tax shortfall penalty provisions in Part 9 of the Tax Administration Act 1994 (eg, not taking reasonable care or taking an unacceptable tax position). 
the new apportionment approach remits adjustments on an adjustment period basis (ie, 12-monthly).

\section{The Apportionment Rules}

\section{General overview}

The new rules provide a new mechanism for initial entitlement to input tax credits and any subsequent adjustments. ${ }^{221}$ The new rules seek to achieve as much accuracy as possible in the first instance by requiring taxpayers to make a fair and reasonable estimate of the intended taxable and non-taxable uses of acquired goods and services at the time of acquisition. ${ }^{222}$ Intended use includes items intended to be used, but which are not yet applied in the taxable period in which they were acquired (eg, raw materials not yet used for making goods). Accordingly, taxpayers are able to claim a full input tax credit in respect of goods and services "available for use" in making a taxable supply. ${ }^{223}$

Following the initial input tax credit claim, taxpayers will be required to make an adjustment if the actual taxable use of an asset is different from its intended taxable

${ }^{221}$ A more detailed explanation of the new apportionment rules is provided in Tax Information Bulletin Vol 23:1 (February 2011) 33-42.

${ }^{222}$ However, the new rules do not define the meaning of "acquired" or "time of acquisition". Do the terms "acquired" and "time of acquisition" refer to the moment that legal and equitable ownership is obtained, possession, performance, or the time payment is made. Case T35 (1997) 18 NZTC 8,235 (TRA) suggests there are problems with word "acquired" and determining the exact period of acquisition might prove difficult in relation to intangible or continuous services (rather than goods). Officials considered that the terms "acquired" and "time of acquisition" should be given their normal meaning and do not consider that attempting to define the terms would be helpful. This is because the legislation relies on the notion that input tax may only be claimed "to the extent" that an asset is "used" for making taxable supplies. In most situations, a purchaser will not be able to use goods or services until they obtain ownership of the goods and services. However, it is possible for goods and services to be acquired in other ways. The focus is on the time of actual "use" for the taxable activity - this is the point of acquisition.

223 Taxation (GST and Remedial Matters) Bill 2010 (182-2) Officials' Report to the Finance and Expenditure Committee on Submissions on the Taxation (GST and Remedial Matters) Bill (IRD, Wellington, October 2010) 57. Document available at $<\mathrm{http} / / /$ taxpolicy.ird.govt.nz/sites/default/files/2010-or-grm.pdf> (viewed 20 March 2011). This is consistent with the UK Lennartz Mechanism which allows a full input tax credit to be acquired, with output tax credits counting for any subsequent non-taxable use: Lennartz v Finazamt Munchen III, CFEC Case C-97/90; [1995] STC 514. See Tolley's Value Added Tax 2007 (1 ${ }^{\text {st }}$ Ed, Lexis Nexis Ltd, 2007) 739 at [35.7(3)]. 
use at the end of an adjustment period. ${ }^{224}$ However, no adjustment will be required if the percentage difference of the adjustment is no more than 10 per cent and the adjustment does not exceed $\$ 1,000$ in total. ${ }^{225}$

The first adjustment period is a period that starts on the date of acquisition and ends at least 12 months after the date of acquisition on the taxpayer's first balance date. All subsequent adjustment periods are annual 12-month periods that start from the end of each adjustment period.

The number of adjustment periods for all supplies (excluding real property) is capped. ${ }^{226}$ There is no limit on adjustment periods for land. ${ }^{227}$ The number of adjustment periods for which adjustments are required is based on the GSTexclusive value of the supply (see Table 1.1 below). Alternatively, taxpayers will be able to select the maximum number of adjustments by reference to the estimated useful life of the asset specified in the Tax Depreciation Rates Determinations. ${ }^{228}$

Depending on the value of the goods and services acquired, the number of adjustments that have to be made for "substantial" changes in the use of goods and services will be determined by the value of the transaction. The higher the value of an asset, the greater number of adjustments the taxpayer will have to make over a longer period of time. ${ }^{229}$

\footnotetext{
${ }^{224}$ Goods and Services Tax Act 1985, s 21(3). An adjustment arises on the last day of the relevant adjustment period.

${ }^{225}$ Goods and Services Tax Act 1985, s 21(2)(c) and (d). Officials acknowledged that a 5 per cent safe harbour threshold had originally been proposed in the 2009 discussion document GST: Accounting for Land and Other High-Value Assets - A Government Discussion Document (IRD, Wellington, November 2009), but declined to adopt a safe harbour rule instead favouring a 10 per cent de minimis rule. Officials declined to remove $\$ 1,000$ financial cap on the de minimis rule during submissions on the Bill on the basis that adjustments of $\$ 1,000$ were substantial.

${ }^{226}$ Goods and Services Tax Act 1985, s 21G(4).

${ }^{227}$ Goods and Services Tax Act 1985, s 21G(5).

${ }^{228}$ Goods and Services Tax Act 1985, s 21G(4). Adopting an estimated useful life (EUL) approach for adjustments addresses one of the recommendations made for the improvement to the Australian rules. It will be interesting to see if Australia follow.

229 According to officials, by requiring taxpayers to make adjustments in relation to high-value assets for longer periods of time, the new rules aim to minimise the possibility of taxpayers under-claiming or over-claiming input tax in relation to those assets, so that the final amount of the input tax claimed
} 
No change-in-use adjustment will be required for goods and services acquired for the GST-exclusive value of $\$ 5,000$ or less. ${ }^{230}$ For assets with a value of more than $\$ 5,000$, no adjustment will be required in the relevant adjustment period if the recipient makes both taxable and exempt supplies and the total value of their exempt supplies in the adjustment period is no more than the lesser of $\$ 90,000$ or 5 per cent of the total consideration for all taxable and exempt supplies for that adjustment period. $^{231}$

There appear to be three opportunities to avoid an adjustment:

- The supply is $\$ 5,000$ (excluding GST) or less; or

- The change-in-use is less than 10 per cent (capped at $\$ 1,000$ maximum); or

- Over a 12-month period, the total value of all exempt supplies does not exceed 5 per cent of the total value of all supplies (capped at $\$ 90,000$ maximum).

by the taxpayer corresponds as closely as possible with the actual taxable use of the asset in question. Although relaxing the thresholds would reduce compliance costs to taxpayers stemming from having to make continuous adjustments for changes in use, it would also reduce the accuracy of the final amounts of input tax claimed by taxpayers. Officials considered that the thresholds strike a good balance between the need for accuracy and the reduction of compliance costs. Taxation (GST and Remedial Matters) Bill 2010 (182-2) Officials' Report to the Finance and Expenditure Committee on Submissions on the Taxation (GST and Remedial Matters) Bill (IRD, Wellington, October 2010) 47.

${ }^{230}$ The $\$ 5,000$ exclusion (or safe harbour) is intended to act as a compliance and administration costsaving measure. However, officials acknowledged it might also potentially result in a loss to the tax base. Officials declined to increase the safe harbour threshold from $\$ 5,000$ to $\$ 20,000$. According to officials, increasing the de minimis threshold (better described as a safe harbour) to $\$ 20,000$ would increase the potential losses to $\$ 3,000$ (ie, GST at 15 per cent, $\$ 20,000 \times 15$ per cent $=\$ 3,000$ ). At this level (ie above the loss of $\$ 750=15$ per cent $\times \$ 5,000$ ), officials considered the requirement to make adjustments seemed warranted. Taxation (GST and Remedial Matters) Bill 2010 (182-2) Officials' Report to the Finance and Expenditure Committee on Submissions on the Taxation (GST and Remedial Matters) Bill (IRD, Wellington, October 2010) 49. However, the $\$ 750$ loss is less than the $\$ 1,000$ capped loss that would be incurred under the 10 per cent de minimis rule.

${ }^{231}$ Goods and Services Tax Act 1985, ss 21(2)(a) and 20(3D). This is effectively a roll over of the former de minimis rule. Officials observed that s $20(3 \mathrm{D})$ is intended to relieve taxpayers from having to apportion input tax if they make mixed supplies and have reasonable grounds to believe that they will make a minimal amount of GST-exempt supplies. However, there was confusion as to whether the exclusion applied from the date of initial acquisition or at the end of the adjustment period. Officials agreed guidance was required and it will be interesting to see in what form it is provided (ie, ruling or policy statements). It is noted that the discussion document specified "on the date of acquisition". See P Dunne GST: Accounting for Land and Other High-Value Assets - A Government Discussion Document (IRD, Wellington, November 2009) 24 at [7.18]. 
Table 1.1: Adjustment Periods

\begin{tabular}{|l|c|l|c|}
\hline \multicolumn{2}{|l|}{ Proposed } & Enacted \\
\hline Threshold & Adjustment Period \\
\hline$\$ 0-\$ 1,000$ & 0 & Threshold $*$ & 0 \\
\hline$\$ 1,001-\$ 5,000$ & 2 & $\$ 0-\$ 5,000$ & 2 \\
\hline$\$ 5,001-\$ 499,999$ & 5 & $\$ 10,001-\$ 500,000$ & 5 \\
\hline Above $\$ 500,000$ & 10 & Above $\$ 500,000$ & 10 \\
\hline
\end{tabular}

*GST Exclusive.

The enacted thresholds are different to those originally proposed in the discussion document. $^{232}$ The increase from the proposed $\$ 1,000$ threshold to $\$ 5,000$ threshold for no adjustment, appears to have now created an overlap with the 10 per cent de minimis rule (capped at $\$ 1,000$ ), such that it will only apply to supplies between $\$ 10,000$ and above $\$ 5,000$, as anything below $\$ 5,000$ is already excluded from making an adjustment (making the 10 per cent de minimis irrelevant).

In contrast to Australia, no distinctions are made for different entities (ie financial institutions) or between types of non-taxable activity (ie private use or exempt use). New Zealand has also provides a much large exclusion from adjustments at \$5,000, whereas Australia excludes adjustments at either $\$ 1,000$ or $\$ 10,000$ (depending on the entity or activity). New Zealand has followed the Australian maximum threshold of 10 adjustments at $\$ 500,000$. However, New Zealand has not adopted the Australian reform proposal to reduce the maximum number of adjustment to five or cap land transaction adjustments.

\section{Calculation methodology}

Direct or indirect methods for ascertaining the extent of the difference between intended and actual use remain available. However, unlike the former adjustment rules, the respective methods are not prescribed in the legislation.

\footnotetext{
232 P Dunne GST: Accounting for Land and Other High-Value Assets - A Government Discussion Document (IRD, Wellington, November 2009) 25.The thresholds were increased in response to submissions on the discussion document suggesting the thresholds were too low. See Comments on submissions to the discussion document GST: Accounting for Land and Other High-Value Assets (Policy Advice Division, IRD, Undated) 4. Document available at <www.minterellison.co.nz/pdfs/Consultation_note_9_April_2010.pdf> (viewed 20 March 2011).
} 
Significantly, the new apportionment methodology has sought to provide a connection between subsequent adjustment periods when calculating the value of the adjustment. The former adjustment rules did not do this. Under the new rules the first adjustment compares the difference between the intended use of the goods or services against their actual use. ${ }^{233}$ All subsequent adjustments compare either: (1) actual use against actual use in the earlier period (if there was an earlier adjustment); or (2) actual use against intended use (if the earlier adjustment was nil). ${ }^{234}$

\section{General apportionment methodology}

The amount of a change-in-use adjustment for an adjustment period is determined using the following formula: ${ }^{235}$

full input tax deduction $\times$ percentage difference

The "full input tax deduction" is the total amount of input tax credit received on the taxable supply. The "percentage difference" 236 is the difference between the "percentage actual use" and either: (1) the "percentage intended use"; or (2) the "previous actual use" if the person has already made an adjustment in an earlier adjustment period.

The second element is a significant change from the former adjustment rules and provides a connection between subsequent adjustments to ensure, that irrespective of the number of adjustments, the total value of the adjustments does not exceed the original input tax credit received.

Specific rules are also provided for adjustments on disposal. ${ }^{237}$

\footnotetext{
${ }^{233}$ Goods and Services Tax Act 1985, s 21C(a). This process is consistent with the former rules.

${ }^{234}$ Goods and Services Tax Act 1985, s 21C(b)(i) and (ii).

${ }^{235}$ Goods and Services Tax Act 1985, s 21D.

${ }^{236}$ Goods and Services Tax Act 1985, s 21G(1)(c).

${ }^{237}$ Goods and Services Tax Act 1985, s 21F.
} 


\section{Apportionment methodology for concurrent use of land}

Unlike the former adjustment approach, a specific formula has been provided for apportioning concurrent use between taxable or non-taxable supplies (ie, "consideration for taxable supply" / "total consideration for supply"). ${ }^{238}$ The concurrent use formula measures the difference between the cost of the land (taxable supply) and the amount of rental income (non-taxable supply). ${ }^{239}$ If the cost of land is not available, the value of the land will be the market value at the time of the adjustment (not acquisition). If no rental income was paid, the market value of rental income that would have been derived over the adjustment period may be used. If market values are not available another method that is fair and reasonable maybe used. $^{240}$

It is clear that this formula is not a codification of the approach applied in Lundy (where the land and building values were compared to derive an apportionment), but instead has codified the argument presented by the Commissioner (and rejected by the Court of Appeal) that the rental income should have been used. ${ }^{241}$ Furthermore, a market value approach would effectively include holding costs. Again, this was an argument presented by the Commissioner and rejected by the Court of Appeal in Lundy.

\section{Transitional rules}

The new rules will apply to all goods and services acquired after 1 April 2011 (see Table 1.2). For goods and services acquired before 1 April 2011, taxpayers may

\footnotetext{
${ }^{238}$ Goods and Services Tax Act 1985, s 21E. The taxpayer may also apply to the Commissioner for approval for an alternative approach if the circumstances make the application of the formula unworkable.

${ }^{239}$ Goods and Services Tax Act 1985, s 21E(3).

${ }^{240}$ Goods and Services Tax Act 1985, s 21E(6).

${ }^{241}$ Officials declined to remove this provision in the face of compliance cost concerns of adjusting for an exempt use, when the exempt use was temporary and would probably not be reflected in the final wash-up calculation when the asset was disposed of. Officials considered that a timing allowance in the first adjustment period provided sufficient relief from compliance costs. Officials also considered that the provisions were constrained to land only. Furthermore, the provision was only intended to provide guidance regarding the methodology to be used to apportion concurrent uses of land and allowed taxpayers to apply to the Commissioner for an alternative approach.
} 
choose to defer the application of the apportionment rules (ie the obligation to make adjustments) depending on the 1 April 2011 market value or book value of goods or services. $^{242}$

Table 1.2: Application Date for Assets Acquired Before 1 April 2011

\begin{tabular}{|l|l|}
\hline Book or Market Value & Application Date \\
\hline$\$ 5,000$ or less & 1 April 2011 \\
\hline$\$ 5,000$ and $\$ 10,000$ & 1 April 2013 \\
\hline Above $\$ 10,000$ & 1 April 2016 \\
\hline
\end{tabular}

\section{Some Comparative Observations of the Two Approaches}

The new apportionment approach is based on "use", not "purpose". As Judge Bathgate observed in Case M53: ${ }^{243}$

“... 'purpose' and 'use' are not the same concepts. The purpose of an exercise is the object for which it was undertaken, the intended action to attain a goal. On the other hand, 'use' is the act or fact of the using or employing a thing, whether for a particular object or not. A use is normally, easily capable of perception from the objective facts involved. On the other hand a 'purpose' is usually a far more subjective concept, as a goal or an end in view."

The former adjustment rules involve awarding (or not) a full input tax credit on the basis of a "principal purpose" threshold. It applied an all or nothing approach. Where

${ }^{242}$ During submissions on the Bill, Officials rejected any deferral of the application date or retaining the current rules for the benefit of some taxpayers, as this was considered to undermine the objectives of the proposed rules (eg, simplification benefits). However, officials subsequently agreed to provide a 5-year transitional window to the new rules (rather than at 1 April 2011), deferring the recalculation of adjustments for goods and services (excluding land) under the new rules to 1 April 2016 (ie, a deemed sale of goods at market value for output tax and deemed acquisition on the estimated use for input tax credits). IRD acknowledged that the finance and property sector were the other main sectors affected by the apportionment rules, although the number and range of assets held by the property sector was necessarily far more limited than for the financial services sector. This effectively is a deferral of the new rules and will provide larger taxpayers sufficient time to put in place appropriate systems before opting into the new rules. Officials also considered that special rules to negotiate fair and reasonable apportionment methods (for the benefit of financial services sector) would provide the necessary flexibility to agree on future approaches as well as to accommodate existing apportionment agreements already in place (subject to modifications). Officials considered that this would address most of the compliance cost concerns raised in submissions.

${ }^{243}$ Case M53 (1990) 12 NZTC 2,312 (TRA). Case N22 (1991) 13 NZTC 3,187 (TRA) also discusses the distinction between 'use' and 'applied'. 
there were mixed uses on acquisition (or mixed uses subsequently materialised) adjustments were manufactured by deeming a supply (when there was none actually made) on the basis of identifying a subsequent purpose separate from the principal purpose.

In contrast, the apportionment approach seeks to reflect non-taxable use in the apportionment of the initial input tax credit (based on a fair and reasonable estimate) at the first time of supply, and then provide for a capped number of subsequent adjustments (if required) based on the difference between what was estimated and what was actually supplied. If the estimate is accurate no subsequent adjustment is required. In contrast, the principal purpose approach in providing an up-front 100 per cent input tax credit invites subsequent adjustments to correct the over-payment (illustrated in Figure 1.19). Both approaches provide de minimis rules for adjustments.

A new feature of the apportionment rules is a capped adjustment mechanism, not provided in the adjustment rules. This new process will cap the number of adjustments that can be made. However, the new mechanism also calculates adjustments by measuring changes between adjustments. This approach ensures output tax credits can never exceed initial input tax credits. In contrast, the adjustment rules calculated subsequent adjustments against the initial input tax credit and ignored the impact of earlier adjustments. This approach without judicial intervention would have resulted in output tax credits exceeding initial input tax credits. This was a major failure of the former adjustment mechanism. The unlimited nature of periodic adjustments only accentuated this problem. 
Figure 1.19: Comparison of Current and Proposed Rules

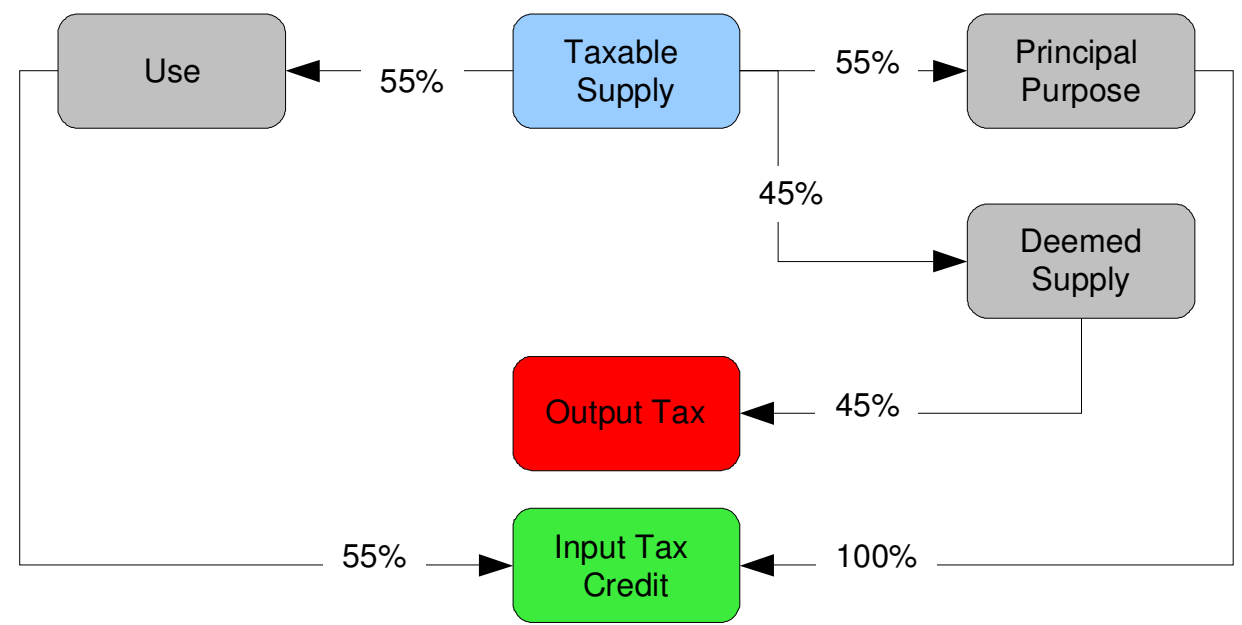

\section{N. Examples}

The following examples illustrate and compare the operation of the respective rules.

Example 1.1: Computer (Capital property) $)^{244}$

Cian is a graphic designer and purchases a computer for $\$ 4,000$ (plus GST of $\$ 600$ ) to use both for business ( 80 per cent) and private purposes ( 20 per cent). Cian's principal purpose of buying the computer is for the taxable activity of graphic design. Cian files GST returns every two months. In the second year of operation, private use increases to 40 per cent due to his children's use of the computer. However, no other changes in use occur over the lifetime of the computer.

Under an adjustment approach, each adjustment is 20 per cent $\times \$ 600=\$ 120$. Under an apportionment approach the supply would be apportioned in the input tax claim between taxable $((\$ 600 \times 80$ per cent $=\$ 480)$ and non-taxable use $(\$ 600 \times 20$ per cent $=\$ 120)$.

No subsequent adjustment for change-in-use in year two is required. While the amount of change is above the 10 per cent de minimis an adjustment is not required

\footnotetext{
${ }^{244}$ Based on example provided in Tax Information Bulletin Vol 21:1 (February 2011) 36, Example 7.
} 
because the value of the transaction is within the safe harbour threshold of $\$ 5,000$. No subsequent adjustment calculation is required. ${ }^{245}$

\begin{tabular}{|l|r|r|r|r|}
\hline Adjustments & \multicolumn{2}{|c|}{ Change-in-Use Approach } & \multicolumn{2}{|c|}{ Apportionment Approach } \\
\hline & & Adjustment & $* \$ 480$ & Adjustment \\
\hline Input tax credit & $\$ 600$ & & $\$ 120$ \\
\hline Adjustment 1 & $\$ 480$ & $\$ 120$ & $\$ 0$ & $\$ 0$ \\
\hline Adjustment 2 & 240 & $\$ 120$ & $\$ 480$ & $\$ 0$ \\
\hline Adjustment 3 & 120 & $\$ 120$ & $\$ 480$ & $\$ 0$ \\
\hline Adjustment 4 & $\$ 0$ & $\$ 120$ & $\$ 480$ & $\$ 480$ \\
\hline Adjustment 5 & $\$ 0$ & & $\$ 120$ & $\$$ \\
\hline Balance & & & $\$ 40$ \\
\hline
\end{tabular}

* Cian could possibly opt for a 100 per cent claim of $\$ 600$ (based on the Lennartz rule $)^{246}$ and make an adjustment in the next adjustment period. ${ }^{247}$ Because the value of the goods acquired is less than $\$ 5,000$, Cian would not be required to make any adjustment for the private use.

Example 1.2: Property Development (Real property) ${ }^{248}$

The GST rate is 15 per cent. Louise, a property developer purchases a house and land for $\$ 500,000$ and intends to sell the development on completion. Louise is not a builder or associated with one. The land cost $\$ 300,000$ (plus GST of $\$ 45,000$ ) and the house $\$ 200,000$ (plus GST of $\$ 30,000$ ). The market value of the property is

${ }^{245}$ PWC GST Direct Newsletter (August 2010) 3.

${ }^{246}$ Lennartz v Finazamt Munchen III, CFEC Case C-97/90; [1995] STC 514. See Tolley's Value Added Tax 2007 (1st Ed, Lexis Nexis Ltd, 2007) 739 at [35.7(3)]. It is unclear if this rule would apply in New Zealand as the taxpayer is required to make a "fair and reasonable" estimation of the extent of the taxable use at the time of acquisition. The fact the IRD example does not refer to the $\$ 5,000$ safe harbour threshold would suggest they do not consider the Lennartz approach can apply to the New Zealand rules.

247 Officials acknowledged that the $\$ 5,000$ safe harbour would allow taxpayers to claim a full input tax credit up to the value of $\$ 750$ (ie, 15 per cent $\times \$ 5,000$ ) if following the acquisition, the taxpayer changed their use to solely non-taxable use. "For example, a taxpayer may purchase an asset for a GST-exclusive value of $\$ 5,000$ and claim the full available input tax of $\$ 750$ (at 15 per cent). If, immediately following the acquisition, the taxpayer changes their use of the asset to solely private use, the taxpayer will not be required to make a subsequent change-in-use adjustment and will therefore have claimed $\$ 750$ more in input tax than they would have claimed if they were required to make ongoing adjustments." See Taxation (GST and Remedial Matters) Bill 2010 (182-2) Officials' Report to the Finance and Expenditure Committee on Submissions on the Taxation (GST and Remedial Matters) Bill (IRD, Wellington, October 2010) 48-49.

${ }^{248}$ Based on example provided in Tax Information Bulletin Vol 21:1 (February 2011) 38, Example 9. 
$\$ 650,000$. The development does not sell and the development is rented until a buyer can be found. The rent returns $\$ 25,000$ per annum. Insurance and rates cost $\$ 10,000$ per annum (plus GST of $\$ 1,500$ ). The depreciation rate for the house is 10 per cent per annum. Louise claims an input tax credit of $\$ 75,000$ on the purchase price of $\$ 500,000$. Louise is entitled to an initial 100 per cent claim. The subsequent change in use will create an adjustment.

Under the adjustment approach for concurrent purposes adopted in Lundy ${ }^{249}$ the apportionment ratio for the property is: $\$ 200,000: \$ 300,000=(\$ 200,000 / \$ 500,000)$ 40 per cent (non-taxable). Depreciation of the house is $\$ 30,000$ (10 per cent $x$ $\$ 300,000$ ) per annum (or $\$ 5,000$ per 2-monthly period). The adjustment (per taxable period) is 40 per cent $\times \$ 5,000=\$ 2,000$. The apportionment ratio for insurance and rates is 75 per cent (non-taxable) and 25 per cent (taxable). The adjustment is: 75 per cent $\times \$ 11,500 / 6=\$ 1,437.50$. The total adjustment for 2-monthly period is $\$ 2,000+$ $1,437.50=\$ 3,437.50$. Under an apportionment approach, the total supply is $\$ 650,000+\$ 25,000=\$ 675,000$. The taxable use of the house is: $\$ 650,000$ / $\$ 675,000=96$ per cent . The non-taxable use is 100 per cent -96 per cent $=4$ per cent. The first adjustment is $\$ 25,000 \times 4$ per cent $=\$ 1,000$. The second adjustment calculates the total supply as $\$ 675,000+\$ 25,000=\$ 700,000$. The taxable use of the house is now: $\$ 650,000 / \$ 700,000=92$ per cent. The non-taxable use is 96 per cent - 92 per cent $=4$ per cent. The second adjustment would be $\$ 25,000 \times 4$ per cent $=$ $\$ 1,000$.

\begin{tabular}{|l|r|r|r|r|}
\hline Taxable Periods & \multicolumn{2}{|c|}{ Change-in-Use Approach } & \multicolumn{2}{c|}{ Apportionment Approach } \\
\hline & & Adjustment & & Adjustment \\
\hline Input tax credit & $\$ 75,000$ & & 75,000 & \\
\hline Period 1 & & $\$ 3,437.50$ & & \\
\hline Period 2 & & $\$ 3,437.50$ & & \\
\hline Period 3 & & $\$ 3,437.50$ & & \\
\hline Period 4 & & $\$ 3,437.50$ & & \\
\hline Period 5 & & $\$ 3,437.50$ & & \\
\hline Period 6 & & $\$ 20,625.00$ & & \\
\hline 12 month Balance & & & \\
\hline
\end{tabular}

${ }^{249}$ CIR v Lundy Family Trust and Behemoth Corp Ltd (2005) 22 NZTC 19,637 (CA). 
As the transaction involves land, there is no cap on the number of adjustments.

\section{O. Conclusion}

It is evident from all the empirical evidence that the former adjustment rules were overly complex and difficult to apply. They resulted in a substantial amount of litigation which provided less than satisfactory clarity. The judiciary struggled with the artificial nature of the rules and the abstract distinctions that are inherent in purpose tests.

Several problems are inherent in the rules. First, the adjustment rules create an artificial (or fictional) deemed supply arising from the identification of another purpose, that is not the principal purpose. This fiction appears to have created confusion between identifying the deemed supply and the purpose that brought the deemed supply into being, which might be based on identification of a non-taxable activity (eg, an exempt supply). Implicit in the adjustment rules is an apportionment between a principal purpose and another purpose, rather than apportionment between actual uses. The possibility for some assets to have concurrent purposes (across time and space) posed serious problems for apportionment and has resulted in the courts being compelled to make rough and ready apportionment decisions. This was an inherent problem in apportioning purpose rather than use.

These problems (and their manifestation into a disproportionate amount of litigation) are not surprising (and were even expected), given the concept of purpose contained in the adjustment rules appears to have been imported from income tax law, where they have created similar difficulties of interpretation. ${ }^{250}$ It would appear from the litigation activity that the adjustment rules have failed to provide sufficient certainty

\footnotetext{
${ }^{250}$ For example, the discussion of "purpose" by the Court of Appeal in CIR v National Distributors Ltd [1989] 3 NZLR 661 (CA) at 666-669, (1989) 11 NZTC 6,346 at 6,350-6,352 at [12] where Richardson J observed that: "Where there is more than one purpose present taxability turns on whether the dominant purpose was one of sale or other disposition: CIR $v$ Walker [1963] NZLR 339 (CA); CIR v Hunter [1970] NZLR 116 (CA); and Holden v CIR [1974] 2 NZLR 52 (PC). The analysis may become more complicated where different purposes may be more significant depending on whether the focus is on the short term, the medium term or the ultimate object. Adoption of a dominant purpose test in relation to the particular property purchased allows a sensible focus as a practical matter on what was truly important to the taxpayer at the time of acquisition. ... In some factual situations it may be necessary to draw a careful distinction between motives and intentions and purposes, even though the ideas conveyed by the respective words merge into each other without a clear line of differentiation."
} 
for all the protagonists (eg, taxpayers, advisors, and the revenue authority). An examination of the cases reveals that the judiciary have struggled with the front and back-end of the adjustment rules. The rules have been prone to different lines of interpretation by lower courts which has added to the difficulties facing higher courts. The fact that there has been a steady stream of litigation and appeal is evidence that there is something wrong with the adjustment rules (andlor their drafting). The cost of complying with the rules, from a litigation perspective, has been high.

The new apportionment approach reduces compliance costs by recognising mixed use at the time of acquisition rather than relying on an adjustment mechanism to correct overpayment of input tax credits. The new rules also introduce a new mechanism for calculating adjustments that overcomes many of the problems experienced from using an existing set of supply rules that never contemplated repetitive recalculation of supplies in order to provide accurate adjustments. The new rules have lost none of the compliance cost features of the former adjustment mechanism and carry-over many of the prior de minimis rules (as well as new ones) in order to further reduce compliance costs. Harmonisation of apportionment rules with Australia should also reduce litigation activity, provide improved opportunities to leverage guidance, and improve judicial outcomes. Overall it would appear that the new rules will reduce compliance costs for the majority of taxpayers. 


\section{THE AUSTRALIAN EXPERIENCE}

"The present law is overly complex, having too many differing thresholds and drawing a generally unhelpful distinction between business finance and other types of activity." $\sim$ Australian Board of Taxation. ${ }^{1}$

"The existing Division 129 provision places an unreasonable compliance burden on taxpayers and this inevitably leads to a lack of integrity in relation to the practical application of the Division." Australian Bankers Association ${ }^{2}$

\section{A. Introduction}

It has been 10 years since the commencement of Australia's GST. This is a sufficient period of time to examine whether Australia's change-in-use rules provide a possible model for other jurisdictions to emulate or avoid — or in light of recent reform proposals, refine.

Similar to the New Zealand experience, the change-in-use rules have largely remained untouched since their introduction. But unlike New Zealand, the amount of case law surrounding the rules has not been substantial — quite the opposite. Judicial intervention has been markedly absent.

If a lack of legislative and judicial activity is a measure of success, why have the Australian change-in-use rules been so successful? Why has the Australian experience been so different to New Zealand? Is it due to the rules themselves, or is it due to revenue authority guidance or the drafting style and structure of the legislation? Clearly, any apparent success has to be tempered against a recent Board of Taxation review of the change-in-use rules, which has attempted to address

1 E Mayne Review of the Legal Framework for the Administration of the Goods and Services Tax: A Report to the Assistant Treasurer and Minister for Competition Policy and Consumer Affairs (The Board of Taxation, Canberra, December 2008) 34 at [2.2.33]. Document available at

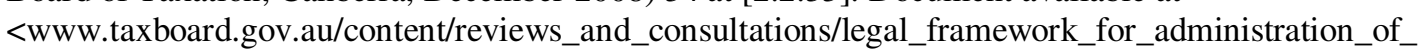
gst/report/downloads/legal_framework_for_administration_of_gst_report.pdf> (viewed 20 March 2011).

2 Australian Bankers Association Submission on the Implementation of the Recommendations of the Board of Taxation's Review of the Legal Framework for the Administration of the Goods and Services Tax (22 June 2009) 2. Document available at $<$ www.treasury.gov.au/documents/1578/PDF/Australian_Bankers_Association.pdf $>$ (viewed 20 March 2011). 
concerns that the compliance costs to taxpayers arising from the change-in-use rules are far too high. ${ }^{3}$

To answer such a broad question requires not only an examination of the legislation and the specific rules, but also the broader tax landscape within which the Australian rules have existed.

This chapter first examines the key provisions that provide the basis for entitlements to input tax credits and change-in-use adjustments (on an apportionment basis). The chapter then examines problems with the practical implementation of those rules, which have been highlighted in the literature and by taxpayers, and proposals from the Board of Taxation and Treasury to mitigate them.

\section{Part 1: The Rules}

The rules for claiming entitlement to input tax credits on acquisitions and adjustments for change-in-use are provided for in the GST legislation, interpreted through case law, and guided by Taxation Office rulings.

\section{B. Legislation}

Australian GST law essentially comprises a principal GST Act ${ }^{4}$, a Transitional GST $\mathrm{Act}^{5}$, and subordinate legislation (eg, regulations and determinations) ${ }^{6}$. While the GST Act has received a reasonable level of remedial legislative activity, the input tax rules and the change-in-use rules (Divisions 11 and 129) have largely remained untouched since enactment (illustrated in Figure 2.1). ${ }^{7}$

3 E Mayne Review of the Legal Framework for the Administration of the Goods and Services Tax: A Report to the Assistant Treasurer and Minister for Competition Policy and Consumer Affairs (The Board of Taxation, Canberra, December 2008).

4 A New Tax System (Goods and Services Tax) Act 1999. Hereafter the "GST Act".

5 A New Tax System (Goods and Services Transitional Tax) Act 1999.

6 A New Tax System (Goods and Services Tax) Regulations 1999. Hereafter the "GST Regulations".

Between enactment and commencement the GST Act was amended by six remedial amendment Acts, containing 372 amendments. Of those six remedial amendment Acts, three amended Divisions 11 and 129. Since the introduction of the GST Act there have been 54 amendment Acts. Of those 54 amendment Acts, only five have amended Divisions 11 and 129. The five amendment Acts are: A New Tax System (Indirect Tax and Consequential Amendments) Act 1999 (No 176); A New Tax System (Indirect Tax and Consequential Amendments) Act (No 2) 1999 (No 177); Indirect Tax 


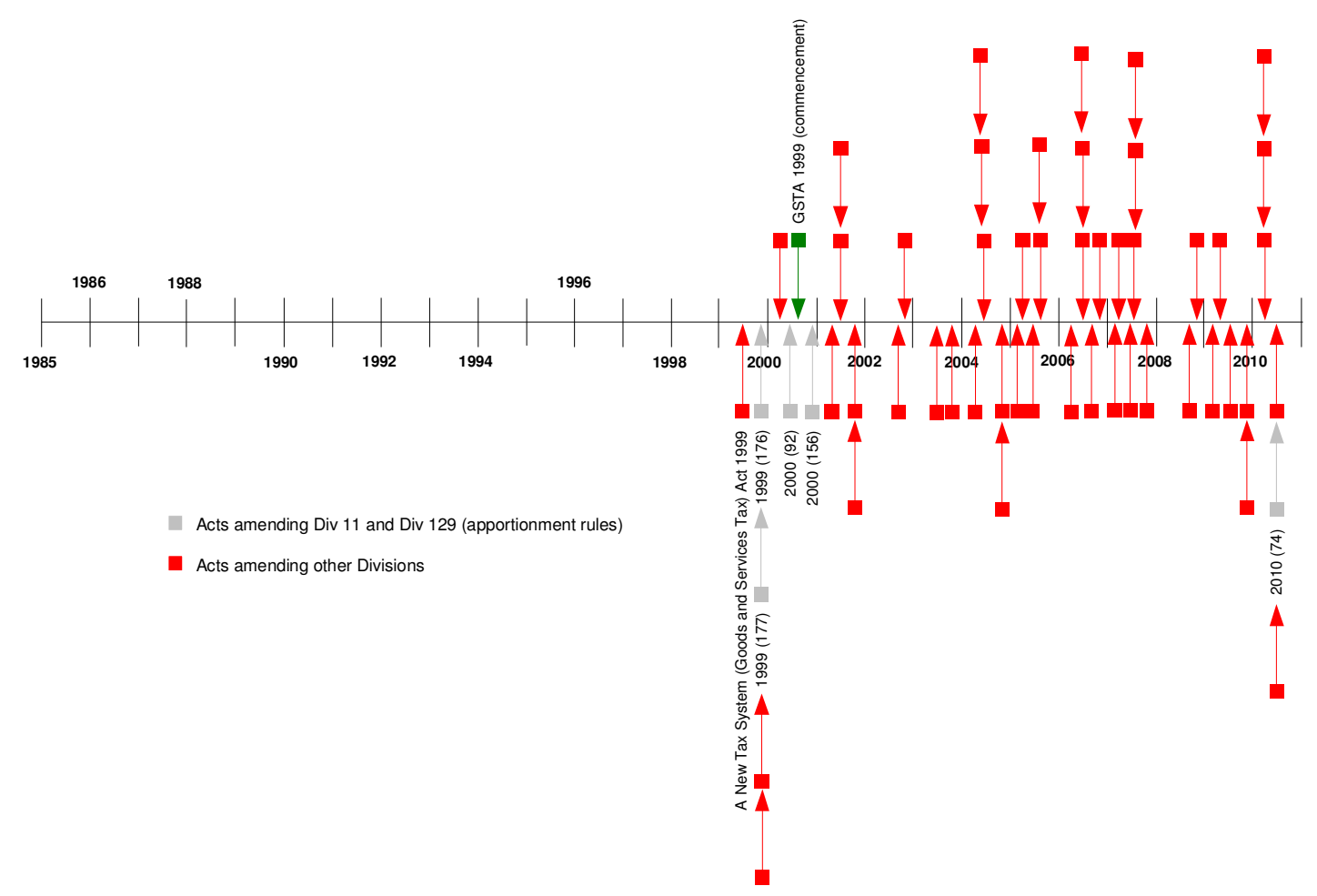

This level of legislative stability over a period of 10 years would at first glance appear to suggest the rules are working well.

Generally, the GST Act is highly detailed ${ }^{8}$ and contains diagrams, notes, and examples. The GST Act is structured in a step-by-step manner (and quite prescriptive) and is written in plain language. ${ }^{9}$ Numbering of provisions and divisions are sequential, but not consecutive. This allows for expansion without the need for complex numbering. ${ }^{10}$ Definitions are located at the back of the Act in

Legislation Amendment Act 2000 (No 92); Taxation Laws Amendment Act (No 8) 2000 (No 156); and Tax Laws Amendment (2010 GST Administration Measures No 2) Act 2010 (No 74).

8 Reflective of the high number of provisions it contains — just over 800 individual sections.

9 The style of drafting of the GST Act is quite unique. The legislative provisions appear to be written from the purchaser's point of view (hence reference to "acquisitions") and would appear to be written for the general public, rather than for advisors or lawyers. Generally each provision outlines a general proposition and then is subject to cut-outs.

${ }^{10}$ Rewritten New Zealand income tax legislation has also removed complex numbering through the use of alpha-numeric numbering. 
Division 195 which is described as the "dictionary". Most defined terms are highlighted by an asterisk. However, not all defined terms are highlighted.

The GST Act comprises six Chapters and each Chapter is made up of Parts and Divisions. Each Chapter has consecutively numbered Parts that restart from Part 1 in each Chapter. Divisions are numbered sequentially from Division 1 (in Chapter 1) to Division 195 (in Chapter 6). They do not restart from Division 1 in each chapter this allows individual provisions to be cited with their Division number. For example s 10 is cited as "s 2-10" (ie, Division $2-$ s 10). Divisions are also cited with their respective Parts. For example "Part 2-2" (ie, Part 2 - Division 2). All GST administration, collection and recovery provisions are contained in a Tax Administration Act. ${ }^{11}$

The GST Act also contains provisions for empowering subordinate legislation (eg, regulations and determinations). This is because much of the GST Act does not contain the mechanical aspects of the GST system (eg, prescribed information to be contained in a tax invoice, or the rate of GST). ${ }^{12}$

\section{Input Tax Rules}

GST in Australia is a tax imposed on consumers and payable on taxable supplies or taxable importations. ${ }^{13}$ To enure only the final consumer pays the tax, the GST Act provides a mechanism to reimburse entities for the payment of any output tax incurred from an acquisition by way of input tax credits.

The GST Act entitles a registered entity to claim input tax credits for creditable acquisitions ${ }^{14}$ used to the extent of the creditable purpose. ${ }^{15}$ Registered entities claim

${ }^{11}$ Taxation Administration Act 1953. Originally, GST administration provisions were inserted in a new Part 6 of the Act. However, from 1 July 2006, Part 6 was repealed and replaced by a new Chapter 3 in Schedule 1 of the GST Act.

${ }^{12}$ Interestingly, the rate of GST is set outside of the GST Act by regulation. This contrasts markedly with New Zealand, who chose to include the rate within the GST Act in order to ensure any rate changes had the full consideration of Parliament, rather than just the executive body.

${ }^{13}$ In Australia, importations have different rules and a parallel set of provisions. For the purposes of this paper their consideration has been excluded to avoid complexity.

${ }^{14}$ A New Tax System (Goods and Services Tax) Act 1999, s 11-20. 
input tax credits based on the extent of their creditable purpose when they make the acquisition. The amount of the input tax credit that an entity is entitled too depends on the extent that the acquisition is for a creditable purpose.

The input tax rules are contained in Division 11 of the GST Act. ${ }^{16}$ An entitlement to input tax credits arises from acquisitions that are solely or partly for a creditable purpose. Creditable purpose is defined in s 11-15. Unlike New Zealand, Australia has adopted an apportionment approach to input tax entitlement from the outset.

Section 11-15(1) provides that an entity acquires a thing for a creditable purpose to the extent that the acquisition is for the purposes of carrying on an enterprise. ${ }^{17}$ This includes an acquisition that is partly for a creditable purpose. ${ }^{18}$ The creditable purpose tests in s 11-15 focuses on a registered entity's intended or planned use of an acquisition. ${ }^{19}$ The meaning of the phrases "to the extent", "carrying on", "relates to" and "would be" are central to understanding an entitlement to input tax credits and are discussed briefly below.

\section{The starting point - a positive test}

As Hill J recognised in HP Mercantile Pty Ltd $v F C T,{ }^{20}$ the test for entitlement to input tax credits in s 11-15(1) is a positive one:

“... In both the GST provision and the income tax provisions, there is a need to pass first through a positive test. In the case of GST, the positive test is the requirement that the acquisition has been in whole or in part acquired in carrying on an enterprise. In the income tax context, there is the need to find that the loss or outgoing be incurred in gaining or producing assessable income, or in carrying on a business. In both cases apportionment arises where the positive test is only partly satisfied."

\footnotetext{
${ }^{15}$ A New Tax System (Goods and Services Tax) Act 1999, s 7-1. The term "input tax credit" is defined in s 195-1 and means "an entitlement arising under ss 11-20 or 15-15."

${ }^{16}$ Division 11 is entitled "Creditable Acquisitions" and is located in Chapter 4, Part 4 of the GST Act.

${ }^{17}$ A New Tax System (Goods and Services Tax) Act 1999, s 11-15(1).

${ }^{18}$ A New Tax System (Goods and Services Tax) Act 1999, s 11-5(a).

${ }^{19}$ GSTR 2009/04 at [8].

${ }^{20}$ HP Mercantile Pty Ltd v FCT [2005] FCAFC 126 at [21], (2005) 60 ATR 106 at 112-113.
} 
The test is also very broad. It makes no distinction between capital or revenue. The Explanatory Memorandum of the GST Bill stated that: ${ }^{21}$

"3.25 The creditable purpose test is broader than the test of the deductibility for income tax in Section 8-1 of the Income Tax Assessment Act 1997. For example: input tax credits may be available in relation to the acquisition of capital items where your capital purchases are not deductible for income tax. The acquisition of services for preparing your tax returns must satisfy the creditable purpose test, even though these are only deductible under a specific provision for income tax."

\section{Carrying on your enterprise}

While the entitlement test is positive, it is also conditional. Entitlement to input tax credits can be denied if the supply is not acquired in carrying on a business enterprise. $^{22}$ The term "carrying on" is defined in s 195-1 to include the commencement or termination of an enterprise. The term "enterprise" is broadly defined and includes activities where the taxpayer is engaged in a business. ${ }^{23}$ This broad approach to entitlement is consistent with New Zealand's approach..

\section{To the extent}

The expression "to the extent" indicates apportionment is required and is drawn from the well settled income tax principles set down by the Australian High Court in Ronpibon Tin NL v FCT. ${ }^{24}$ According to these principles, where costs are capable of dissection, one must apportion between identifiable components. The methodology used to apportion must also be fair, reasonable, and appropriate. ${ }^{25}$ This is consistent

${ }^{21}$ A New Tax System (Goods and Services Tax) Bill 1998 (explanatory memorandum) at [3.25].

${ }^{22}$ A number of Division 11 cases relate to the meaning and scope of "enterprise".

${ }^{23}$ A New Tax System (Goods and Services Tax) Act 1999, s 9-20. The activities of charitable and religious organisations, government bodies and trusts are considered to be an enterprise. There are several exclusions including activities of employees and activities done as a private hobby.

${ }^{24}$ Ronpibon Tin NL Tongkah Compound NL v FCT (1949) 78 CLR 47 (HCA). Cited with approval in HP Mercantile Pty Ltd v FCT [2005] FCAFC 126, (2005) 60 ATR 106 at [37].

${ }^{25}$ Ronpibon Tin NL Tongkah Compound NL v FCT (1949) 78 CLR 47 (HCA) at 55-56. The fair and reasonable principle was used by the High Court in the context of the apportionment of expenditure serving more than one object indifferently. The ATO's view in GSTR 2006/4 at [32-33] is that the fair and reasonable principle applies equally to the choice of method for allocating or apportioning acquisitions in all circumstances. 
with New Zealand interpretations. ${ }^{26}$ The extent of the entity's creditable purpose is based on their planned use of the acquisition or importation. ${ }^{27}$ There must be an intention at the time of making the acquisition.

\section{Exclusions}

If $s$ 11-15(1) is the positive test, then the negative tests are those set out in s 11-15(2) and further refined in ss 11-15(3)-(5). Acquisitions of input taxed supplies, ${ }^{28}$ or of a private or domestic nature, ${ }^{29}$ are not treated as acquisitions for a creditable purpose and are excluded.

\section{Relates to making supplies}

The expression "relates to making supplies that would be input taxed" in s 1115(2)(a) has been examined by the courts on several occasions. However, HP Mercantile Pty Ltd v FCT ${ }^{30}$ remains Australia's leading case on the interpretation of Division 11 and widely cited as the approach to interpreting GST legislation by subsequent cases and rulings.

The court established that the expression "relates to" signified a connection between two subject matters. The connection or association signified by the words "relates to" can be direct or indirect, substantial, or real. ${ }^{31}$ The words do not infer the need for tracing between acquisition and actual supply. However, the relationship has to

${ }^{26}$ Europa Oil (NZ) Ltd (No 2) v CIR [1974] 2 NZLR 737, (1974) 1 NZTC 61,169 (CA).

${ }^{27}$ GSTR 2006/4 at [17].

${ }^{28}$ A New Tax System (Goods and Services Tax) Act 1999, s 11-15(2)(a). Input tax supplies are known as "exempt supplies" in New Zealand. Input taxed supplies (or exempt supplies) will normally not attract output tax, and an entity that makes an exempt supply will not be able to obtain an input tax credit for the tax payable on acquisitions it makes in the course of its enterprise of making input taxed supplies. A definition of what constitutes an input taxed supply is found in Division 40 of the GST Act. Financial supplies, residential rent, residential premises, precious metals, school tuckshops and canteens, and fundraising events conducted by charitable institutions are classified as input taxed supplies. Financial supplies that are input taxed are set out in the regs 40-5.09 and 40-5.10 of the GST Regulations.

${ }^{29}$ A New Tax System (Goods and Services Tax) Act 1999, s 11-15(2)(b).

${ }^{30}$ HP Mercantile Pty Ltd v FCT [2005] FCAFC 126, (2005) 60 ATR 106.

${ }^{31}$ Hill J observed at [36] that s 11-15(5) would appear to contemplate that an acquisition having an indirect connection with a financial supply would otherwise fall within s 11-15(2)(a). 
be relevant, not one that is trivial. A remote connection will not suffice. The court also observed that the word "making" indicates that the relationship must relate to the making of the supply, not the supply itself. Finally, the word "would" suggests conditionality, not futurity.

Choi has suggested the tests in HP Mercantile do not provide sufficient guidance and would be difficult for taxpayers to apply in any practical manner and that further litigation is required to provide sufficient clarity. ${ }^{32}$ While the principles have been criticised for lacking imprecision, they have stood the test of time. The case has not been over-turned or distinguished and the lack of subsequent litigation would suggest they may not be as imprecise as suggested. The broad approach of the court in HP Mercantile has also been endorsed in subsequent GST rulings. In contrast, New Zealand courts held divergent views on the interpretation of the equivalent input tax test (ie, principal purpose) for a lengthy period of time.

It remains to be seen whether a call for more litigation provides the clarity Choi seeks. Indications are that the law is settled and that the disputes are more often one of fact. According to James et al, ${ }^{33}$ while the courts maybe of assistance: ${ }^{34}$

\footnotetext{
"Once the interpretational approach has been decided upon, apportionment issues become more concerned with fact than law, and as such are more likely to be negotiated between the taxpayer and the administrator, than they are to be the subject of judicial pronouncement."
}

The recent American Express case, ${ }^{35}$ which examined the application of the indirect (revenue) apportionment methodology, does not appear to have provided the clarity Choi might have anticipated. Admittedly, the apportionment issue in this case was probably one more about the facts (eg, turning on the scope of an agreed formula), than the law. If this is the case, then the American Express decision would appear to

${ }^{32}$ E Choi "Principles of creditable purpose following HP Mercantile" (2006) 6 Australian GST Journal 117 at 119 .

${ }^{33}$ C James, I Jeffrey, and H Miller “Apportionment Principles: Part I" (2004) 4(1) Australian GST Journal 24 and "Apportionment Principles: Part II" (2004) 4(2) Australian GST Journal 10.

${ }^{34}$ C James, I Jeffrey, and H Miller "Apportionment Principles: Part II" (2004) 4(2) Australian GST Journal 10 at 26.

${ }^{35}$ FCTv American Express Wholesale Currency Services Pty Ltd [2010] FCAFC 122, (2010) 77 ATR 12. 
suggest that most of the interpretational issues surrounding the apportionment rules are settled and the arguments are one of fact.

\section{Financial acquisitions threshold}

Normally, financial supplies will be treated as exempt supplies. However, s 11-15(4) provides a claw-back from this position, where the financial supplies for a 12 month period are below the lesser of $\$ 50,000$ or 10 per cent of the total amount of the input tax credits claimed. ${ }^{36}$ A qualifying taxpayer under s 11-15(4) is entitled to an input tax credit for the full input tax imposed on the acquisition used partly for a creditable purpose and partly to make a financial supply. Qualifying financial acquisition threshold (FAT) supplies attract a reduced input tax credit of 75 per cent. ${ }^{37}$

The policy reason behind this claw-back from exemption was to ensure that the financial sector did not bring what were outsourced activities before the GST Act was enacted, back in-house after the GST Act was enacted. ${ }^{38}$ This claw-back from the financial supply exemption is a unique feature of the Australian GST Act and has corresponding change-in-use adjustment thresholds. ${ }^{39}$

\section{Input tax credit calculations - apportionment}

Input tax credits that are partly creditable are apportioned ${ }^{40}$ according to a formula: $^{41}$

Full input tax credit $\times$ Extent of creditable purpose $\times$ Extent of consideration

\footnotetext{
${ }^{36}$ A New Tax System (Goods and Services Tax) Act 1999, s 189-15. The \$50,000 and/or 10\% threshold is known as the 'financial acquisitions threshold' (FAT). The thresholds were originally present in s 11-15(4) and later removed to Division 189 . The $10 \%$ rate was originally $5 \%$.

${ }^{37}$ Division 70 of the GST Act and reg 70-5.03 of the GST Regulations. The arbitrary figure of 75\% was determined after consultation with the finance industry (eg, if the function was taken in-house it would have cost $25 \%$ more than out-sourcing).

38 The financial acquisition threshold is explained in GSTR 2003/9.

${ }^{39}$ A New Tax System (Goods and Services Tax) Act 1999, s 129-15(2).

${ }^{40}$ A New Tax System (Goods and Services Tax) Act 1999, s 11-25.

${ }^{41}$ A New Tax System (Goods and Services Tax) Act 1999, s 11-30(3).
} 
Effectively, the formula prescribes a method of apportionment based substantially upon quantifying the extent of the creditable purpose as a percentage of the total purpose of acquisition and apportioning the input tax credits on a pro rata basis.

The Commissioner may also agree to other ways of calculating the extent to which a creditable acquisition is for a creditable purpose. ${ }^{42}$

The ATO has provided detailed guidance on the calculation of creditable purpose in GST ruling GSTR 2006/4 ${ }^{43}$ and for financial supplies in GSTR 2006/3. ${ }^{44}$ The rulings endorse the approach taken by the High Court in Ronpibon Tin $^{45}$ and contain several approved apportionment methods (and examples) that are broadly categorised as direct or indirect methods. Taxpayers are able to select the best method that provides the most advantageous result without the preferred approach being treated as an avoidance arrangement. ${ }^{46}$ Taxpayers are also able to select an alternative method, provided it accords with what is "fair and reasonable", reflects the intended use of the acquisition, and is appropriately documented. ${ }^{47}$

However, the ATO consider the application of depreciation (based on estimated useful life) not to be a fair and reasonable method of apportionment. ${ }^{48}$ This is because depreciation apportions value over the estimated useful life (EUL) of the asset, rather than the actual use of the asset over the relevant periods. In contrast, New Zealand's new apportionment rules have allowed taxpayers the option of utilising EUL for adjustment purposes.

${ }^{42}$ A New Tax System (Goods and Services Tax) Act 1999, s 11-30(5).

${ }^{43}$ GSTR 2006/4 replaced GSTR 2000/15.

${ }^{44}$ GSTR 2006/3 replaced GSTR 2000/22. Additional guidance is provided by the ATO on calculating input tax credits on motor vehicles in GSTR 2006/1 (formerly GSTR 2000/2).

${ }^{45}$ Ronpibon Tin NL Tongkah Compound NL v FCT (1949) 78 CLR 47 (HCA).

${ }^{46}$ GSTR 2006/4 at [35].

${ }^{47}$ GSTR 2006/4 at [34-35].

${ }^{48}$ GST 2009/04 at [128]. It is noted (see discussion below on proposed reforms to the Australian rules), that submissions have suggested utilising EUL for particular assets in order reduce compliance costs, as this is already done for income tax purposes. 
Direct methods seek to identify a direct quantifiable measure of the use of the acquisition. According to the ATO, measures based on inherent characteristics or factors (referred to in management accounting and costing systems as drivers) directly connected with the acquisition usually give a fair reflection of the use of the thing. ${ }^{49}$ Australian Accounting Standards (or prudential requirements of equivalent rigour), are considered an appropriate foundation for applying the direct method. The use of direct methods for apportioning the intended use of acquisitions to the activities of an enterprise appears to be the preferred default method by the ATO "as it would best reflect the intended use of your acquisitions". ${ }^{50}$

Indirect methods are based on estimated usage and extrapolate measurable ratios to what is not so readily measurable. For this reason, the ATO acknowledge they may not give an accurate measure of the creditable use, but they do provide a reasonable measure. ${ }^{51}$ The 2 main types of indirect method are input based and output based methods. Input based methods employ a measure based on costs. For example, identifiable costs of acquisition directly related to supplies are extrapolated to costs that cannot be easily apportioned (eg, overheads). Output based methods utilise measures of output (revenue from sales) in a similar fashion. Of the two indirect methods the ATO prefer an input based method. ${ }^{52}$

The former New Zealand adjustment approach does away with the need for any apportionment measures when determining the entitlement to input tax credits. Rather, it allocates 100 per cent input tax credits under a principal purpose test. The weakness with this approach is that the principal purpose test was not only open to competing interpretations, but still remains rather fluid — there is no minimum threshold under a principal purpose test (unless it is meant to be a more than 50 per cent threshold — which it is not), so there is still room to litigate.

\footnotetext{
${ }^{49}$ Some examples of these factors and characteristics are provided in GSTR 2006/4 and include: distance (ie, kilometres travelled); time (ie, processing time); volume (ie, transaction numbers); space (ie, floor area); or staff numbers.

${ }^{50}$ GSTR 2006/4 at [106].

${ }^{51}$ GSTR 2006/4 at [112].

${ }^{52}$ GSTR 2006/4 at [115].
} 


\section{Litigation}

To date there has been only one line of reported cases that has litigated the apportionment methodology used to obtain input tax credits. ${ }^{53}$ Although, this does not discount the possibility that there may have been other disputed instances involving apportionment, there is no quantifiable data to indicate the contrary. ${ }^{54}$ Instead most of the litigation (which is relatively sparse) has centred on input tax credit entitlement and whether acquisitions qualify or are excluded (eg, exempt supplies). Alternatively, this low level of litigation could be explained on the basis that many disputes are resolved by way of adjustments. Equally, a low level of litigation could suggest that the rules are working well.

\section{Change-in-Use Rules}

Registered entities claim input tax credits based on the extent of their creditable purpose when they make an acquisition. They may later use the acquisition in a different way to what was originally intended (eg, for a private or exempt use). To ensure the registered entity remains liable for GST only to the extent of their creditable purpose, the GST Act provides an adjustment mechanism called the change-in-use rules. ${ }^{55}$

${ }^{53}$ FCT v American Express Wholesale Currency Services Pty Ltd [2010] FCAFC 122, (2010) 77 ATR 12. A successful appeal from FCT v American Express International Inc [2009] FCA 683, (2009) 73 ATR 173 (Emmett J). The case involved a special formula agreed to between the ATO and the taxpayer under s 11-30(5). The formula (which was not a statutory concept) applied an indirect method that looked to the extent to which its supplies to others were input taxed. The issue before the Court was whether certain amounts (called "Fee Payments") received by American Express (which were derived from input-taxed supplies), should be treated as "revenue" for the purposes of the agreed formula: "[1 - (revenue derived from input taxed supplies) $\times 100] /$ total revenue". The ATO believed they should be included in the numerator and the denominator of the revenue formula. American Express argued that the Fee Payments should only be included in the denominator, therefore increasing the extent of creditable purpose (and input tax credit). The majority of the Full Federal Court found for the ATO holding that the Fee Payments were not in relation to a payment system and therefore did not fall under the exception to financial supplies. An appeal to the High Court is expected.

${ }^{54}$ As will be discussed below, there have been well over 800 cases filed since the GST Act was enacted, yet only 142 reported cases.

55 The GST Act contains a number of adjustment provisions separated into specific Divisions. Each Division addresses a different type of adjustment. For example: (1) cancellation of a supply or acquisition; (2) changes in consideration (eg, a change in price due to a discount); (3) changes in GST status (eg, when goods intended for export are not exported within the time limit and may change status from GST free to taxable); (4) changes in intended use; (5) debts becoming bad or overdue for 12 months or more; or (6) changes in enterprise or registration status. 
The change-in-use rules are contained in Division $129^{56}$ of the GST Act. ${ }^{57}$ The rules provide for an adjustment where there is a subsequent difference between the planned use and actual application. ${ }^{58}$ Section $129-40$ is the operational provision and provides a four step process to working out the adjustment. ${ }^{59}$

For the purposes of s 129-40, the term "creditable purpose" is defined in s 129-50. While this repeats the test found in s 11-15 to determine when an acquisition is acquired for a creditable purpose, it contains 2 important differences. First, it refers to "apply" input taxed" rather than to "making supplies that would be input taxed". Both differences confirm that the change-in-use provisions are focused on the actual application of the acquisition, not its intended use. ${ }^{61}$ This was confirmed in $R e$ GXCX $v F C T^{62}$

${ }^{56}$ Contained in Chapter 4, Part 4 of the GST Act. Division 129 contains the following four subdivisions: Subdivision 129-A outlines the general rules about making adjustments; Subdivision 129-B outlines when an adjustment must be made; Subdivision 129-C outlines how an entity will determine whether it must make an adjustment for an acquisition; Subdivision 129-D contains the rules for working out the quantum of the adjustment; and Subdivision 129-E provides the attribution rules for Division 129 adjustments.

${ }^{57}$ For the purposes of this paper, Division 130 has not been discussed. However, it is noted that Division 129 is subject to Division 130 which contains two provisions: ss 130-1 (what this Division is about) and 130-5 (goods applied solely to private or domestic use). Division 130 focuses on acquisitions made solely for a creditable purpose that are subsequently applied solely for a private or domestic use and provides for a $100 \%$ increasing adjustment for goods subsequently consumed by the registered entity. A Division 130 adjustment is available only where there has not been a previous adjustment under Division 129.

${ }^{58}$ Alternatively, an adjustment arises where there is a difference between the actual application (to the end of the previous adjustment period) and the actual application (ie, the end of the current adjustment period).

${ }^{59}$ A New Tax System (Goods and Services Tax) Act 1999, s 129-40(3) was inserted in 1999 by Amendment Act (177) from 1 July 2000. Related ATO publications include: rulings GSTR 2000/24, GSTR 2003/6, GSTR 2006/3, GSTR 2006/4, GSTR 2009/4; advice ruling GSTA TPP/61, and GSTA TPP/67.

${ }^{60}$ A New Tax System (Goods and Services Tax) Act 1999, s 129-55 defines the word "apply".

${ }^{61}$ A criticism of the adjustment rules is the subtle difference in tests between entitlement to input tax credits (under s 11-15) and their subsequent adjustment (under s 29-40) produces a mismatch between measuring input tax credits based on intention (or planned use), and measuring adjustments based on application at the point of inquiry.

${ }^{62} \operatorname{Re} G X C X v F C T$ [2009] AATA 569, (2009) 73 ATR 380. 
Where the actual use is less than planned use, the registered entity returns the difference. This is known as an increasing adjustment and will increase the amount of GST liable on a taxable supply. Where the planned use is less than the actual use, the registered entity receives an increase in the entitled input tax credit. This is known as a decreasing adjustment and will decrease the amount of GST liable on a supply.

The differences are calculated on an apportionment basis with the respective formulae provide in ss 129-70 (increasing adjustment) or s 129-75 (decreasing adjustment). The formulae provide:

$$
\begin{aligned}
& \text { Increasing adjustment }=\text { full input tax credit } \times(\text { intendedlformer use }- \text { actual use }) \\
& \text { Decreasing adjustment }=\text { full input tax credit } \times(\text { actual use }- \text { intendedlformer use })
\end{aligned}
$$

If an acquisition was acquired for a non-creditable purpose and later applied for a creditable purpose, the registered entity would be entitled to a decreasing adjustment (under s 129-75), which reduces the GST liability and increases the refund.

Alternatively, if a supply was acquired for a creditable purpose and later applied for a non-creditable purpose, the registered entity would be required to make an increasing adjustment (under s 129-70) which increases the GST liability and decreases any refund.

No adjustments are required for acquisitions under a specified minimum threshold. ${ }^{63}$ A $\$ 1,000$ minimum threshold applies to acquisitions that do not relate to business finance. ${ }^{64}$ Where an acquisition relates to business finance, a $\$ 10,000$ minimum threshold applies. ${ }^{65}$ An acquisition will relate to business finance where the acquisition is in connection with financial supplies and has no element of private or domestic use. ${ }^{66}$ The effect of the distinction between acquisitions that are related to

${ }^{63}$ A New Tax System (Goods and Services Tax) Act 1999, s 129-10.

${ }^{64}$ A New Tax System (Goods and Services Tax) Act 1999, s 129-10(2).

${ }^{65}$ A New Tax System (Goods and Services Tax) Act 1999, s 129-20(2).

66 The expression "relates to business finance" is defined s 129-10(3) as an acquisition that is related to "making financial supplies" (and not of a private or domestic nature). The definition of a financial acquisition in s $189-15$ is "an acquisition that relates to the making of a financial supply". 
business finance and those that are not, is to group exempt acquisitions (that are not related to business finance) with the treatment of acquisitions for private and domestic use. ${ }^{67}$ This distinction in the type of use for adjustment purposes is illustrated in Figure 2.2 and is useful in understanding the changes being proposed to the adjustment rules by the Board of Taxation and Treasury (discussed below).

Figure 2.2: Adjustment Period Distinctions Related to Use

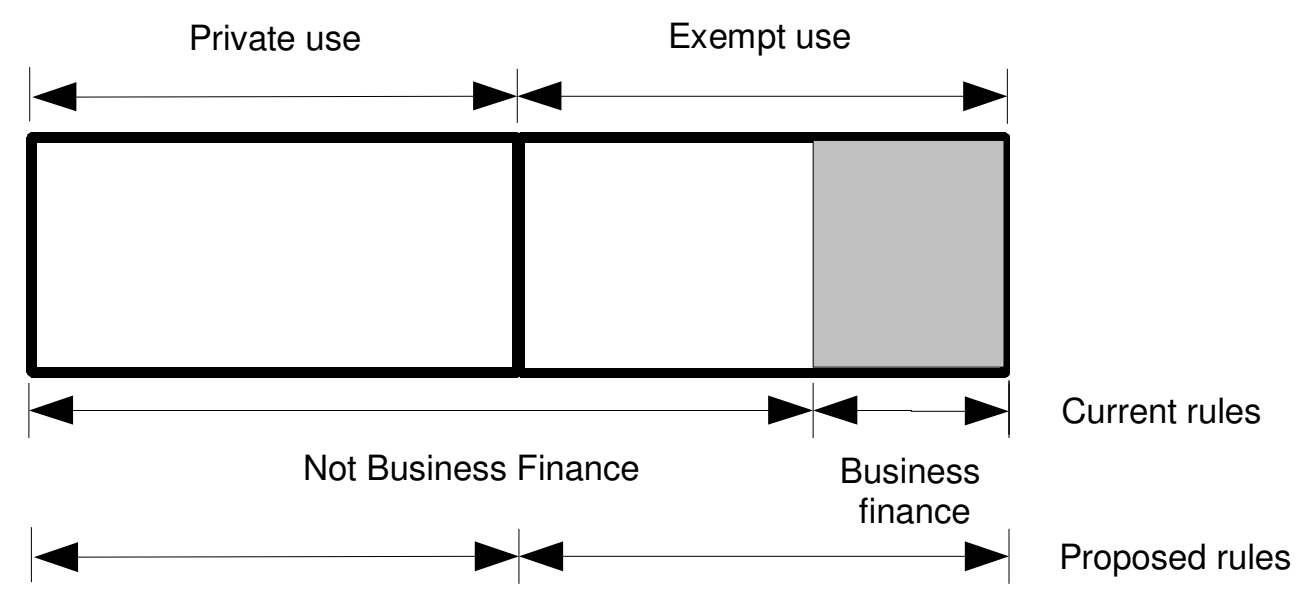

A unique feature of the rules is the creation of adjustment periods (under s 129-20) which provide for a maximum number of adjustments that can be made for a change in use. ${ }^{68}$ The distinction between acquisitions that are related to business finance and those that are not, is extended to establishing the number of adjustment periods.

In addition, the number of adjustment periods is determined by the GST-exclusive value of the acquisition. ${ }^{69}$ The resulting matrix of elements is illustrated in Table 2.1. An entity can also elect to have yearly adjustments where their GST turnover is $\$ 2$ million or less per annum.

${ }^{67}$ Effectively, this is another mismatch between the input credit rules and adjustment rules. Recall, that input tax credits are not available for exempt or private use under s 11-15(2).

${ }^{68}$ This contrasts markedly with the deemed supply mechanism that exists in the former New Zealand adjustment rules, where the number of adjustments is conceptually unlimited.

${ }^{69}$ A New Tax System (Goods and Services Tax) Act 1999, s 129-20(2) and (3). 
Table 2.1: Adjustment Period Thresholds

\begin{tabular}{|l|l|c|}
\hline \multicolumn{2}{|l|}{ Expenditure Value } & Number of Adjustment Periods \\
\hline Not Business Finance & Business Finance & \\
\hline$\$ 0-\$ 1,000$ & $\$ 0-\$ 10,000$ & 2 \\
\hline$\$ 1,001-\$ 5,000 *$ & $\$ 10,001-\$ 50,000 *$ & 5 \\
\hline$\$ 5,001-\$ 499,999$ & $\$ 50,001-\$ 499,999$ & 10 \\
\hline$\$ 500,000+$ & $\$ 500,000+$ & \\
\hline$*$ GST exclusive amounts. & & \\
\end{tabular}

\section{Litigation}

There has only been one reported case on Division 129. The lack of litigation would suggest the rules are working well. The case also illustrates the difference in focus between the New Zealand adjustment cases that focus on intention and the Australian rules that focus on application.

In $\operatorname{Re} G X C X v F C T^{70}$ the taxpayer developed 69 apartments that were marketed for sale before and during construction. By December 2001, 22 remained unsold and a decision was made to rent them until sold. The apartments were rented on 6-month leases. By 2009, a further 10 had been sold, and the remaining 12 were unsold. The taxpayer claimed input tax credits on the construction costs of $\$ 1,200,000$ on the basis that it intended to sell the apartments on completion. In the taxpayer's June 2003 quarterly business activity statement it included an adjustment of $\$ 52,837$ due to a change in creditable purpose (eg, the decision to rent the remaining 22 apartments was exempt). The ATO considered the adjustment calculation was incorrect and reassessed the adjustments, increasing them to $\$ 210,300$ (although subsequently adjusted to $\$ 137,140.00$ ). The question before the court was whether an intention to sell in the future amounted to an "actual application" for the purposes of the method statement in s 129-40. The taxpayers argued that the 22 apartments were applied for dual purpose: sale (a creditable purpose) and residential rental (a non-

${ }^{70} \operatorname{Re} G X C X v$ FCT [2009] AATA 569, (2009) 73 ATR 380. 
creditable purpose); and that the expression "application" encompassed a holding for future sale.

The Administrative Appeals Tribunal (AAT) accepted that a taxpayer could hold a dual purpose, with the New Zealand cases of Morris $^{71}$ and Carswell $^{72}$ cited with approval for this proposition, although distinguished on the facts. Hack J observed that: ${ }^{73}$

"... in Morris it was found that the flats were always available for sale. I cannot, on the evidence of the directors, reach the same conclusion in this matter. There were no overt acts demonstrating the fact that the apartments were available for sale and the evidence of the directors, set out above, demonstrates that the intention was not to sell in the short term. The intention to sell was predicated upon the market reaching a level where the capital growth could be realised."

While the AAT accepted that the taxpayer held the intention to sell at some time in the future it did not regard the holding of that intention, without more, as amounting to an "application" of the goods and services for a creditable purpose. Rather, the application during this period was entirely for a non-creditable purpose (eg, an exempt supply of residential renting). Hack J observed that: ${ }^{74}$

"... the language of the statute focuses upon the present application during the period of time made relevant by Subdiv 129-B of the GST Act. The method statement in s 129-40 of the GST Act directs attention to 'the extent (if any) to which you have applied the thing acquired ... for a credible purpose.' Whilst 'apply' is defined in s 129-55 of the GST Act it is defined inclusively. But what seems to me of greatest importance is the tense used in the method statement; it refers to 'have applied'."

The case highlights the difference between the New Zealand and Australian adjustment rules and confirms the prior interpretation of those rules in GST rulings. In New Zealand, establishing an intention will get you across the line. This is because the New Zealand approach is effectively deeming a new supply utilising the

${ }^{71}$ CIR v Morris [1998] 1 NZLR 344, (1997) 18 NZTC 13,385 (HC).

${ }^{72}$ CIR v Carswell Investments Ltd (2001) 20 NZTC 17,149 (HC).

${ }^{73} \operatorname{Re} G X C X v F C T$ [2009] AATA 569, (2009) 73 ATR 380 at [33].

${ }^{74} \operatorname{Re} G X C X v F C T$ [2009] AATA 569, (2009) 73 ATR 380 at [34]. 
input tax rules. The Australian adjustment rules require more, they require an application of the acquisition for the creditable purpose. The case highlights that there is little dispute surrounding the rules for entitlement to input tax credits or entitlement to adjustments. Rather, the dispute is with the calculation of those adjustments.

The ATO has since stated in a GST Ruling ${ }^{75}$ that the act of marketing a premises for sale together with other factors (eg, an earlier history of sales), will be sufficient evidence of an application of those premises for a creditable purpose.

\section{E. Summary of the Rules}

Input tax credits are provided for creditable acquisitions. ${ }^{76}$ An acquisition is a creditable acquisition when it is acquired solely or partly for a creditable purpose ${ }^{77} \mathrm{~A}$ creditable purpose exists to the extent it is acquired in carrying on an enterprise. ${ }^{78} \mathrm{~A}$ creditable purpose will not include acquisitions for a private use or exempt use (except for financial acquisitions). Where there is a change-in-use input tax credits are adjusted to the extent of the change for private or exempt use above $\$ 1,000$, or for acquisitions elated to business finance above $\$ 10,000$. Figure 2.3 illustrates this process.

${ }^{75}$ GSTR 2009/4 at [45-46].

${ }^{76}$ A New Tax System (Goods and Services Tax) Act 1999, s 11-10.

${ }^{77}$ A New Tax System (Goods and Services Tax) Act 1999, s 11-5.

${ }^{78}$ A New Tax System (Goods and Services Tax) Act 1999, s 11-15. 
Figure 2.3: The Adjustment Process
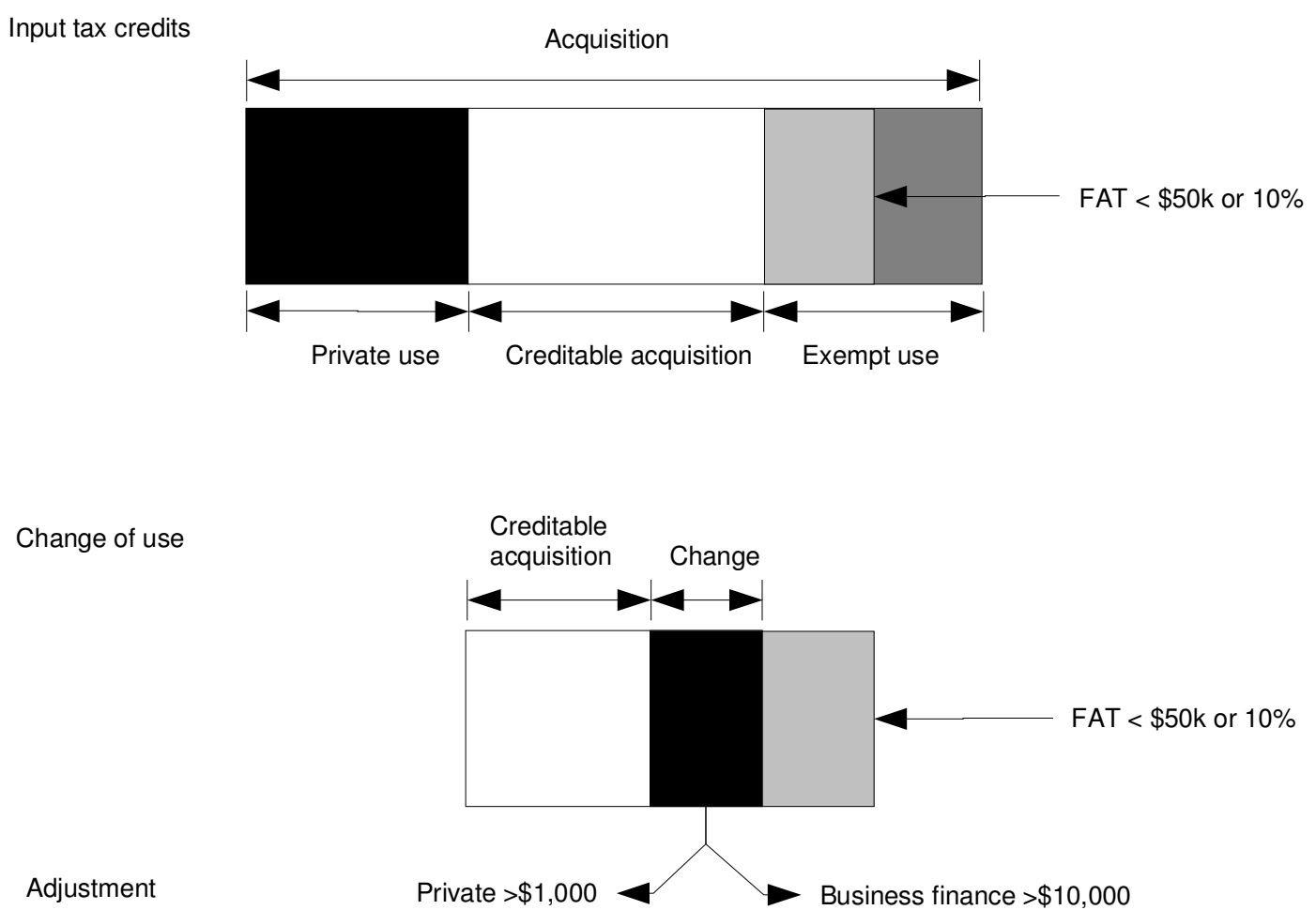

\section{F. Examples}

The following examples are provided to illustrate the rules and methods discussed above.

Example 2.1: Computer (Capital property) ${ }^{79}$

The GST rate is 10 per cent. Cian is a graphic designer and purchases a computer for $\$ 4,000$ (plus GST of $\$ 400$ ) to use both for business (80 per cent) and private purposes (20 per cent). The principal purpose of the computer is for the taxable activity of graphic design. Cian files tax GST returns every two months. In the second year of operation, private use increases to 40 per cent due to his children's use of the computer. No other changes in use occur over the life-time of the computer.

${ }^{79}$ Based on examples in GST Ruling 2009/04, Example 14, at [153-156]. 
Under an apportionment approach, the supply would be apportioned in the input tax claim between taxable $((\$ 400 \times 80$ per cent $=\$ 360)$ and non-taxable use $(\$ 400 \times 20$ per cent $=\$ 80)$. Cian will also be required to track the goods for any changes in use for two adjustment periods This is because the transaction falls within the first adjustment bracket (ie between $\$ 1,000$ and $\$ 5,000$ ).

An adjustment for change-in-use in year two is required. This is because the amount of change is above the 5 per cent de minimis and is not within the safe harbour threshold of $\$ 1,000$. The second year adjustment will require Cian to remit an additional $\$ 80$. $^{80}$

\begin{tabular}{|l|r|r|}
\hline Adjustments & \multicolumn{2}{|c|}{ Apportionment Approach } \\
\hline & & \multicolumn{1}{|c|}{ Adjustment } \\
\hline Input tax credit & $\$ 360$ & $\$ 80$ \\
\hline Adjustment 1 & & $\$ 80$ \\
\hline Adjustment 2 & & $\$ 0$ \\
\hline Balance & $\$ 280$ & $\$ 160$ \\
\hline
\end{tabular}

\section{Example 2.2: Property Development (Real property) ${ }^{81}$}

The GST rate is 10 per cent. Louise, a property developer purchases a house and land for $\$ 500,000$ and intends to sell the development on completion. Louise is not a builder or associated with one. The land cost \$300,000 (plus GST of \$30,000) and the house $\$ 200,000$ (plus GST of $\$ 20,000$ ). The market value of the property is $\$ 650,000$. The development does not sell and the development is rented until a buyer can be found. The rent returns $\$ 25,000$ per annum. Insurance and rates cost $\$ 10,000$ per annum (plus GST of $\$ \$ 1,000$ ). The depreciation rate for the house is 10 per cent per annum. Louise claims an input tax credit of $\$ 50,000$ on the purchase price of $\$ 500,000$. Louise's intended application of the property is 100 per cent for creditable purpose. As the actual application of the property is less than its intended application, Louise has an increasing adjustment for her acquisition.

${ }^{80}$ GSTR 2006/04 at [128] suggests that a reasonable estimate based on a diary or log of the use of the computer over a period of one month would be sufficient.

${ }^{81}$ Based on examples in GST Ruling 2009/04, Examples 6 to 11, at [69-97]. 
Under an apportionment approach the total supply is $\$ 650,000+\$ 25,000=$ $\$ 675,000$. The taxable use of the house is: $\$ 650,000 / \$ 675,000=96$ per cent. The non-taxable use is 100 per cent -96 per cent $=4$ per cent. The first adjustment is $\$ 25,000 \times 4$ per cent $=\$ 1,000$. The second adjustment calculates the total supply as $\$ 675,000+\$ 25,000=\$ 700,000$. The taxable use of the house is now: $\$ 650,000$ / $\$ 700,000=92$ per cent . The non-taxable use is 96 per cent -92 per cent $=4$ per cent . The second adjustment would be $\$ 25,000 \times 4$ per cent $=\$ 1,000$. As the transaction is above $\$ 500,000$, there will be a maximum of 10 annual adjustments.

\begin{tabular}{|l|r|r|}
\hline Adjustments & \multicolumn{2}{|c|}{ Apportionment Approach } \\
\hline & & \multicolumn{1}{|c|}{ Adjustment } \\
\hline Input tax credit & $\$ 50,000$ & \\
\hline Adjustment 1 & & $\$ 1,000$ \\
\hline Adjustment 2 & $\$ 1,000$ \\
\hline Adjustment 3 & & $\$ 1,000$ \\
\hline Adjustment 4 & & $\$ 1,000$ \\
\hline Adjustment 5 & & $\$ 1,000$ \\
\hline Adjustment 6 & & $\$ 1,000$ \\
\hline Adjustment 7 & $\$ 1,000$ \\
\hline Adjustment 8 & & $\$ 1,000$ \\
\hline Adjustment 9 & & $\$ 1,000$ \\
\hline Adjustment 10 & & $\$ 1,000$ \\
\hline Balance & $\$ 40,000$ & \\
\hline
\end{tabular}

\section{Part 2: Implementation and Operation - Empirical Evidence}

The practical implementation of the input tax and change-in-use apportionment rules suggests that the rules are well understood. However, the recent Board of Taxation review and recent literature has raised concerns about the compliance costs that apportionment methods place on taxpayers. It remains to be seen whether reforms will mitigate these concerns. 


\section{G. Judicial Activity}

The latest Australian statistics for February 2010 indicate that over the last 10 years there have been 839 GST cases filed with the courts. ${ }^{82}$ Of those cases filed with the courts, 132 had been decided by the courts, with an additional nine cases to be determined (a total of 141$){ }^{83}$

These figures appear to support earlier observations from D'Ascenzo and White. In 2006, D'Ascenzo reported that GST cases filed in Australian courts had risen from 9 cases in the 2001-02 financial year to 141 cases by the end of the 2005-06 financial year. ${ }^{84}$ At the same time, White reported that in the 5 years to April 2005 more than 180 GST cases had been filed in Australian courts. ${ }^{85}$ Ignoring the small disparity in figures (no doubt due to timing), it is interesting to note the rapid growth of cases being filed in the last five years, from between 141 to 180 cases filed by 2005, to 839 cases filed by 2010 - a growth rate in excess of 300 per cent.

The rapid growth of cases being filed in the last five years is confirmed by international experience, which reports that consumption tax litigation dramatically and suddenly increases after a peaceful introduction. Analysis by White of the New Zealand experience would tend to confirm this trend. ${ }^{86}$ Certainly, an examination of cases relating to change-in-use in New Zealand has also indicated such a trend.

${ }^{82}$ See Table 2.2 (below).

${ }^{83}$ GST minutes (ATO, March 2010) at [15.6] (GST litigation update). Document available at $<$ http://ato.gov.au/taxprofessionals/content.asp?doc=/content/00239910.htm\&page=31\&H31> (viewed 20 March 2011).

${ }^{84}$ M D'Ascenzo "The Australian Approach to GST Administration” in R Krever and D White (eds) GST in Retrospect and Prospect (Brookers Ltd, Wellington, 2007) 389 at 411.

${ }^{85}$ D White “Appellate Interpretation of NZ's GST Legislation: An Initial Survey: 1986-2005” (2005) 5 Australian GST Journal 2 at 15 citing the Australian Taxation Office GST Litigation Report, reported in KPMG Australia, GST - 5 Years On (2005) 6. Document available at <www.kpmg.com.au/Portals/0/GST-5yearson.pdf> (viewed 20 March 2011).

${ }^{86}$ D White “Appellate Interpretation of NZ’s GST Legislation: An Initial Survey: 1986-2005” (2005) 5 Australian GST Journal 2 at 9 (Figure 3). 
Interestingly, the ATO have suggested that case filings peaked after 7 years and are now in decline. Yet the rate of reported cases continues to climb (although not as rapidly as the spike in 2008). According to the ATO $:{ }^{87}$

"The number of new cases filed in 2008-09 has dropped by $22 \%$ compared to 2007-08. The reductions have occurred in income tax disputes involving small business and large corporates as well as GST matters. The decline in GST disputes is similar to overseas experiences where the introduction of a consumption tax is followed by a period of adjustment which tends to peak after about 7 years and is then followed by a steady decline in the number of disputes."

Table 2.2: GST Litigation (2000-2010)

\begin{tabular}{|l|l|l|}
\hline \multicolumn{1}{|l|}{ How finalised? } & Number of cases & \% total \\
\hline Court/Tribunal Decision - favourable to the Commissioner & 91 & $10.8 \%$ \\
\hline Court/Tribunal Decision - favourable to the taxpayer & 24 & $2.9 \%$ \\
\hline $\begin{array}{l}\text { Court/Tribunal Decision - favourable to the Commissioner in } \\
\text { part, favourable to the taxpayer in part }\end{array}$ & 17 & $2.0 \%$ \\
\hline \multicolumn{1}{|c|}{ Total } & 132 & \\
\hline Cases heard - awaiting decision & $141 \%$ \\
\hline Settled before Hearing & 221 & $16.8 \%$ \\
\hline Case withdrawn by Taxpayer/Major concession by taxpayer & 174 & $26.4 \%$ \\
\hline Case conceded by ATO & 188 & $20.7 \%$ \\
\hline Taxpayer's case struck out/dismissed & 74 & $22.4 \%$ \\
\hline Other (including FOI, ABN, ADJR and 'watching brief' matters) & 41 & $8.8 \%$ \\
\hline
\end{tabular}

Source: GST minutes (ATO, March 2010) at [15.6] (GST litigation update). ${ }^{88}$

${ }^{87}$ ATO Annual Report, Section 2.4 (2009) 44. Document available at <www.ato.gov.au/content/downloads/cor00216293AR0809Part02.pdf> (viewed 20 March 2011).

${ }^{88}$ GST minutes (ATO, March 2010). Document available at $<$ http://ato.gov.au/taxprofessionals/content.asp?doc=/content/00239910.htm\&page=31\&H31> (viewed 20 March 2011). 
According to the ATO data, reported cases only makes up only 17 per cent of all cases filed (see Table 2.2 above).

An audit of GST cases in Thomson Reuters TaxPoint database (as at October 2010) records 142 reported GST cases (illustrated in Figure 2.4 and Figure 2.5). Including the various State Supreme Courts, the number of reported GST cases increases to 185.

Figure 2.4: Reported GST Cases 2000-2010 (Accumulated) ${ }^{89}$

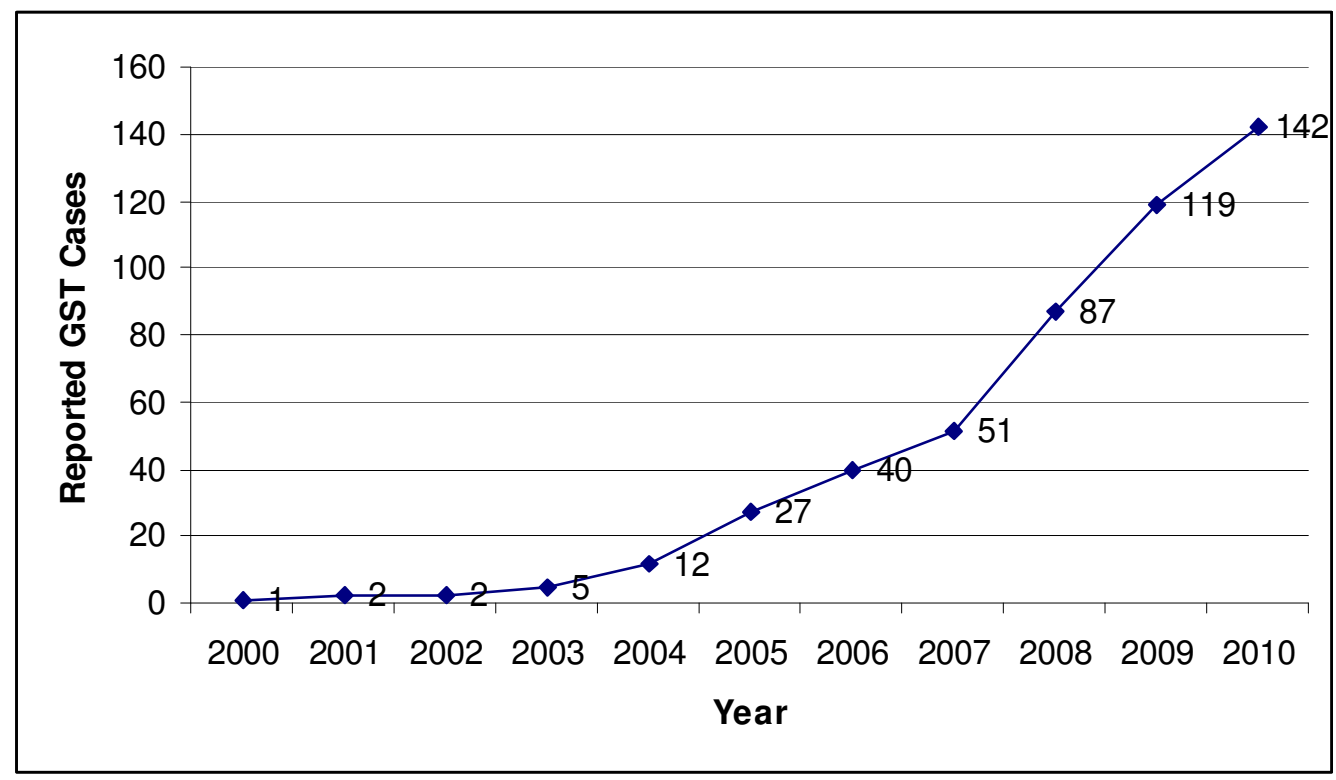

Source: Thomson Reuters (Australia) TaxPoint GST Cases (excluding State Supreme Court cases).

${ }^{89}$ Based on data contained in ThomsonReuters (Australia) TaxPoint GST Cases (as at 20 October 2010). 
Figure 2.5: Reported GST Cases 2000-2010 (Federal Courts) ${ }^{90}$

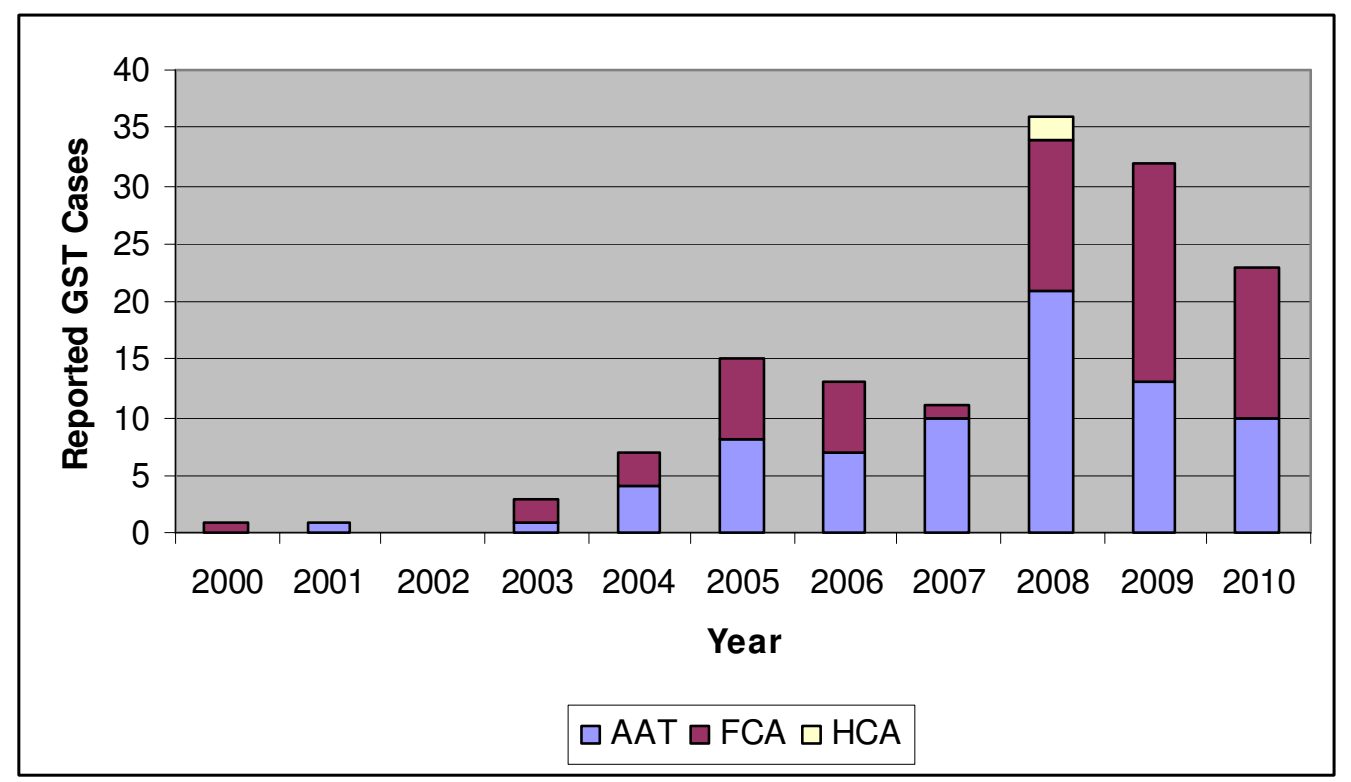

Source: Thomson Reuters (Australia) TaxPoint GST Cases (excluding State Supreme Court cases).

Of all reported GST cases, only eight lines of cases (12 cases in total) have examined Division 129 or Division 11. ${ }^{91}$ And only one case of those eight lines of cases has examined Division 129. ${ }^{92}$ The level of judicial activity would indicate there is an acceptable level of certainty with the rules (illustrated in Figure 2.6). ${ }^{93}$

${ }^{90}$ Based on data contained in ThomsonReuters (Australia) TaxPoint GST Cases (as at 20 October 2010).

${ }^{91}$ Section 11-15 cases: HP Mercantile Pty Ltd v FCT [2005] FCAFC 126, (2005) 60 ATR 106, appeal from Recoveries Trust $v$ FCT (2004) 57 ATR 1038 (AAT); Peerless Marine Pty Ltd and FCT [2006] AATA 765, (2006) 63 ATR 1303; Peet Ltd v Richmond (No 2) [2009] VSC 585 (Vic SC); FCT v Secretary to the Department of Transport (Victoria) [2010] FCAFC 84, (2010) 76 ATR 306, appeal from Secretary to the Department of Transport (Victoria) v FCT [2009] FCA 1209, (2009) 73 ATR 690; Trustee of the Family Trust v FCT [2010] AATA 876; and Russell v FCT [2011] FCAFC 10, appeal from Russell v Commissioner of Taxation [2009] FCA 1224, 74 ATR 466. Section 11-30 cases: American Express Wholesale Currency Services Pty Ltd [2010] FCAFC 122, (2010) 77 ATR 12, appeal from FCT v American Express International Inc [2009] FCA 683, (2009) 73 ATR 173.

${ }^{92}$ A New Tax System (Goods and Services Tax) Act 1999, s 129-40. See GXCX v FCT [2009] AATA 569, (2009) 73 ATR 380.

93 A total of 102 cases have cited a Division 11 provision. A total of four cases have cited a Division 129 provision. 


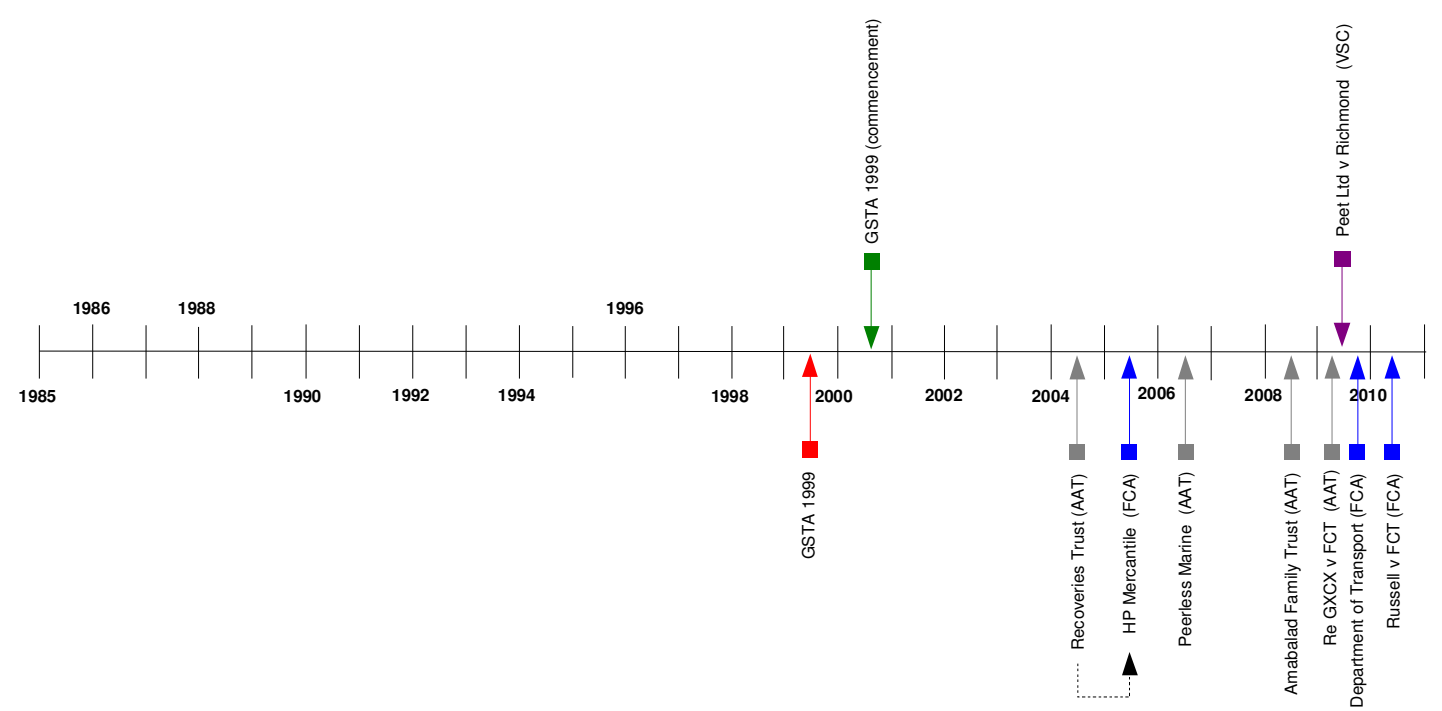

The decline in case filings and an increase in reported cases would suggest that more cases are not being withdrawn, dismissed, or settled out of court. This might indicate either a more refined examination of widely accepted rules, or a greater focus on disputes of fact. Yet, irrespective of case filing rates, the number of reported GST cases is still relatively low, in comparison to New Zealand.

The even smaller proportion of reported Division 129 and Division 11 cases would appear to suggest that there is a high degree of clarity and compliance with the rules. Of course it might also suggest that there is a lower level of audit activity or enforcement of those rules. In contrast, the equivalent rules in New Zealand have experienced a high degree of uncertainty and confusion, reflected in a high level of litigation. $^{94}$

\section{H. Revenue Authority Guidance}

Over an 11 year period, the Australian Tax Office (ATO) has provided a total of 103 finalised GST rulings (see Table 2.3). A number of rulings have been amended (some 3-4 times), withdrawn, or replaced with an updated ruling. Each finalised ruling was pre-empted with a draft ruling for broad consultation and at the time of

94 There have been 46 cases in New Zealand that have considered the adjustment rules (ie, the "principal purpose test or deemed supply mechanism). It is little wonder that New Zealand has after 25 years and three major reviews, finally stepped back from its principled position (ie, to tax consumption when it happens) and pragmatically reformed their equivalent input tax and change-in-use rules. 
writing 5 draft rulings were still yet to be finalised. Of the 103 finalised GST rulings, 21 rulings provided guidance on adjustments or input tax apportionment rules (see Table 2.4 and illustrated in Figure 2.7). As Choi acknowledges, these rulings "provide evidence of the considerable work undertaken by the Tax Office to provide guidance on the issue of apportionment". 95

However, a criticism of the apportionment and input tax credit rulings is they do not expand on the various methods for calculating the extent of creditable purpose beyond the principles enunciated in Ronpibon Tin. ${ }^{96}$ Nor do they provide any analysis of their limitations. Kraal concludes that Ronpibon Tin therefore remains the benchmark for GST apportionment. A similar point could be made with regard to the consideration and application of HP Mercantile $e^{97}$ by various GST rulings.

Kraal's criticism while alluding to the fact that the rulings are not prescriptive enough to provide sufficient certainty and therefore reduce compliance costs overlooks the need to maintain flexibility. As James et al suggests, ${ }^{98}$ it is more important that the ATO establishes guidelines that are sufficiently flexible to accommodate the very broad range of circumstances in which apportionment calculations are performed..$^{99}$ Certainly the low level of reported litigation would appear to suggest that such an approach is working.

${ }^{95}$ E Choi "Principles of creditable purpose following HP Mercantile" (2006) 6 Australian GST Journal 117 at 125 .

${ }^{96}$ D Kraal "GST Apportionment and Industry Superannuation Funds" (2008) 8 Australian GST Journal 265 at 271. Document available at <www.taxboard.gov.au/content/reviews_and_consultations/legal_framework_for_administration_of_ gst/submissions/Kraal\%20submission.pdf> (viewed 20 March 2011).

${ }^{97}$ HP Mercantile Pty Ltd v FCT [2005] FCAFC 126, (2005) 60 ATR 106.

${ }^{98}$ C James, I Jeffrey, and H Miller "Apportionment Principles: Part I" (2004) 4(1) Australian GST Journal 24 and "Apportionment Principles: Part II" (2004) 4(2) Australian GST Journal 10.

${ }^{99}$ C James, I Jeffrey, H Miller “Apportionment Principles: Part II” (2004) 4(2) Australian GST Journal 10 at 24. 
Table 2.3: ATO Rulings (1999-2010)

\begin{tabular}{|c|c|c|c|c|c|}
\hline Year & Rulings & Amendments & Withdrawals & $\begin{array}{l}\text { Adjustments, } \\
\text { or Input tax }\end{array}$ & $\begin{array}{c}\text { Pending } \\
\text { Drafts }\end{array}$ \\
\hline 1999 & 1 & 2 & 1 & 0 & \\
\hline 2000 & 37 & 44 & 6 & 7 & \\
\hline 2001 & 8 & 7 & 1 & 1 & \\
\hline 2002 & 6 & 8 & 1 & 1 & \\
\hline 2003 & 16 & 13 & $1 *$ & 4 & \\
\hline 2004 & 9 & 8 & 1 & 3 & \\
\hline 2005 & 6 & 4 & 0 & 1 & \\
\hline 2006 & 11 & 11 & 0 & 2 & \\
\hline 2007 & 2 & 0 & 0 & 0 & \\
\hline 2008 & 3 & 1 & 0 & 2 & 3 \\
\hline 2009 & 4 & 2 & 0 & 0 & 1 \\
\hline 2010 & 0 & 0 & 0 & 0 & 1 \\
\hline Total & 103 & 100 & $11 *$ & 21 & 5 \\
\hline
\end{tabular}

$*+2$ partial withdrawals

Table 2.4: Input Tax Credit and Adjustment Related Rulings (1999-2009)

\begin{tabular}{|l|c|c|c|c|}
\hline Year & Division 11 & \multicolumn{2}{l|}{ Division 129 } \\
\hline 1999 & About & Discussed & About & \\
\hline 2000 & $1 *$ & 4 & & 2 \\
\hline 2001 & & 1 & 1 & 1 \\
\hline 2002 & & 1 & & 1 \\
\hline 2003 & & 1 & & 2 \\
\hline 2004 & 3 & 1 & 2 & 1 \\
\hline 2005 & & & & \\
\hline 2006 & 2 & & & \\
\hline 2007 & 7 & & & \\
\hline 2008 & & & & \\
\hline 2009 & & & & \\
\hline Total & & & & \\
\hline
\end{tabular}

* Includes a withdrawn ruling. ** Draft ruling also pending. 
Figure 2.7: Timeline of GST Rulings Discussing Division 11 and Division 129

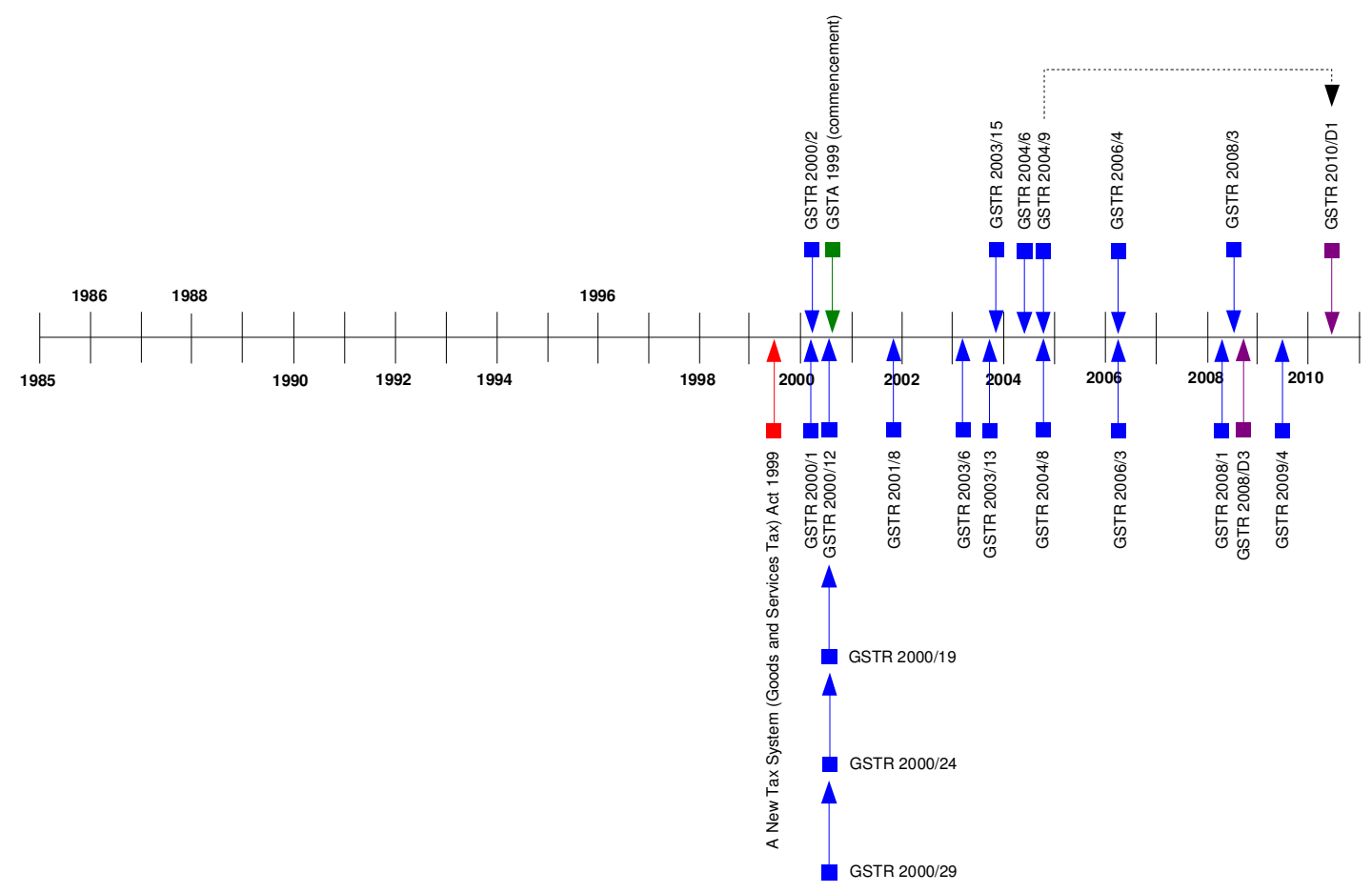

\section{Compliance Concerns}

What is notable with the current apportionment rules is the high level of compliance costs. The current rules are generally viewed in the literature and by taxpayers as an unnecessarily burdensome area of GST law.

According to PWC, the apportionment rules are: ${ }^{100}$

"... one of the most problematic areas of the GST legislation ..."

The Australian Bankers Association (ABA) who are well placed to judge the apportionment rules, have observed that: ${ }^{101}$

“The existing Division 129 provision places an unreasonable compliance burden on taxpayers and this inevitably leads to a lack of integrity in relation to the practical application

${ }^{100}$ E Mayne Review of the Legal Framework for the Administration of the Goods and Services Tax: A Report to the Assistant Treasurer and Minister for Competition Policy and Consumer Affairs (The Board of Taxation, Canberra, December 2008) 31 at [2.2.14].

${ }^{101}$ Australian Bankers Association Submission on the Implementation of the Recommendations of the Board of Taxation's Review of the Legal Framework for the Administration of the Goods and Services Tax (22 June 2009) 1-2. 
of the Division. ... the ongoing cost and effort associated with tracking acquisitions and making adjustments has overwhelmingly exceeded the magnitude of 'change of use' adjustments."

$\mathrm{Kraal}^{102}$ too has observed that the superannuation funds industry also considers the adjustment rules to be complex, costly, and time consuming. According to Kraal, ${ }^{103}$ anecdotal evidence indicated that the superannuation funds industry generally did not claim back their full entitlement to input tax credits via indirect methods (ie revenue or balance sheets methods) because it was perceived as too complex or costly to obtain external professional advice on the process. Other funds delay their claims for up to 3 years because they fail to undertake timely reviews of their apportionment rates. According to Kraal, ${ }^{104}$ the reason for these problems is the attempt to smooth out fluctuations, volatility, and subjectivity from using indirect methods when selecting the most "fair and reasonable" apportionment method. ${ }^{105}$

The high number of submissions to the Board of Taxation and Treasury on the reform of the adjustment rules confirms these observations. Adjustments were raised as an area of concern at each of the consultation sessions that the Board of Taxation held during August 2008. At consultation sessions, the change-in-use rules were frequently raised as a mater of concern. They were considered to be excessively onerous, and to result in significant compliance difficulties for businesses. Several submissions suggested that fully complying with obligations under current rules was not possible for many taxpayers. Particular concerns were raised in relation to property and construction activities.

102 D Kraal “GST Apportionment and Industry Superannuation Funds" (2008) 8 Australian GST Journal 265.

${ }^{103}$ D Kraal "GST Apportionment and Industry Superannuation Funds" (2008) 8 Australian GST Journal 265 at 272.

104 D Kraal "GST Apportionment and Industry Superannuation Funds” (2008) 8 Australian GST Journal 265 at 273.

${ }^{105}$ Kraal's solution to these compliance concerns is to recommend that a specific rate of input tax credit entitlement be provided for the superannuation funds industry (similar to the reduced credit acquisition rules) that would replace the variety of indirect methods of apportionment described within various rulings. This would remove the need for industry to rely on complex, costly and time consuming methods of apportionment. 
Views were expressed about the change-in-use rules imposing significant burdens. Taxpayers considered they were required to track too many acquisitions for too long. Further, there were also too many different periods and thresholds for acquisitions, rendering record-keeping and accounting excessively complex (the need to classify acquisitions into acquisitions related to business finance and other acquisitions was especially criticised). Finally, submissions considered that the required calculations are often difficult and the record-keeping onerous (especially given that in some circumstances it may be required for up to 15 years).

In both public consultation sessions and in submissions, concern was expressed about the meaning of "apply" and "application" in the GST change-in-use provisions and elsewhere in the GST Act. This was largely in the context of their interaction with the rules regarding residential property and new residential property.

Kraals' call to reduce business tax compliance costs is supported by industry observations that demand that any law reform in this area must address the key causes of cost and complexity if it is to provide for a meaningful reduction in the associated regulatory burden on business. ${ }^{106}$

\section{J. Reform Proposals}

\section{Background}

Similar to New Zealand, a review of the GST regime was undertaken 10 years after enactment. On 11 June 2008, the Assistant Treasurer and Minister for Competition Policy and Consumer Affairs, the Hon Chris Bowen MP, asked the Board of Taxation to undertake a review of the legal framework for the administration of the goods and services tax (GST) and to report its recommendations to the Government by the end of December 2008.

${ }^{106}$ Australian Financial Markets Association (AFMA) Submissions on the Treasury Report (12 June 2009) 2. Document available at <www.treasury.gov.au/documents/1578/PDF/Australian_Financial_Markets_Association.pdf> (viewed 20 March 2011). 


\section{Issues paper}

In July 2008, the Board of Taxation released an issues paper to facilitate public consultation. ${ }^{107}$ The issues paper provided an overview of the legal framework for the administration of the GST and included a series of questions to assist stakeholders in preparing submissions. In August 2008, the Board of Taxation held extensive consultations with stakeholders in Sydney, Brisbane, Melbourne, Darwin and Perth.

Submissions closed on 15 September 2008. The Board of Taxation received 57 submissions, 38 of which are available to the public and can be obtained from the Board of Taxation's website.

\section{Board of Taxation proposals}

In December 2008, the Board of Taxation submitted its report in response to the July 2008 Issues Paper to the Assistant Treasurer. ${ }^{108}$ The report put forward the Board of Taxation's final recommendations to the Government for consideration.

The consultation raised 90 issues where taxpayers thought the current approach was too complex, too costly or not properly achieving its intended aims. In responding to the 90 issues, the Board of Taxation made a total of 46 recommendations - 36 were substantive recommendations and 10 of a technical nature. ${ }^{109}$ Four recommendations were made in respect of adjustments. ${ }^{110}$

${ }^{107}$ E Mayne Issues Paper (The Board of Taxation, Canberra, 18 July 2008). Document available at <www.taxboard.gov.au/content/reviews_and_consultations/legal_framework_for_administration_of_ gst/issues_paper/downloads/legal_framework_for_administration_of_gst_issues_paper.pdf $>$ (viewed 20 March 2011).

${ }^{108}$ E Mayne Review of the Legal Framework for the Administration of the Goods and Services Tax: A Report to the Assistant Treasurer and Minister for Competition Policy and Consumer Affairs (The Board of Taxation, Canberra, December 2008). Document available at

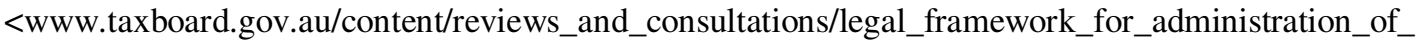
gst/report/downloads/legal_framework_for_administration_of_gst_report.pdf > (viewed 20 March 2011).

${ }^{109}$ Of the other 44 issues raised, 21 were out of scope of the terms of reference of the review.

${ }^{110}$ Recommendation 4 (Change-in-use - adjustments); Recommendation 5 and 8 (Adjustments for cession of registration and for pre-registration acquisitions); and Recommendation 7 (Technical amendment - adjustments). 
The Board of Taxation found that:

"The present law is overly complex, having too many differing thresholds and drawing a generally unhelpful distinction between business finance and other types of activity. The periods over which adjustments are to be made often are excessive. Moreover, there is often insufficient consistency between the compliance obligations created by various GST provisions dealing with change in use as well as in similar rules in other areas of the tax law."

Recommendation 4 (adjustments for changes in use) concluded that: ${ }^{11}$

"The GST law should be amended to provide that higher thresholds, together with fewer and shorter adjustment periods, should apply for adjustments (for example, two years for acquisitions less than $\$ 100,000$, five years for those over $\$ 100,000$, and ten years for real property). Where possible, the existing provisions should be consolidated within the GST law and aligned with other relevant rules elsewhere in the tax system.

Adjustments for private use should be explicitly aligned with the percentage of private use for income tax purposes. Adjustments for input taxed use should only occur where the change in use is significant (for example, greater than 10 per cent change in use)."

The Board of Taxation recommendation to consolidate the thresholds for both private and exempt use was clearly aimed at removing unnecessary confusion and administrative expense (eg, one threshold above $\$ 100,000$, and the other below it, while keeping the existing threshold under which no adjustment is required — plus a separate adjustment period for real property). ${ }^{112}$ Additionally, adjustments for input taxed supplies would only occur where the change in use was significant (eg, greater than 10 per cent change in use). Adjustments for private use would be explicitly aligned with the extent of private use for income tax purposes.

\footnotetext{
${ }^{111}$ E Mayne Review of the Legal Framework for the Administration of the Goods and Services Tax: A Report to the Assistant Treasurer and Minister for Competition Policy and Consumer Affairs (The Board of Taxation, Canberra, December 2008) 36.

${ }^{112}$ Interestingly, the Board of Taxation's Review of the Legal Framework Report suggested that real property should have an adjustment period more than 10 years (at [2.2.37]), but the final recommendation in Treasury's Second Consultation Paper opted for 10 years (at [2.1.39]).
} 
Table 2.5: Board of Taxation Threshold Proposals

\begin{tabular}{|l|l|c|l|}
\hline \multicolumn{2}{|l|}{ Current Thresholds } & & Proposed Thresholds \\
\hline Not Business Finance & Business Finance & $\begin{array}{c}\text { Number of } \\
\text { Adjustment Periods }\end{array}$ & \\
\hline$\$ 0-\$ 1,000$ & $\$ 0-\$ 10,000$ & 0 & \\
\hline$\$ 1,001-\$ 5,000 *$ & $\$ 10,001-\$ 50,000 *$ & 2 & $>\$ 100,000$ \\
\hline$\$ 5,001-\$ 499,999$ & $\$ 50,001-\$ 499,999$ & 5 & Real property \\
\hline$\$ 500,000+$ & $\$ 500,000+$ & 10 & \\
\hline$*$ GST exclusive amounts. &
\end{tabular}

As the Board of Taxation observed: ${ }^{113}$

"Taxpayers considered they were required to track too many acquisitions for too long.

Further, there were also too many different periods and thresholds for acquisitions, rendering record-keeping and accounting excessively complex (the need to classify acquisitions into acquisitions related to business finance and other acquisitions was especially criticised).”

The Board of Taxation also suggested that adjustment periods should be aligned with the filing date for income tax returns. This would reduce the period over which adjustments were required, simplify the timing of adjustments, and allow use of information already gathered for income tax returns. To eliminate the need for ongoing calculations and paperwork presently associated with minor shifts in activity, the Board suggested adjustments should occur only where there was a significant change in use (eg, a change of more than 10 per cent from the intended or prior use).

The Board also suggested that GST and income tax law, in relation to private use adjustments, should be linked to reduce the need for specific GST calculations

${ }^{113}$ E Mayne Review of the Legal Framework for the Administration of the Goods and Services Tax: A Report to the Assistant Treasurer and Minister for Competition Policy and Consumer Affairs (The Board of Taxation, Canberra, December 2008) 31 at [2.2.18]. 
(although it had earlier suggested the private use distinction with business finance should be removed): ${ }^{114}$

"Private use adjustments should be explicitly linked to the extent of private use for income tax. Combined with the alignment of adjustment periods with the lodgement period, the proposals should ensure affected taxpayers only need to perform minimal GST specific calculations."

Treasury response - the first report

On 29 July 2009, the Treasury released its first consultation paper on the Board of Taxation' report. ${ }^{115}$ The purpose of the Treasury's first consultation paper was to provide additional information on how the announced Government measures might operate and to seek feedback on their design and implementation.

The Treasury proposal confirmed the Board of Taxation's proposed thresholds and treatment of real property. However, it differed in relation to the creation of a new separate private use threshold. Under the Treasury proposal the two former threshold groups were merged. However, private use (which was formerly part of the "not related to business finance" group) was separated into a new threshold group.

The proposed thresholds would all be based on the "GST exclusive" monetary value of the acquisition. At present, only the first threshold is GST exclusive. It was also proposed that change-in-use adjustments would be aligned with the due date for filing income tax returns. In addition, no adjustment (either increasing or decreasing) would be made unless the change in use varied by 10 per cent or more from the original percentage on which the original attribution of input tax credits was based, or any subsequent adjustment.

${ }^{114}$ E Mayne Review of the Legal Framework for the Administration of the Goods and Services Tax: A Report to the Assistant Treasurer and Minister for Competition Policy and Consumer Affairs (The Board of Taxation, Canberra, December 2008) 35 at [2.2.40].

115 Treasury Implementation of the Recommendations of the Board of Taxation's Review of the Legal Framework for the Administration of the GST: Treasury Discussion Paper (Commonwealth of Australia, Canberra, July 2009). Document available at <www.treasury.gov.au/documents/1525/PDF/Review_of_the_legal_framework_3.pdf> (viewed 20 March 2011). 
Table 2.6: Proposed Changes to Adjustment Thresholds and Periods

\begin{tabular}{|c|c|c|c|c|}
\hline \multicolumn{3}{|l|}{ Current Rules } & \multicolumn{2}{|l|}{ Proposed Rules } \\
\hline Change in Use & Threshold & Adjustment Periods & Threshold & Adjustment Periods \\
\hline \multirow[t]{6}{*}{$\begin{array}{l}\text { Non Business } \\
\text { Finance }\end{array}$} & & & Private Use & \\
\hline & $\$ 0-\$ 1,000$ & 0 & $\$ 0-\$ 999$ & 0 \\
\hline & $\$ 1,001-\$ 5,000 *$ & 2 & $\$ 1,000$ - $\$ 9,999$ & 2 \\
\hline & $\$ 5,001-\$ 499,999$ & 5 & $\$ 10,000+$ & 5 \\
\hline & $\$ 500,000+$ & 10 & & \\
\hline & & & $\$ 1,000,000+* *$ & 10 \\
\hline \multirow[t]{5}{*}{ Business Finance } & & & Exempt Use & \\
\hline & $\$ 0-\$ 10,000$ & 0 & $\$ 0-\$ 10,000$ & 0 \\
\hline & $\$ 10,001-\$ 50,000 *$ & 2 & $\$ 10,000$ - $\$ 99,999$ & 2 \\
\hline & $\$ 50,001$ - $\$ 499,999$ & 5 & $\begin{array}{l}\$ 100,000- \\
\$ 999,999\end{array}$ & 5 \\
\hline & $\$ 500,000+$ & 10 & $\$ 1,000,000+$ & 10 \\
\hline \multicolumn{3}{|c|}{ * GST exclusive amounts. } & & \\
\hline
\end{tabular}

Treasury response - the second report

On 11 September 2009, the Treasury released its second consultation paper in response to submissions received. ${ }^{116}$ The second report responded to submissions on the first report's proposals and also responded to the technical issue raised about the scope of Division 130 and the meaning of the terms "apply" and "application" terms used consistently in Divisions 129, 130, and 138.

116 Treasury Implementation of the Recommendations of the Board of Taxation's Review of the Legal Framework for the Administration of the GST: Second Consultation Paper (Commonwealth of Australia, September 2009). Document available at <www.treasury.gov.au/documents/1613/PDF/Discussion_Paper_20090911.pdf> (viewed 20 March 2011). 
Treasury considered that a 100 per cent adjustment under Division 130 was not appropriate where the enterprise had received some economic value from the goods while they had been used by the business. Accordingly, Division 130 would be limited to just trading stock and raw materials. For goods other than trading stock or raw materials that are removed from use in an enterprise and subsequently used wholly for private or domestic purposes, increasing adjustments would be made under Division 129. To assist in reducing compliance costs, it was further proposed that Division 130 adjustments would only be required annually and aligned with the due date for filing income tax returns.

As a result of submissions from the second report, the original Division 129 proposals were further refined (see Table 2.7).

Table 2.7: Revised Changes to Proposed Adjustment Thresholds and Periods

\begin{tabular}{|c|c|c|c|c|}
\hline \multicolumn{2}{|l|}{ Current Rules } & \multicolumn{3}{|l|}{ Revised Proposal } \\
\hline Threshold & $\begin{array}{l}\text { Adjustment } \\
\text { Periods }\end{array}$ & Threshold (July) & Threshold (Sept) & Adjustment Periods \\
\hline $\begin{array}{l}\text { Not Business } \\
\text { Finance }\end{array}$ & & Private Use & Private Use & \\
\hline$\$ 0-\$ 1,000$ & 0 & $\$ 0-\$ 999$ & $\$ 0-\$ 1,999$ & 0 \\
\hline$\$ 1,001-\$ 5,000 *$ & 2 & $\$ 1,000-\$ 9,999$ & $\$ 2,000-\$ 14,999$ & 2 \\
\hline$\$ 5,001-\$ 499,999$ & 5 & $\$ 10,000+$ & $\$ 15,000+$ & 5 \\
\hline \multirow[t]{2}{*}{$\$ 500,000+$} & 10 & & & \\
\hline & & $\$ 1,000,000+* *$ & $\$ 1,000,000+* *$ & 10 \\
\hline Business Finance & & Exempt Use & Exempt Use & \\
\hline$\$ 0-\$ 10,000$ & 0 & $\$ 0-\$ 10,000$ & $\$ 0-\$ 19,999$ & 0 \\
\hline$\$ 10,001-\$ 50,000 *$ & 2 & $\$ 10,000-\$ 99,999$ & $\$ 20,000-\$ 499,999$ & 2 \\
\hline$\$ 50,001-\$ 499,999$ & 5 & $\$ 100,000-\$ 999,999$ & $\$ 500,000+$ & 5 \\
\hline \multirow[t]{2}{*}{$\$ 500,000+$} & 10 & $\$ 1,000,000+$ & & 10 \\
\hline & & & $\$ 5,000,000+* *$ & 10 \\
\hline \multicolumn{3}{|c|}{ * GST exclusive amounts. } & \multicolumn{2}{|c|}{ ** Applies to real property only. } \\
\hline
\end{tabular}


Treasury increased the safe harbour threshold for private use adjustments from $\$ 1,000$ to $\$ 2,000$ and the upper threshold to $\$ 15,000$ (originally proposed at $\$ 10,000)$. The adjustment periods remained unchanged. Exempt supply adjustments were reduced from three to two bands with the lower threshold starting at $\$ 20,000$ (originally proposed at $\$ 10,000$ ) and the second band starting at $\$ 500,000$. A separate band for only real property was also provided, starting at $\$ 5$ million.

\section{Industry response}

The response from industry was less than enthusiastic with the Treasury's first round of proposals. ${ }^{117}$ Many submissions were critical of the reforms in not going far enough. The Corporate Tax Association (CTA) believed the recommendations needed to go further to achieve real compliance savings, and the Australian Financial Markets Association (AFMA) considered that any law reform had to address the key causes of cost and complexity if it was to provide for a meaningful reduction in the associated regulatory burden on business.

According to the CTA, anything beyond five adjustment periods would maintain compliance costs "that well outweighs the associated revenue collected." The CTA considered that moving to five adjustment periods would also align the operation of Division 129 with existing record retention requirements.

The Australian Financial Markets Association (AFMA) was equally concerned that the proposed modifications to thresholds would not have a significant impact on compliance costs. Proposed thresholds for input taxed were still far too low for nonreal property transactions. To track every acquisition over $\$ 100,000$, in relation to business finance, and determine not only the intended use of each acquisitions at the time of acquisition, but then recalculate an actual use at the time of review was considered very onerous for financial institutions that had numerous products and businesses.

${ }^{117}$ For example, see submissions from the Corporate Tax Association (dated 22 June 2009), Australian Bankers Association (dated 22 June 2009), and Australian Financial Markets Association (dated 12 June 2009). Documents available at $<$ http://www.treasury.gov.au/contentitem.asp?ContentID=1578\&NavID=> (viewed 20 March 2011). 
According to the AFMA, financial institutions could have hundreds, if not thousands, of transactions over $\$ 100,000$ in a normal year. The AFMA recommended that acquisitions that related to input taxed use should only have two adjustment periods with an initial threshold of $\$ 500,000$ for two periods, and more than $\$ 5,000,000$ for five periods. Table 2.8 illustrates the AFMA proposal in comparison to Treasury's changing position. The AFMA also proposed an alternative approach to simplifying tracking costs. It suggested prescribing a nonexhaustive list of common acquisitions (eg, acquisitions effectively consumed in the period acquired) that need not be tracked for the purpose of Division 129.

Table 2.8: AFMA Proposed Thresholds

\begin{tabular}{|c|c|c|c|c|c|c|}
\hline & \multicolumn{2}{|l|}{ ABA Proposal } & \multicolumn{4}{|l|}{ Treasury Proposals } \\
\hline & & & July & & September & \\
\hline & Threshold & Periods & Threshold & Periods & Threshold & Periods \\
\hline \multicolumn{7}{|l|}{$\begin{array}{l}\text { Exempt } \\
\text { Use }\end{array}$} \\
\hline & $\$ 500,000-\$ 5,000,000$ & 2 & $\$ 10,000$ - $\$ 99,999$ & 2 & $\$ 20,000$ - $\$ 499,999$ & 2 \\
\hline & $\$ 5,000,000+$ & 5 & $\$ 100,000$ - \$999,999 & 5 & $\$ 500,000+$ & 5 \\
\hline & NA & 10 & $\$ 1,000,000+$ & 10 & NA & 10 \\
\hline
\end{tabular}

The Australian Bankers Association (ABA) did not support the Treasury's proposed threshold changes as they considered they would not "provide a sufficient level of administrative relief'. Rather the ABA considered that there had to be substantial change to the scope of the existing Division 129 for real benefits to accrue. The ABA strongly urged the Treasury to consider real and substantial change given the length of time the industry had waited for reform and the fact that it was likely to be another extended period of time before the adjustment provisions were again reviewed.

In respect of the Treasury's proposal to increase adjustment periods for the lowthreshold acquisitions, the ABA was of the opinion that it did not strike an 
appropriate balance, as they were unlikely to minimise compliance costs when considered in conjunction with the increase in adjustment periods.

The ABA proposed establishing two specific categories of acquisitions for which "change of use" adjustments would be required: (1) information technology hardware and (2) real property. The ABA's proposal is illustrated in Table 2.9 and is compared against the Treasury's changing position.

Table 2.9: ABA Proposed Thresholds

\begin{tabular}{|c|c|c|c|c|c|c|}
\hline & \multicolumn{2}{|l|}{ ABA Proposal } & \multicolumn{4}{|l|}{ Treasury Proposals } \\
\hline & & & \multicolumn{2}{|l|}{ July } & \multicolumn{2}{|l|}{ September } \\
\hline & Threshold & Periods & Threshold & Periods & Threshold & Periods \\
\hline IT Hardware & $\$ 500,000$ & 5 & NA & & NA & \\
\hline Real Property & $\begin{array}{l}\$ 1,000,000- \\
\$ 10,000,000\end{array}$ & 5 & $\$ 1,000,000$ & 10 & $\$ 5,000,000$ & 10 \\
\hline \multicolumn{7}{|l|}{ Exempt Use } \\
\hline & & & $\$ 10,000$ - $\$ 99,999$ & & $\begin{array}{l}\$ 20,000- \\
\$ 499,999\end{array}$ & 2 \\
\hline & & & $\begin{array}{l}\$ 100,000- \\
\$ 999,999\end{array}$ & & $\$ 500,000+$ & 5 \\
\hline & $\begin{array}{l}\$ 10,000,000 \\
+\end{array}$ & 10 & $\$ 1,000,000+$ & 10 & NA & 10 \\
\hline
\end{tabular}

CPA Australia fully supported the decision to amend the adjustment rules and align adjustments for private use with the percentages of private use applicable in income tax law. ${ }^{118}$ However, CPA Australia observed that the current calculation of adjustments under Division 129 led to anomalous outcomes when viewed from a timing perspective. This was because current calculation of adjustments under

${ }^{118}$ CPA Australia submissions (dated 22 June 2009) 2. Document available at <http://www.treasury.gov.au/documents/1578/PDF/CPA_Australia.pdf> (viewed 20 March 2011). 
Division 129 did not match entitlement to input tax credits in Division 11, because the tests were different. One was based on intention and the other on application. It recommended that both Divisions should apply an "intention" criterion.

CPA Australia also considered that Division 129 should be amended so that adjustments take into account the effective life of the asset, rather than the fixed adjustment periods, based on the value of the asset. This could be achieved by linking the adjustment period with effective life of an asset in the depreciation provisions contained in Division 40 of the ITAA 1997.

CPA Australia supported the recommendation that adjustments should only be required where the change in use exceeded 10 per cent. However, the ABA considered a higher rate of 20 per cent had significant merit.

\section{K. Analysis}

\section{Apportionment design}

GST is a business tax and operates consistently with the day to day operation of business and normal accounting practices. ${ }^{119}$ Being a business tax, the GST system is ideally geared towards existing accounting practice and therefore minimising compliance costs for businesses. However, the practical reality is that business and accounting functions within many organisations are "not designed around GST requirements alone". ${ }^{120}$ Rather, businesses are often geared towards management accounting, financial reporting, and income tax considerations. For this reason, businesses are often not ideally suited to providing information relevant for apportionment purposes.

According to James et al, there is a delicate trade-off to be managed between the desire to achieve accurate apportionment results, and the cost of doing so. As compliance costs fall on taxpayers, it is important to recognise that any methodology

\footnotetext{
${ }^{119}$ It was this aspect of GST that appealed to Rt Hon R Douglas and convinced him that GST, not retail sales tax (RST), was the better indirect tax. See I Dickson "The NZ GST Policy Choice: An Historical Perspective" in Krever R and White D (eds) GST in Retrospect and Prospect (Brookers Ltd, Wellington, 2007) 45 at 49.

${ }^{120}$ C James, I Jeffrey, H Miller “Apportionment Principles: Part II” (2004) 4(2) Australian GST Journal 10 at 27.
} 
must not impose an onerous burden. The management of these competing objectives is the key to devising a good apportionment model. ${ }^{121}$ According to James et al, it is essential in designing an approach to calculating input tax recovery to obtain an understanding of the business and its processes. ${ }^{122}$ The approach to apportionment needs to be flexible so that taxpayers may select a methodology which is appropriate to their circumstances but still produces a fair and reasonable result.

With these considerations in mind, it is therefore good tax design practice to maximise opportunities to leverage off other accounting considerations, to minimise compliance costs.

\section{Compliance costs}

What is notable with the current adjustment rules is the high level of compliance costs. The current adjustment rules are generally viewed by taxpayers as an unnecessarily burdensome area of GST law. The adjustment rules according to PWC are: ${ }^{123}$

“... one of the most problematic areas of the GST legislation ..."

The number of submissions to the Board of Taxation and Treasury on the adjustment rules is testament to this concern. Adjustments were raised as an issue at each of the consultation sessions which the Board of Taxation held during August 2008. At consultation sessions, the change-in-use rules were frequently raised as a matter of concern. They were considered to be excessively onerous, and to result in significant compliance difficulties for businesses. Several submissions suggested that fully complying with obligations under current rules was not possible for many taxpayers. Particular concerns were raised in relation to property and construction activities.

${ }^{121}$ C James, I Jeffrey, H Miller “Apportionment Principles: Part II” (2004) 4(2) Australian GST Journal 10 at 29.

${ }^{122}$ C James, I Jeffrey, H Miller “Apportionment Principles: Part II” (2004) 4(2) Australian GST Journal 10 at 30.

${ }^{123}$ E Mayne Review of the Legal Framework for the Administration of the Goods and Services Tax: A Report to the Assistant Treasurer and Minister for Competition Policy and Consumer Affairs (The Board of Taxation, Canberra, December 2008) 31 at [2.2.14]. 
The change-in-use rules were said to be imposing significant burdens. Taxpayers considered they were required to track too many acquisitions for too long. Further, there were also too many different periods and thresholds for acquisitions, rendering record-keeping and accounting excessively complex. The need to classify acquisitions into acquisitions related to business finance and other acquisitions was especially criticised. Finally, submissions considered that the required calculations are often difficult and the record-keeping onerous, especially given that in some circumstances it may be required for up to 15 years.

In both public consultation sessions and in submissions, concern was expressed about the meaning of "apply" and "application" in the GST change-in-use provisions and elsewhere in the GST Act. This was largely in the context of their interaction with the rules regarding residential property and new residential property. While concern with a mismatch between the input tax and adjustment rules was highlighted, the ATO has since provided taxpayer's operational clarity around the application of the adjustment rules.

\section{Adjustment rules — threshold changes}

The Australian reform of the adjustment thresholds is intriguing. And it is hard to understand why the system of two adjustment threshold mechanisms has effectively been shifted from 'business finance' to 'private use'. This is especially puzzling for two reasons. First, Australia has special rules for financial acquisitions, so it is reasonably understandable that those acquisitions should be treated differently. Secondly, the Board of Taxation acknowledged that there was confusion in having two threshold mechanisms. So if the drive was to consolidate the thresholds, why then create a new private use threshold previously part of the "not related to business finance" threshold?

Perhaps the answer relates to the fact private use often involves lower value acquisitions and requires separate treatment. The Board of Taxation certainly 
acknowledged in its recommendation that private use needed to be explicitly linked to the extent of private use for income tax purposes. ${ }^{124}$

In contrast, New Zealand's new apportionment rules have adopted a single threshold mechanism for determining adjustment periods that makes no distinction between entity or transaction type. ${ }^{125}$

\section{Adjustment periods - an argument for flexibility}

A major criticism of the apportionment approach is the compliance costs associated with the adjustment process. At present, the system determines the adjustment period based on acquisition value, rather than the estimated life of the asset. The relationship between value and adjustment periods is arbitrary, and reflects tax revenue trade-offs more than the opportunity for an asset to change use over its life time. Surely the estimated useful life of an asset would be a better measure of the opportunity for an asset to change use over its life time. It is also a measure that is already provided for in the income tax depreciation rules.

If the value of the acquisition is the determining factor for allocating adjustment periods, then perhaps the system should leverage off the income tax depreciation rules, which have already calculated value based on estimated useful life.

This suggestion is not new. Submissions to the Board of Taxation raised similar arguments. According to CPA Australia, the current calculation of adjustments (under Division 129) leads to anomalous outcomes when viewed from a timing perspective. The limitation of the assessment period results in many scenarios where the adjustment of input tax credit claims does not reflect the overall application of a thing over its effective life. For example, a taxpayer may apply things used in constructing real property for input taxed purposes for a period of 4 years and then

\footnotetext{
${ }^{124}$ E Mayne Review of the Legal Framework for the Administration of the Goods and Services Tax: A Report to the Assistant Treasurer and Minister for Competition Policy and Consumer Affairs (The Board of Taxation, Canberra, December 2008) 37 and 197 (recommendation 4). Whether the private use adjustment periods are aligned with income tax calculations is not clear (and outside the scope of this thesis).

125 Policy Advice Division and Treasury Options for Strengthening GST Neutrality in Business-toBusiness Transactions: An Officials' Issues Paper (IRD, Wellington, June 2008).
} 
use them for making taxable supplies for 6 years. At the end of all of the adjustment periods under Division 129, the taxpayer will have effectively claimed 60 per cent input tax credits, being 6 out of 10 years of creditable use. However, the current mechanism dos not allow for the prospect that the taxpayer may continue to apply the things for a creditable purpose for the next 20 years left in the effective life of the asset.

CPA Australia sensibly suggest that Division 129 should be amended so that adjustments take into account the effective useful life (EUL) of the asset, rather than the fixed adjustment periods, based on the value of the asset. ${ }^{126}$ In keeping with the need to provide flexibility, the system should provide taxpayers the opportunity to select the most appropriate adjustment period. As the taxpayer is in the best position to assess associated compliance costs, this might mean that adjustment periods should offer taxpayers the choice to select adjustment periods based on EUL or value.

\section{Safe harbour and de minimis changes}

Compliance costs are an important consideration in the good design of the adjustment rules. At present the Australian adjustment rules provide only two opportunities to avoid an adjustment:

- A safe harbour for supplies of $\$ 1,000$ or less; or

- 5 per cent de minimis on changes-in-use (capped on total supplies of $\$ 50,000$ for the 12-month period).

The reforms propose an increase in the safe harbour threshold from $\$ 1,000$ to $\$ 1,999$. In addition, the de minimis rule will be increased to 10 per cent, but remain capped at $\$ 50,000$. In contrast, Canada already has a 10 per cent threshold without a financial cap (eg "substantial change" test), and New Zealand has adopted a 10 per cent de minimis (capped at NZ\$1,000) on all changes-in-use, with a 5 per cent de minimis on exempt supplies (capped on total supplies of NZ\$90,000 for the 12-

\footnotetext{
${ }^{126}$ Note the New Zealand new apportionment rules allow taxpayers the choice of using estimated useful life (EUL) or the prescribed adjustment periods.
} 
month period). Whether New Zealand will revisit a larger de minimis of 10 per cent in light of Australia's reforms proposals being enacted, is hard to judge. The justifications given by officials for constraining the 10 per cent de minimis rule to $\mathrm{NZ} \$ 1,000$, in light of revenue and compliance concerns would suggest it is unlikely.

\section{Conclusion}

The adjustment rules have clearly been successful in terms of legal compliance. The number of reported GST cases that have considered the input tax and adjustment rules is very low, both in terms of reported cases in Australia and in comparative terms with New Zealand. The small proportion of reported cases that have considered input tax and adjustment rules would appear to suggest that there is may be a higher degree of clarity and compliance with the rules, than in New Zealand. It would appear the legislative rules have been easier to comprehend and there has been less room for confusion or litigation. Of course it might also suggest that there is a lower level of audit activity or enforcement of those rules.

Equally, the calculation methodology has not resulted in much litigation. Where it has, the cases appear to have turned on the facts, rather than the law. Viewed broadly, the low litigation rate must be considered a substantial cost saving for both taxpayers and officials. Whether this is attributable to the manner in which the rules have been crafted, the legislative drafting, or the guidance provided by the ATO is unclear. It may well be due to the interplay of all three elements.

In terms of certainty and efficiency, the current rules have been subject to criticism. It has been suggested that the rules are difficult to comply with due to a lack of quality prescriptive guidance. Empirical evidence would appear to suggest the contrary. Litigation is not rife and recent cases on the application of the adjustment rules have not been appealed. Where the courts have considered apportionment, the issues have turned on matters of fact, rather than law.

It has also been suggested that the mismatch between the legal tests for input tax credit entitlement and their subsequent adjustment produces anomalies. While the rules do produce a mismatch, the ATO has been quick to accommodate taxpayer concerns and has adopted a pragmatic position in GST Rulings which has provided clarity for taxpayers. Clearly the challenge for the ATO is to continue improving its 
guidance. But to date, it would appear to have done a far better job than New Zealand in providing certainty for taxpayers.

A feature of the adjustment rules is the creation of adjustment periods based on the type of use and the value of the acquisition. The use of adjustment periods provides a degree of certainty for taxpayers so that adjustments are unable to go on indefinitely. The deemed supply approach in the former New Zealand adjustment rules did not provide this level of certainty.

In terms of compliance costs the current rules have not been as successful. A major criticism of the rules is the arduous tracking and reporting of adjustments that is required. However, much of the criticism is centred not on the over-arching architecture of the rules, but with the operational aspects of the rules (ie the adjustment period thresholds). This criticism is also coming from larger taxpayers who have substantially higher volumes of transactions to monitor and report on. For the majority of smaller taxpayers there appears to be less complaint with the operation of the rules.

The proposed changes to the adjustment thresholds should go some way to reducing compliance cost concerns. An initial threshold of 10 per cent change is a good safe harbour. Whether specific industries or assets should be provided higher thresholds remains to be seen. The creation of higher thresholds and a separate class of transaction for real property in determining the appropriate adjustment period will provide more targeted compliance requirements but may create inefficiency and inequity. Whether other assets or activities receive similar attention also remains to be seen. It will be interesting to see how the draft legislation evolves. Clearly, there is still room to make improvements.

In terms of legal compliance and certainty the rules have been very successful. The trade-off with operational compliance costs in the adoption of adjustment periods should not ignore the litigation cost savings, or the certainty that adjustment periods provide. The alternatives (eg, deemed supply) could well impose much higher compliance and administrative costs. Overall, the Australian experience suggests that the apportionment approach provides a good basis for determining input tax credit entitlement and the appropriate level of GST liability for transactions. 


\section{THE CANADIAN EXPERIENCE}

"The change in use provisions are the most difficult rules contained in the GST Legislation and could result in significant costs for a person who does not properly apply the rules on a timely basis." Allan Schinnour ${ }^{1}$

\section{A. Introduction}

It has been 19 years since the introduction of GST legislation in Canada. This is certainly a more than adequate period of time to conduct a review. Similar to the New Zealand experience, the change-in-use rules have largely remained untouched since their introduction. Surprisingly there have been few reviews of the legislation and certainly none that have undertaken a broad review of the complete GST system.

A unique feature of the Canadian experience is the application of both an adjustment and apportionment approach to change-in-use. By default, the change-in-use rules adopt an apportionment approach to input tax credit entitlement and remittance.

However, for capital personal property an adjustment approach (eg, a "primary purpose" test) is applied that mirrors to a large extent the early New Zealand approach. This dual application of two different approaches is an interesting feature of the Canadian experience and provides a unique opportunity to compare the two different approaches in the same jurisdiction. Unlike Australia or New Zealand, Canada appears to have taken a more pragmatic approach to the change-in-use rules and decided that for particular types of transactions different rules will be applied.

This chapter seeks to provide some insight into the Canadian experience and an assessment of whether the apportionment approach has been successful. If lack of legislative and judicial activity is a measure of success, has the Canadian experience shown that an apportionment approach has been more successful than an adjustment approach? What apportionment lessons can we learn from the Canadian experience?

Accordingly, this chapter first examines the key provisions that provide the basis for entitlements to input tax credits and the change-in-use rules (both on an apportionment and adjustment basis). The chapter also examines the evolution of the "fair and reasonable" test (that is central to the application of apportionment

\footnotetext{
1 AW Schinnour “GST Tips \& Traps” (1994) Vol 7(1) Canadian Petroleum Tax Journal 1 at [53].
} 
approach). The second part of this chapter then examines whether empirical evidence provides any enlightenment on whether an apportionment approach has been successful or not.

\section{Part 1: The Rules}

\section{B. Background}

The Canada Revenue Agency (CRA) is responsible for the administration and collection of GST and harmonised sales tax (HST) for participating provinces. GST in Canada is a broad low single-rate tax. ${ }^{2}$ In 1998-1999 the net GST revenue was \$20.68 billion (derived from total collected GST of \$50.174 billion, less \$23.534 billion of input tax credits, rebates, and credits). ${ }^{3}$ In 2008-09 (ten years later) net GST revenue was $\$ 25.7$ billion (derived from total collected GST of $\$ 167.0$ billion, less $\$ 141.3$ billion of input tax credits, rebates, and credits). ${ }^{4}$

Similar to New Zealand and Australia the rules for claiming entitlement to input tax credits on acquisitions and adjustments for change-in-use are provided for in the GST legislation, interpreted through case law, and guided by rulings. In fact, Canada based its GST model (and its name) on the New Zealand GST Act. ${ }^{5}$ However, unlike New Zealand or Australia, the Goods and Services Tax (GST) in Canada has had a very turbulent history. ${ }^{6}$ According to Bird, GST was the most "heartily disliked tax

2 Originally proposed at 9 per cent, it was enacted at 7 per cent, and subsequently reduced to 6 per cent in 2006 and its current rate of 5 per cent in 2008.

${ }^{3}$ R Domingue and J Soucy The Goods and Services Tax: 10 Years Later (Economics Division, 15 June 2000). Document available at <http://dsp-psd.pwgsc.gc.ca/Collection-R/LoPBdP/BP/prb0003-e.htm> (viewed 20 March 2011).

4 Department of Finance The Fiscal Monitor (March 2010) 2. Document available at $<$ www.fin.gc.ca/fiscmon-revfin/pdf/2010-03-eng.pdf> (viewed 20 March 2011).

5 B Ketterman "VAT? A Look Inside Canada's Experience with Goods and Services Tax" (2006) 8 San Diego International Law Journal 259 at 265. See also BJ Arnold "The April 27, 1989 Federal Budget" (1989) 1 International Tax Notes 41. The Canadian Government's GST proposals were set out in a series of official documents released under the name of the Minister of Finance, Michael Wilson. These documents included: Tax Reform in 1987: Sales Tax Reform (Department of Finance, Ottawa, June 1987), known as "The White Paper"; The Goods and Services Tax (Department of Finance, Ottawa, April 1989); Goods and Services Tax: An Overview (Department of Finance, Ottawa, August 1989); Goods and Services Tax: Technical Paper (Department of Finance, Ottawa, August 1989); and Goods and Services Tax (Department of Finance, Ottawa, December 1989).

6 B Ketterman "VAT? A Look Inside Canada's Experience with Goods and Services Tax" (2006) 8 San Diego International Law Journal 259. The Canadian federal government originally planned to 
in Canada". ${ }^{7}$ Its introduction in 1991 was fraught with resistance at nearly every step and it was very nearly repealed two years later in $1993 .{ }^{8}$

The GST legislation was also introduced at a time when Canada was going through a deep recession. According to Domingue \& Soucy, the 1990s were one of the worst decades for Canadian economic performance and this situation lent itself poorly to tax reform of any kind. ${ }^{9}$ Table 3.1 illustrates the Federal and Provincial rates and adoption (or resistance) of HST in Canada. ${ }^{10}$ Against this political backdrop it is little wonder that the GST legislation and subsequently Harmonised Sales Tax (HST) ${ }^{11}$ has been designed in the manner it has — an indirect tax system that "no one in their right mind would have designed from scratch". ${ }^{12}$

introduce GST in 1987 as part of a two stage tax reform program — replacing an underperforming manufacturers' sales tax with GST. However, resistance from the provincial governments (who were opposed to a consolidation of provincial taxes) and small businesses (who opposed the heavy compliance burden that was expected to result), mixed with a lack of political will (no doubt a reflection of heavy public opposition), meant the reform proposals did not get traction until 1989. A major political problem in introducing GST was the prior existence in the provinces (except Alberta) of retail sales taxes (RST) ranging from 7 per cent to 12 per cent. Generally, the provincial sales taxes exclude services from the tax base. When the Bill was passed by Parliament on 10 April 1990, it was only due to the application of a little known constitutional rule (enabling the stacking of votes) that it successfully passed through the Senate (although only after lengthy filibustering attempts) and assented on 13 December 1990.

7 RM Bird Where Do We Go From Here? Alternatives to the GST (KPMG Centre for Government, Toronto, 1994). See also RM Bird and PP Gendron "Sales Tax in Canada: The GST- QST-PST System" (2009) 63 Tax Law Review 517.

8 The Liberal Government's election manifesto promised to replace GST and the House of Commons Finance Committee charged with reviewing GST subsequently recommended replacing it with a harmonised Federal-Provincial sales tax (ie, HST). See Creating Opportunity: the Liberal Plan for Canada (Ottawa: Liberal Party of Canada, 1993), and Standing Committee on Finance Replacing the GST: Options for Canada (House of Commons, Ottawa, June 1994).

9 R Domingue and J Soucy The Goods and Services Tax: 10 Years Later (Economics Division, 15 June 2000).

${ }^{10}$ Table 3.1 is based on Table 1 in RM Bird and PP Gendron "Sales Tax in Canada: The GST- QSTPST System" (2009) 63 Tax Law Review 517. The provincial rate in Quebec increased to 8.5 per cent 1 January 2011 and to 9.5 per cent from 1 January 2012 with corresponding adjustments to the consolidated federal rate.

${ }^{11}$ Harmonised sales tax (HST) was introduced in 1997 to harmonise (and consolidate) all provincial taxes into GST. It is a broad multi-rate system (that accommodates the different tax rates it replaces in each province) with higher rates than GST (although part of the revenue equating to approximately half the HST tax rate is remitted back to the provinces). Effectively, HST seeks to accomplish the consolidation aspiration that GST originally promised, but was unable to deliver. On introduction the GST legislation was partially harmonised with Quebec and it was not until 1997 that Newfoundland, Nova Scotia, and New Brunswick agreed to harmonise. Incidentally, these three provinces are also the poorest provinces in Canada and it has been suggested that the cost of collection may have played a 
Table 3.1: Indirect Tax in Canada

\begin{tabular}{|c|c|c|c|c|c|c|}
\hline Jurisdiction & $\begin{array}{l}\text { Name } \\
\text { of Tax }\end{array}$ & $\begin{array}{l}\text { Type } \\
\text { of Tax }\end{array}$ & $\begin{array}{l}\text { Fed } \\
\text { Rate } \\
(\%)\end{array}$ & $\begin{array}{l}\text { Prov } \\
\text { Rate } \\
(\%)\end{array}$ & Administration & Comments \\
\hline Canada & $\begin{array}{l}\text { GST / } \\
\text { HST }\end{array}$ & VAT & $5 / 13$ & & $\begin{array}{l}\text { Federal except in } \\
\text { Quebec, where it } \\
\text { is provincial }\end{array}$ & $\begin{array}{l}\text { The Federal GST rate is 5\% } \\
\text { and applied throughout all } \\
\text { provinces. Government also } \\
\text { administers PST in } \\
\text { participating HST provinces } \\
\text { (consolidated rate of 13\%) }\end{array}$ \\
\hline Alberta & GST & VAT & 5 & 0 & Federal & Alberta has no PST \\
\hline $\begin{array}{l}\text { Newfoundland } \\
\text { and Labrador }\end{array}$ & HST & VAT & 13 & 8 & Federal & $\begin{array}{l}\text { HST revenues collected in } \\
\text { HST provinces are } \\
\text { distributed to participating } \\
\text { provinces based on } \\
\text { estimated taxable } \\
\text { consumption }\end{array}$ \\
\hline Nova Scotia & HST & VAT & 15 & 10 & Federal & $\begin{array}{l}\text { Same as for Newfoundland } \\
\text { (except sum is } 15 \% \text { ) }\end{array}$ \\
\hline $\begin{array}{l}\text { New } \\
\text { Brunswick }\end{array}$ & HST & VAT & 13 & 8 & Federal & Same as for Newfoundland \\
\hline $\begin{array}{l}\text { Prince Edward } \\
\text { Island }\end{array}$ & PST & RST & 15 & 10 & Provincial & $\begin{array}{l}\text { Applied to retail sales price } \\
\text { (including GST) }\end{array}$ \\
\hline Quebec & $\begin{array}{l}\text { QST } \\
\text { (TVQ) }\end{array}$ & VAT & 12.5 & 7.5 & Provincial & $\begin{array}{l}\text { Applied to GST base plus } \\
\text { GST }\end{array}$ \\
\hline Ontario & HST & VAT & 13 & 8 & Federal & Same as for Newfoundland \\
\hline Manitoba & PST & RST & 12 & 7 & Provincial & $\begin{array}{l}\text { Applied to retail sales price } \\
\text { (excluding GST) }\end{array}$ \\
\hline Saskatchewan & PST & RST & 10 & 5 & Provincial & $\begin{array}{l}\text { Applied to retail sales price } \\
\text { (excluding GST) }\end{array}$ \\
\hline $\begin{array}{l}\text { British } \\
\text { Columbia }\end{array}$ & HST & VAT & 12 & 7 & Federal & $\begin{array}{l}\text { Same as for Newfoundland } \\
\text { (except sum is } 12 \% \text { ) }\end{array}$ \\
\hline
\end{tabular}

part $\mathrm{n}$ opting into a Federal collection system. See B Ketterman "VAT? A Look Inside Canada's Experience with Goods and Services Tax" (2006) 8 San Diego International Law Journal 259 at 268, fn 56. On introduction of HST, Alberta was the only province with no retail sales tax policy. British Columbia, Saskatchewan, Manitoba and Ontario applied provincial sales tax (PST) to the selling price and simply added it to the GST, whereas Prince Edward Island and Quebec applied PST to the total amount of the selling price and the GST. The HST legislation still has yet to be fully harmonised with all the provinces. Ontario and British Columbia subsequently adopted HST in 2010.

${ }^{12}$ RM Bird and PP Gendron "Sales Tax in Canada: The GST- QST-PST System" (2009) 63 Tax Law Review 517. 
It has been suggested that the GST legislation's painful birth was due in part to "certain structural defects". ${ }^{13}$ Perhaps it also explains why it has not received the type of broad-based central government reviews that have occurred in New Zealand and Australia.

\section{Legislation}

The Canadian Goods and Services Tax (GST) system is multi-layered. It comprises GST legislation (containing transitional measures), ${ }^{14}$ subordinate legislation (eg, regulations and remission orders), ${ }^{15}$ and a Harmonisation Sales Tax (HST) ${ }^{16}$ that attempts to harmonise Provincial Sales Taxes (PSTs) with the Federal GST system. ${ }^{17}$

Canada's GST rules are not contained in their own unique Act. Rather they are located within Part 9 of the Excise Act $1985 .{ }^{18}$ The GST Legislation was enacted on 17 December 1990 and came into force from 1 January 1991. It is divided into 12 Divisions which comprise various subdivisions (ss 122-368). The GST Act comprises a total of 379 active provisions. ${ }^{19}$

${ }^{13}$ RM Bird and PP Gendron "Sales Tax in Canada: The GST- QST-PST System" (2009) 63 Tax Law Review 517. at 521

${ }^{14}$ Excise Act RSC 1985, Part 9 (GST Legislation) and Part 8 (Transitional Measures).

${ }^{15}$ Comprising: 45 Regulations, 47 General Remission Orders, and 84 Private Remission Orders.

${ }^{16}$ The HST rules are integrated into the GST Legislation in Division 10 (HST Transitional Provisions). For additional detail see Canada Revenue Agency Technical Information Bulletin B-077, Transitional Provisions under the HST (28 February 1997), Harmonized Sales Tax Questions and Answers (23 October 1996) and Canada Revenue Agency Fact Sheet HST: Transitional Rules (March 1997). As a result of introducing HST the change-in-use rules for capital property (ss 195 to 211), and many other specific provisions, were changed to replace the tax fraction representing the rate of GST (eg, "7/107" at the time) with the term "basic tax content".

${ }^{17}$ Harmonised Sales Tax (HST) was first announced on 23 April 231996 and subsequently released as a Bill (c.70) on 23 October 1996. The HST Legislation was assented on 20 March 1997 and came into force from 1 April 1997, in the participating provinces (ie, Nova Scotia, New Brunswick, and Newfoundland and Labrador). HST replaces the Goods and Services Tax (GST) and Provincial Sales Tax (PST) in participating provinces. Ontario and British Columbia adopted HST from 1 July 2010. The HST rate is currently 13 per cent in all participating provinces except British Columbia where the rate is 12 per cent, and Nova Scotia where the rate is 15 per cent (from 1 July 2010). The Canada Revenue Agency (CRA) administers the HST for all participating provinces.

${ }^{18}$ Hereafter referred to as the "GST Legislation".

${ }^{19}$ Division 1 (interpretation, ss 123 to 164.2); Division 2 (imposition, input tax credits and capital property (real and personal); ss 165 to 211); Division 3 (Tax on Importation of Goods; ss 212 to 216); Division 4 (Tax on Imported Taxable Supplies; ss 217 to 220); Division 4.1 (Tax on Property and 
While the GST legislation has received a reasonable level of remedial legislative activity (in a large part a reflection of harmonisation), the input tax rules and changein-use rules have largely remained untouched since enactment. This level of stability over a period of 19 years appears to suggest the rules are working well. However, the volume of litigation would appear to suggest that there is not an even level of certainty across all of the rules. ${ }^{20}$ However, on closer examination much of the litigation with regard to input tax credit entitlement under an apportionment approach is related to boundary issues, rather than apportionment methodology. The number of cases related to change-in-use is much lower. ${ }^{21}$ When one compares the economic size of the jurisdictions, the proportion of cases is lower than for New Zealand or Australia.

Despite its small size (only 379 provisions), the GST Legislation is quite prescriptive. This is especially the case with regard to the input tax credit and change-in-use rules. Unlike New Zealand or Australia (who tend to favour general rules and therefore few legislative provisions), Canada has adopted a much more prescriptive approach, that has resulted in very precise rules for particular types of property and entities. $^{22}$

Services Brought into a Participating Province; ss 220.01 to 220.09); Division 5 (Collection and Remittance of Division 2 Tax; ss 221 to 251); Division 6 (Rebates; ss 252 to 264); Division 7 (Miscellaneous; ss 265 to 274.2); Division 8 (Administration and Enforcement; ss 275 to 335); Division 9 (Transitional Provisions; ss 336 to 347); Division 10 (Transitional Provisions for Participating Provinces; ss 348 to 363.2); Division 11 (Tax Inclusive Pricing; ss 364 to 368). New provisions are inserted as points (eg, s 164.1 is inserted below s 164).

${ }^{20}$ Section 169 is cited in 295 cases (based on research conducted in Carswell's TaxNetPro). See Figure 3.4 (below).

${ }^{21}$ There are 19 cases that have examined the change-in-use rules (based on research conducted in Carwell's TaxNetPro). If the specific change-in-use rules for builders (ss 190, 191) are excluded the number of cases reduces to 16 cases. Gatineau (Ville) v $R$ [2010] FCA 82; SLX Management Inc $v R$ [2010] TCC 148; Lavoie v R [2009] TCC 501, [2009] GSTC 142; Gatineau (Ville) v R [2009] TCC 130; [2009] GSTC 41; Nikel Ltd v R [2008] GSTC 195; Polley v R [2008] GSTC 99; Université de Sherbrooke v $R$ [2007] GSTC 77, [2008] GSTC 27; British Columbia Transit v $R$ [2006] GSTC 103; Simard v R [2005] GSTC 183, [2006] GSTC 172; Wiley v R [2005] GSC 164; Immeubles le Séjour Inc $v R$ [2002] GSTC 98, [2003] GSTC 180; 510628 Ontario Ltd v R [2000] GSTC 58; MM Leasing $v$ $R$ [1995] GSTC 9 (FCA); Strachan $v R$ [1999] GSTC 72; 475588 Ontario Inc $v R$ [1994] GSTC 50; and Kramer Ltd v R [1994] GSTC 47. Excluding: Samson Bélair Deloitte \& Touche Inc v R [2004] GSTC 155; [2006] GSTC 86; Manoussi v Davis [2006] QCCS 1631, [2009] GSTC 48; and Sand, Surf \& Sea Ltd v R [2008] GSTC 71.

${ }^{22}$ In Australia, property, entity, and value distinctions are utilised at the reporting and tracking stages, rather than at the stage of input tax credit and subsequent change-in-use entitlement. New Zealand's 
An obvious difference with the Australian and New Zealand rules is the distinctions made between types of property. ${ }^{23}$ The Canadian rules have provided a distinction between capital property, ${ }^{24}$ real property, ${ }^{25}$ and non-capital property. ${ }^{26}$ The later type of property (eg, non-capital property) provides the general rule. Non-capital property also includes prescribed property, although no property has yet been prescribed by regulation. ${ }^{27}$ These distinctions appear to be made to enable different rules and tests to apply to different types of property (and entities). Table 3.2 and Table 3.3 summarises these distinctions.

Table 3.2 Canadian Input Tax Credits and Change in Use Rules

\begin{tabular}{|l|l|l|l|l|l|}
\hline Asset Type & \multicolumn{2}{|l|}{ Input tax credits (ITCs) } & \multicolumn{2}{l|}{ Change-in-use rules } \\
\hline & Section & Test & Method & Section & Method \\
\hline $\begin{array}{l}\text { Personal } \\
\text { property } \\
\text { (non-capital) }\end{array}$ & s 169 & Intended use * & use \% & $\begin{array}{l}\text { ss 172 (non- } \\
\text { commercial), } \\
196.1 \text { (capital) } \\
* *\end{array}$ & Actual use (FMV) \\
\hline $\begin{array}{l}\text { Personal } \\
\text { property } \\
\text { (capital) }\end{array}$ & s 199 & $\begin{array}{l}\text { Primary purpose } \\
(>50 \%)\end{array}$ & $100 \%$ or 0\% & ss 199, 200 ** & $\begin{array}{l}\text { Deemed supply, } \\
<\text { FMV or price } \\
\text { paid }\end{array}$ \\
\hline $\begin{array}{l}\text { Real property } \\
\text { (capital) }\end{array}$ & $\begin{array}{l}\text { ss } 169, \\
208\end{array}$ & Intended use $*$ & use \% & $\begin{array}{l}\text { ss 206, 207, } \\
208 * *\end{array}$ & $\begin{array}{l}\text { Deemed supply, } \\
\text { (apportion use) } \\
<\text { FMV or price } \\
\text { paid }\end{array}$ \\
\hline
\end{tabular}

old rules made no distinctions at either the entitlement or tracking stages. However, the New Zealand rules (prior to reform in 2010) did codify the methodology for quantifying change-in- use which is something neither Australia nor Canada have done (or propose doing). In Australia, valuation methodologies are explained in binding rulings. Prior to legislative codification in New Zealand, the valuation methodologies were merely interpretation statements.

${ }^{23}$ Unfortunately the legislation does not provide a guiding provision that identifies and clearly demarcates the distinctions being made in the GST Legislation and where the rules for each category are located. Rather Division 2 is divided into Subdivisions: (a) imposition of tax; (b) input tax credits; (c) special cases; and (d) capital property. These later subdivisions (eg, capital property) are then divided into: capital property (ss 195 to 198.2); capital personal property (ss 199 to 205); and capital real property (ss 206 to 211 ).

${ }^{24}$ Excise Act RSC 1985, ss 195 to 205 . The capital property (described in ss 199 to 205) is personal property and not real property. These sections do not apply to financial institutions. Capital personal property of financial institutions is governed generally by the rules for capital real property.

${ }^{25}$ Excise Act RSC 1985, s 206 to 211.

${ }^{26}$ Excise Act RSC 1985, s 169.

${ }^{27}$ Excise Act RSC 1985, s 195. 
* 10:90 rule: must be $10 \%$ or more to qualify. Greater than $90 \%$ deemed $100 \%$ (s 141 ).

** 10\% minimum change threshold (eg, "insignificant" change ignored) (s 197).

Table 3.3: Canadian Capital Property Rules (Division 2, Subdivision D) ${ }^{28}$

\begin{tabular}{|c|c|c|c|c|}
\hline Type of property & Acquisition & $\begin{array}{l}\text { Increase in use in commercial } \\
\text { activities }\end{array}$ & $\begin{array}{c}\text { Decrease in use in commercial } \\
\text { activities }\end{array}$ & Sale \\
\hline $\begin{array}{l}\text { Personal property } \\
\text { (general rule) }\end{array}$ & $\begin{array}{l}\text { 199(2): full ITC if }>50 \% \text { for use in } \\
\text { commercial activities; no ITC } \\
\text { otherwise. }\end{array}$ & $\begin{array}{l}\text { 199(3): on change from } \leq 50 \% \text { to } \\
>50 \% \text {, claim ITC based on FMV. }\end{array}$ & $\begin{array}{l}200 \text { (2): on change from }>50 \% \text { to } \\
\leq 50 \% \text {, remit tax based on } \mathrm{FMV} \text {. }\end{array}$ & $\begin{array}{l}200(3) \text { : if used } \leq 50 \% \text { in commer- } \\
\text { cial activities, sale is not a taxable } \\
\text { supply (otherwise, taxable: } \\
141.1(1)(a)) \text {. }\end{array}$ \\
\hline $\begin{array}{l}\text { Automobile of an indi- } \\
\text { vidual or partnership } \\
\text { ("passenger vehicle") }\end{array}$ & $\begin{array}{l}\text { 201: ITC limited to } 7 \% \text { of } \$ 24,000 \\
\text { plus taxes; } 202(2) \text { : ITC only if } \\
\geq 90 \% \text { for use in commercial activ- } \\
\text { ities; 202(4): CCA-based ITC if } \\
<90 \% \text {. }\end{array}$ & $\begin{array}{l}\text { No credit until sale. However, in- } \\
\text { crease in business use will lead to } \\
\text { an increased CCA claim resulting } \\
\text { in a higher annual claim under } \\
202(4) \text {. }\end{array}$ & $\begin{array}{l}203(2) \text { : on change from } \geq 90 \% \text { to } \\
<90 \% \text {, remit tax based on FMV. }\end{array}$ & $\begin{array}{l}203(1) \text { : if used } 90 \% \text { in commercial } \\
\text { activities, recover previously dis- } \\
\text { allowed ITC on current value of ve- } \\
\text { hicle; } 203(3) \text { : if used }<90 \% \text { in } \\
\text { commercial activities, sale is not a } \\
\text { taxable supply. }\end{array}$ \\
\hline $\begin{array}{l}\text { Personal property of a } \\
\text { financial institution }\end{array}$ & $\begin{array}{l}\text { Same as real property general } \\
\text { rule, below. }\end{array}$ & $\begin{array}{l}\text { 204: same as real property general } \\
\text { rule, if property cost over } \$ 50,000 \text {. }\end{array}$ & $\begin{array}{l}\text { 204: same as real property general } \\
\text { rule, if property cost over } \$ 50,000 \text {. }\end{array}$ & $\begin{array}{l}204,141.1(1)(a) \text { : same as real } \\
\text { property general rule, if property } \\
\text { cost over } \$ 50,000 \text {. }\end{array}$ \\
\hline $\begin{array}{l}\text { Real property (general } \\
\text { rule) }\end{array}$ & $\begin{array}{l}169(1) B(c), 141(1) \text { : full ITC if } \geq 90 \% \\
\text { for use in commercial activities; } \\
\text { proportional ITC otherwise. }\end{array}$ & $\begin{array}{l}206(2) \text { on change from } \leq 10 \% \text { to } \\
>10 \% ; 206(3) \text { on any other in- } \\
\text { crease. Claim ITC for fraction of } \\
\text { increased use, based on lesser of } \\
\text { tax paid and FMV. }\end{array}$ & $\begin{array}{l}206(4) \text { on change from }>10 \% \text { to } \\
\leq 10 \% ; 206(5) \text { on any other de- } \\
\text { crease. Remit tax based on } \\
\text { deemed sale of all or part of the } \\
\text { property. }\end{array}$ & $\begin{array}{l}\text { 193(1): on taxable sale, ITC avail- } \\
\text { able for portion of tax paid not pre- } \\
\text { viously recovered. }\end{array}$ \\
\hline $\begin{array}{l}\text { Real property of an in- } \\
\text { dividual }\end{array}$ & $\begin{array}{l}\text { 208(1): no ITC if primarily for per- } \\
\text { sonal use and enjoyment. }\end{array}$ & $\begin{array}{l}208(2) \text { where no ITC claimed pre- } \\
\text { viously; } 208(3) \text { otherwise. Claim } \\
\text { ITC for fraction of increased use, } \\
\text { based on lesser of tax paid and } \\
\text { FMV. No claim if still primarily for } \\
\text { personal use and enjoyment. }\end{array}$ & $\begin{array}{l}207(1) \text { on change from }>10 \% \text { to } \\
\leq 10 \% ; 207(2) \text { on any other de- } \\
\text { crease. Remit tax based on } \\
\text { deemed sale of all or part of the } \\
\text { property. Remit tax under } 190(2) \\
\text { where property appropriated for } \\
\text { personal use. }\end{array}$ & $\begin{array}{l}\text { 193(1): on taxable sale, ITC avail- } \\
\text { able for portion of tax paid not pre- } \\
\text { viously recovered. }\end{array}$ \\
\hline $\begin{array}{l}\text { Real property of a pub- } \\
\text { lic sector body (that is } \\
\text { not a financial institu- } \\
\text { tion), unless election } \\
\text { made under } 211(1) \text {. }\end{array}$ & $\begin{array}{l}\text { 209(1), 199(2): full ITC if }>50 \% \text { for } \\
\text { use in commercial activities; no } \\
\text { ITC otherwise. }\end{array}$ & $\begin{array}{l}209(1), 199(3) \text { : on change from } \\
\leq 50 \% \text { to }>50 \% \text {, claim ITC based } \\
\text { on FMV. }\end{array}$ & $\begin{array}{l}209(1), 200(2) \text { : on change from } \\
>50 \% \text { to } \leq 50 \% \text {, remit tax based on } \\
\text { FMV. }\end{array}$ & $\begin{array}{l}209(1), 200(3) \text { : if used } \leq 50 \% \text { in } \\
\text { commercial activities, sale is not a } \\
\text { taxable supply, except where } \\
209(2) \text { applies (otherwise, taxable: } \\
141.1(1)(\text { a).) } 193(2) \text { : special ITC } \\
\text { available on certain sales. }\end{array}$ \\
\hline
\end{tabular}

An interestingly aspect of the Canadian rules is the use of two approaches - an apportionment approach for real property and non-capital property, and a threshold test (not too dissimilar to New Zealand's "principal purpose" test) for capital property. The GST Legislation also identifies particular entities (eg, builders, public sector, and financial institutions) for different treatment (see Table 3.4). ${ }^{29}$ Automobiles are also singled out for different treatment. ${ }^{30}$

${ }^{28}$ D Sherman TaxNetPro GST Commentary (Carswell, Last updated: 16 November 2001). The table was kindly provided by David Sherman during email correspondence (24 November 2010). Note that the automobile capital cost threshold has increased from $\$ 24,000$ to $\$ 30,000$ and the GST rate has reduced from 7 per cent to 5 per cent since this table was last updated. "ITC" means input tax credit. "FMV" means fair market value. "CCA" means capital cost allowance.

${ }^{29}$ Section 195.1 outlines the change-in-use rules for builders and tidies up an overlap between two provisions. Section 195.1 ensures that the change-in-use rules in ss 206 to 207 do not apply at the same time as the self-supply rules in s 191, by giving priority to the self-supply rules. Effectively, s 195.1 deems any capital real property as inventory (for use in a commercial activity) until it is deemed to be sold under s 191.

${ }^{30}$ Excise Act RSC 1985, ss 201, 202 and 203. 
Table 3.4: Extent of Commercial Activity by Different Entities

\begin{tabular}{|c|c|c|c|c|c|}
\hline Asset Type & $\begin{array}{c}\text { Commercial } \\
\text { Use }\end{array}$ & $\begin{array}{c}I T C \\
\text { Individual }\end{array}$ & $\begin{array}{c}I T C \\
\text { Corporation }\end{array}$ & $\begin{array}{c}I T C \\
\text { Public Sector }\end{array}$ & $\begin{array}{c}I T C \\
\text { Financial }\end{array}$ \\
\hline & & $s 208$ & $s 206$ & $s 209$ & ss 206, 141(6) \\
\hline \multirow{2}{*}{$\begin{array}{l}\text { Capital } \\
\text { Real property }\end{array}$} & $<10 \%$ & $0 \%$ & $0 \%$ & $0 \%$ & use $\%$ \\
\hline & $10 \%-50 \%$ & use $\%$ & use $\%$ & $0 \%$ & use $\%$ \\
\hline \multirow{2}{*}{$\begin{array}{l}\text { and } \\
\text { Non-Capital } \\
\text { property }\end{array}$} & $50 \%-90 \%$ & use $\%$ & use $\%$ & $100 \%$ & use \% \\
\hline & $>90 \%$ & $10 \%$ & $10 \%$ & $100 \%$ & use $\%$ \\
\hline & & s 199 & s 199 & s 199 & s 199 \\
\hline \multirow{2}{*}{$\begin{array}{l}\text { Capital } \\
\text { Personal } \\
\text { property }\end{array}$} & $<50 \%$ & $0 \%$ & $0 \%$ & $0 \%$ & use \% \\
\hline & $>50 \%$ & $100 \%$ & $100 \%$ & $100 \%$ & use $\%$ \\
\hline
\end{tabular}

Source: Canada Revenue Agency GST Memoranda (New Series) ch 19.1 at [103].

\section{Input Tax Credits}

The general rule - non-capital and real property

Sections 169 and 170 provide the general rules for claiming input tax credits for noncapital property (eg, inventory) and real property (eg, land).

Capital property (eg, a business computer) is treated differently under separate rules. ${ }^{31}$ Passenger vehicles and aircraft are also treated differently under their own specific rules. ${ }^{32}$ Selected listed financial institutions (SLFIs) are specifically excluded from claiming input tax credits. ${ }^{33}$ There are also simplified rules (that do not require tracking and claiming specific input tax credits) for small businesses and public service bodies. ${ }^{34}$

${ }^{31}$ Excise Act RSC 1985, ss 199.

${ }^{32}$ Excise Act RSC 1985, ss 200, 201, and 2002.

${ }^{33}$ Excise Act RSC 1985, s 169(3). The identification of financial institutions is not unique and their separation (and different treatment) is also applied throughout the two other jurisdictions (eg, New Zealand and Australia) examined in this thesis. See Ryan ULC Value Added Taxation in Canada: GST, HST and QST (3 ${ }^{\text {rd }}$ ed, CCH Canada Ltd, Toronto, 2009) 557.

${ }^{34}$ Excise Act RSC 1985, s 227. 
Generally, a registered entity is eligible to claim an input tax credit for GST paid on purchases of non-capital property or services acquired for use or supply in the course of a commercial activity. ${ }^{35}$ The focus of inquiry is at the time of acquisition. ${ }^{36}$

Where a registered entity makes mixed supplies (eg, a combination of taxable and exempt supplies), a partial input tax credit (based on an apportionment approach) is available to the extent that the purchases relates to the making of taxable supplies. The apportionment method adopted must be "fair and reasonable" and used consistently throughout the year. ${ }^{37}$ Financial institutions are treated differently and must obtain prior approval by the CRA before adopting an apportionment method. ${ }^{38}$ The apportionment approach is also subject to a 90:10 threshold rule. ${ }^{39}$ No apportionment is made for commercial activity below 10 per cent or above 90 per cent (except for financial institutions and residential carve-outs). ${ }^{40}$

${ }^{35}$ Excise Act RSC 1985, s 123(1) defines “commercial activity”.

${ }^{36}$ The word "acquire" is not defined in the Act. The ordinary dictionary definition of the term "acquire" is to get, obtain, have control over or possess. With respect to property, relevant case law indicates that property is "acquired" by obtaining ownership or possession. The words "consumption" and "use" are also not defined in the Act.

${ }^{37}$ Excise Act RSC 1985, s 141.01(5), formerly s 147 (repealed). Section 141.01 was introduced to clarify the requirement to apportion GST paid on indirect inputs, as well as direct inputs (eg, overhead expenses). It remains unclear whether a business that pays an amount in legal fees to settle a lawsuit against it arising in the course of making taxable supplies could claim an ITC. Section 141.01(2) would appear to prevent a claim. It has been suggested that s 141.1(3) might operate to allow the credit to be claimed. However, given there is no direction of priority between the provisions, Parliament must have intended the later amendment to preside over the earlier provision, if there is a conflict. The new provision also consolidated in s 147. The amendment received Royal Assent on 12 May 1994 and applied retrospectively from 1 January 1991 (the introduction of the GST Legislation). See Department of Finance News Release 93-027 (30 April 1993). For a discussion of the reasons for the introduction of this provision, see: R Resendes "Proposed New Input Tax Credit Rules and Retroactive GST Changes" in Commodity Tax Symposium (Canadian Institute of Chartered Accountants, 1993) tab 27; D Huggett "Legislative Thievery" (July/August 1993) 21(3) Canadian Tax News 1; A Taitz and WJ Millar "Apportionment Requirement Confirmed" (June 1993) 7(5) GST \& Commodity Tax Newsletter 33; RG Kreklewetz and V Vipul "Limitations on Claiming Input Tax Credits: British Columbia Transit v The Queen" (February 2007) 17(2) Taxation Law (Ontario Bar Association Taxation Law Section Newsletter) 23.

${ }^{38}$ Excise Act RSC 1985, s 141.02.

${ }^{39}$ Excise Act RSC 1985, s 141.

${ }^{40}$ Financial institutions must apportion on an exact basis under s 141(6), and must use special ITC allocation rules under s 141.02. The 90:10 rule also does not apply to residential premises. Under s 141(5) the residential portion of a commercial activity is deemed to be separate from commercial activity (ie, a residential carve-out). This exception to the 90:10 rule (ie, re-enabling exact apportionment below 10 per cent) is intended to allow apportionment of operating expenses related to 
In a departure from convention, Canada ignores exempt transactions in businesses that make "substantially all" supplies in taxable circumstances. If "substantially all" of a property is used (or intended to be used) in commercial activities, then all of the property is deemed to be used (or intended to be used) in commercial activities. ${ }^{41}$ The expression "substantially all" has been interpreted to mean 90 per cent or more. ${ }^{42}$ Effectively, a 100 per cent input tax credit is available where purchases relate exclusively (eg, 90 per cent or more) to commercial activities. Equally, if "substantially all" of a property is used (or intended to be used) in other activities (eg, for personal use or in making exempt supplies), then all of the property is deemed to be used (or intended to be used) in other activities. ${ }^{43}$ Effectively, a 0 per cent input tax credit will apply where purchases relate exclusively (eg, 90 per cent or more) to non-commercial activities (ie, commercial activity is below 10 per cent). ${ }^{44}$

Where a taxable supply is made for a single consideration and includes other supplies reasonably regarded as incidental, the other supplies are deemed to form part of the taxable supply. ${ }^{45}$ Supplies made for separate consideration cannot be regarded as incidental. ${ }^{46}$

the commercial activities, even if the commercial activity falls below 10 per cent. See On-Guard SelfStorage Ltd v Canada [1996] GSTC 9 (TCC). See also the Canada Revenue Agency GST Memoranda (New Series), Chapter 19.1 (October 1997) at [101, 102 and 104]. The Canada Revenue Agency GST Memoranda is the equivalent to the former IRD Technical Rulings Manual (NZ) which ceased updated publication in 1998. IRD staff now use TIB database's as their principal guidance manual.

${ }^{41}$ Excise Act RSC 1985, s 141(1) and (2).

42 The 90 per cent figure has no statutory basis.

${ }^{43}$ Excise Act RSC 1985, s 141(3) and (4).

${ }^{44}$ Section 141(5) provides an exception to the 10 per cent threshold for commercial property that makes up less than 10 per cent of a residential complex. This is achieved by deeming the residential complex a separate supply from the remaining property (ie, any commercial property). This deeming provision is intended to enable the operating expenses of the commercial arm of the residential complex to claim input tax credits. Effectively, s 141(5) allows a claim for ITCs that are not available under s 141(3) or (4).

${ }^{45}$ Excise Act RSC 1985, s 138.

${ }^{46}$ In New Zealand, the Courts have grappled with what is "reasonably incidental". In Taxation Review Authority (TRA) Case S81 (1996) 17 NZTC 7,505 at [24], Judge Barber considered that the supply of flats in a property development might be considered to be reasonably incidental to property development. While the TRA decision was overturned in CIR v Morris (1997) 18 NZTC 13,385 (HC), this line of reasoning was not challenged. The Canadian approach introduces the additional 
Section 170(1) provides a number of explicit restrictions on entitlement to input tax credits that are provided in s $169 .{ }^{47}$ Section $170(2)$ also requires claims for input tax credits to be reasonable.

\section{Capital property (personal)}

Section 199(2) sets out rules for claiming input tax credits on capital personal property. ${ }^{48}$ A full input tax credit is available where the registrant intends to use the property "primarily" in commercial activities.

The terms "primary use" or "used primarily" are not defined in the GST Legislation. Generally, case law has held that "primarily" means "more than 50 per cent" and this interpretation is supported by the CRA. ${ }^{49}$ However, the courts have also been open to a more flexible interpretation of "primarily" as meaning "first importance, principal, or chief" in appropriate circumstances. ${ }^{50}$ To date all cases that have applied the test have exceeded the 50 per cent threshold and it will be interesting to observe if the courts are willing to step below 50 per cent, where there are more than two purposes at play — an approach that would be consistent with the New Zealand "principal purpose" test.

aspect of 'single consideration' into the required mix. This is a tangible fact that the Courts can more readily use in determining an incidental supply.

${ }^{47}$ These restrictions and are explained in GST Memoranda (New Series) ch 8.2. Restrictions include: club membership fees, home office expenses, supplies primarily or exclusively for personal consumption, use or enjoyment.

${ }^{48}$ Capital property is defined in s 123(1) and is consistent with the equivalent income tax meaning, subject to an exclusion for certain classes of depreciable property. Section 169 provides the rules for capital real property.

${ }^{49}$ Canada Revenue Agency GST Memorandum (Old Series) ch 400 (18 May 1990) at [60-77]. In MidWest Feed Ltd v Minister of National Revenue (1987) 87 DTC 394 (TCC), Couture CJ held that the world "primarily" means in excess of 50 per cent of the total use of the asset. This is in contrast to New Zealand's "principal purpose" test which began life as a "more than 50 per cent" test in early Taxation Review Authority decisions, but was subsequently interpreted by the Courts as a dominant purpose test, where something less than 50 per cent was possible: Morris v CIR (1997) 18 NZTC $13,385(\mathrm{HC})$.

${ }^{50}$ Calgary (City) $v R$ [2009] GSTC 85 at [71]. See also Lacina $v R$ [1997] GSTC 69 (FCA); Burrows $v$ $R$ [1998] GSTC 78 (TCC); Berube v R [2001] GSTC 129 (TCC); and Colleges of Applied Arts and Technology Pension Plan v R [2003] GSTC 143 (TCC). 
The courts have acknowledged that the focus of the test is on the purpose of the acquisition, not its use. Although Bowman J observed that use was probably a fair indicator of purpose: ${ }^{51}$

“'... 'for use primarily...' (en vue d'être utilisé) requires the determination of the purpose of the acquisition, not the actual use. Nonetheless, I should think that as a practical matter if property is in fact used primarily for commercial purposes it is a reasonable inference that it was acquired for that purpose."

If the intention of the registered entity at the time of acquisition is to use the capital personal property primarily in non-commercial activities, no input tax credit will be available at that time. A registered entity may not claim input tax credits for the acquisition or improvement of real capital property if the property is acquired "primarily" (eg, more than 50 per cent) for the individual's personal use and enjoyment or the personal use and enjoyment of a related individual. ${ }^{52}$

\section{Basic tax content}

The 'basic tax content' (BTC) is the net GST rate of the depreciated value of the property. ${ }^{53}$ BTC is calculated on the depreciated value of the property at its current fair market value, but not on the appreciated value where the value of the property has increased. Fair market value is the fair market value of a property less any applicable taxes (eg, provincial levies). ${ }^{54}$

${ }^{51} 510628$ Ontario Ltd $v R$ [2000] GSTC 58 at [11].

${ }^{52}$ Excise Act RSC 1985, s 208(1) to (4).

${ }^{53}$ Excise Act RSC 1985, s 123(1). The term "basic tax content" replaced the former "tax fraction" term. The change in terminology was brought about by the introduction of Harmonized Sales Tax (HST) in Nova Scotia, New Brunswick and Newfoundland (from 1 April 1997) which had different tax rates of GST and the possibility that property could be moved from one HST province to another. Outside the HST zones is 5/105. See GST Memorandum (New Series) ch 8.3 for further details.

${ }^{54}$ The provincial levies that are excluded when determining the fair market value of real property are specified in regulations. 
The general formula is:

$$
(\mathrm{A}-\mathrm{B}) \times \mathrm{C}
$$

where

$\mathrm{A}=$ the total of:

(i) tax payable on the claimant's last acquisition or importation of the property;

(ii) tax payable in respect of improvements to the property acquired, imported or brought into a participating province after the property was last acquired or imported;

(iii) tax that would have been payable in either of the preceding situations but for subsection 153(4) or section 167 applying or the fact that the property or improvements were acquired by the claimant for consumption, use or supply exclusively in commercial activities; and

(iv) tax under section 218 and section 218.1 (tax payable on imported taxable supplies), and Division IV.1 (tax self-assessed on property brought into a participating province from a non-participating province) that the person would have been liable to pay if the property or improvement were not for consumption, use or supply exclusively in the course of commercial activities of the person;

$\mathrm{B}=$ the total of

(i) any tax included in A (above) that the person was exempt from paying under any other Act or law;

(ii) all amounts of tax referred to in A(i) and A(ii) above which the claimant was entitled to recover by way of a rebate, refund, or remission or would have been entitled to recover, if the property or improvement had been acquired for use exclusively in activities that are not commercial activities, other than ITCs and amounts referred to in $\mathrm{B}(\mathrm{i})$;

(iii) the amounts of tax referred to in A(iii) and A(iv) above which the claimant was entitled to recover by way of a rebate, refund, remission or otherwise under this or any other Act or law or would have been entitled to recover if the tax had been payable and the property or improvement had been acquired for use exclusively in activities that were not commercial activities, other than ITCs and amounts referred to in $\mathrm{B}(\mathrm{i})$; and

$\mathrm{C}=$ the lesser of 1 , and 
((fair market value at the time the basic tax content is being determined) / (consideration payable on the last acquisition + consideration for improvements.))

For example, an item is purchased for $\$ 100$ plus $\$ 5$ GST, and is now worth $\$ 60$. The BTC is: $(\$ 5-0) \times 60 / 100=\$ 3$.

According to Sherman, BTC is "by far the most complex definition in the GST legislation". ${ }^{55}$ Unfortunately there is very little case law that has examined the topic. ${ }^{56}$ The basic tax content is mainly used in the capital property (personal and real) change-in-use rules. ${ }^{57}$ A consequence of the BTC formula is that appreciating values appear to have been removed from the change-in-use calculation, and thereby removed the source of many problems experienced in New Zealand.

\section{Financial services}

Generally, financial services are exempt supplies and are not entitled to any input tax credits. This exemption is extended to any mixed supplies that comprise financial services, where 50 per cent or more of the consideration for the supply relates to financial services. ${ }^{58}$ Mixed supplies below 50 per cent are apportioned so that only the non-exempt supply is entitled to input tax credits. However, financial services that are "incidentally" acquired or supplied during the course of commercial activities by a registered entity (that is not a listed or deemed financial institution) are not treated as exempt and no apportionment is required. ${ }^{59}$ This claw-out from exempt treatment reduces compliance costs by eliminating the need for apportionment of input tax credits between exempt supplies and commercial activities, where the exempt supply is incidental.

\footnotetext{
${ }^{55}$ D Sherman "Editorial Comment" in Gatineau (Ville) v $R$ [2010] FCA 82, [2010] CarswellNat 657.

${ }^{56}$ British Columbia Transit v R [2006] GSTC 103 (TCC) is the only case to have examined the definition.

${ }^{57}$ Excise Act RSC 1985, ss 195 to 211.

${ }^{58}$ Excise Act RSC 1985, s 139.

${ }^{59}$ Excise Act RSC 1985, ss 185 (non-capital property) and 198 (capital property). Section 138 provides a similar rule for financial institutions.
} 


\section{E. Change-In-Use Rules}

Like many other jurisdictions, change-in-use rules apply to ensure the correct amount of tax has been collected. To prevent the constant application of the changein-use rules there is a threshold test which provides that the rules will not apply where there is an "insignificant" change in use. ${ }^{60}$ Generally, an insignificant change in use is one where there is less than a 10 per cent change, from the last time a change in use was triggered or the property was acquired.

\section{Non-capital property}

The change-in- use rules for non-capital property are contained in ss 172 and 196.1.

Where non-capital property is acquired for commercial use, but subsequently diverted to personal use, a deemed supply is triggered and the value of the deemed supply will equal its fair market value at the time of the deemed supply. ${ }^{61}$ Section 172(1) effectively operates to require repayment of the input tax credit claimed under $\mathrm{s} 169 .^{62}$ While a change is use from non-capital property to capital property is available, there is no legislative provision for the opposite (eg, a change in use from capital to non-capital property), and the courts have rejected any notion that it could work the other way, in the absence of a legislative provision. ${ }^{63}$

Where non-capital property is subsequently used as capital property (or incorporated into capital property as an improvement), the non-capital property is deemed to have been sold for its fair market value at the time of the deemed supply. ${ }^{64}$ Where noncapital property is converted into capital property or incorporated into capital property as an improvement, the registered entity is required to self-assess and remit

\footnotetext{
${ }^{60}$ Excise Act RSC 1985, s 197. This rule is similar to the 90:10 threshold rule for ITC entitlement in s 141.

${ }^{61}$ Excise Act RSC 1985, s 172(1). See Canada Revenue Agency GST Memoranda (New Series) ch 3.1, "Liability for Tax" (August 1999) at [101 and 103]. See Callahan v R [1996] GSTC 15 (TCC).

${ }^{62}$ Section 172(1) does not apply to capital property. The change-in-use rules for capital property apply instead (see below). Section 172(1) also does not apply to a change from a commercial use to one making exempt supplies.

${ }^{63}$ Holand Leasing Ltd $v R$ [1995] GSTC 8 at [18] (TCC).

${ }^{64}$ Excise Act RSC 1985, s 196.1.
} 
GST based upon the fair market value of the property at that time. If the appropriated property is used in commercial activities they will be entitled to offset the GST liability from the deemed sale with an input tax credit. However, if the use is not for commercial activities they will incur a GST liability from the deemed sale.

The conversion of non-capital property into capital property by deemed sale also allows the change-in-use rules for capital property ${ }^{65}$ to apply to property that was not capital property (or not intended to be capital property), when it was first acquired.

\section{Real property}

Section 206 contains the change in use rules for real property. ${ }^{66}$ The provision deals with four scenarios: (1) non-commercial to commercial; ${ }^{67}$ (2) commercial to noncommercial $;{ }^{68}$ (3) increasing commercial use $;{ }^{69}$ and (4) decreasing commercial use. ${ }^{70}$

Where the real property changes from non-commercial to commercial the registered entity is deemed to have received a supply of the real property at the time of the change. The amount of GST which is deemed to have been paid is equal to the lesser of GST on the fair market value of the property at that time and the actual amount of GST paid on the acquisition of the property (minus any rebates). ${ }^{71}$ The extent to which the property is then used in commercial activities under s 169 , then determines the amount input tax credit entitlement.

Where there is an increase in commercial use, the registered entity is entitled to claim an input tax credit equal to the percentage of the increase in use times the

\footnotetext{
${ }^{65}$ Excise Act RSC 1985, ss 195 to 211 (discussed below).

${ }^{66}$ As stated above the rules are subject to a 10 per cent minimum threshold test. Any changes below 10 per cent are considered "insignificant" and the change in use will not be triggered.

${ }^{67}$ Excise Act RSC 1985, s 206(2).

${ }^{68}$ Excise Act RSC 1985, s 206(4).

${ }^{69}$ Excise Act RSC 1985, s 206(3).

${ }^{70}$ Excise Act RSC 1985, s 206(5).

${ }^{71}$ This deemed supply approach is similar to the New Zealand's former approach for triggering recalculation of input tax credit entitlements.
} 
lesser of the tax originally paid (minus any rebates) and the GST exigible on the fair market value of the property at that time. Where there is a decrease in commercial use, a similar calculation is undertaken, except the registered entity will pay back the difference to the CRA. The resulting tax liability has the effect of recapturing previously claimed ITCs and takes into account the current fair market value of the property where it has depreciated in value.

Where the real property changes from commercial to non-commercial the registered entity is deemed to have sold the property at that time and to have collected GST.

\section{Capital property}

Sections 199 and 200 contain the change in use rules for capital personal property. Effectively, the provisions provide a self-supply mechanism that enables the recalculation of input tax credit entitlement.

Section 196 is the triggering mechanism for capital property. ${ }^{72}$ Effectively, the provision expands the concept of "use" to encompass the "intended use" or "purpose" and deems the actual use of the property after the acquisition to be the intended use at the time of acquisition. Thus, if the actual use is other than the deemed intended use, the change-in-use rules for capital property are triggered. ${ }^{73}$

Section 199(3) provides for circumstances where there is an increase in commercial use. When a change in use of capital personal property occurs from being used primarily in non-commercial activities to use primarily in commercial activities (eg, commercial use is greater than 50 per cent) the registered entity is deemed to have purchased the property and paid GST equal to the basic tax content of the property (eg the fair market value of the property or the initial price paid - whichever is lower). ${ }^{74}$ The registered entity is then entitled to claim a full 100 per cent input tax credit at that time.

\footnotetext{
72 Section 196 provides that it applies "for the purposes of this Part". However, it only applies to property that is intended to be used as "capital" property. This may well be a drafting oversight. A more correct drafting would restrict it to the relevant Subparts.

${ }^{73}$ This mechanism is subject to s 197 (discussed above).

${ }^{74}$ Excise Act RSC 1985, s 199(3).
} 
Section 200 provides for circumstances where there is a decrease in commercial use. When a change in use of capital personal property occurs from being used primarily in commercial activities to use primarily in non-commercial activities (eg, commercial use less than 50 per cent, therefore not primarily a commercial use), the registered entity is deemed to have sold the property and to be liable for GST based upon the fair market value of the property at that time. ${ }^{75}$

\section{Financial institutions}

Generally, financial institutions are subject to the same change-in-use provisions as other registered entities. However, for financial institutions the rules are modified. ${ }^{76}$ Any capital personal property that costs more than $\$ 50,000$ is deemed to be capital real property and subject to the real property rules, not the capital personal property rules. ${ }^{77}$ Importantly, the "substantially all" rule (discussed above) does not apply to financial institutions. Accordingly, capital real property will only cease to be used for commercial activities only when it is used totally for other purposes. ${ }^{78}$

\section{General overview}

Figure 3.1 illustrates the operation of the two different approaches (noting that real capital property receives the same treatment as non-capital property).

\footnotetext{
${ }^{75}$ Excise Act RSC 1985, s 200(2).

${ }^{76}$ These modifications to the general rules are extended to apportionment methods (discussed below).

${ }^{77}$ Excise Act RSC 1985, s 204(1) and (2).

${ }^{78}$ Excise Act RSC 1985, s 206(4). For registered entities, the term "exclusively" means 90 per cent or more, but for a financial institution, "exclusively" means 100 per cent. Listed financial institutions also have a different 'basic tax content' formula.
} 
Figure 3.1: Non-Capital and Capital Property Treatment Flowchart

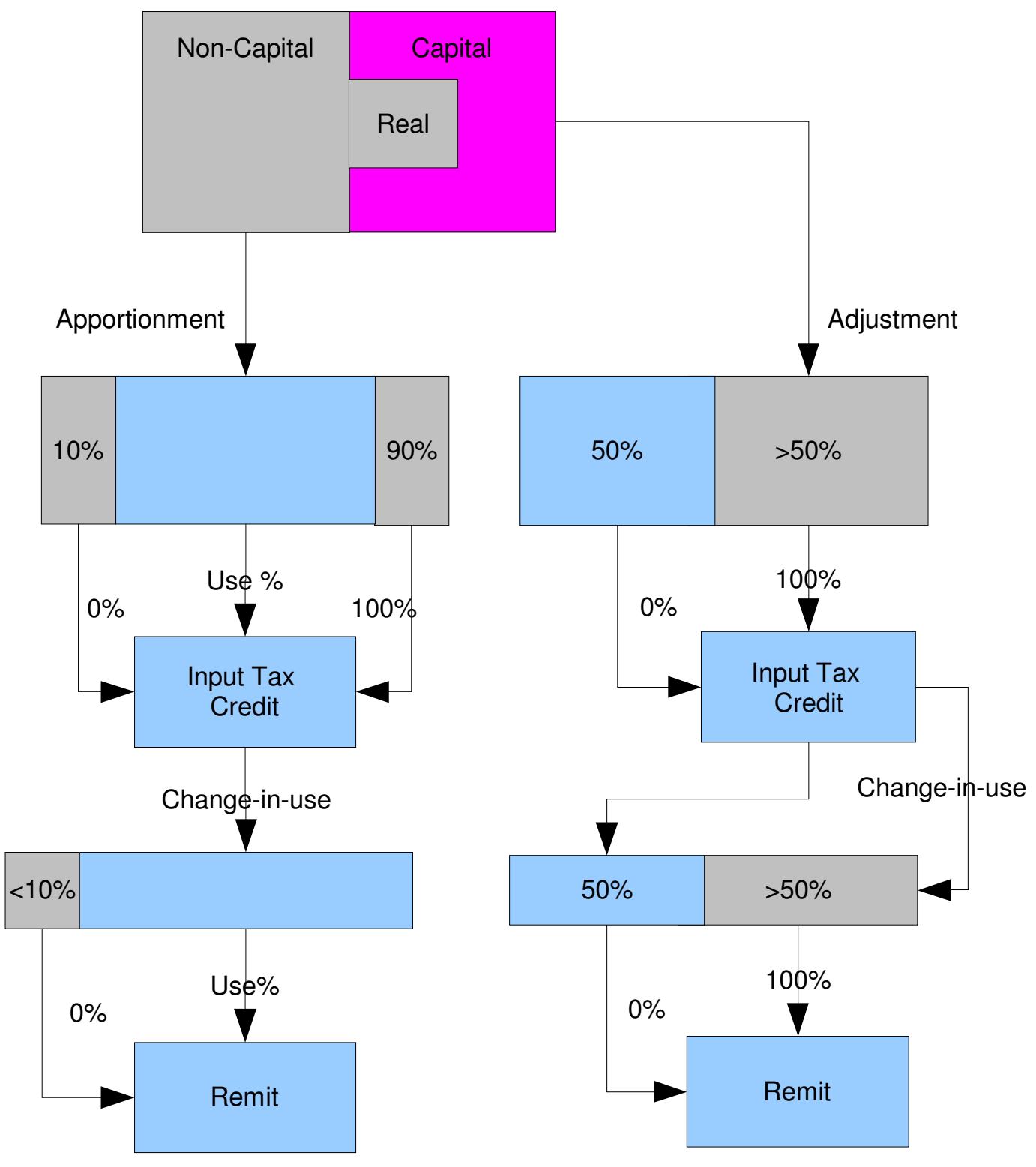

\section{F. Apportionment Methodology}

The GST Legislation does not explicitly provide for any method that must be used to apportion property or services acquired partly for commercial activities. ${ }^{79}$ Rather the use of any method (direct or indirect) is at the option of the registered entity. The legislation merely provides that the method chosen "shall be fair and reasonable in

\footnotetext{
${ }^{79}$ This contrasts to New Zealand's former adjustment rules, where the apportionment methodology was codified.
} 
the circumstances and shall be used consistently throughout the year" ${ }^{80}$ However, for financial institutions the CRA must provide prior approval of the method used. ${ }^{81}$

Once a method has been adopted by the registered entity it must be "used consistently throughout the year" and be supported by documentation. Any adopted method used must be supportable by sufficient documentation to show that it was fair and reasonable in the particular circumstances. The CRA also require that the supporting documentation should address why the method was appropriate and deal with possible distorting factors when using an output method (ie, an indirect revenue based approach). ${ }^{82}$

\section{Registered entities}

The apportionment of inputs between exempt and taxable outputs for purposes of determining input tax credits may have had very little judicial examination in Canada, ${ }^{83}$ but it has had substantially more examination than in Australia or New Zealand. ${ }^{84}$ The few cases that are reported do provide some guidance on what is considered "fair and reasonable". ${ }^{85}$ Importantly, what is considered "fair and reasonable" does not have to be the "best" method. ${ }^{86}$ Unfortunately, recent court

${ }^{80}$ Excise Act RSC 1985, s 141.01(5). Both New Zealand and Australia utilise a "fair and reasonable" test.

${ }^{81}$ Excise Act RSC 1985, s 141.02.

${ }^{82}$ Policy Statement P063 (Output Based Method for Input Tax credit Allocation).

${ }^{83}$ There have only been 10 cases: Navaho Inn v R [1995] GSTC 21 (TCC); Cosmopolitan Music Society $v R$ [1995] GSTC 19 (TCC); Royal Canadian Legion Branch No $164 v$ R [1996] GSTC 98 (TCC); Magog (City) $v R$ [2000] GSTC 81 (TCC), [2001] GSTC 98 (FCA); Blanchard $v R$ [2001] GSTC 94 (TCC); Pension Positive Inc v R [2002] GSTC 56 (TCC); Immeubles Le Sejour Inc v $R$ [2003] GSTC 180 (TCC); Bay Ferries Ltd v R [2004] GSTC 135 (TCC); Iles-de-la-Madeleine v $R$ [2008] GSTC 24 (TCC); and Nikel $v R$ [2008] GSTC 195 (TCC).

${ }^{84}$ New Zealand's pending adoption of the "fair and reasonable" test will undoubtedly lead to reliance on the Canadian and Australian experience for guidance. This is not to suggest that the New Zealand Courts are not familiar with determining what is "reasonable".

${ }^{85}$ Excise Act RSC 1985, s 141.01(5). Section 141.02 provides the rules for financial institutions and limits the "fair and reasonable" test by requiring financial institutions to have methods approved by the CRA.

${ }^{86}$ Magog (Ville) v R [2001] GSTC 138 (FCA); Bay Ferries Ltd v R [2004] GSTC 135 (TCC); Nikel Ltd $v R$ [2008] GSTC 195 (TCC). 
decisions have been somewhat obscure about whether an alternative method, that is "more" fair and reasonable (but not the best method), could be applied.

In the recent case of Nickel Ltd $v R^{87}$ the court early in the judgment suggest that as long as the taxpayer's method is fair and reasonable, the fact that there may be another method that is "more" fair and reasonable does not matter. ${ }^{88}$ However, later in the judgement (see quote below) the court appears to suggest that alternative practical methods, that might have given a "more reasonable" apportionment (and that "might have changed the outcome of the case"), were not argued. As the court observed: ${ }^{89}$

“... It is appropriate to take into account practical considerations, specifically that methods used must be relatively straightforward for the taxpayer to comply with and the Minister to administer.

Given that it is not apparent that there is a practical allocation method that gives a more reasonable allocation, given that the complex is professionally managed, that the condo is available for rent whenever the Appellant is not using it, that there are facilities in the complex aimed at obtaining year-round customers, and given the expenditures the Appellant incurs to keep the condo on the market during the year, notwithstanding that there are serious weaknesses in the Appellant's method, I find that it is a fair and reasonable method.

${ }^{87}$ Nikel Ltd $v R$ [2008] GSTC 195 (TCC). In Nikel, the registered entity bought a condominium in a year-round resort complex and claimed 100 per cent input tax credits. The condominium was available for private use for 36 days and for the remaining days of the year was available for rental as a commercial activity. Over a 2-year period the condominium was used 16 to 33 days a year for private use and but available for rental 131 to 268 days a year, although it was actually rented out 53 to 74 days a year. The CRA sought to recover part of the claimed input tax credits on the basis of a reduced commercial use of the property under s 207(2). The Tax Court of Canada (TCC) found for the taxpayer. Although the Court found Nikel's method of treating all days "available for rent" as commercial use had "serious weaknesses" (and underestimated personal use), it was nevertheless a fair and reasonable method, and thus was acceptable despite not being the best method. The Court did not accept that the CRA's alternative method of counting only "actual rented days" as commercial use was appropriate. In Sherman's opinion, the fact that there was a reasonable expectation of rentals year-round (albeit often with low occupancy rates), was sufficient to justify Nikel's method.

${ }^{88}$ Nikel Ltd $v$ R [2008] GSTC 195 (TCC) at [29]. citing Magog (Ville) $v R$ [2001] GSTC 138 (FCA) with approval.

${ }^{89}$ Nikel v R [2008] GSTC 195 (TCC) at [41-43]. The Court noted that the CRA (respondent) "did not argue any alternative approaches to the assessment method. Whether the existence of an alternative allocation method that is reasonable and practical to apply in circumstances such as these (if such a method exists), would change the outcome was a question for another case" (fn 16). 
Given my conclusion there is no change in use of $10 \%$ or more. As a result of the operation of section 197 of the GST, there is no deemed supply pursuant to subsection 207(2) of the GST and no resulting output tax.”

With respect, it would appear that this obiter observation in the judgment (and footnotes) of the court's judgment in Nickel $v R$ is not supported by earlier judgments from the Federal Court of Appeal (FCA) or Tax Court of Canada (TCC). Rather, the earlier decisions appear to require that the apportionment method merely has to be in the ball park of what is fair and reasonable to qualify, thus allowing the court to avoid the situation of having to pick better methods, should there be more than one in the park. As Noel $\mathrm{J}$ in Magog (Ville) $v$ R observed $:^{90}$

"The only issue before the judge was whether the method elected by the appellant was fair and reasonable, as required by subsection 141.01(5). She did not have to determine which of the two methods in question was the best. Moreover, Memorandum 700-5-1 acknowledges in its 23rd paragraph that more than one method may be fair and reasonable within the meaning of the Act .."

Thus the role of the court is one of determining if the method in question is fair and reasonable. If it's not, then alternatives may then be explored. This is certainly the approach adopted in Bay Ferries Ltd $v R,{ }^{91}$ which examined whether an output or input method of apportionment was fair and reasonable. As the court acknowledged: ${ }^{92}$

“... This decision clearly and definitively supports non-interference with a taxpayer's chosen method provided it is fair, reasonable and consistent."

${ }^{90}$ Magog (Ville) $v R$ [2001] GSTC 138 (FCA) at [15].Cited with approval in Nikel Ltd v R [2008] GSTC 195 (TCC) at [29].

${ }^{91}$ Bay Ferries Ltd $v R$ [2004] GSTC 135 (TCC). The taxpayer operated a passenger ferry service between Canada and the United States and revenue from ferry tolls was zero rated. The taxpayer also received revenue from leasing space onboard the vessel to food vendors and from vending machines (both exempt supplies). The taxpayer apportioned their taxable and exempt supplies on square footage basis (eg, an input method). They concluded that 30.29 per cent of the vessel was used for taxable supplies and reduced this figure to 25 per cent due to the fact that some spaces were shared equally with crew. The CRA disagreed and applied an output method, on the basis that the input method was not fair and reasonable in the circumstances. The CRA contended that only 1.2 per cent of the taxpayer's total revenue came from these supplies (eg, an output method). Consequently, the CRA determined that substantially all of the taxpayer's expenses were incurred in the supply of ferry services. As 90 per cent of total revenue can from exempt activities, no input tax credit was allowed. The Court found for the taxpayer.

${ }^{92}$ Bay Ferries Ltd v R [2004] GSTC 135 (TCC) at [38]. 
Adding: ${ }^{93}$

"I believe that a taxpayer must always be able to satisfactorily substantiate that the chosen method is, in fact, fair and reasonable and consistent. But if he is able to do so, subsection 141.01(5) allows a registrant a broad latitude of flexibility in choosing a method, provided it can be shown to be fair and reasonable. This implies that the chosen method will reasonably reflect the actual use of the property and services and the manner in which it conducts its business generally."

With regard to the application of the input method, the court acknowledged that it provided a higher degree of consistency and could be applied whether the taxpayer leased the space to a food operator or decided to provide the services itself. According to the court, an allocation method should not distort the financial reality of the commercial activity. While the leasing of space was a small fraction of the taxpayer's total revenue, the evidence clearly supported the fact that it was an essential part of the taxpayer's commercial activity. These factors may provide some guidance in situations where the taxpayer's method is found not to be suitable and alternatives are examined.

\section{Financial institutions}

Financial institutions are required to use an apportionment method that is specifically provided by the CRA. ${ }^{94}$ It is clear from the CRA's position (before the introduction of these rules), that the requirement for prior approval provides a mechanism to ensure that financial institutions do not take advantage of revenue-based approaches to apportionment which may not be indicative of input use (eg, revenue from late payment charges on accounts receivable may be significant, but requires little property or minimal services to generate). ${ }^{95}$ Large banks, insurers, and securities

${ }^{93}$ Bay Ferries Ltd v R [2004] GSTC 135 (TCC) at [40].

${ }^{94}$ Excise Act RSC 1985, s 141.02(14) and (15). To avoid the complexities associated with financial institutions these rules were introduced from 1 April 2007.

${ }^{95}$ Canada Revenue Agency GST Memorandum (Old Series) ch 700. These memoranda are progressively republished in the GST Memorandum (New Series) ch 17. A similar approach of "prior approval" is provided in New Zealand's new apportionment rules, although in most cases taxpayers are likely to use the prescribed statutory method. It would appear the approval process in New Zealand is to enable a carry over of existing agreements with financial institutions, and also to keep compliance costs to a minimum, as New Zealand shifts to a new apportionment method. In contrast to 
dealers are also required to use a prescribed percentage or obtain pre-approval from the CRA to use their own ITC allocation methods. ${ }^{96}$

\section{G. Examples}

The following examples illustrate and compare the operation of the respective rules.

Example 3.1: Capital Personal Property ${ }^{97}$

The GST rate is 5 per cent. Cian is a graphic designer and purchases a computer for $\$ 4,000$ (plus GST of \$200) to use both for business (80 per cent) and private purposes (20 per cent). The principal purpose of the computer is for the taxable activity of graphic design. Cian files tax GST returns every two months. In the second year of operation private use increases to 40 per cent, due to his children's use of the computer. No other changes in use occur over the life-time of the computer.

The computer is capital personal property. As Cian is not a financial institution and the transaction is below $\$ 50,000$ the apportionment rules do not apply. The test to be applied is whether the property is used primarily (eg, more than 50 per cent) in the course of the registered entity's commercial activities. If it is, a 100 per cent input tax credit is available upon acquisition (eg, \$200 input tax credit).

\begin{tabular}{|l|r|r|}
\hline Adjustments & \multicolumn{2}{|c|}{ Apportionment Approach } \\
\hline & & Adjustment \\
\hline Input tax credit & $\$ 200$ & $\$ 0$ \\
\hline Adjustment 1 & & $\$ 0$ \\
\hline Adjustment 2 & & $\$ 0$ \\
\hline Balance & $\$ 200$ & $\$ 0$ \\
\hline
\end{tabular}

New Zealand and consistent with Canada, Australia allow any method of apportionment provided it is "fair and reasonable".

${ }^{96}$ Excise Act RSC 1985, s 141.02(7) to (8) and (18) to (22). A similar approach to pre-approved methods is available in both Australia and New Zealand's apportionment rules.

${ }^{97}$ Based on an example in Canada Revenue Agency GST Memorandum (New Series) ch 8.1 at [43]. 
If the property was used 50 per cent for commercial activities and 50 per cent for personal use, no input tax credit would be available, as the property is not used "more" than 50 per cent in the course of commercial activities. If the commercial activity subsequently falls to 50 per cent or less, the full input tax credit is remitted. While Cian's commercial use has fallen to just 60 per cent in the second year of operation, it remains above 50 per cent so no adjustment is required.

\section{Example 3.2: Changing Value of Capital Real Property ${ }^{98}$}

The GST rate is 5 per cent. Louise, a property developer purchases a house and land for $\$ 500,000$ and intends to sell the development on completion. Louise is not a builder or associated with one (in Canada builders are subject to the self-supply rules). The land cost $\$ 300,000$ (plus GST of $\$ 15,000$ ) and the house $\$ 200,000$ (plus GST of $\$ 10,000)$. The market value of the property is $\$ 650,000$. The development does not sell and the development is rented until a buyer can be found. The rent returns $\$ 25,000$ per year. Insurance and rates cost $\$ 10,000$ per annum (plus GST of $\$ 500)$. The depreciation rate for the house is 10 per cent per annum. Louise claims an input tax credit of $\$ 25,000$ on the purchase price of $\$ 500,000$.

The basic tax content (BTC) of the property at the time of the acquisition is:

$$
\begin{gathered}
\mathrm{BTC}=(\mathrm{A}-\mathrm{B}) \times \mathrm{C} \\
=((\$ 25,000)-0) \times \text { the lesser of: } 1 \text { or }(\$ 650,000 /(\$ 500,000)) \\
=\$ 25,500 \times \text { the lesser of: } 1 \text { or } 1.3 \\
\text { BTC }=\$ 25,000 \times 100 \% \\
\text { ITC entitlement }=\$ 25,000
\end{gathered}
$$

Louise is entitled to a $\$ 25,000$ input tax credit. Operating costs are apportioned similarly.

As there has been a change-in-use an adjustment is required. An apportionment allocation could be based on one of several methods provided the method is fair and

\footnotetext{
${ }^{98}$ Based on examples in Canada Revenue Agency GST Memoranda (New Series) ch 19.4.2 at [21-36].
} 
reasonable and reasonably reflects the actual use of the property and services. As use is concurrent, an output based method is a good candidate. The following breakdown of the actual use from direct allocation can be provided:

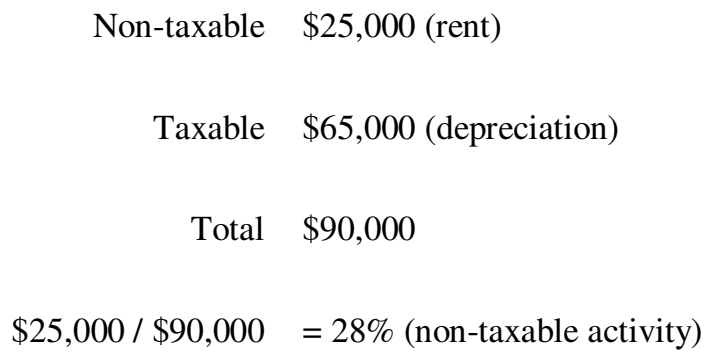

The basic tax content (BTC) of the property after the annualised adjustment is:

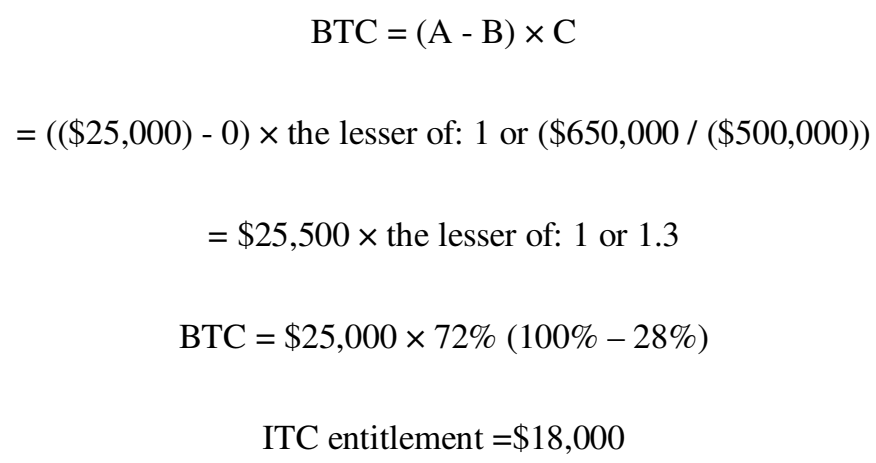

Louise has to remit $\$ 7,000(\$ 25,000$ - $\$ 18,000)$. Operating costs are apportioned similarly. No further adjustments are required unless there is a change in the input tax credit entitlement. For example, non-taxable activity increases another 2 per cent (due to rent increase of $\$ 30,000$ in following year) to a total of 30 per cent so that the ratio decreases from 72 per cent to 70 per cent.

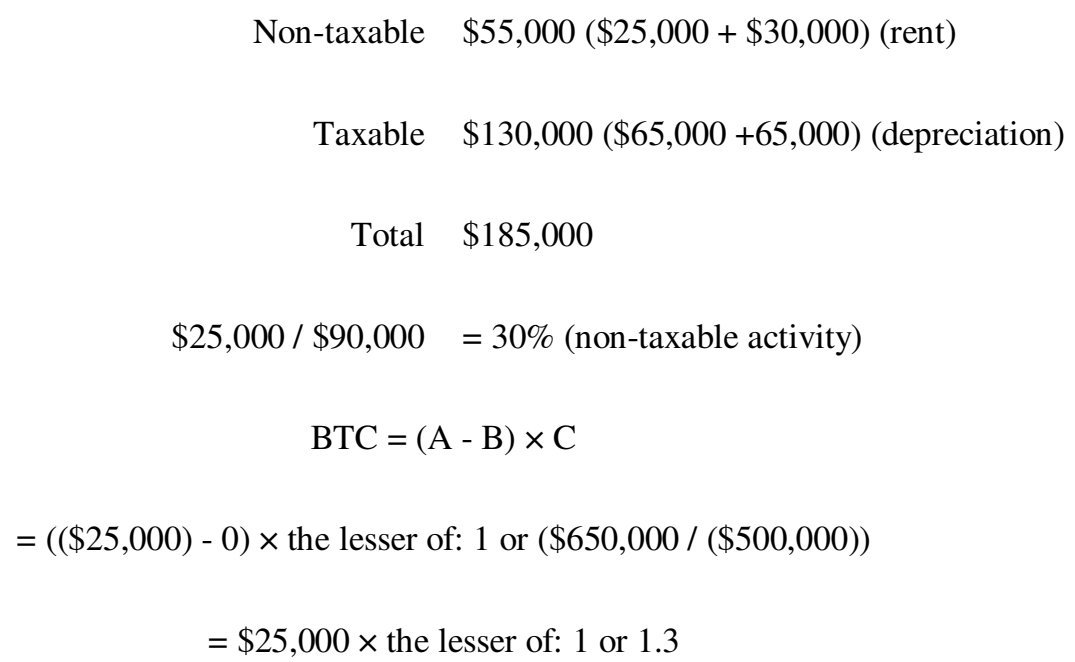




$$
\mathrm{BTC}=\$ 25,000 \times(72 \%-2 \%)
$$

ITC entitlement $=\$ 17,500$

Louise has to remit an additional $\$ 500(\$ 18,000-\$ 17,500)$.

If the property development reduces its taxable activities to below 10 per cent (eg, the property is used 90 per cent or more for non-commercial purposes), all the input tax is returned. Operating expenses are not subject to 90:10 rule and can be apportioned below 10 per cent or above 90 per cent.

The number of adjustments are not unrestrained (ie, indefinite), but are constrained by the BTC calculation methodology. Effectively, the BTC calculation operates according to a "used-up" model.

\section{Part 2: Implementation and Operation - Empirical Evidence}

Does the litigation evidence of the two different approaches to the change-in-use rules provide an indication that apportionment is to be preferred?

From the litigation evidence, it appears that the practical implementation of the input tax credit rules for non-capital and real property is more often an area of dispute in Canada than capital personal property. Furthermore, the volume of litigation appears to suggest that disputes are more concerned with entitlement (eg, a question of scope) than in determining the amount of input tax credits (through the application of an apportionment or adjustment approach).

\section{H. Judicial Activity}

The volume of GST litigation in Canada is far higher than in Australia or New Zealand. An audit of GST cases in Thomson Reuters TaxNetPro database records a total of 2,424 reported GST cases in Canada (illustrated in Figure 3.2). The volume of reported cases per year in Canada appears to have stabilised around 160-170 case per year since 2003 (illustrated in Figure 3.3). ${ }^{99}$ Initially this might be surprising given New Zealand has had 6 more years than Canada to litigate their GST

\footnotetext{
99 The CRA report a lower average figure of 57 GST cases per year. See Canada Revenue Agency Annual Report (2007-08) 58. Document available at <www.cra-arc.gc.ca/gncy/nnnl/20072008/prfrmnc-e/rc4425-08eng.pdf> (viewed 20 March 2011).
} 
legislation. However, given the comparative size of the Canadian economy (and number of potential transactions that provide an opportunity for disputes), this might be expected.

Figure 3.2: Total Reported GST Cases 1991-2010 (Accumulated) ${ }^{100}$

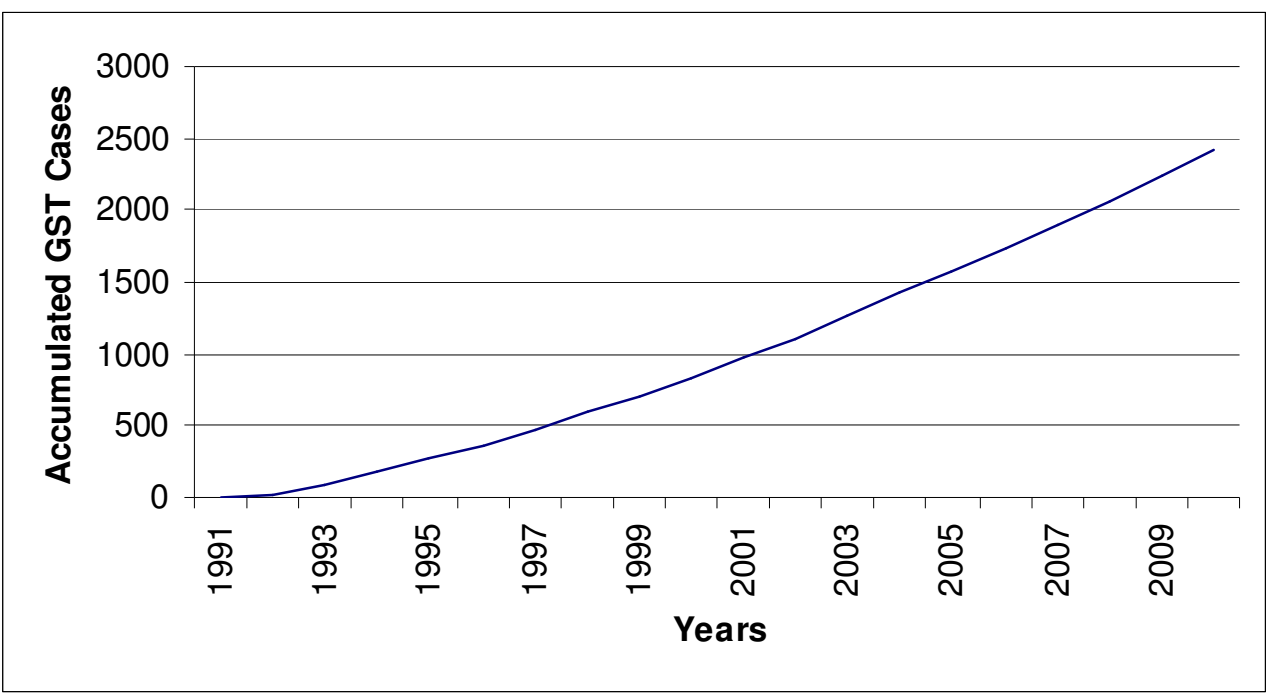

Figure 3.3: Total Reported GST Cases 1991-2010 (Per Year) ${ }^{101}$

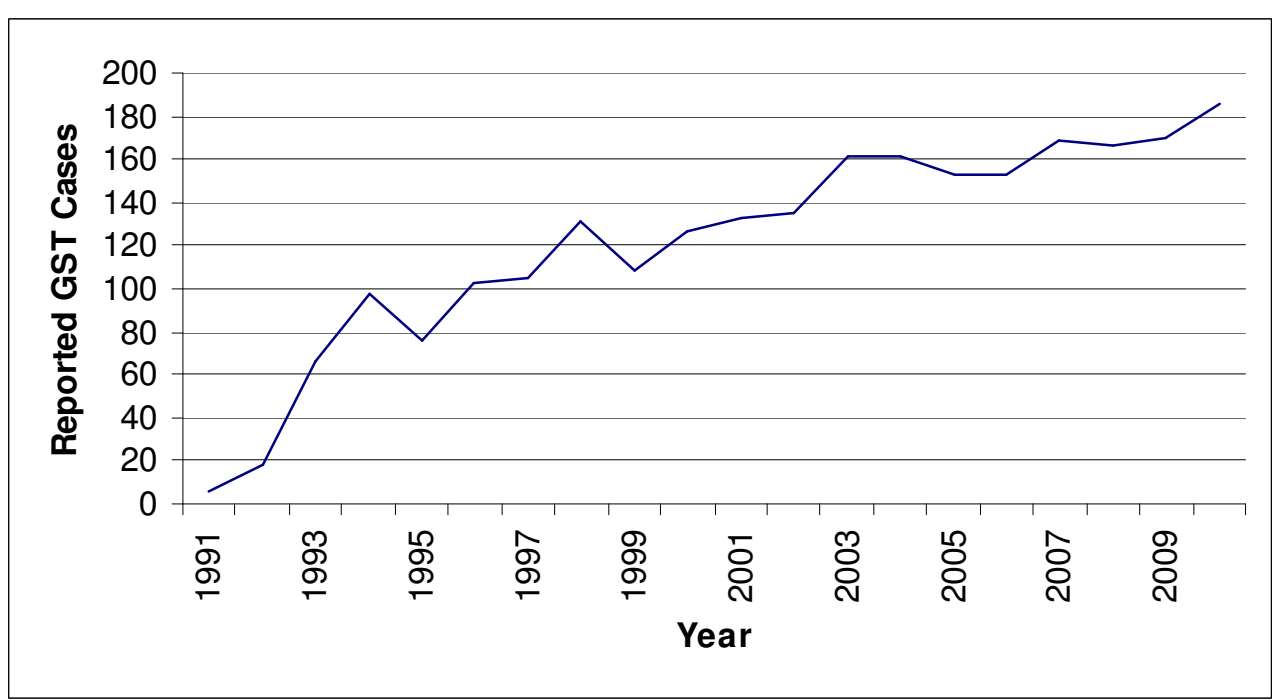

${ }^{100}$ Figures obtained from Carswell's TaxNetPro by searching reported GST cases in the year field (as at 20 November 2010).

${ }^{101}$ Figures obtained from Carswell's TaxNetPro by searching reported GST cases in the year field (as at 20 November 2010). 
Figure 3.4: Reported GST Cases 1991-2010 (Per Section) $)^{102}$

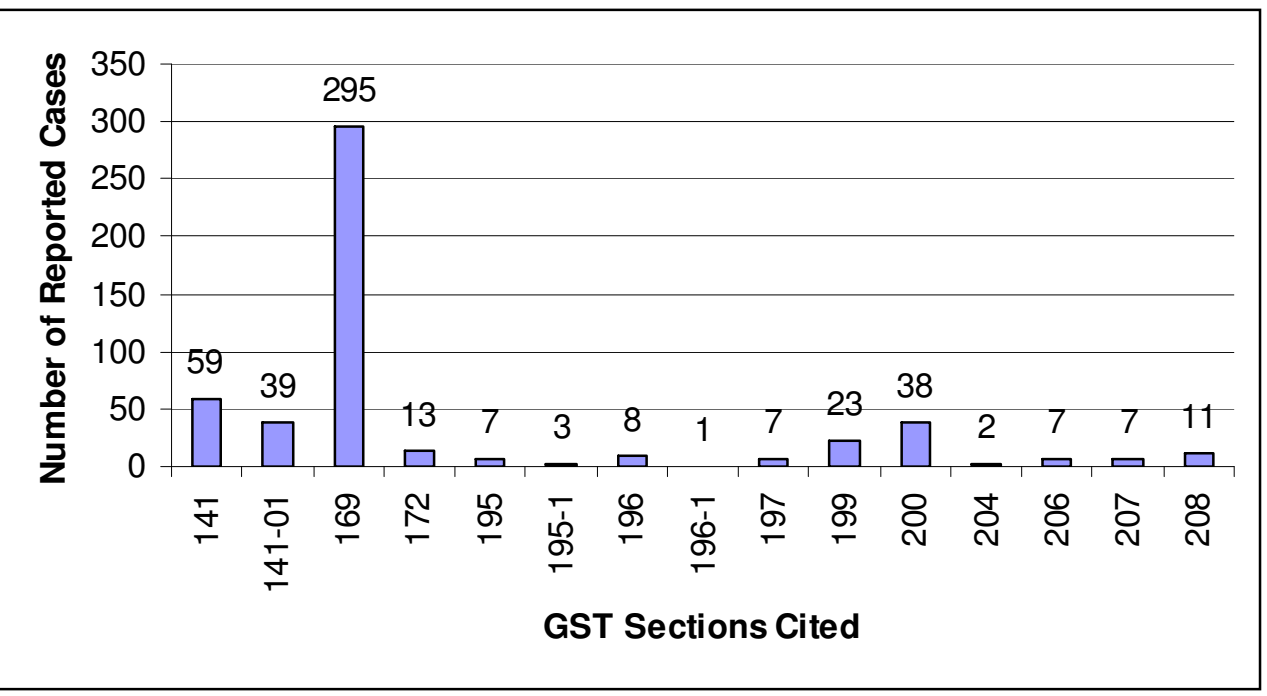

The volume of litigation between the apportionment line of cases ${ }^{103}$ and the adjustment line of cases that apply the primary purpose test ${ }^{104}$ does not immediately provide any clear indications as to the comparative success of the two distinct approaches. The adjustment line of cases, comprise 58 reported cases, ${ }^{105}$ compared to the apportionment line of cases that comprise approximately 334 cases (although 295 of those cases relate to input tax entitlement). ${ }^{106}$

A better comparison can be made in relation to those cases that have only examined change-in-use issues. Of those cases that are identified as change-in-use cases (and excluding the self-supply rules for builders in s 191 and transitional rules cases), all 11 cases relate to capital property. ${ }^{107}$ Of those 11 cases, 5 cases related to the

${ }^{102}$ Figures obtained from Carswell's TaxNetPro by searching reported GST cases for provisions in the headnote field (as at 20 November 2010).

${ }^{103}$ Excise Act RSC 1985, ss 169, 172, 196.1, 206, 207 and 208.

${ }^{104}$ Excise Act RSC 1985, ss 199 and 200.

105 Three cases have been cited in both s 199 (23 cases) and s 200 ( 38 cases). Of the 23 cases related to s 199, 18 cases related to entitlement to input tax credits under s 199(2) and one case related to change in use under s 199(3).

${ }^{106}$ Of the 295 cases, 191 relate to s $169(1)$.

${ }^{107}$ Figures obtained from Carswell's TaxNetPro by searching for the expression "change in use" across the headnote field. 
adjustment line of cases (ss 199 and 200) and 6 cases related to the apportionment of real property (ss 206, 207 and 208). Unfortunately, this does not provide a clear winner, apart from perhaps the fact that there are very few cases identified as relating to change-in-use, in comparison to the total number of reported GST cases (eg, 11/2424).

A comparison might also be obtained by comparing cases that have examined apportionment (16 cases), ${ }^{108}$ or are related to the "fair and reasonable" application of apportionment under s 141.01 (39 cases). ${ }^{109}$ This does appear to illustrate that there is far less litigation about the application of apportionment (16 or 39 cases) than in relation to the adjustment line of cases (58 cases). However, comparing the total number of cases under ss 199(3) and 200 (which also total 39 cases) would suggest there is no difference in the extent of litigation.

Overall, it would appear there are no strong comparative differences in the litigation of the apportionment or primary purpose approaches to change-in-use within Canada. Whether this is compounded by a parallel difference in transaction type (eg, personal vs real property) is unclear. It could be suggested that capital personal property (eg, business assets) maybe less prone to rigorous audit due to its nature and lower value. Real property, on the other hand is normally higher in value and therefore may be more prone to the watchful eye of the CRA, in its protection of the tax revenue base. However, it has been suggested by some commentators that a common exploitation of GST in Canada is the personal use of business assets (ie, business assets are frequently used for personal use). ${ }^{110}$

\footnotetext{
${ }^{108}$ Figures obtained from Carswell's TaxNetPro by searching for the expression "apportionment" across the headnote field.

${ }^{109}$ Figures obtained from Carswell's TaxNetPro by searching for the provision across the headnote field. Although TaxNetPro records 47 related cases under its "judgments" tab.

${ }^{110}$ B Ketterman "VAT? A Look Inside Canada's Experience with Goods and Services Tax" 8 San Diego International Law Journal (2006) 275 citing G Carlson Value Added Tax: European Experience and Lessons for the United States (1980) 59, fn 5.
} 
Whether this is a reflection of audit activity is hard to determine. The general impression provided by the CRA is that audit activity is high. ${ }^{111}$ Certainly the increasing number of disputes resolved by the CRA commodity tax dispute resolution service (see Table 3.5), would appear to indicate it is high. ${ }^{112}$

Table 3.5: Commodity Tax Disputes

\begin{tabular}{|l|l|l|}
\hline Year & Intake & Resolved \\
\hline $2007-08$ & 7,146 & 6,504 \\
\hline $2008-09$ & 6,906 & 6,903 \\
\hline $2009-10$ & 8,151 & 6,778 \\
\hline
\end{tabular}

\section{Audit activity}

According to the CRA, one indicator of audit compliance is GST registration, which steadily improved from when the CRA first began measurement in 2003-04, from 86.6 per cent to 98.4 per cent in 2007-08 (dropping to 93.5 per cent in 2009-10). ${ }^{113}$ Another indicator of audit compliance is GST revenue, which according to the CRA Annual Report was steadily growing until several GST rate reductions (illustrated in Figure 3.5). ${ }^{114}$

Other data also appears to suggest compliance is high. For example, the estimated percentage of businesses identified by the CRA with significant non-compliance fell from over 9 per cent in 1998-99 to less than 4 per cent in 2003-04. ${ }^{115}$ By 2008-09, it

${ }^{111}$ Canada Revenue Agency Annual Report (2009-10) 74 and Canada Revenue Agency Annual Report (2007-8) 20-21. Document available at http://www.cra-arc.gc.ca/gncy/nnnl/menu-eng.html (viewed 20 March 2011).

112 The CRA provides a commodity tax dispute resolution service that includes GST issues, as part of a wider tax dispute resolution system. Taxpayers can dispute GST assessments through a CRA provided dispute resolution process and if they are not satisfied can then appeal to the Courts. Income tax disputes comprised about 90 per cent of the files received by this service.

${ }^{113}$ Canada Revenue Agency Annual Report (2009-10) 31.

${ }^{114}$ Canada Revenue Agency Annual Report (2007-08) 25.

${ }^{115}$ Canada Revenue Agency GST/HST Regulatory Compliance Evaluation Study Non-Registration (Government of Canada, Ottawa, July 2008). Document available at <www.cra- 
was estimated at 5.5 per cent and the total dollar value of identified non-compliance ranged between C\$12.2 million (in 2007-08) and C\$14.4 million (in 2009-10). ${ }^{116}$

Figure 3.5: Growth in Net GST/HST Revenue ${ }^{117}$

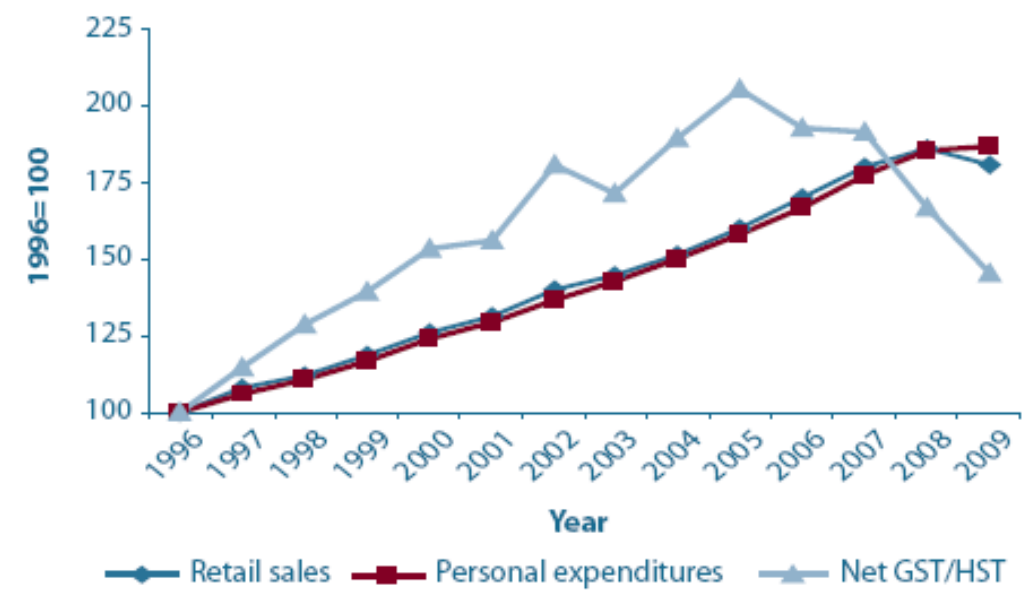

The CRA also launched a major 'risk analysis' program in 2000 (though not fully implemented until 2004) which was partly focused on fraudulent refund claims. For three fiscal years (2001-02, 2002-03 and 2003-04), approximately 1,300 GST returns with fraudulent refund claims (totalling C $\$ 9$ million) were detected. ${ }^{118}$ In the 200607 fiscal year the CRA observed that about 600,000 "non-compliance occurrences" resulted in additional GST assessments of C $\$ 1.1$ billion and 63,000 GST audits yielded an additional $\mathrm{C} \$ 600$ million.

The evidence would appear to suggest that the level of audit activity is high.

However, it is unclear whether this translates to an equal audit focus on capital personal property, as well as real property. It might be that the level of litigation around capital personal property is far lower than what it perhaps could (or should) be, and this may have skewed the litigation data to give a false impression that the

arc.gc.ca/gncy/ntrnl/2008/rgst-cmp-vl-eng.html> cited in RM Bird and PP Gendron "Sales Tax in Canada: The GST- QST-PST System” (2009) 63 Tax Law Review 517 at 538, fn 89.

${ }^{116}$ Canada Revenue Agency Annual Report (2009-10) 36-37.

${ }^{117}$ Canada Revenue Agency Annual Report (2009-10) 38.

${ }^{118}$ Canada Revenue Agency The Canada Revenue Agency: The First Five Years (Government of Canada, Ottawa, 2005) 61, cited in RM Bird and PP Gendron "Sales Tax in Canada: The GST- QSTPST System” (2009) 63 Tax Law Review 517 at 538, fn 88. 
adjustment approach (eg, primary purpose test) is no worse or better than an apportionment approach. Furthermore, almost a decade after the introduction of the GST, the Auditor-General of Canada was still pointing out serious flaws in GST administration, particularly with respect to audit. ${ }^{119}$

\section{Revenue Authority Guidance}

The Canada Revenue Agency (CRA) publishes a wide variety of technical publications on how the GST and HST legislation is applied. ${ }^{120}$ Unlike New Zealand or Australia, the CRA does not issue general public rulings. However, the CRA does issue private rulings (called "application rulings") and considers itself bound with respect to the particular taxpayer that the ruling is issued, and provided the material facts were not misstated and the law or administrative policy has not changed since the ruling was issued. ${ }^{121}$

Table 3.6 illustrates the volume of guidance (ie, rulings, interpretation and policy statements, and HQ letters) provided in relation to the main apportionment and adjustment provisions. Figures 3.6 to 3.11 illustrates the publication volume and timing of these documents. Generally, there have been few rulings issued, except in regard to s 169. Of the rulings issued, the majority appear to have been issued in the first 10 years. The main method of guidance for registered entities appears to be HQ Letters that make pronouncements on the interpretation of legislation in relation to specific issues for particular entities. Similar to interpretation and policy statements, the HQ letters are not binding. It would appear that the preferred method of CRA guidance in the last 10 years has been HQ letters. Unfortunately these documents lack the detail provided in rulings or interpretation statements.

\footnotetext{
${ }^{119}$ Office of the Auditor General of Canada Report of the Auditor General of Canada (Government of Canada, Ottawa, 1999).

${ }^{120}$ For example, the Canada Revenue Agency Memoranda Series, Technical Information Bulletins (TIBs), Interpretation and Policy Statements, Quarterly Newsletters, Information Sheets, and Application Rulings. Documents available at $<w w w . c r a . g c . c a / g s t h s t t e c h>,<w w w . c r a-$ arc.gc.ca/menu/GTIB_50-e.html> (TIBS), <www.cra-arc.gc.ca/menu/GTPP_50-e.html> (interpretation statements).

${ }^{121}$ See Phelps Appliances Ltd v Deloitte \& Touche [1999] GSTC 13 (BCSC), where the CRA refused to honour a ruling because not all of the facts had been disclosed.
} 
Table 3.6: CRA Guidance Materials (1991-2010) ${ }^{122}$

\begin{tabular}{|l|c|c|c|}
\hline Section & Application Rulings & HQ Letters & $\begin{array}{c}\text { Interpretation \& } \\
\text { Policy Statements }\end{array}$ \\
\hline 141.1 & 3 & 36 & 12 \\
\hline 169 & 52 & 35 & 24 \\
\hline 199 & 5 & 10 & 1 \\
\hline 200 & 3 & 3 & 0 \\
\hline 206 & 3 & 13 & 2 \\
\hline 208 & 1 & 4 & 45 \\
\hline Total & 67 & 101 & \\
\hline
\end{tabular}

Overall, the documents do provide evidence of considerable work undertaken by the CRA to provide guidance on the issue of apportionment and to a lesser extent adjustments. This may well have contributed to a lower level of litigation in relation to the total volume of reported GST cases when compared to New Zealand or Australia.

Figure 3.6: CRA Documents for Section 141.1 (1991-2010)

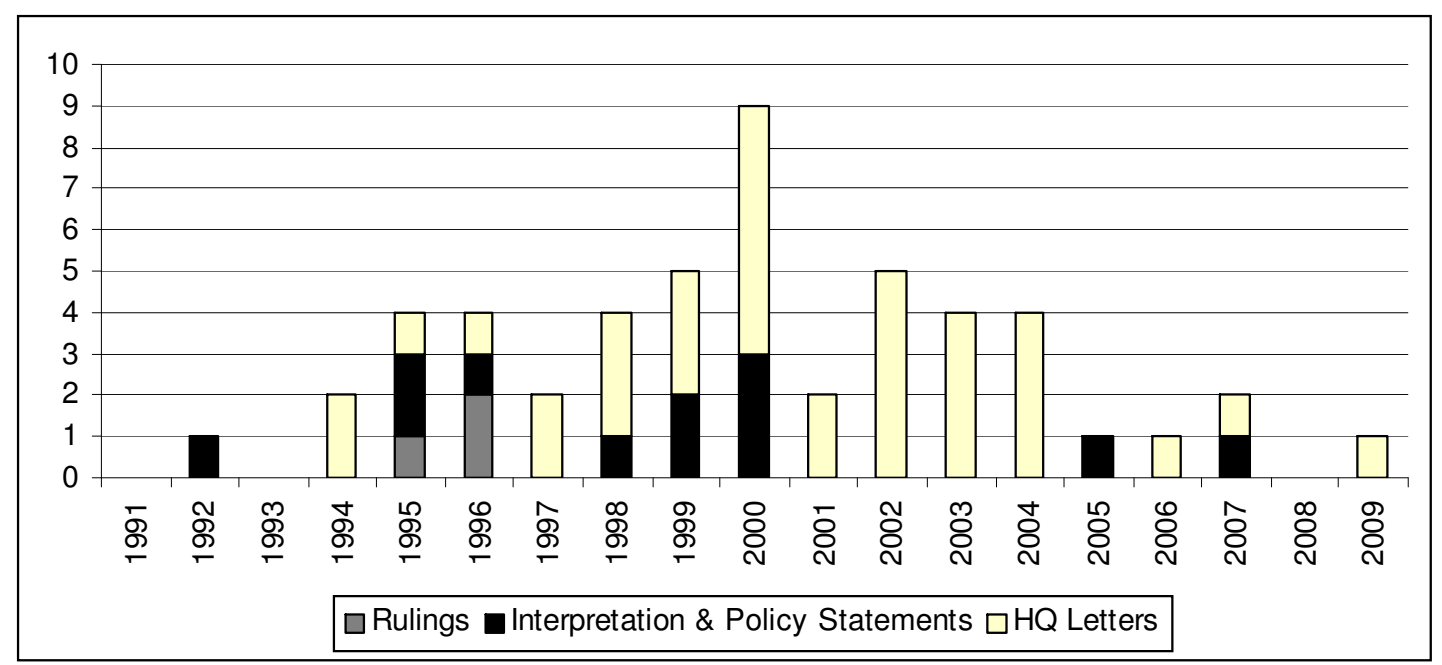

${ }^{122}$ Figures were acquired from research across Carwell's TaxNetPro listed under the "government" publications tab of each provision (20 November 2010). 
Figure 3.7: CRA Documents for Section 169 (1991-2010)

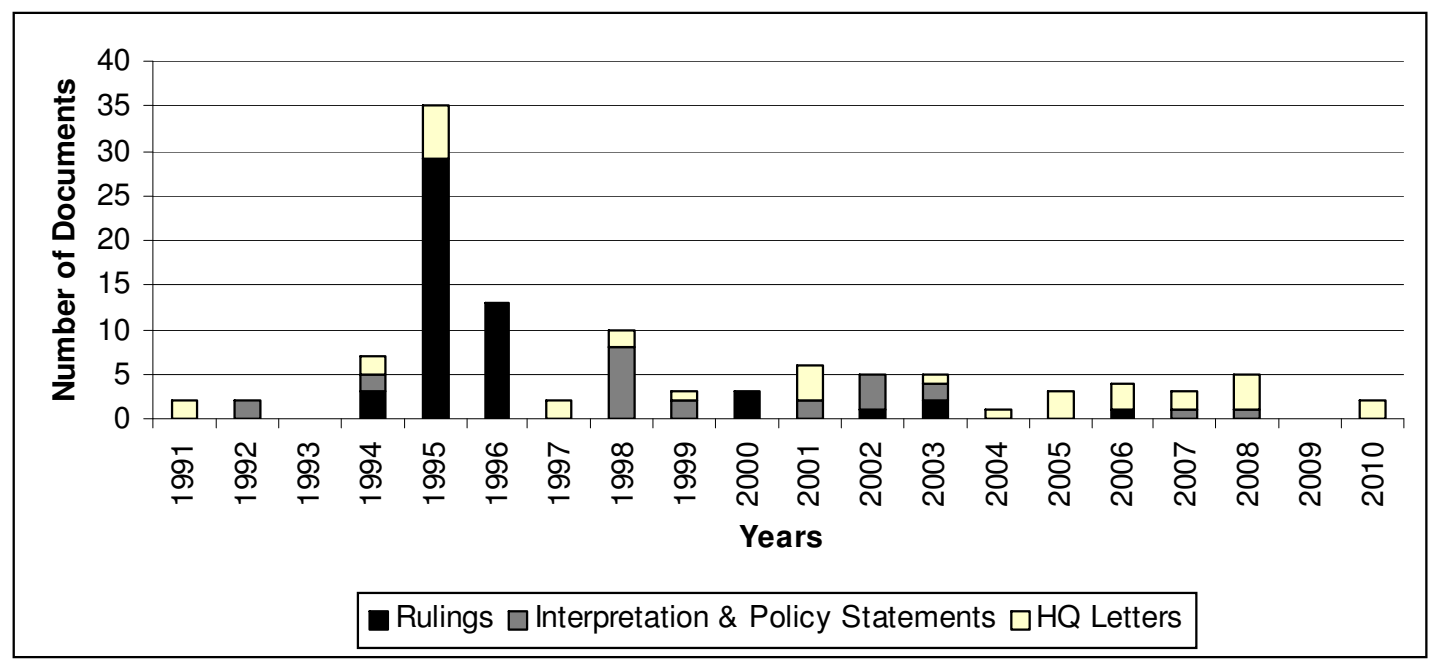

Figure 3.8: CRA Documents for Section 199 (1991-2010)

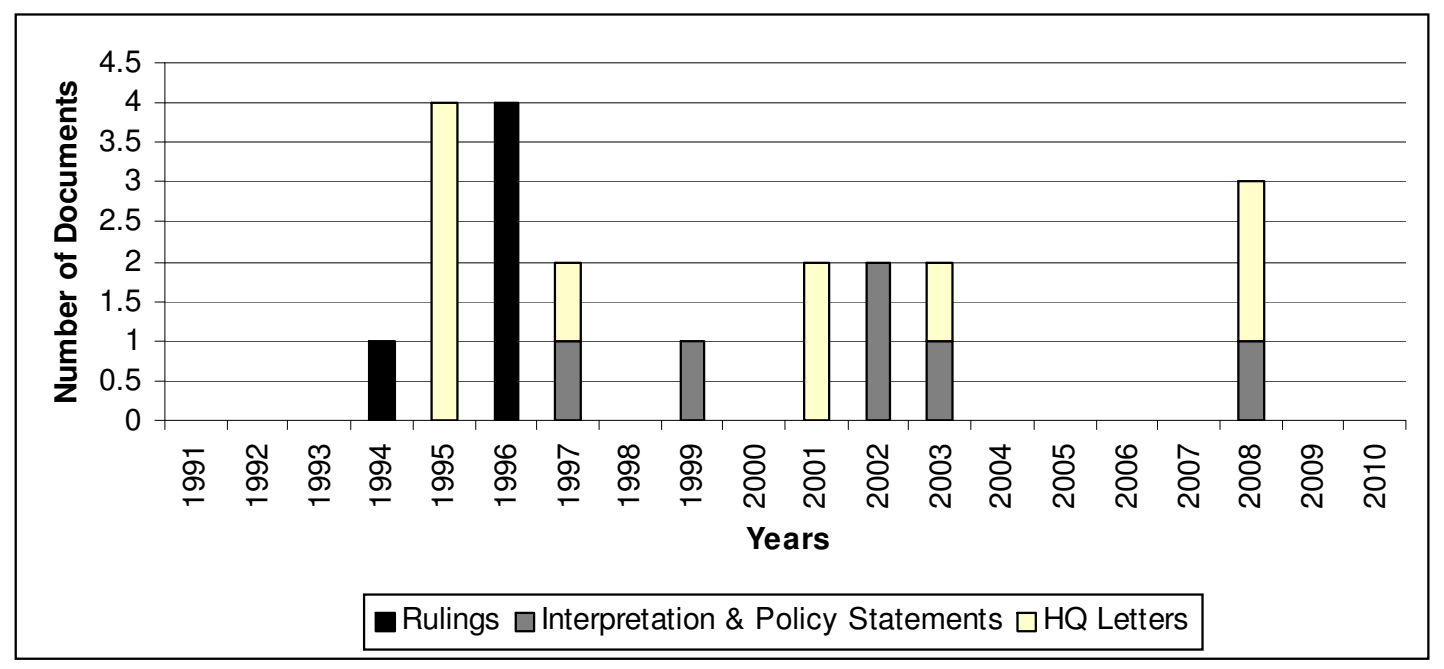

Figure 3.9: CRA Documents for Section 200 (1991-2010)

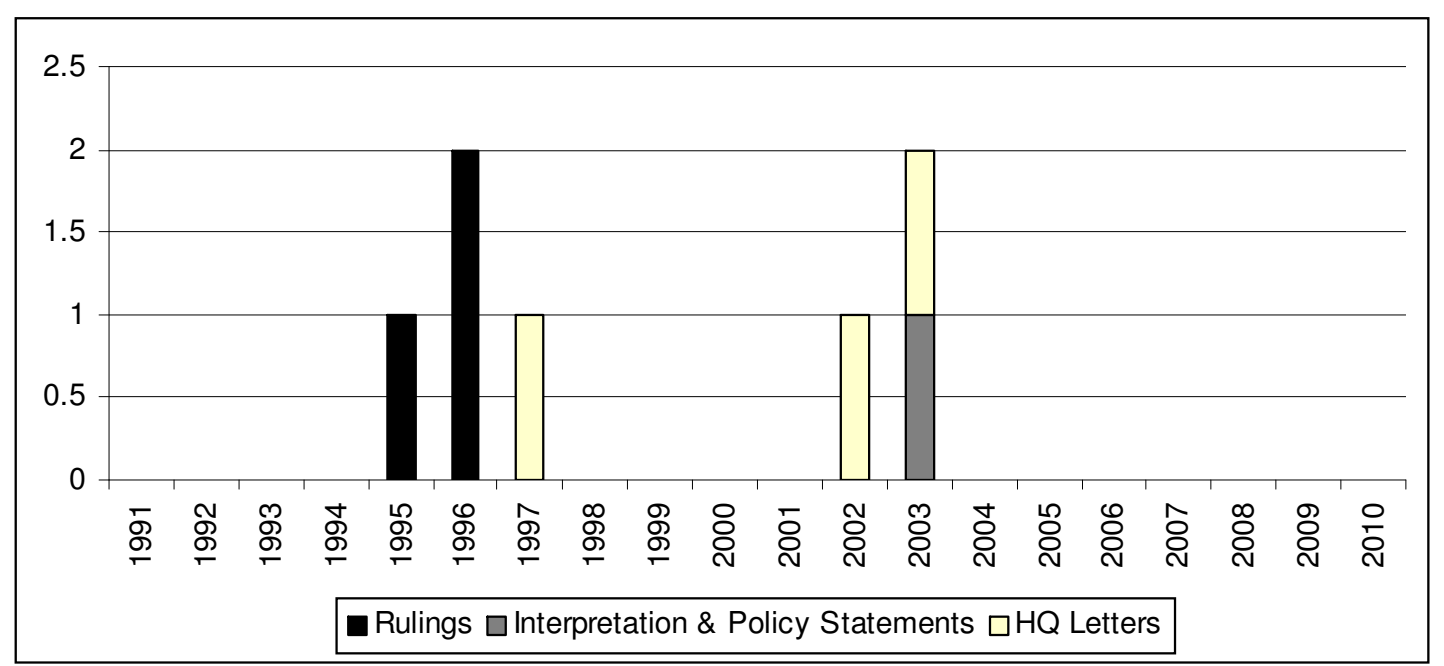


Figure 3.10: CRA Documents for Section 206 (1991-2010)

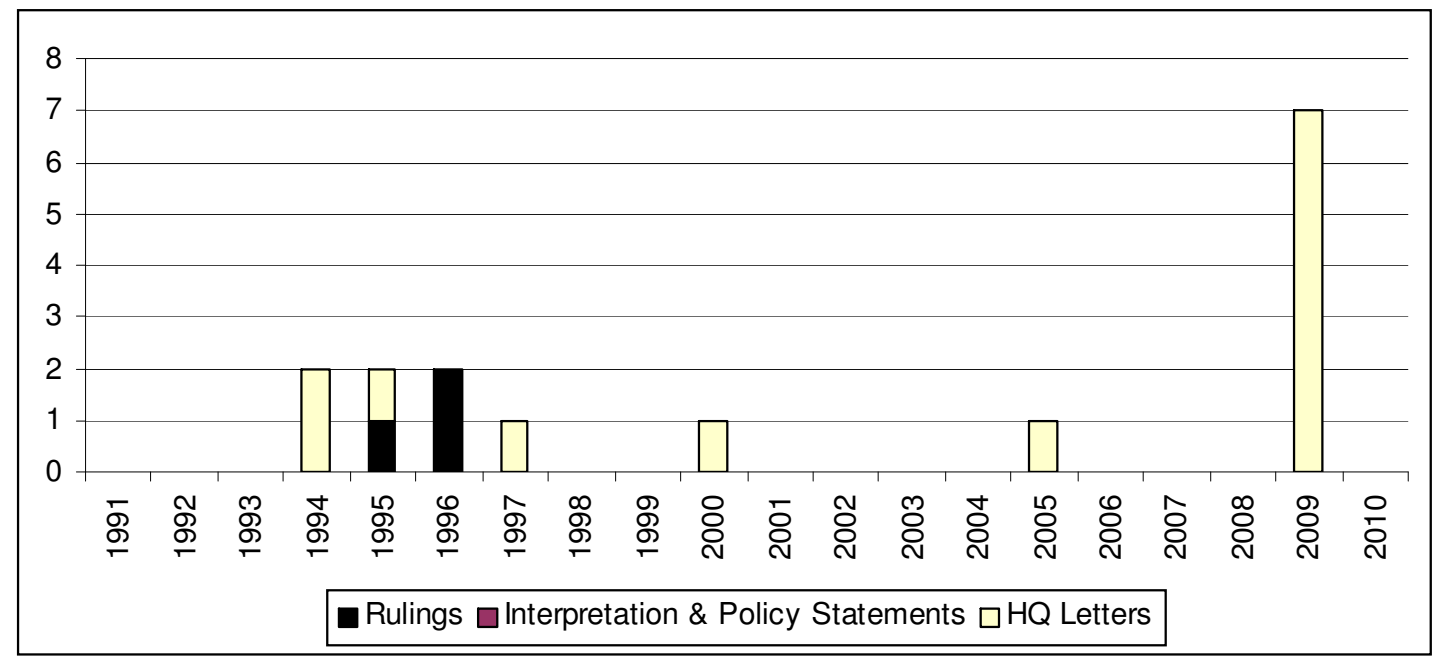

Figure 3.11: CRA Documents for Section 208 (1991-2010)

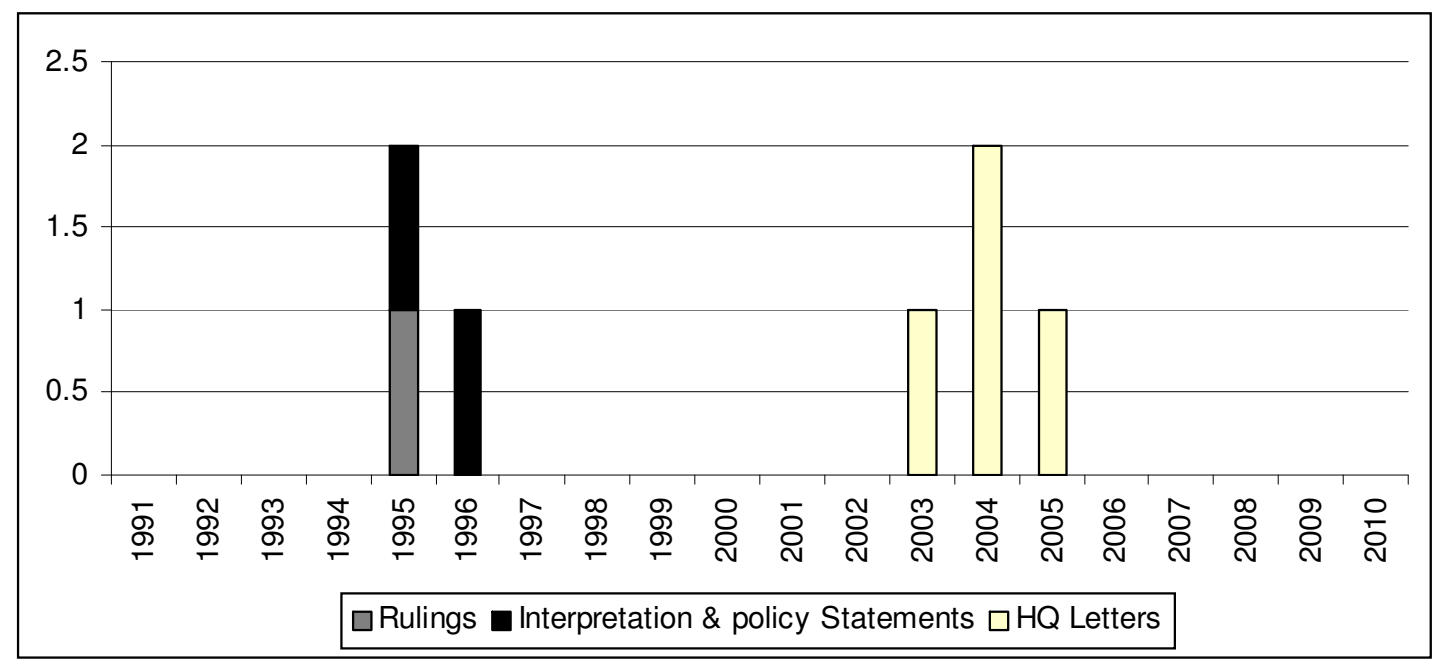

\section{J. Compliance Concerns}

Why does the Canadian GST legislation create a distinction between capital and noncapital property? No such distinction exists in the Australian or New Zealand GST legislation. ${ }^{123}$ The answer may lay in initial compliance concerns raised when the GST legislation was first being formulated.

${ }^{123}$ Calls for a similar distinction for capital assets has been suggested (in relation to financial acquisition thresholds) in submissions on the reform proposals of Australian GST Act. For example, Australian Financial Markets Association (AFMA) Submissions on the Treasury Report (12 June 2009) 3. Document available at 
According to a Technical Paper on GST $T^{124}$ (that provided an overview of the objectives and operation of the proposed GST legislation), the capital property distinction was created to reduce the "complex calculations and burdensome recordkeeping" that would be involved if apportionment was adopted for capital property - particularly, when the useful life of capital property extended over a number of years.

As the Technical Paper acknowledges: ${ }^{125}$
"Under the normal input tax credit rules, a credit for the GST paid on a capital good would be allowed to the extent that the asset is for use in a commercial activity. For example, if the asset was for use 60 per cent in a commercial activity, then 60 per cent of the GST would be creditable on acquisition. Adjustments would be required, however, every time the commercial usage of the asset changed. Given that the useful life of capital goods generally extends over a number of years, the frequent application of change-of-use rules would involve complex calculations and burdensome record-keeping in many cases.

Therefore, to simplify the operation of the GST, an exception to the normal input tax credit rules will apply in the case of capital goods. Unlike inventory and other business purchases which will be creditable to the extent they are for use in a commercial activity, a full input tax credit will be allowed in respect of a capital good if it is acquired for use primarily in a commercial activity. If this condition is not satisfied, then no part of the tax will be creditable. Similar rules will apply in determining any input tax credits in respect of improvements to capital goods.

Where the use of a capital asset for which an input tax credit has been claimed subsequently fails to satisfy the primarily commercial use test, the registrant will be deemed to have disposed of the asset and be required to account for GST on the asset's fair market value at that time."

But has this policy aim been achieved? According to Bird, the administrative burden of GST "does not seem excessive”, although Bird acknowledges that it is difficult to

\footnotetext{
<www.treasury.gov.au/documents/1578/PDF/Australian_Financial_Markets_Association.pdf> (viewed 20 March 2011).

${ }^{124}$ Department of Finance Technical Paper on GST TP0889 (Canada, 8 August 1989). See also TP1289 Technical Paper on GST (19 December 1989).

${ }^{125}$ Department of Finance TP0889 Technical Paper on GST (8 August 1989) at [2.3].
} 
be very precise since little information is available. ${ }^{126}$ However, for many commentators, the ITC rules place a significant administrative and compliance costs on registered entities. ${ }^{127}$ For many small businesses and especially service firms, GST constituted an unwanted additional compliance burden. ${ }^{128}$ As Schinnour observes: ${ }^{129}$

"These rules combined with the change in use rules place significant onus on the registrant to track the use of capital and real property both in calculating the initial input tax credit entitlement and in accounting for any subsequent changes in use."

The change-in-use rules are considered quite complex, due to the different rules for capital goods. Schenk has suggested that the rules could be simplified (and the "capital property" distinction removed) by limiting the rules to changes to assets above a set threshold value - a proposal that is striking similar to the Australian approach. $^{130}$

Schinnour's observation would appear to suggest that regardless of litigation volume, tracking use under either an apportionment or adjustment approach continues to impose high compliance costs on taxpayers. It would also appear to suggest that there is no sizeable advantage in Canada for either approach - if the measure of success is tracking costs.

It may well be that this desire to reduce the compliance burden for change-in-use was the underlying reason for New Zealand initially adopting a similar input tax credit test (eg "principal purpose"). ${ }^{131}$ Unfortunately, the New Zealand courts appear

${ }^{126}$ RM Bird and PP Gendron "Sales Tax in Canada: The GST- QST-PST System" (2009) 63 Tax Law Review 517 at 538.

$127 \mathrm{~J}$ Whalley and D Fretz The Economics of the Goods and Services Tax (Canadian Tax Foundation, Toronto, 1990).

${ }^{128}$ Plamondon and Associates Inc GST Compliance Costs for Small Business in Canada (Department of Finance, Ottawa, 1993), cited in RM Bird and PP Gendron, "Sales Tax in Canada: The GST- QSTPST System” (2009) 63 Tax Law Review 517 at 540, fn 93.

${ }^{129}$ AW Schinnour "GST Tips \& Traps" (Spring 1994) 7(1) Canadian Petroleum Tax Journal 1 at [59].

${ }^{130}$ A Schenk and O Oldman Value Added Tax: A Comparative Approach (Cambridge Tax Law Series, Cambridge University Press, 2007) 124.

${ }^{131}$ Certainly there were concerns raised in submissions to the GST Bill. The Australian reform submissions have also raised similar concerns. 
to have increased the compliance burden by subsequently adopting a less stringent test that increased the opportunity for change-in-use adjustments (and therefore the compliance costs of tracking).

\section{K. Analysis}

Given the length of time the GST legislation has had to bed down it should not be surprising that a sizeable bank of case law has been established - a picture not dissimilar to New Zealand's own experience. However, what is surprising is that the amount of case law on the change-in-use rules that has been established is not substantial. ${ }^{132}$ This is especially the case when you compare the relative size of the economies or the tax revenue generated from the respective GST systems is taken into account.

In comparison to both New Zealand and Australia, the Canadian GST legislation has adopted a very prescriptive approach, rather than providing more general (and flexible) rules. The approach is far from simple. ${ }^{133}$ The legislation has made a conscious effort to provide a high level of consistency with the income tax legislation when it was initially drafted and this is evident in the change-in-use rules. The object was no doubt in order to provide greater clarity and reduce the need to relitigate similar issues. As Bird and Gendron, observe: ${ }^{134}$

\footnotetext{
“... GST in Canada is definitely not a simple tax. The original law was long and complicated owing to the many special treatments of different sectors and activities already mentioned. It was also complex because many aspects of the income tax law were carried over into the GST. ... the scope of the Canadian GST was deliberately designed to be more comprehensive than that of most European VATs"
}

The result is very lengthy and repetitive provisions that focus on specific transactions (eg, vehicles or land), assets (eg, capital vs real vs non-capital), and entity (eg,

\footnotetext{
${ }^{132}$ For example, "primary purpose" is either $11 / 2424$ or $39 / 2424$, and "apportionment" is either $16 / 2423$ or $39 / 2424$.

${ }^{133}$ Numerous other instances of the complexity of the GST system are detailed in RM Bird "The Cost and Complexity of Canada's VAT: The GST in International Perspective" (1994) 8 Tax Notes International 37.

${ }^{134}$ RM Bird and PP Gendron "Sales Tax in Canada: The GST- QST-PST System" (2009) 63 Tax Law Review 517 at 534.
} 
builders) types. Unfortunately, it is difficult to conclude with any certainty whether the prescriptive approach adopted by Canada has provided a greater degree of certainty for taxpayers (as evidenced by the low volume of litigation) and therefore reduced compliance costs, due to the existence of other complicit factors (eg, a high volume of CRA guidance, or the consistency with income tax legislation). In fact it might well be suggested that the amount of CRA guidance is evidence of the high cost in interpreting and translating complex rules, so that they can be easily applied by taxpayers (thus avoiding potential litigation).

While there have been minor technical changes that have accommodated the arrival of HST, there has not been any fundamental reform of the change-in-use rules. The lack of reform (or lack of widespread calls for reform) in this area would appear to indicate that the rules are generally working well. Unfortunately, it is also difficult to conclude if the absence of reform indicates that it is working well, or that the political system has avoided a wider examination of the GST system, for fear of opening the door too wide to its repeal.

\section{Conclusion}

The adoption of both approaches to change-in-use has provided a unique opportunity to compare the approaches under similar conditions, as well as compare them to the approaches in New Zealand and Australia. Unfortunately, it is hard to conclude which approach (apportionment or adjustment) has performed better in Canada. Whether this is attributable to the manner in which the rules have been crafted, the legislative drafting, audit activity, or the guidance provided by the CRA is unclear. It may well be due to the interplay of all these elements.

Clearly, the change-in-use rules have been successful in terms of legal compliance. The number of reported GST cases that have considered the change-in-use rules is very low, both in terms of reported cases in Canada and in comparative terms with New Zealand and Australia. This would appear to suggest that there is a high degree of clarity and compliance with the rules. While audit activity appears to be high, it is not clear if there is an audit bias towards non-capital and real property that uses an apportionment approach. Anecdotal observation indicates there could well be such a bias. If this is the case, then it is probable that the apportionment approach produces more favourable cost savings in terms of reduced litigation, than the evidence 
provides. Equally the low level of litigation may demonstrate a high degree of clarity with the rules due to substantial guidance from the CRA. The fact the legislation has drawn on comparable change-in-use rules from the income tax legislation may have helped. It certainly does not appear to have hindered.

Judicial consideration of the "fair and reasonable" test in Canada will be of substantial assistance to New Zealand courts and will provide much needed certainty with the application of the new rules.

Clearly, the distinctions made between capital and non-capital are worth exploring in more detail, if different approaches have resulted in reduced litigation for both. As alluded to above, this may just be the result of adopting existing income tax rules. Certainly, calls in Australia for such distinctions to be made in order to reduce compliance costs warrant further investigation both in New Zealand and Australia. 
"if taxes had existed in the Garden of Eden, the serpent would not have needed an apple; the promise of a simpler tax system alone would have seduced Eve."”

\section{A. Introduction}

During the course of comparing the Australian, Canadian and New Zealand changein-use provisions it became apparent that each jurisdiction has adopted different policies in resolving and measuring change-in-use. Australia had adopted apportionment, New Zealand had originally adopted a threshold adjustment approach (eg, principal purpose), and Canada had a mix of both policies depending on the nature of the property (eg, capital vs non-capital vs real). ${ }^{2}$

It also became apparent that each jurisdiction had adopted styles of drafting (eg, plain language or classic legislative drafting). New Zealand was the only jurisdiction that had different drafting styles between direct and indirect tax legislation. In contrast, Australia and Canada have maintained similar drafting styles between direct and indirect tax legislation and this appeared to more readily enable concepts to be shared where appropriate (eg, apportionment). At present, Australia has completed the rewrite of its GST legislation (rewritten upon enactment) into plain language, and has made it half-way through a rewrite of its income tax legislation. In contrast, New Zealand and Canada have not rewritten their respective GST Acts, although New Zealand has completed rewriting its Income Tax Act.

Within this matrix of different policies and drafting styles, each jurisdiction has experienced different outcomes. Both Australia and Canada have experienced minimal litigation. In contrast, the original New Zealand rules have experienced a much higher level of litigation activity. Why was this? Does drafting style explain the different outcomes, or is it policy (ie, an apportionment or adjustment approach)?

1 A Abreu "Untangling Tax Reform: Simple Taxes, Complex Choices" (1996) 33 San Diego Law Review 1355, as cited in GS Cooper "Legislating Principles as a Remedy for Tax Complexity" (2010) British Tax Review 334.

2 Canada, had not adopted the methodological thresholds used in Australia (and to be adopted in New Zealand from 1 April 2011) in applying an apportionment approach, preferring instead the common law approach developed from Canadian income tax law. 
With this question in mind, it appeared that this comparative study provided a good case study to determine whether the expression of New Zealand's change-in-use rules (and the wider GST Act) are unnecessarily complex in comparison to other jurisdictions. Significantly, this study provides for the first time, a much broader assessment of the readability of the entire New Zealand GST Act and the potential impact it might be having on compliance costs for business taxpayers.

\section{B. Tax Complexity and Legislative Simplification}

\section{Definitions of tax complexity}

There are many definitions of tax complexity. No doubt this is because complexity (and simplicity), like various other concepts used to measure performance (eg, efficiency or equity), are concepts lacking simple definitions.

White, ${ }^{3}$ suggests a complex law is one that requires a greater volume of information (other than the legislation) in order to accurately predict the outcome of a dispute. ${ }^{4}$ Alternatively, it has been suggested that tax complexity is primarily related to compliance costs. ${ }^{5}$ The higher the cost of compliance (eg, large volumes of litigation), the more complex the legislation will be. According to James et al, ${ }^{6}$ the New Zealand GST Act, for its comparative size, attracts almost as much litigation as income tax. At present, the New Zealand GST Act has accumulated approximately 349 reported GST cases (and growing) since its enactment (with 532 reported cases having cited or considered GST provisions). ${ }^{7}$

3 MJ White "Why are Taxes so Complex and Who Benefits" (1990) Tax Notes International 341 at 342. See also AJ Sawyer "Why Are Taxes So Complex and Who Benefits (1996) Tax Notes International 1,337 at 1,338 .

4 This argument is consistent with the principle of predictability.

5 J Slemrod "Complexity, Compliance Costs and Tax Evasion" in JA Roth and JT Sloth (eds) Taxpayer Compliance (University of Pennsylvania Press, Philadelphia, 1989) 156, cited in M Richardson and A Sawyer "Complexity in the Expression of New Zealand's Tax Laws: An Empirical Analysis" (1998) 14 Australian Tax Forum 325 at 328.

${ }^{6}$ S James, A Sawyer and I Wallschutzky "The Complexities of Tax Simplification: Progress in Australia, New Zealand and the United Kingdom” (1998) 14 Australian Tax Forum 29 at 32.

7 See Chapter 1 (The New Zealand Experience). As discussed in Chapter 1, the New Zealand changein-use rules have experienced a disproportionately high volume of litigation (in comparison to either 
Such attempts at providing a broad definition often invite categorisation of different types of complexity. Milliron ${ }^{8}$ identified four dimensions of complexity: the nature of the topic; the quantitative nature of presentation; the vulnerability of law to misuse; and the readability of law. During the consultative phase of the Australian tax rewrite, the Ralph Committee suggested three broad categories of complexity: technical complexity (eg, ascertaining the meaning of tax law); structural complexity (eg, poor structuring of provisions and the unintended or inconsistent interaction of different provisions); and compliance complexity (eg, the excessive burden of compliance activity, information demands, record keeping). ${ }^{9}$ A comprehensive review of the various compliance studies is provided by McKerchar, ${ }^{10}$ Tan \& Sawyer, ${ }^{11}$ and Sawyer. ${ }^{12}$

This case study will evaluate the tax complexity of the respective change-in-use provisions across the three jurisdictions in terms of structural and technical complexity. ${ }^{13}$ It will not only evaluate readability (ie, the ability to ascertain meaning and be understood), but will also examine their structure (ie, total words and paragraphs-per-provision, use of definitions, exceptions, provisos and external legislative references).

Australia or Canada), and this would tend to suggest that the New Zealand GST rules are overly complex.

8 VC Milliron “A Behavioural Study of the Meaning and Influence of Tax Complexity” (1985) 23 Journal of Accounting Research 794 at 807.

9 Review of Business Taxation A Strong Foundation (23 November 1998) at [3.1]. Document available at: <www.rbt.treasury.gov.au/publications/paper1/index.htm> (viewed 20 March 2011).

${ }^{10}$ M McKerchar The Impact of Complexity Upon Tax Compliance: A Study of Australian Personal Taxpayers (Australian Tax Research Foundation, Sydney, 2003) Chapter 2.

${ }^{11}$ LM Tan and A Sawyer "A Synopsis of Taxpayer Compliance Studies: Overseas Vis-Vis New Zealand” (2003) 9 New Zealand Journal of Taxation Law and Policy 431.

12 AJ Sawyer "Enhancing Compliance Through Improved Readability: Evidence from New Zealand's Rewrite 'Experiment"” (2011) IRS Research Bulletin 225 (publication forthcoming).

${ }^{13}$ The methodology and results of the study are explained below. 


\section{Reasons for tax complexity}

A number of explanations for tax complexity have been advanced by commentators. According to Richardson \& Sawyer, ${ }^{14}$ the most common explanation is one advanced by Sir Ivor Richardson, who suggests that tax legislation is inherently complicated due to the nature of the topic and the perverse incentives for the main protagonists (eg, the revenue authority and tax advisors) to be continually in combat over the exploitation of those rules. ${ }^{15}$ According to Sir Ivor Richardson: ${ }^{16}$

\footnotetext{
"the greater the burden of income tax, the greater the effort on the part of taxpayers, and their astute advisers, to utilise the advantages of the system so as to minimise the total tax paid in respect of their productive efforts. In turn, the draftsmen of tax legislation recognise that, to an extent not met in other areas, entry into commercial transactions and the shaping of commercial transactions will be influenced by the detail of legislation."
}

Adding: ${ }^{17}$

"Such legislation is invariably long and complex, reflecting the inevitable compromises that the subject matter demands, and it bears the hands of many draftsmen in the numerous amendments made over the years. So it is unwise to expect perfect logical symmetry in the drafting, particularly of provisions which are not closely related."

However, Sir Ivor Richardson was also mindful that it was important that tax legislation should not become inordinately long and complex. ${ }^{18}$

White goes further to suggest that the protagonists (eg, the revenue authority and tax advisors) have vested interests in maintaining tax complexity in order to maximise

${ }^{14}$ M Richardson and A Sawyer "Complexity in the Expression of New Zealand's Tax Laws: An Empirical Analysis" (1998) 14 Australian Tax Forum 325 at 328.

15 ILM Richardson “The Concept of Income and Tax Policy” (1990) 4 Canterbury Law Review 187.

${ }^{16}$ ILM Richardson “Appellate Court Responsibilities and Tax Avoidance” (1986) 3 Australian Tax Forum 3 at 4.

${ }^{17}$ ILM Richardson “Appellate Court Responsibilities and Tax Avoidance” (1986) 3 Australian Tax Forum 3 at 8 .

${ }^{18}$ As the evidence provided in this paper suggests, not only are sentences inordinately long in the provisions of the New Zealand GST Act, but the GST Act as a whole can be categorised (on the basis of the FRE index) as inordinately complex and unreadable. 
their respective incomes. ${ }^{19}$ Dabner \& Burton describe this conflict in terms of liberal individualism which views taxation as the compulsory expropriation of a person's private property. ${ }^{20}$ From this perspective, the individual is entitled to minimise (by legal means), the extent to which the state expropriates an individual's wealth. Under this model the tax authority administers and applies the law with a view to maximising government revenue and pursuing government policy, whilst the tax advisor's ethical obligation is to minimise the tax liabilities of its clients by employing tax planning techniques and asserting interpretations of the tax law that are to the advantage of their client. However, while these theoretical models (which are very similar to economic models of the selfish consumer) might explain an underlying motivation for maintaining complexity, they do not necessarily explain its birth, which comes from the policy acts (and omissions) of Parliament and expressed in the form of legislation.

As Sir Ivor Richardson recognised, tax legislation does not necessarily have a fully coherent scheme or consistent pattern of purposes. It is this inherent complexity in income tax law that Prebble has described (on numerous occasions) as ectopic. ${ }^{21}$ According to Prebble, the legal concept of income is based on unnatural foundations and tax law is dislocated from its subject matter. Unlike other laws, income tax law recharacterises the actual facts and legal relationships of business activity and is effectively divorced from commercial reality. While direct taxation (eg, income tax) is often identified as ectopic, indirect taxation (which has inherited many income tax concepts in its initial formulation and ongoing application) is also prone (albeit it to

${ }^{19}$ MJ White "Why Are Taxes So Complex and Who Benefits?" (1990) Tax Notes International 341 at 342, See also AJ Sawyer "Why Are Taxes So Complex and Who Benefits (1996) Tax Notes International 1,337 at 1,338 .

${ }^{20}$ J Dabner and M Burton "The Relationship Between Tax Administrators and Tax Practitioners: The Australasian Environment” (2008) 14 New Zealand Journal of Taxation Law and Policy 31 at [2.1].

${ }^{21}$ J Prebble "Should Tax Legislation be Written from a Principles and Purpose Point of View or a Precise and Detailed Point of View?" (1998) British Tax Review 112, updated in (2001) 7 New Zealand Journal of Taxation Law and Policy 235; J Prebble "Ectopia, formalism, and anti-avoidance rules in income tax law" (1994) in W Krawietz, N MacCormick, and GH von Wright (eds)

Prescriptive Formality and Normative Rationality in Modern Legal Systems, Festschrift for Robert $S$ Summers (Duncker and Humblot, Berlin 1994) 367; J Prebble "Philosophical and design problems that arise from the ectopic nature of income tax law and their impact on the taxation of international trade and investment" (1995) 13 Chinese Yearbook of International Law and Affairs 111; J Prebble "Can income tax law be simplified?" (1996) 2 New Zealand Journal of Taxation Law and Policy 187; and J Prebble "Why is tax law Incomprehensible?" (1994) British Tax Review 380. 
a lesser extent due to its more constrained scope) to inherent complexity, disconnection, and perverse results. Although this inherent complexity and perversity in GST legislation is more often due to poor drafting, as the New Zealand Supreme Court recently recognised in Contract Pacific Ltd $v$ CIR. $^{22}$ According to Blanchard $\mathrm{J}^{23}$
"It has to be accepted that the section is poorly drafted. Necessarily, therefore it has to be given a remedial construction so that it can operate without producing perverse results which can never have been within the legislative purpose." (emphasis added)

While the provision examined by the Supreme Court does not relate to the changein-use rules, it nevertheless provides additional empirical evidence that the judiciary have experienced difficulty with the drafting style of the GST Act. ${ }^{24}$ This criticism is supported by the high litigation activity of the original New Zealand change-in-use rules and also the poor readability of many other provisions in the GST Act (as illustrated in the Appendix to this Chapter).

Tax law may also be complex due to the underlying social and economic objectives that tax legislation is called upon to perform - objectives that may not always be consistent with other tax policies and might be forever changing with the tide of governments. ${ }^{25}$ According to James et al, ${ }^{26}$ if the underlying complexity of the tax system and the changing requirements of tax policy are not addressed, tax legislation will continue to be complex, regardless how many times it is rewritten.

Unfortunately no application of plain language rewriting may be able to make a

\footnotetext{
${ }^{22}$ Contract Pacific Ltd v CIR [2010] NZSC 136 (SC).

${ }^{23}$ Contract Pacific Ltd v CIR [2010] NZSC 136 (SC) at [39]. The Court was considering s 46 GSTA 1985 which comprises 530 words, 888 syllables, 27 paragraphs, and 7 sentences. The provision has a word-per-sentence score of 75.71 and a FRE score of -11.8 (or zero), which also happens to be the median average FRE score for the entire GST Act. In lay-terms, s 46 is your typical GST provision.

${ }^{24}$ The Supreme Court was examining the application of s 43 GSTA 1985. Of concern is the empirical evidence of this study, which places the provision in the middle of the readability range. This range appears to suggest that the New Zealand GST Act is complex and difficult to read.

25 J Strader and CE Fogiliasso "An Investigation of Some Factors Affecting Taxpayer NonCompliance" (1989) 20 Accounting and Business Research 39.

${ }^{26}$ S James, A Sawyer and I Wallschutzky "The Complexities of Tax Simplification: Progress in Australia, New Zealand and the United Kingdom" (1998) 14 Australian Tax Forum 29 at 33.
} 
poorly defined policy intelligible. ${ }^{27}$ This position is supported by Cooper in his critique of plain language drafting and its underlying assumption that there is always a clear policy intent (or perhaps a series of basic principles), to be found. ${ }^{28}$

However, while this critique of plain language drafting may be well founded, several empirical studies have also established that the rewriting process has simplified legislation in terms of significant reductions in sentence length and to a lesser degree understanding (as measured by the Flesch Reading Ease index). ${ }^{29}$ This evidence appears to support the argument that simplifying the language of complex legislation would at least be an improvement. Furthermore, while the drafter cannot always influence the complexity of policy, they are still responsible for (and capable of) ensuring everyone who is suppose to comply with it, is able to read and understand it. $^{30}$

A number of commentators have also suggested that tax complexity might have much to do with the manner in which tax rules are drafted and structured, than the underlying policy. ${ }^{31}$ For example, the reorganisation of the New Zealand Income Tax Act (eg, restructuring the organisation of the rules), provided a surprising improvement to readability, without changing the expression or the underlying policy of the rules themselves. ${ }^{32}$

${ }^{27}$ Review of Business Taxation A Strong Foundation (23 November 1998) at [3.1].

${ }^{28}$ GS Cooper "Legislating Principles as a Remedy for Tax Complexity" (2010) British Tax Review 334 at 340-341.

${ }^{29}$ For example, K Saw and A Sawyer "Complexity of New Zealand Income Tax Legislation: The Final Instalment" (2010) 25 Australian Tax Forum 213.

${ }^{30}$ S Krongold "Writing Laws: Making The Easier to Understand" (1992) 24 Ottawa Law Review 495 at 505 .

${ }^{31}$ L Kaplow "How Tax Complexity and Enforcement Affect the Equity and Efficiency of the Income Tax" (1996) 49 National Tax Journal 135; GS Cooper "Themes and Issues in Tax Simplification" (1993) 10 Australian Tax Forum 417; DJ Sherbaniuk "Tax Simplification - Can Anything Be Done About It?" in 1988 Conference Report: Report of the Proceedings of the $40^{\text {th }}$ Tax Conference (Canadian Tax Foundation, Toronto, 1988) 13.

${ }^{32}$ M Richardson and A Sawyer "Complexity in the Expression of New Zealand's Tax Laws: An Empirical Analysis" (1998) 14 Australian Tax Forum 325 at 352. 
Finally, as Smith \& Richardson argue, any effort to simplify tax legislation has to be desirable, if it improves taxpayer compliance and reduces compliance costs. ${ }^{33}$ According to the Melbourne Institute, tax compliance costs in Australia have been estimated at 12 per cent of tax revenue. ${ }^{34}$ Estimates of tax compliance costs in New Zealand have been put at 7.3 per cent. ${ }^{35}$ Such high compliance costs should also provide a sufficient incentive for simplifying tax legislation, if it is established that it is complex.

\section{Tax simplification}

Tax simplification is frequently advocated on the basis it will increase efficiency and certainty. The general literature (and there is much of it) appears to suggest that an important factor in tax compliance and the consequent impact on compliance costs, is tax complexity. According to Anderson \& Sawyer, ${ }^{36}$ tax complexity has long been recognised as one of the factors affecting taxpayer compliance. James \& Wallshutzky, ${ }^{37}$ suggest that overly complex and incomprehensible legislation reduces voluntary compliance and increases compliance costs and that this is a major concern for tax systems that rely on self-assessment (eg, New Zealand).

In terms of certainty, Lortie \& Bergeron suggest that "good government requires that laws be expressed clearly". ${ }^{38}$ The state has a fundamental obligation to ensure that

${ }^{33}$ D Smith and G Richardson "The Readability of Australia's Taxation Laws and Supplementary Materials: An Empirical Investigation” (1990) 20 Fiscal Studies 321.

${ }^{34}$ Melbourne Institute Tax Reform, Equity and Efficiency (1998) 43, cited in G Richardson and D Smith "The Readability of Australia's Goods and Services Tax Legislation: An Empirical Investigation" (2002) 30 Federal Law Review 475 at 477.

${ }^{35} \mathrm{C}$ Sandford and J Hasseldine The Compliance Costs of Business Taxes in New Zealand (Institute of Policy Studies, Wellington, 1992) cited in R Stephens "Economic and Equity Effects of GST in New Zealand" in R Krever and D White (eds) GST in Retrospect and Prospect (Brookers Ltd, Wellington, 2007) 65 at 77.

${ }^{36} \mathrm{~W}$ Anderson and A Sawyer "Legislative Complexity - The Need for Appropriate Variables and Some Likely Candidates" (1997) 3 New Zealand Journal of Taxation Law and Policy 3.

${ }^{37}$ S James and I Wallshutzky "Tax Law Improvement in Australia and the UK: The Need for a Strategy for Simplification" (1997) 18 Fiscal Studies 445, cited in K Saw and A Sawyer "Complexity of New Zealand Income Tax Legislation: The Final Instalment" (2010) 25 Australian Tax Forum 213 at 216.

${ }^{38}$ S Lortie and RC Bergeron "Legislative Drafting and Language in Canada" (2007) 28 Statute Law Review 83. 
the law (as manifested in the form of legislation) is carefully composed, clearly expressed, and of consistent high quality for it to be understood. Citizens (individuals and entities) are also obliged to know the law (as ignorance of the law is no defence). Legislation that is not readily accessible to citizens increases the cost to the public and the state. However, a number of commentators have pointed out that tax legislation is often interpreted by lawyers and the Judiciary, not the public. ${ }^{39}$ While this is a valid argument, it fails to acknowledge that in a democracy, all people (not just lawyers) should understand the law. Fairness alone demands that the law should not be drafted on the assumption that a trained lawyer will be available to interpret it. As Donaldson MR observed: ${ }^{40}$

"The efficiency and maintenance of the rule of law, which is the foundation of any parliamentary democracy, has at least two pre-requisites. First, people must understand that it is in their interests, as well as in that of the community as a whole, that they should live their lives in accordance with the rules and al the rules. Second they must know what those rules are."

Adding: ${ }^{41}$

It is of vital importance ... that they must be able to find this out for themselves by reading plain and simple words of guidance. The judges of this court are very skilled lawyers of very considerable experience, yet it has taken us hours to ascertain what is and what is not offside, even with the assistance of highly experienced counsel. This cannot be right."

As the court also acknowledges, even lawyers and Judges have difficulty interpreting poorly drafted legislation. As Krongold observes, "a statute that is difficult to understand makes decision-making more difficult, makes administration more costly, and increases the need for legal services." 42

${ }^{39}$ For example, G Thornton "Drafters, the Nature of Drafting, and the Complexity of Tax Drafting" (1997) 3 New Zealand Journal of Taxation Law and Policy 148 and W Anderson and A Sawyer "Legislative Complexity - The Need for Appropriate Variables and Some Likely Candidates" (1997) 3 New Zealand Journal of Taxation Law and Policy 3.

${ }^{40}$ Merkur Island Shipping Co v Laughton [1983] 1 All ER 334; [1983] 2 WLR 45.

${ }^{41}$ Merkur Island Shipping Co v Laughton [1983] 1 All ER 334; [1983] 2 WLR 45.

42 S Krongold "Writing Laws: Making The Easier to Understand" (1992) 24 Ottawa Law Review 495 at 502 . 
The general view is that tax complexity can only be reduced effectively by an entire overhaul of the tax system which would entail a rewrite of laws. ${ }^{43}$ This position is supported by Graetz, who has suggested that simplifying the tax system may be the most effective way to increase taxpayer compliance. ${ }^{44}$ The research of Woellner et $\mathrm{al},{ }^{45}$ also suggests that simplified drafting styles do provide benefits to both novice and experienced users and that this in turn "supports an inference that simplified tax legislation may assist in reducing total tax compliance costs". ${ }^{46}$

But is this enthusiasm for legislative simplification misplaced (as Cooper would suggest it is) $?^{47}$ Was it legislative complexity or poorly defined policy that resulted in New Zealand's original change-in-use rules experiencing a high level of litigation activity? Does an assessment of the readability of the respective change-in-use provisions provide any guidance?

\section{Prior Research}

To date, there has not been an empirical study of the complete New Zealand GST Act to determine its readability. While some GST Act provisions were included in Tan \& Tower's 1992 study, their inclusion was neither comprehensive, nor inclusive of the change-in-use provisions. However, the Tan \& Tower study did provide a broad benchmark to make subsequent comparisons against (see Table 4.1 below). ${ }^{48}$

According to the Tan \& Tower study, the GST Act had an average range of 125 to 128 words-per-sentence (with a sizeable standard deviation of 60 to 62 words) and

${ }^{43}$ E Trombitas "Tax Reform Issue - No Need for a General Anti-Avoidance Provision in the Income Tax Act 1994" (1999) 5 New Zealand Journal of Taxation Law and Policy 121.

${ }^{44}$ M Graetz The Decline (and Fall?) of the Income Tax (New York, WW Norton, 1997).

${ }^{45}$ R Woellner, C Coleman, M McKerchar, M Walpole, and J Zetler "Can Simplified Legal Drafting Reduce the Psychological Costs of Tax Compliance? An Australian Perspective" (2007) British Tax Review 717.

${ }^{46}$ R Woellner, C Coleman, M McKerchar, M Walpole, and J Zetler "Can Simplified Legal Drafting Reduce the Psychological Costs of Tax Compliance? An Australian Perspective" (2007) British Tax Review 717 at 733 .

${ }^{47}$ GS Cooper "Legislating Principles as a Remedy for Tax Complexity" (2010) British Tax Review 334 at 337 .

${ }^{48}$ LM Tan and G Tower "The Readability of Tax Laws: An Empirical Study in New Zealand" (1992) 9 Australian Tax Forum 355 at 365 (Table 1). Hereafter referred to as the "Tan \& Tower" study. 
an FRE score of zero. As Tan \& Tower rightly observed, the GST Act was "very difficult to read". However, the main reason for the poor FRE scores (and high reading difficulty), was due to very long sentences, rather than word or syllable length. As Tan \& Tower observed, many readers of the GST Act would not have had much difficulty reading words containing an average syllable length of 1.57.

Table 4.1: GST Legislation (Selected Provisions) - Average Readability

\begin{tabular}{|l|r|r|r|r|r|r|}
\hline GST Act & \multicolumn{2}{|c|}{ Flesch Reading Ease } & \multicolumn{1}{|c|}{ Words per Sentence } & \multicolumn{2}{|c|}{ Syllables per Word } \\
\hline & FRE & \multicolumn{1}{|c|}{ STD } & WPS & STD & \multicolumn{1}{c|}{ SPW } & \multicolumn{1}{c|}{ STD } \\
\hline Original & 0.3 & 0.9 & 125.69 & 62.66 & 1.57 & 0.09 \\
\hline Revised & 0 & 0 & 128.11 & 60.41 & 1.56 & 0.08 \\
\hline
\end{tabular}

The Richardson \& Sawyer study ${ }^{49}$ examined Parts A and B (see Table 4.2 below) of the rewritten income tax legislation (enacted in the ITA 2004) and was subsequently followed up by the Pau et el study ${ }^{50}$ (examining the rewritten Parts C, D and E) in 2007, and the Saw \& Sawyer study ${ }^{51}$ (examining the completed ITA 2007) in 2010. All three studies are important, not only in providing an assessment of New Zealand's income tax legislation (using Flesch scores), but also in providing a benchmark to assess the readability of other New Zealand legislation (ie, the GST Act).

Table 4.2: New Zealand Income Tax Legislation (2002) - Average Readability

\begin{tabular}{|l|r|r|r|r|r|r|}
\hline & \multicolumn{2}{|c|}{ Flesch Reading Ease } & \multicolumn{1}{|c|}{ Words per Sentence } & \multicolumn{2}{|c|}{ Syllables per Word } \\
\hline ITA 1994 (rewrite) & FRE & \multicolumn{1}{|c|}{ STD } & WPS & \multicolumn{1}{|c|}{ STD } & \multicolumn{1}{|c|}{ SPW } & \multicolumn{1}{c|}{ STD } \\
\hline Part A & 44.65 & 12.34 & 39 & 11.03 & 1.26 & 0.17 \\
\hline Part B & 10.92 & 13.56 & 43.73 & 24.88 & 1.63 & 0.13 \\
\hline Part A and B & 16.11 & 18.09 & 43 & 23.35 & 1.58 & 0.19 \\
\hline
\end{tabular}

${ }^{49}$ M Richardson and A Sawyer "Complexity in the Expression of New Zealand's Tax Laws: An Empirical Analysis" (1998) 14 Australian Tax Forum 325 at 347 (Table 7). Hereafter referred to as the "Richardson \& Sawyer" study.

${ }^{50}$ C Pau, A Sawyer, and A Maples "Complexity of the New Zealand Tax Laws: An Empirical Study" (2007) 22 Australian Tax Forum 59. Hereafter referred to as the "Pau et al" study.

${ }^{51}$ K Saw and A Sawyer "Complexity of New Zealand Income Tax Legislation: The Final Instalment" (2010) 25 Australian Tax Forum 213. Hereafter referred to as the "Saw \& Sawyer" study. 
The Richardson \& Sawyer study confirmed that the main contributor to difficulty in understanding and complying with tax rules was the use of long sentences, and that this remained a major inhibitor in improving FRE scores. ${ }^{52}$ As the Richardson \& Sawyer study observed, the average sentence length of the pre-rewrite provisions significantly reduced after rewrite. ${ }^{53}$ As the above data illustrates, the words-persentence in the rewritten income tax legislation averages around 43 words-persentence (markedly lower than the rate in the GST Act). Unsurprisingly, the FRE scores are also substantially above those of the GST Act (especially in Part A).

As originally observed by Tan \& Tower, ${ }^{54}$ the Richardson \& Sawyer study also recognised that there was a general reluctance within the legislative drafting to break sections or subsections into more than one sentence. ${ }^{55}$ However, guidance on the New Zealand income tax rewrite has provided that: ${ }^{.6}$

"sections and subsections need not be restricted to a single sentence and may be broken into shorter sentences."

While such guidance appeared not to have initially materialised during the rewrite (at least not according to the Richardson \& Sawyer study), it is hoped that a rewrite of the GST Act will provide an opportunity to adhere more to the guidelines for shorter sentences. An interesting observation from the Richardson \& Sawyer study was the impact of the re-organisation of the Income Tax Act on reducing sentence length.

${ }^{52}$ M Richardson and A Sawyer "Complexity in the Expression of New Zealand's Tax Laws: An Empirical Analysis” (1988) 14 Australian Tax Forum 325 at 351-353.

${ }^{53}$ M Richardson and A Sawyer "Complexity in the Expression of New Zealand's Tax Laws: An Empirical Analysis" (1988) 14 Australian Tax Forum 325, 344 (Table 2). According to the comparative data the average sentence length in the ITA 1976 was 324.1 words-per sentence, which was reduced to 93.4 when the provisions were reorganised in the ITA 1994, and reduced further to 53.4 words-per sentence, post rewrite. In contrast, Tan \& Tower observed that the average sentence length in the ITA 1976 was 135 words-per-sentence (with a standard deviation of 67.87 words).

${ }^{54}$ LM Tan and G Tower "The Readability of Tax Laws: An Empirical Study in New Zealand" (1992) 9 Australian Tax Forum 355 at 364.

${ }^{55}$ M Richardson and A Sawyer "Complexity in the Expression of New Zealand's Tax Laws: An Empirical Analysis” (1988) 14 Australian Tax Forum 325 at 351.

${ }^{56}$ B Birch and W Creech Rewriting the Income Tax Act 1994 - Objectives, Process, Guidelines: A Discussion Document (IRD, Wellington, December 1994) at [7.3]. 
According to Richardson \& Sawyer such a dramatic (and surprising) reduction of sentence length "was not predicted". 57 This outcome suggested: ${ }^{58}$

"a significant cause of the excessively long sentences in the ITA 1976 was poor
organisation, as opposed to difficulty in the concise expression of complex ideas."

The Richardson \& Sawyer concluded that a major inhibiting factor to improving FRE scores was a failure to reduce average sentence length — "a legacy of the decision not to simplify policy and underlying concepts."59

The most recent Australian empirical study on the Australian GST Act has been the 2002 Richardson \& Smith study ${ }^{60}$ (not to be confused with the earlier Smith \& Richardson study ${ }^{61}$ on Australian income tax legislation). As discussed above, the study adopted the FRE index utilising the Word97 readability function in preference to a manual calculation process. However, unlike the Richardson \& Smith study, all legislative provisions (including those below 50 words), except the defined terms section (referred to as the "dictionary" in the Australian legislation) have been included in this study. ${ }^{62}$

The Richardson \& Smith study observed that "efforts made to simplify any form of taxation legislation, including the GST, could be considered to be a desirable means of helping to reduce business taxpayer compliance costs" ${ }^{63}$ However, the study

${ }^{57}$ M Richardson and A Sawyer "Complexity in the Expression of New Zealand's Tax Laws: An Empirical Analysis" (1988) 14 Australian Tax Forum 325 at 349.

${ }^{58}$ M Richardson and A Sawyer "Complexity in the Expression of New Zealand's Tax Laws: An Empirical Analysis” (1988) 14 Australian Tax Forum 325 at 350.

${ }^{59}$ M Richardson and A Sawyer "Complexity in the Expression of New Zealand's Tax Laws: An Empirical Analysis” (1988) 14 Australian Tax Forum 325 at 353.

${ }^{60}$ G Richardson and D Smith "The Readability of Australia's Goods and Services Tax Legislation: An Empirical Investigation” (2002) 30 Federal Law Review 475.

${ }^{61}$ D Smith and G Richardson "The Readability of Australia's Taxation Laws and Supplementary Materials: An Empirical Investigation” (1999) 20 Fiscal Studies 321.

${ }^{62}$ In terms of comparative analysis, the online data is preferred for its accuracy, unless making comparisons to the Richardson \& Smith study, in which case the Word97 data is used.

${ }^{63}$ G Richardson and D Smith "The Readability of Australia's Goods and Services Tax Legislation: An Empirical Investigation" (2002) 30 Federal Law Review 475 at 484 . Hereafter referred to as the "Richardson \& Smith" study. 
concluded (see Table 4.3 below) ${ }^{64}$ that overall, the Australian GST Act remained very difficult to read and understand on the basis of an average FRE score of 40.3 (below the benchmark of 60), and had implications for business taxpayers in the form of potentially higher GST compliance costs. Although the study did identify that the average sentence length (ie, words-per-sentence) was $20.9 .^{65}$

Table 4.3: Australian Tax Legislation - Average Readability

\begin{tabular}{|l|c|c|c|c|}
\hline Legislation & Flesch(FRE) & F-KGL & $\begin{array}{c}\text { Passive } \\
\text { Sentence (\%) }\end{array}$ & $\begin{array}{c}\text { Words-Per- } \\
\text { Sentence (WPS) }\end{array}$ \\
\hline GST Act & 40.3 & 11.0 & 20 & 20.9 \\
\hline ITAA 1936 & 38.44 & 10.79 & 17.1 & 39.02 \\
\hline ITAA 1997 & 46.42 & 10.76 & 20.81 & 22.27 \\
\hline
\end{tabular}

The Pau et al study, ${ }^{66}$ confirmed that the income tax rewrite had made further readability improvements since the Richardson \& Sawyer study (which had only examined Parts A and B of the ITA 2004). Similar to the Richardson \& Smith study, the Pau et al study utilised Microsoft Word (albeit Word2003 instead of Word97) to correlate FRE scores. According to the Pau et al study, the average sentence length had shortened to approximately 34 words-per-sentence and a KRE score of 41.7 since the earlier Richardson \& Sawyer study (see Table 4.4 below). The Pau et al study concluded the rewrite project had been successful in improving the overall readability of the income tax legislation and that the considerable increase in the KRE score was largely due to a significant reduction in the average sentence length (from 324 words in the ITA 1976 to 34 words per sentence in the ITA 2004).

\footnotetext{
${ }^{64}$ Average data on the Australian income tax legislation (eg, ITAA 1936 and ITAA 1997) was obtained from the earlier 1999 Smith \& Richardson study: D Smith and G Richardson "The Readability of Australia's Taxation Laws and Supplementary Materials: An Empirical Investigation” (1999) 20 Fiscal Studies 321.

${ }^{65}$ This result would tend to support a much higher FRE score than identified in the study. The rewritten ITAA 1997 returned a FRE score of 46.42 on the basis of an average sentence length of 22.27 wordsper-sentence (2 words more than the GST Act).

${ }^{66}$ C Pau, A Sawyer, and A Maples "Complexity of the New Zealand Tax Laws: An Empirical Study" (2007) 22 Australian Tax Forum 59.
} 
Table 4.4: New Zealand Income Tax Legislation (2004) - Average Readability

\begin{tabular}{|l|c|c|c|}
\hline ITA 2004 & Average FRE & Average F-KEL & Average WPS \\
\hline Part A & 49.1 & 10.9 & 28.5 \\
\hline Part B & 39.1 & 11.8 & 35.9 \\
\hline Part C & 44.4 & 10.5 & 31.4 \\
\hline Part D & 40.5 & 11.2 & 29.1 \\
\hline Part E & 35.3 & 11.4 & 45.2 \\
\hline Average & 41.7 & 11.2 & 34.0 \\
\hline
\end{tabular}

The Saw \& Sawyer study, ${ }^{67}$ revisited the work of the earlier Pau et al study, and provided a final assessment of the then completed (and fully rewritten) ITA 2007 (see Table 4.5 below). The Saw \& Sawyer study observed that the rewrite had "significantly improved readability" with average FRE scores improving from 33.5 (in the ITA 2004) to 42.8 (in the ITA 2007) and average sentence length reducing from 37 to 25 words.

Table 4.5: New Zealand Income Tax Legislation (2007) - Average Readability

\begin{tabular}{|l|r|r|r|r|r|r|}
\hline & \multicolumn{2}{|c|}{ Average FRE } & \multicolumn{2}{|c|}{ Average F-KEL } & \multicolumn{2}{c|}{ Average WPS } \\
\hline & ITA 2007 & ITA 2004 & ITA 2007 & ITA 2004 & ITA 2007 & ITA 2004 \\
\hline Part C & 45.18 & 24.04 & 13.16 & 22.59 & 25.89 & 49.59 \\
\hline Part D & 34.61 & 33.71 & 13.62 & 15.74 & 21.09 & 29.11 \\
\hline Part E & 54.83 & 48.93 & 10.50 & 12.76 & 19.86 & 25.64 \\
\hline Part F & 35.88 & 27.17 & 14.78 & 17.26 & 26.49 & 34.49 \\
\hline Part G & 42.42 & 30.91 & 12.45 & 18.16 & 20.80 & 45.49 \\
\hline Part H & 36.74 & 39.15 & 14.43 & 14.43 & 28.17 & 27.85 \\
\hline Part I & 45.96 & 29.43 & 14.43 & 21.13 & 30.69 & 44.64 \\
\hline Part L & 45.06 & 27.20 & 13.64 & 24.95 & 28.16 & 54.17 \\
\hline Part M & 37.27 & 35.84 & 15.24 & 15.73 & 29.09 & 32.01 \\
\hline Part O & 46.05 & 32.42 & 12.22 & 21.21 & 21.89 & 40.06 \\
\hline Part R & 41.20 & 31.94 & 15.28 & 20.07 & 30.97 & 42.13 \\
\hline Part Y & 44.79 & 35.16 & 12.79 & 17.20 & 23.46 & 35.72 \\
\hline Part Z & 45.62 & 44.40 & 11.78 & 12.27 & 19.92 & 21.00 \\
\hline Average & 42.77 & 33.52 & 13.38 & 17.74 & 25.03 & 36.63 \\
\hline
\end{tabular}

${ }^{67}$ K Saw and A Sawyer "Complexity of New Zealand Income Tax Legislation: The Final Instalment" (2010) 25 Australian Tax Forum 213. 
The most recent Sawyer study (yet to be published), ${ }^{68}$ has raised some questions about the readability of the ITA 2007 using a Cloze Procedure analysis. However, the general trend of improved readability from plain language rewriting remains. Sawyer confirms earlier observations that the "rewrite project had been successful in improving readability" $" 69$ and providing "potentially understandable"70 legislation.

The Richardson \& Sawyer, Pau et al, Saw \& Sawyer, and more recent Sawyer studies, all confirm that the readability of ITA 2007 is now comparable to the Australian Income Tax Act (based on the Smith \& Richardson study) and Australian GST Act (based on the Richardson \& Smith study). The studies also demonstrate that plain language drafting styles do improve the readability of tax legislation. In contrast, evidence suggests that the New Zealand and Canadian GST Acts continue to score poorly (both in terms of average FRE scores and words-per-sentence) and remain in reading equivalence to the former New Zealand Income Tax Act 1976 an Act considered overly complex by the 1989 Waugh Committee. ${ }^{71}$

\section{Research Methodology}

According to Tran-Nam, ${ }^{72}$ tax complexity is strictly speaking a comparative concept. However, in many empirical studies it is a measurable concept that associates a piece of legislation with a unique score. The magnitude of these scores tell us how much a tax law is simpler (or more complex) than another. While a universally accepted numerical measure of legal complexity has yet to be agreed upon, in most of the

${ }^{68}$ A Sawyer "Enhancing Compliance Through Improved Readability: Evidence from New Zealand's Rewrite 'Experiment"' (2011) IRS Research Bulletin 225. It is suggested that the less than encouraging results may also be due to reliance on less than accurate data provided from Word generated FRE scores. Although the author acknowledges that the Cloze analysis might have also been compromised by the methodology.

${ }^{69}$ K Saw and A Sawyer "Complexity of New Zealand Income Tax Legislation: The Final Instalment" (2010) 25 Australian Tax Forum 213 at 237.

${ }^{70}$ A Sawyer "Enhancing Compliance Through Improved Readability: Evidence from New Zealand's Rewrite 'Experiment”' (2011) IRS Research Bulletin 225 at 246.

${ }^{71}$ D Caygill Consultative Document on Tax Simplification (IRD, Wellington, December 1989) [the Waugh Committee]. See also J Waugh Tax Simplification: Final Report of the Consultative Committee (IRD, Wellington, 1990).

${ }^{72}$ B Tran-Nam "Tax Compliance Research: An Economic Perspective" (2003) 9 New Zealand Journal of Taxation Law and Policy 455 at 462. 
recent empirical studies that have been conducted, the preferred measurement has been the Flesch Reading Ease (FRE) index. ${ }^{73}$

Consistent with earlier empirical studies of tax legislation provisions (notably Tan $\&$ Tower, ${ }^{74}$ Richardson \& Sawyer, ${ }^{75}$ Smith \& Richardson, ${ }^{76}$ Richardson \& Smith, ${ }^{77}$ Pau et $\mathrm{al}^{78}$ and Saw $\&$ Sawyer $^{79}$ ), this study has adopted the Flesch Readability Ease (FRE) index to determine the readability of selected GST change-in-use provisions from New Zealand, Canada, and Australia.

As all four tax research studies have observed, the FRE index is the most commonly used method for assessing the readability of tax legislation. The FRE score is a measure of readability and generates a reading ease index from " 0 " (most difficult) to "100" (least difficult). Scores below zero are treated as zero on the index (and vice-versa). The lower the FRE score the harder a document is considered to read, and the higher the score tends to "100", the easier a document is considered to read. For the purposes of this study, scores below zero have been left in the data (rather than deemed a zero) to provide more extensive comparisons (and provide a clear picture of the gravity of the situation for many legislative provisions).

${ }^{73}$ R Flesch How to Write Plain English (Harper and Row, New York, 1979) cited in C Pau, A Sawyer, and A Maples "Complexity of the New Zealand Tax Laws: An Empirical Study" (2007) 22 Australian Tax Forum 59 at 69 (fn 51).

${ }^{74}$ LM Tan and G Tower "The Readability of Tax Laws: An Empirical Study in New Zealand" (1992) 9 Australian Tax Forum 355. Hereafter referred to as the "Tan \& Tower" study.

${ }^{75}$ M Richardson and A Sawyer "Complexity in the Expression of New Zealand's Tax Laws: An Empirical Analysis" (1988) 14 Australian Tax Forum 325. Hereafter referred to as the "Richardson \& Sawyer" study.

${ }^{76}$ D Smith and G Richardson “The readability of Australia's Taxation Laws and Supplementary Materials: An Empirical Investigation" (1999) 20 Fiscal Studies 321. Hereafter referred to as the "Smith \& Richardson" study.

${ }^{77}$ G Richardson and D Smith "The Readability of Australia's Goods and Services Tax Legislation: An Empirical Investigation" (2002) 30 Federal Law Review 475. Hereafter referred to as the "Richardson \& Smith" study.

${ }^{78}$ C Pau, A Sawyer, and A Maples "Complexity of the New Zealand Tax Laws: An Empirical Study" (2007) 22 Australian Tax Forum 59.

${ }^{79}$ K Saw and A Sawyer "Complexity of New Zealand Income Tax Legislation: The Final Instalment" (2010) 25 Australian Tax Forum 213. 
However, as Tan \& Tower observe, ${ }^{80}$ there are limitations in the use of readability indexes. This is because most readability formulae are based on simple measurable factors (eg, sentence length and word length) and fail to take into consideration other more complex factors that will often be part of legislation (eg, conceptual difficulty or semantics). Due to these limitations, readability indexes do not provide an absolute measure of clarity. However, they do provide a good indication of readability in the absence of any better measure.

Initially the research methodology for this study intended to adopt the Richardson \& Smith study approach of using only Word97's internal readability system that returns two FRE scores (the Flesch readability score and the Flesch-Kincaid grade level score). ${ }^{81}$ This approach has a degree of merit in that it would provide comparability with the Richardson \& Smith study while providing internal consistency with the other jurisdictions examined in this study. ${ }^{82}$ Furthermore, as the Richardson \& Smith study points out, automated computer calculations were demonstrated to be considerably more accurate than human calculations. ${ }^{83}$ However, when benchmarking data from the Tan \& Tower study sufficient irregularities were observed in Word97 to cause some concern with the Word97 FRE scores. ${ }^{84}$ Similar

${ }^{80}$ LM Tan and G Tower "The Readability of Tax Laws: An Empirical Study in New Zealand" (1992) 9 Australian Tax Forum 355 at 361.

${ }^{81}$ The Flesch Reading Ease (FRE) and Flesch-Kincaid Grade Level (F-KGL) indexes were first developed in the 1940's and are designed to indicate comprehension complexity. Both tests use the same core measures (eg, word length and sentence length), but have different weighting factors. The lower the FRE score the more difficulty and less comprehendible the language. The F-KGL formula effectively inverts the FRE score in order to provide an indication of the equivalent school grade level required to comprehend language. The FRE formula is: $206.838 \times 1.015$ (total words $\backslash$ total sentences) -84.6 (total syllables $\backslash$ total words). The F-KGL formula is: $0.39 \times 015$ (total words $\backslash$ total sentences $)+11.8$ (total syllables $\backslash$ total words) -15.59 .

${ }^{82}$ It is noted that the Pau et al study used Word2003and Saw \& Sawyer study Word2007. However, to ensure absolute consistency with the Richardson \& Smith GST Act data (and remove any doubt that Word2003 might compute FRE scores differently) Word97 has been used.

${ }^{83}$ G Richardson and D Smith "The Readability of Australia's Goods and Services Tax Legislation: An Empirical Investigation" (2002) 30 Federal Law Review 475 at 480 . However, it is noted that while both calculations are computer generated (and therefore more technically accurate), they did provide different results.

${ }^{84}$ The first irregularity concerned the total word counts. Word97 appeared to provide two different total word counts depending on which Word97 tool was being used (ie, the default word count, or the word count after "readability" was selected). In a number of instances the word count appeared to drop by one or two units after the readability option in Word97 was selected. The second concern related to the words-per-sentence (WPS) scores. After the readability option was selected, Word97 would 
concerns were raised in the Sawyer study (although subsequently discounted in the Richardson \& Smith study for the above reasons) and Pau et al and Saw \& Sawyer studies. ${ }^{85}$ Additionally, Word97 was unable to provide syllable length data that was comparable with the data provided in the Tan \& Tower study. ${ }^{86}$

For the above reasons an alternative automated computer-generated calculation from an online readability-score tool ${ }^{87}$ was applied to the legislation in order to provide equivalent data to that provided in the Tan $\&$ Tower study (eg, syllable scores). ${ }^{88}$ The online tool also provided additional scores using the Gunning-Fog, ${ }^{89}$ ColemanLiau, ${ }^{90}$ SMOG,${ }^{91}$ and Automated Readability ${ }^{92}$ scoring systems. ${ }^{93}$ This additional

provide WPS scores. However, these score did not often reflect the total word score divided by the total sentence score. In some instances they were much lower, particularly when the legislative provision also contained a number of paragraphs. This irregularity in WPS did not appear in the Online tool. Benchmarking the s 16 GST Act data from Tan \& Tower against Word97 and the Online tool also highlighted an apparent error in the Tan \& Tower data. Section 16 (as originally enacted and subsequently amended) only comprised 2 sentences, yet Tan \& Tower returned an average sentence length of 71 words which would require 3 sentences (not 2), for a provision comprising approximately 213 words at that time.

${ }^{85}$ M Richardson and A Sawyer "Complexity in the Expression of New Zealand's Tax Laws: An Empirical Analysis" (1988) 14 Australian Tax Forum 325 at 336-337. The Richardson \& Sawyer study observed that Word97 failed to accurately compute FRI scores and considered that Word97 had particular difficulty in calculating long sentences. However, the inaccuracies may also have something to do with irregularities in syllable and sentence counting. The Pau et al study also identified irregularities with the use of colons and semi colons in the calculation of sentence length in Word2003. The Saw \& Sawyer study also observed a similar problem in Word2007. According to the Pau et al study, Word2003 treated semi-colons as full-stops and thus inflated the FRE scores by increasing the number of words-per-sentence scores. The online tool used in this study did not experience these problems.

${ }^{86}$ Furthermore, in order to stabilise word counts, spaces were removed from section references (eg, "CB 23" changed to "CB23"). In some instances spaces were inserted between words, where digital versions of legislative provisions had accidentally removed them.

${ }^{87}$ See <http://www.addedbytes.com/code/readability-score/> (viewed 20 March 2011).

${ }^{88}$ Benchmarking the s 16 GST Act data from the Tan \& Tower study against the data from the Online tool provided a high degree of consistency (eg, similar syllable counts), which Word97 was not able to provide.

${ }^{89}$ The Gunning-Fog (G-Fog) index was developed in 1952 and also estimates the years of formal education required to understand written language. Unlike the Flesch index it measures complex words (eg, words with 3 or more syllables), rather than just syllables. The G-Fog formula is: 0.4 ((words \sentence) +100 (complex words \words))

${ }^{90}$ The Coleman-Liau (C-Liau) index was developed in 1975 and is a readability test that determines the understanding of written language and returns a score similar to the F-KGL index. Unlike syllablebased readability indices, it does not require that the character content of words be analysed, only their length in characters. The C-Liau formula is: 0.0588 (number of charcters $\backslash 100$ words) -0.296 (sentences $\backslash 100$ words) -15.8 . 
data also provides an alternative means of comparison between the three jurisdictions tested.

Accordingly, in order to enable comparability with all four studies, two Flesch scores were recorded from two different sources - the first from Word97 (as used by the Smith study), and the second from the online readability-score tool. ${ }^{94}$ In order to ensure comparability between all three jurisdictions, the change-in-use provisions from New Zealand, Canada, and Australia have been examined using the aforementioned two-pronged approach. The resulting data from this research should enable comparability with all four studies and perhaps provide a greater element of objectivity to the overall results, due to the addition of other scoring systems. In addition, data on the Australian GST change-in-use provisions presented in the Richardson \& Smith study is compared to data acquired in this study. Theoretically, the data from this study should be similar (subject to any subsequent changes to the legislation since 2002) to the data in the Richardson \& Smith study. If this proved to be the case (which it was), computations for the other jurisdictions could be accurately compared with one another (albeit that the Word97 computations are not accurate).

According to Richardson \& Smith, a legislative provisions needs to achieve a FRE score of 60 or more to be considered readable. ${ }^{95}$ According to Tan $\&$ Tower, ${ }^{96}$ and

${ }^{91}$ The Simple Measure of Gobbledygook (SMOG) index was developed in 1969 as a more accurate substitute for the G-Fog index. The formula for SMOG is: $1.043 \times$ SquareRoot $[30 \times$ (number of polysyllables $\backslash$ number of sentences)] +3.1291 .

${ }^{92}$ The Automated Readability (ARI) index is similar to the C-Liau index and relies on a factor of characters per word, instead of the usual syllables per word. The ARI formula is: 4.71 (characters $\backslash$ words $)+0.5$ (words $\backslash$ sentence $)-21.43$.

${ }^{93}$ Greater confidence was also experienced with the total word, sentence, and words-per-sentence scores. Both Word97 and the online tool returned the same sentence cores. However, (as explained above), Word97 appeared to experience a number of anomalies with its word-per-sentence scores. Often the word-per-sentence scores did not equal the total word count divided by sentence numbers. For this reason, the word-per-sentence scores (and thus the FRE scores) derived from the Online tool were preferred over the equivalent Word97 scores for accuracy. However, by computing Word97 generated FRE scores, comparability of legislative performance between studies (and legislation) could be made.

${ }^{94}$ See <http://www.addedbytes.com/code/readability-score/> (viewed 20 March 2011).

${ }^{95}$ G Richardson and D Smith “The Readability of Australia's Goods and Services Tax Legislation: An Empirical Investigation” (2002) 30 Federal Law Review 475 at 480-481. 
applied in the Richardson \& Sawyer study, ${ }^{97}$ this equates roughly to the school leaving age. A score of less than 60 equates to a tertiary level or undergraduate qualification and a score of less than 30 equates to a university graduate qualification. ${ }^{98}$ The Pau et al and Saw \& Sawyer studies also applied this standard in reaching its conclusions.

In the course of this research, it became apparent that it would be necessary to benchmark the various iterations of the New Zealand change-in-use provisions against the average GST Act provision from the same period. ${ }^{99}$ For this reason, the complete New Zealand GST Act was measured and the data presented in an Appendix at the end of this chapter.

\section{E. Interpretation of Readability Scores}

\section{Australia}

In comparison to both New Zealand and Canada, the Australian change-in-use rules (contained in Division 129) record substantially better FRE scores, both in Word97 and from the Online tool (see Table 4.6 below). The 2010 data provides an interesting picture of Australian GST Act, and in particular the Division 129 rules. The average provision in Division 129 contains approximately 135 words, 6 paragraphs-per-section, 2.9 sentences-per-section (SPS), 222.79 syllables-persection, 55 words-per-sentence (WPS), and an FRE score of $18.81 .^{100}$

${ }^{96}$ LM Tan and G Tower "The Readability of Tax Laws: An Empirical Study in New Zealand" (1992) 9 Australian Tax Forum 355 at 370-371 (Table 5 and Table 6).

${ }^{97}$ M Richardson and A Sawyer "Complexity in the Expression of New Zealand's Tax Laws: An Empirical Analysis" (1988) 14 Australian Tax Forum 325 at 348 (Table 8 and Table 9).

${ }^{98}$ As will become apparent from the data, the GST Act currently requires the equivalent of a university graduate (or higher) to read it.

${ }^{99}$ While the 1992 Tan \& Tower study provided a benchmark in which to compare the results from the change-in-use provisions, the averages from the Tan $\&$ Tower study were generated from a very small sample and were over 8 years old. A complete and more recent sample would not only provide a more accurate benchmark, it would also provide an opportunity to see if the readability of the GST Act had improved since it was last measured.

${ }^{100}$ Word97 provides an average sentence length of 27 words-per-sentence and an FRE score of 28.89. While this is more consistent with Richardson \& Smith, it does not appear to be an accurate picture. 
In 2002, the Richardson \& Smith study provided an average Word97 FRE score of 40.3 and a words-per-sentence score of 20.9. Averaging the original Richards \& Smith study data for Division 129 provides an average Word97 FRE score of 32.75 and an average words-per-sentence length of 19.2 (see Table 4.7 below). This additional analysis of the Richardson \& Smith data would appear to suggest that the Australian change-in-use rules are generally less readable than the average provision in the Australian GST Act. Nevertheless they are still substantially more readable than either the New Zealand or Canadian change-in-use rules.

Table 4.6: 2010 Australian Change-in-Use Provisions -Readability

\begin{tabular}{|c|c|c|c|c|c|c|c|c|c|c|}
\hline & \multicolumn{7}{|c|}{ Online Tool } & \multicolumn{3}{|c|}{ Word97 } \\
\hline Sections & Words & Paras & $S P S$ & WPS & Syllable & $S P W$ & $F R E *$ & $\begin{array}{l}M S- \\
F R E\end{array}$ & $\begin{array}{l}M S- \\
\text { Words }\end{array}$ & $\begin{array}{l}M S- \\
W P S\end{array}$ \\
\hline $11 \sim 1$ & 37 & 1 & 2 & 18.5 & 66 & 1.78 & 37.1 & 37.1 & 37 & 18.5 \\
\hline $11 \sim 5$ & 53 & 5 & 1 & 53 & 86 & 1.62 & 15.8 & 75.5 & 53 & 9 \\
\hline $11 \sim 10$ & 148 & 14 & 3 & 49.33 & 249 & 1.68 & 14.4 & 45.9 & 148 & 18 \\
\hline $11 \sim 15$ & 215 & 11 & 5 & 43 & 333 & 1.55 & 32.2 & 58.5 & 215 & 19.8 \\
\hline $11 \sim 20$ & 15 & 1 & 1 & 15 & 26 & 1.73 & 45 & 44.9 & 15 & 15 \\
\hline $11 \sim 25$ & 43 & 1 & 2 & 21.5 & 70 & 1.63 & 47.3 & 43.3 & 43 & 21.5 \\
\hline $11 \sim 30$ & 261 & 10 & 6 & 43.5 & 440 & 1.69 & 20.7 & 31.5 & 259 & 32 \\
\hline Average & 110.29 & 6.14 & 2.86 & 34.83 & 181.43 & 1.67 & 30.36 & 48.10 & 110.00 & 19.11 \\
\hline $129 \sim 1$ & 51 & 1 & 2 & 25.5 & 81 & 1.59 & 46.6 & 42.7 & 50 & 25 \\
\hline $129 \sim 5$ & 89 & 8 & 2 & 44.5 & 162 & 1.82 & 7.7 & 30.2 & 89 & 18.5 \\
\hline 129 10 & 117 & 5 & 3 & 39 & 205 & 1.75 & 19 & 11.2 & 113 & 28 \\
\hline $129 \sim 15$ & 36 & 1 & 1 & 36 & 62 & 1.72 & 24.6 & 9.3 & 35 & 35 \\
\hline 129 20 & 366 & 15 & 5 & 73.2 & 613 & 1.67 & -9.2 & 17 & 361 & 31.4 \\
\hline $129 \sim 25$ & 223 & 15 & 3 & 74.33 & 358 & 1.61 & -4.4 & 30 & 221 & 20 \\
\hline $129 \sim 40$ & 338 & 15 & 14 & 24.14 & 564 & 1.67 & 41.2 & 42.8 & 335 & 16.6 \\
\hline 129 45 & 182 & 7 & 3 & 60.67 & 305 & 1.68 & 3.5 & 23.5 & 177 & 33.6 \\
\hline 129 50 & 110 & 5 & 3 & 36.67 & 172 & 1.56 & 37.3 & 47 & 110 & 27.3 \\
\hline $129 \sim 55$ & 36 & 4 & 1 & 36 & 55 & 1.53 & 41 & 60.7 & 36 & 12 \\
\hline 129 70 & 125 & 5 & 1 & 125 & 192 & 1.54 & -50 & 36.1 & 120 & 31 \\
\hline $129 \sim 75$ & 124 & 5 & 1 & 124 & 191 & 1.54 & 49.3 & 36.1 & 120 & 31 \\
\hline 129 80 & 57 & 1 & 1 & 57 & 86 & 1.51 & 21.3 & 0 & 55 & 55 \\
\hline 129 90 & 41 & 2 & 1 & 20.5 & 73 & 1.78 & 35.4 & 17.9 & 40 & 13 \\
\hline Average & 135.36 & 6.36 & 2.93 & 55.47 & 222.79 & 1.64 & 18.81 & 28.89 & 133.00 & 26.96 \\
\hline
\end{tabular}

Furthermore, a comparison of the 2010 Word97 data for Division 129 against the 2002 Richardson \& Smith study data for Division 129 would appear to suggest that 
there has been no significant change. Since 2002, the Word97 words-per-sentence scores have only dropped marginally from 19.2 to 20.8, and the Word97 FRE scores have dropped only slightly from 32.75 to 34.48 (or if comparing the Online FRE score of 32.58 - no change at all). However, a more accurate picture of Division 129 (eg, including Division 129 provisions excluded in the Richardson \& Smith study) provides an average Word97 FRE score of 28.89 with an average words-persentence length of 26.9 (see Table 4.7 below). ${ }^{101}$

Table 4.7: Comparison of Richardson \& Smith Data Against 2010 Study

\begin{tabular}{|c|c|c|c|c|c|c|c|c|}
\hline \multirow[t]{2}{*}{ Section } & \multicolumn{4}{|c|}{ Richardson \& Smith (2002) } & \multicolumn{4}{|c|}{2010 Study } \\
\hline & FRE & F-KGL & PS & WPS & MS-WPS & MS-FRE & FRE * & $\begin{array}{c}\text { Average } \\
\text { FRE scores }\end{array}$ \\
\hline $11 \sim 1$ & 37.1 & 12 & 0 & 18.5 & 18.5 & 37.1 & 37.1 & 37.1 \\
\hline $11 \sim 5$ & 30.5 & 10.7 & 0 & 7 & 9 & 75.5 & 15.8 & 45.65 \\
\hline $11 \sim 10$ & 40.2 & 11.8 & 33 & 17 & 18 & 45.9 & 14.4 & 30.15 \\
\hline $11 \sim 15$ & 50.8 & 11 & 40 & 19.8 & 19.8 & 58.5 & 32.2 & 45.35 \\
\hline $11 \sim 20$ & 27.6 & 12 & 0 & 13 & 15 & 44.9 & 45 & 44.95 \\
\hline $11 \sim 25$ & 39.7 & 12 & 33 & 18 & 21.5 & 43.3 & 47.3 & 45.3 \\
\hline $11 \sim 30$ & 30.5 & 12 & 16 & 31.3 & 32 & 31.5 & 20.7 & 26.1 \\
\hline Average & 36.62 & & & 17.8 & 19.11 & 48.1 & 30.35 & 39.22 \\
\hline $129 \sim 1$ & 42.7 & 12 & 50 & 25 & 25 & 42.7 & 46.6 & 44.65 \\
\hline $129 \sim 10$ & 12.3 & 12 & 0 & 27 & 28 & 11.2 & 19 & 15.1 \\
\hline 129 25 & 27.4 & 12 & 0 & 17.2 & 20 & 30 & -4.4 & 12.8 \\
\hline $129 \sim 40$ & 43.1 & 11.2 & 0 & 16.3 & 16.6 & 42.8 & 41.2 & 42.0 \\
\hline $129 \sim 55$ & 49.5 & 9 & 0 & 11 & 12 & 60.7 & 41 & 50.85 \\
\hline 129 75 & 31.5 & 12 & 0 & 19 & 31 & 36.1 & 49.3 & 42.7 \\
\hline 129 90 & 22.8 & 12 & 0 & 19 & 13 & 17.9 & 35.4 & 26.65 \\
\hline Average & 32.75 & & & 19.2 & 20.8 & 34.48 & 32.58 & 33.53 \\
\hline
\end{tabular}

* FRE scores from online tool.

The insignificant difference in respective Word97 scores for the same sample group used in the Richardson \& Smith study should be expected given there has been very few amendments to these provisions since 2002. Importantly, the 2010 Word97 data appears to benchmark very well against the Richardson \& Smith data, and would

${ }^{101}$ The average Online FRE score for Division 129 is 18.81 with an average words-per-sentence length of 55.47, and is probably a more accurate picture of the readability and sentence length of the Australian change-in-use rules contained in Division 129. 
therefore appear to validate the comparative value of the resulting 2010 Word97 scores for the New Zealand and Canadian legislation. ${ }^{102}$

\section{New Zealand}

The Tan \& Tower study provided that the average GST Act provision (based on a small portion of selected provisions) had an average Word97 FRE score of zero, an average syllable score of 1.56, and an average sentence length of 125 words-persentence (as enacted), that had increased to 128 words-per-sentence (WPS) after the first round of amendments. ${ }^{103}$

This study has revisited the average scores for the revised GST Act and change-inuse provisions and confirms that both the average GST provision and the original change-in-use provision (pre-10 October 2000) have changed little since the 1992 Tan \& Tower study and remain difficult to read. ${ }^{104}$ Although (as discussed below) it would appear that the change-in-use provisions are more readable than the average GST Act provision.

According to this study the average GST Act provision in 2010 had an average sentence length of 99.53 WPS and an average Word97 FRE score of 34.91. ${ }^{105}$ However, an FRE score of zero is probably more accurate. ${ }^{106}$ While this is a small (and possibly insignificant) improvement on the averages obtained in 1992 by Tan \& Tower (eg, 128 WPS), it is still below the benchmark of 43 WPS set by the rewritten

${ }^{102}$ Although as discussed above, the accuracy of Word based FRE scores could be questionable in terms of accuracy, and it is suggested that the Online FRE scores generated from this study are more likely to provide a more accurate FRE score and words-per-sentence (WPS) score.

103 The apparent error with s 16 may have made the words-per-sentence mean average higher, as the score should have been 106.5 (ie, 213/2), rather than 71 (ie, 213/3).

104 The original change-in-use provision would certainly appear to support Tan \& Towers conclusions. In fact if $\mathrm{s} 21$ had been included in the Tan \& Tower study it may well have further degraded the results from the Tan $\&$ Tower study.

105 The Word97 score of 37.58 WPS is difficult to reconcile given that the average provision comprises 5.13 sentences and an average total of 510 words.

${ }^{106}$ If we accept that the Word97 WPS score of 37.58 is not accurate, then it follows that the resulting Word97 FRE score is also inaccurate. Thus the online FRE score of -25.8 (or zero) is preferred as a more accurate picture of the state of the average provision in the GST Act (see Table 4.9 below). 
Income Tax Act and 30 WPS set by the Working Party on the Reorganisation of the Income Tax Act 1976.

According to this study, the original change-in-use provision (just prior to amendment on 10 October 2000 and 8 years after the Tan \& Tower study) had a Word97 FRE score of zero, an average sentence length of 201 WPS, and an average syllable length of $1.46 .^{107}$

The revised change-in-use provision has made a substantial improvement on readability and average sentence length. The total word count for the provisions has dropped markedly from 1,611 words to 561 words, which translates to a reduction in sentence length from 201 to 112 WPS. ${ }^{108}$ Readability has also improved from a Word97 FRE score of zero to 31.5. ${ }^{109}$ However, in terms of educational equivalence this still equates to a university graduate qualification (or higher).

Averaging all the revised change-in-use provisions (ss 21 to 21I) would appear to indicate an even more dramatic improvement. The average total word length for all the change-in-use provisions is 224 words and demonstrates a substantial decrease from 1,611 words in the original provision. Not surprisingly, the average sentence length is 61.32 WPS and an equally dramatic reduction from 201 WPS in the original provision. ${ }^{110}$ However, it is likely that this improvement is due the codified inclusion of the rules relating to methodology that were originally written in a nonlegislative style. ${ }^{111}$

${ }^{107}$ The 1992 Tan \& Tower GST Act average was 128 words-per-sentence, 1.57 syllables, and an FRE score of zero. The Online tool actually provided a FRE score of -120.7 which is treated as zero. The Word97 average sentence length of 81.5 WPS is difficult to reconcile given that the provision comprises 8 sentences and a total of 1611 words.

${ }^{108}$ The Word97 score of 41.2 WPS is difficult to reconcile given that the provision comprises 5 sentences and a total of 561 words.

${ }^{109}$ However, given Word97 is producing extremely low WPS scores, it is more likely that the real FRE score is -29.4. While this is an improvement on -120.7 it is still technically considered to be a zero FRE score, and as such would not be considered to be an improvement.

${ }^{110}$ The Word97 average WPS of 28.6 is difficult to reconcile given that the average provision comprises 3.4 sentences and an average total of 224 words.

${ }^{111}$ See Tax Information Bulletin Vol 5:8 (January 1994) 1. Document available at: <www.ird.govt.nz/resources/1/9/194616004bbe4243b4bdf4bc87554a30/tib5-08.pdf> (viewed 20 March 2011). 
A wider comparison of the change-in-use provisions against the average GST Act provision (see Table 4.8 below and discussed above) confirms that the revised change-in-use provisions are one of the most readable provisions of the GST Act.

Table 4.8: 2010 New Zealand Change-in-Use Provisions-Readability

\begin{tabular}{|c|c|c|c|c|c|c|c|c|c|c|}
\hline & \multicolumn{7}{|c|}{ Online Tool } & \multicolumn{3}{|c|}{ Word97 } \\
\hline Sections & Words & Paras & $S P S$ & WPS & Syllables & $S P W$ & $F R E *$ & $M S-F R E$ & $\begin{array}{c}M S- \\
\text { Words }\end{array}$ & $\begin{array}{l}M S- \\
W P S\end{array}$ \\
\hline Old & & & & & & & & & & \\
\hline 21 & 1611 & 27 & 8 & 201.38 & 2345 & 1.46 & -120.7 & 0 & 1608 & 81.5 \\
\hline Revised & & & & & & & & & & \\
\hline 21 & 561 & 15 & 5 & 112.2 & 814 & 1.45 & -29.8 & 31.5 & 560 & 41.2 \\
\hline $21 \mathrm{~A}$ & 113 & 6 & 3 & 37.67 & 191 & 1.69 & 25.6 & 38.6 & 113 & 17 \\
\hline $21 \mathrm{~B}$ & 167 & 5 & 3 & 55.67 & 256 & 1.53 & 20.6 & 3.8 & 167 & 35.6 \\
\hline $21 \mathrm{C}$ & 167 & 7 & 4 & 41.75 & 252 & 1.51 & 36.8 & 50.3 & 167 & 25 \\
\hline $21 \mathrm{CB}$ & 89 & 3 & 1 & 89 & 128 & 1.44 & -5.2 & 66.1 & 89 & 9 \\
\hline $21 \mathrm{D}$ & 90 & 3 & 1 & 90 & 136 & 1.51 & -12.4 & 31 & 90 & 41 \\
\hline $21 \mathrm{E}$ & 313 & 16 & 4 & 78.25 & 441 & 1.41 & 8.2 & 52.1 & 312 & 29.5 \\
\hline $21 \mathrm{~F}$ & 116 & 4 & 2 & 58 & 161 & 1.39 & 30.5 & 68.7 & 116 & 14 \\
\hline $21 \mathrm{G}$ & 212 & 7 & 5 & 42.4 & 315 & 1.49 & 38.1 & 42.1 & 211 & 34.6 \\
\hline $21 \mathrm{H}$ & 248 & 13 & 4 & 62 & 389 & 1.57 & 11.2 & 38 & 247 & 30.7 \\
\hline 21I & 388 & 13 & 5 & 7.6 & 575 & 1.48 & 2.7 & 38 & 388 & 37.2 \\
\hline Average & 224 & 8.36 & 3.36 & 61.32 & 32.54 & 1.49 & 11.48 & 41.83 & 223.6 & 28.6 \\
\hline New & & & & & & & & & & \\
\hline 21 & 261 & 10 & 5 & 52.2 & 406 & 1.56 & 22.3 & 30.8 & 257 & 33 \\
\hline $21 \mathrm{~A}$ & 73 & 4 & 1 & 73 & 121 & 1.66 & -7.5 & 35.9 & 72 & 25 \\
\hline $21 \mathrm{~B}$ & 209 & 12 & 4 & 52.25 & 307 & 1.47 & 29.5 & 57.3 & 206 & 24 \\
\hline $21 \mathrm{C}$ & 99 & 5 & 1 & 99 & 150 & 1.52 & -21.8 & 50.6 & 98 & 15 \\
\hline $21 \mathrm{D}$ & 174 & 8 & 3 & 58 & 289 & 1.66 & 7.5 & 48.1 & 171 & 21.6 \\
\hline $21 \mathrm{E}$ & 444 & 18 & 9 & 49.33 & 684 & 1.54 & 26.4 & 46.3 & 436 & 25.2 \\
\hline $21 \mathrm{~F}$ & 176 & 10 & 3 & 58.67 & 289 & 1.64 & 8.4 & 44.5 & 171 & 21 \\
\hline $21 \mathrm{G}$ & 671 & 27 & 9 & 74.56 & 1041 & 1.55 & -0.1 & 29.9 & 661 & 32.8 \\
\hline $21 \mathrm{H}$ & 220 & 6 & 4 & 55 & 316 & 1.44 & 29.5 & 38.9 & 217 & 31 \\
\hline Average & 258.55 & 11.11 & 4.33 & 63.55 & 400.33 & 1.56 & 10.46 & 42.47 & 254.33 & 25.4 \\
\hline
\end{tabular}

The new change-in-use provisions (that apply from 1 April 2011) have made little (if no) improvement, recording an average Word97 FRE score of 42.47. 
An FRE score of 10.46 is probably a more accurate reading. ${ }^{112}$ Again, a wider comparison against the average GST Act provisions confirms these provisions are still some of the most readable provisions of the GST Act. However, an FRE score of 10.46 is still very low and shows little improvement since the 1992 Tan \& Tower study.

Table 4.9: 2010 Word97 vs Online Tool-Average Readability of GST Act

\begin{tabular}{|c|c|c|c|c|c|c|c|c|c|}
\hline \multirow[b]{2}{*}{ GST Act } & \multirow{2}{*}{$\begin{array}{c}\text { Words } \\
\text { per } \\
\text { Section }\end{array}$} & \multirow{2}{*}{$\begin{array}{c}\text { Sentences } \\
\text { per } \\
\text { Section }\end{array}$} & \multirow{2}{*}{$\begin{array}{c}\text { Paras } \\
\text { per } \\
\text { Section }\end{array}$} & \multicolumn{2}{|c|}{$\begin{array}{c}\text { Flesch Reading } \\
\text { Ease (FRE) }\end{array}$} & \multicolumn{2}{|c|}{$\begin{array}{c}\text { Words per } \\
\text { Sentence (WPS) }\end{array}$} & \multicolumn{2}{|c|}{$\begin{array}{l}\text { Syllables per } \\
\text { Word }(S P W)\end{array}$} \\
\hline & & & & $F R E$ & $S T D$ & $W P S$ & $S T D^{*}$ & $S P W$ & $S T D^{*}$ \\
\hline Online tool & 511.73 & 5.13 & 17.37 & -25.08 & 62.88 & 99.53 & 61.09 & 1.54 & 0.12 \\
\hline Word97 & 510.93 & 5.13 & 17.37 & 34.91 & 18.66 & 37.58 & 15.78 & NA & NA \\
\hline
\end{tabular}

* STD is the standard deviation.

\section{Canada}

The Canadian picture is not dissimilar to New Zealand prior to reform (see Table 4.10 below). The total average FRE score is -69.56 (deemed to be zero). ${ }^{113}$ Similar to the old New Zealand change-in-use rule, the provisions have very high words-persentence cores (ranging from 75 to 265). Generally, readability is extremely poor across all the Canadian provisions (especially ss 196.1 and 207). Yet, despite the poor average readability, the volume of litigation is relatively low.

A comparison between the legislative provisions associated with the two approaches of apportionment of non-capital and real property (ss 141, 169, 172, 196.1, 206, 207, 208) and adjustment of capital property (ss 141.01, 196, 199, and 200), while removing any provisions that are used by both approaches (s 197), provides a more interesting picture. The apportionment provisions have much higher average wordsper-sentence (WPS) scores than the adjustment provisions (158.11 vs 83.12) and poorer average FRE scores (-94.74 vs -19.13). This would suggest a higher degree of

\footnotetext{
${ }^{112}$ Word97 provides an FRE score of 42.47. The difficulty with the Word97 FRE score is that the WPS score (as discussed above) does not match the raw data. If Word97 is using the WPS score of 37.58, it may well be undermining the FRE score it delivers. For this reason the online FRE score of 10.46 is preferred, unless making comparisons to the Richardson \& Smith study.

${ }^{113}$ The Word97 FRE score is 20.62.
} 
complexity in applying the apportionment rules, and one would correspondingly expect greater litigation activity for these rules. However, the fact there is no major difference in litigation activity between the two approaches might suggest that apportionment approach is better than the adjustment approach.

Table 4.10: 2010 Canadian Change-in-Use Provisions - Average Readability

\begin{tabular}{|c|c|c|c|c|c|c|c|c|c|c|}
\hline & \multicolumn{7}{|c|}{ Online Tool } & \multicolumn{3}{|c|}{ Word97 } \\
\hline Sections & Words & Paras & $S P S$ & $W P S$ & Syllables & $S P W$ & FRE & $\begin{array}{l}\text { MS- } \\
F R E\end{array}$ & $\begin{array}{r}M S- \\
\text { Words }\end{array}$ & $\begin{array}{l}M W- \\
W P S\end{array}$ \\
\hline 197 & 165 & 6 & 1 & 165 & 256 & 1.55 & -91.9 & 0 & 165 & 92 \\
\hline \multicolumn{11}{|c|}{ Apportionment provisions } \\
\hline 141 & 447 & 7 & 5 & 89.4 & 696 & 1.56 & -15.6 & 0 & 447 & 79.2 \\
\hline 169 & 1128 & 29 & 10 & 112.8 & 1759 & 1.56 & -39.6 & 27.7 & 1119 & 45.3 \\
\hline 172 & 338 & 9 & 3 & 129.3 & 651 & 1.68 & -66.4 & 45.7 & 387 & 23.6 \\
\hline 196.1 & 265 & 7 & 1 & 265 & 438 & 1.65 & -202 & 53.1 & 265 & 16 \\
\hline 206 & 690 & 24 & 5 & 138 & 135 & 1.64 & -72.4 & 41.4 & 688 & 34 \\
\hline 207 & 473 & 15 & 2 & 236.5 & 821 & 1.74 & -180.1 & 42.3 & 472 & 36.5 \\
\hline 208 & 543 & 15 & 4 & 135.75 & 1002 & 1.85 & -87.1 & 0 & 542 & 60 \\
\hline Average & 554.86 & 15.14 & 4.28 & 158.11 & 786 & 1.67 & -94.74 & 30 & 560 & 42.08 \\
\hline \multicolumn{11}{|c|}{ Adjustment provisions } \\
\hline 141.01 & 1145 & 39 & 14 & 81.79 & 1791 & 1.56 & -8.5 & 32.8 & 1141 & 35.3 \\
\hline 196 & 150 & 2 & 2 & 75 & 261 & 1.74 & -16.5 & 0 & 150 & 75 \\
\hline 199 & 466 & 11 & 5 & 93.2 & 813 & 1.74 & -35.4 & 8.9 & 466 & 51.8 \\
\hline 200 & 660 & 17 & 8 & 82.5 & 1086 & 1.65 & -16.1 & 20.6 & 655 & 51.7 \\
\hline Average & 605.25 & 17.25 & 7.25 & 83.12 & 987.75 & 1.67 & -19.13 & 15.58 & 603 & 53.45 \\
\hline \multicolumn{11}{|c|}{ All Provisions } \\
\hline Average & 539.17 & 15.08 & 5 & 133.69 & 809.08 & 1.66 & -69.30 & 22.71 & 541.42 & 50.03 \\
\hline
\end{tabular}

Comparing the main apportionment provision for non-capital and real property (s 169) against the main adjustment provisions for capital property (ss 199 and 200), it appears there is no substantial difference in the WPS scores (1128 words vs $466+$ 660 words) or FRE scores (-39.6 vs -35.4 ). Taking into consideration the poor readability and the relatively low litigation history, it would appear that the success of Canada's change-in-use provisions must be due to other factors. The invariable conclusion (in the absence of low audit activity) is that the Canadian GST legislation has been able to draw upon earlier experiences in other areas of law (eg, income tax law). While this appears to account for the low litigation rate, it still does not 
mitigate what must be high compliance costs for taxpayers in terms of reading and understanding the law.

\section{F. Analysis}

\section{Sentence Length}

The Working Party on the Reorganisation of the Income Tax Act 1976 identified an average of 30 words per sentence as a benchmark to guide the rewrite process. ${ }^{114}$ Kongold also suggests that the length and complexity of many legislative sentences provides an unnecessary challenge for readers. ${ }^{115}$ Legislative sentences that are long tend to contain too many elements (ie, ideas, actions, or exemptions) for a reader to absorb. ${ }^{116}$ After two or three ideas the reader needs to pause and digest what has been said. According to Kongold, ${ }^{117}$ "every modern authority on legislative drafting condemns long sentences, even if they are accurate and grammatical".

Subsequent studies have returned varying average scores (see Table 4.11 below). Only the Australian GST Act (according to the Richardson \& Sawyer study) and to a lesser extent the New Zealand Income Tax Act (according to the Pau et al and Saw \& Sawyer study) meet the Working Party guidelines. The New Zealand GST Act appears to lag behind the New Zealand Income Tax Act 2007 and Australian GST Act.

However, the New Zealand change-in-use provisions (see Table 4.12 below) indicate that since their revision (and codification) average sentence length has been within the Working Party guidelines. While the study confirms Australia is also within the

\footnotetext{
${ }^{114}$ Working Party on the Reorganisation of the Income Tax Act 1976 Second Report of the Working Party (Wellington, September 1993), Chapter 7.

${ }^{115}$ S Krongold "Writing Laws: Making The Easier to Understand" (1992) 24 Ottawa Law Review 495 at 514. See also G Thornton Legislative Drafting ( $3^{\text {rd }}$ ed, Butterworths, Toronto, 1987). Both authors discuss elements of good legislative drafting (eg, language, structure, and typography). Their suggestions are ones that drafters would be wise to accommodate. It would appear the Australian GST legislation has taken them on board.

${ }^{116}$ VR Charrow and MK Erhardt Clear and Effective Legal Writing (Little, Brown and Co, Boston, 1986) 96-97.

${ }^{117}$ S Krongold "Writing Laws: Making The Easier to Understand" (1992) 24 Ottawa Law Review 495 at 515. See also EA Dreidger A Manual of Instructions for Legislative and Legal Writing (Ottawa, 1982) 556-557.
} 
Working Party guidelines, this 2010 study has produced markedly higher average sentence lengths than recorded in the 2002 Richardson \& Smith study.

Table 4.11: Comparison of Empirical Studies - Average Word FRE and WPS Scores

\begin{tabular}{|l|c|c|c|c|c|c|}
\hline & 2010 & 2010 & 2007 & 2002 & 2002 & 1992 \\
& $\begin{array}{c}\text { Thesis } \\
\text { (GSTA 1985) }\end{array}$ & $\begin{array}{c}\text { S\&S } \\
\text { (ITA 2007) }\end{array}$ & $\begin{array}{c}\text { PM\&S } \\
\text { (ITA 2004) }\end{array}$ & $\begin{array}{c}\text { R\&S } \\
\text { (ITA 2004) }\end{array}$ & $\begin{array}{c}\text { R\&S } \\
\text { (GST 2002) }\end{array}$ & $\begin{array}{c}\text { T\&T } \\
\text { (GSTA 1985) }\end{array}$ \\
\hline FRE & 34.91 & $42.77 * *$ & $41.7 *$ & 16.11 & 40.3 & 0 \\
\hline WPS & 37.58 & $25.03 * *$ & $34 *$ & 43 & 20.9 & 128.11 \\
\hline
\end{tabular}

* Scores based on Word 2003. ** Scores based on Word2007. All others based on Word97.

As illustrated above, the discrepancy in data is probably due to the Richardson \& Smith study not including all the Division 129 provisions. When a true comparison is made by only comparing those provisions measured by Richardson \& Smith, this study returned a WPS score of 20.8 (and FRE score 34.48), which is very similar to the scores returned by the Richardson \& Smith study. The Canadian and old New Zealand GST change-in-use rules provisions on the other hand provide sentence lengths that are substantially higher than the Working Party guidelines.

Not only does the Australian GST legislation have the lowest number of words-persentence (WPS), but it also has the lowest average number of sentences-per-section (SPS). ${ }^{118}$ This observation, in conjunction with the average number of paragraphs and words per section, provides an interesting picture of the structure of the Australian GST Act.

In contrast, both the Canadian and New Zealand GST Acts have markedly longer sections in terms of total words and number of paragraphs. The New Zealand and Canadian GST Acts would also appear to use substantially more paragraphs than the Australian GST Act, probably to break up elements of a provision. The Australian approach would appear to separate elements into separate provisions. As Kongold points out, a section with too many subsections is difficult to read and understand. ${ }^{119}$

\footnotetext{
${ }^{118}$ This probably accounts for its high volume of provisions.

${ }^{119}$ S Krongold "Writing Laws: Making The Easier to Understand" (1992) 24 Ottawa Law Review 495 at 510 .
} 
The presence of a high number of paragraphs in the New Zealand and Canadian GST Acts would also appear to suggest that they are overly complex.

Table 4.12: Comparison of Change-in-Use Provisions - Average FRE and WPS Scores

\begin{tabular}{|c|c|c|c|c|c|c|c|c|c|c|}
\hline & \multicolumn{7}{|c|}{ Online Tool } & \multicolumn{3}{|c|}{ Word97 } \\
\hline Sections & Words & Paras & SPS & WPS & Syllables & $S P W$ & $F R E *$ & $\begin{array}{l}M S- \\
F R E\end{array}$ & $\begin{array}{c}M S- \\
\text { Words }\end{array}$ & $\begin{array}{l}M S- \\
W P S\end{array}$ \\
\hline NZ (Old) & 1611 & 27 & 8 & 201.38 & 2345 & 1.46 & -120.7 & 0 & 1608 & 81.5 \\
\hline NZ (Revised) & 224 & 8.36 & 3.36 & 61.32 & 32.54 & 1.49 & 11.48 & 41.83 & 223.6 & 28.6 \\
\hline NZ (New) & 258.55 & 11.11 & 4.33 & 63.55 & 400.33 & 1.56 & 10.46 & 42.47 & 254.33 & 25.4 \\
\hline Canada & 557.45 & 15.64 & 5.18 & 134.09 & 823.45 & 1.66 & -69.56 & 20.62 & 555.45 & 54.15 \\
\hline Australia & 135.36 & 6.36 & 2.93 & 55.47 & 222.79 & 1.64 & 18.81 & 28.89 & 133.00 & 26.96 \\
\hline Benchmarks & & & & & & & & & & \\
\hline 2002 R\&S study & & & & & & & & 32.75 & & 19.2 \\
\hline 2010 GST study & & & & & & & & 34.91 & & 37.58 \\
\hline
\end{tabular}

\section{Syllable scores}

Tan \& Tower found that the New Zealand GST Act (based on a small sample of GST provisions) returned a syllable-per-word (SPW) score of 1.56 to 1.57 (with a standard deviation of 0.08 to 0.09 ). This study (based on data returned from the Online tool) confirmed those original syllable scores from the provisions tested by Tan \& Tower. This study found that the New Zealand GST Act had an average SPW score of 1.54 (with a standard deviation of 0.12 ). ${ }^{120}$ It also identified that the average SPW scores (see Table 4.12 above) for the respective change-in-use provisions have been increasing since the New Zealand GST Act was first enacted (from 1.46 to 1.56). It would appear words are getting bigger. Technically (all other elements remaining constant) this should result in a poor FRE score. However, the reverse is evident and is due principally to the marked reduction in the total words-per-section. In comparison, both the Australian and Canadian change-in-use provisions have higher syllable scores.

\footnotetext{
${ }^{120}$ The difference (albeit surprisingly marginal) can be attributable to a larger data sample, thus providing a more accurate score. Moreover, the Tan \& Tower scores fall within the standard deviations of this study.
} 
The New Zealand GST Act returned an average (Word97) FRE score that was only slightly higher than the average score returned in the Richardson \& Smith study (see Table 4.12 above). This result appears to suggest the New Zealand GST Act is slightly better drafted than the Australian GST Act. Moreover, the revised (and new) New Zealand change-in-use provisions appeared to return an average FRE score higher than the average for both the New Zealand and Australian GST Acts. However, not surprisingly, both the old New Zealand and current Canadian changein-use provisions returned poorer FRE scores. The similarity in (Word97) FRE scores is somewhat surprising, especially given the significant disparity in the total amount of words that appear in the respective provisions.

This unexpected result would appear to be due to the manner in which Word97 returns equally surprising low word-per-sentence scores (in complete incongruence to actual word and sentence scores). Accordingly, it is submitted a more accurate picture of comparative FRE scores is obtained from the data generated from the Online tool.

As Table 4.12 illustrates, the Australian change-in-use provisions provide a FRE score nearly twice as good as the revised (and new) New Zealand change-in-use provisions, and no doubt a larger gap would appear between the Act averages, if the Australian data had used the online tool, rather than Word97. Similarly, a much larger gap appears between the old New Zealand change-in-use provisions and Canadian change-in-use provisions, compared to the Australia provisions.

\section{Alternative measures of complexity}

Redish \& Selzer ${ }^{121}$ suggest that readability formulae are inadequate measures of how difficult technical material is to read on the grounds that readability formulae do not take into account the content, organisation and layout of reading material. The Flesch Reading Ease (FRE) index is itself based only on two elements: words-per-sentence

${ }^{121}$ J Redish and J Selzer "The Place of Readability Formulas in Technical Communication" (1985) 32 Technical Communication 46, cited in A Sawyer "New Zealand's Tax Rewrite Program - In Pursuit of the (Elusive) Goal of Simplicity" (2007) British Tax Review 405 at 419. Document available at: <www.rbainformationdesign.com.au/Readability“Formulas.pdf> (viewed 20 March 2011). 
(eg, sentence length) and syllables-per-word (eg, word length). FRE fails to take into account structure (eg, the use of paragraphs to break up content), the use of diagrams and flowcharts, or the total number of words in a provision (eg, some provisions contain over 1,000 words in some instances, which would tend to suggest the existence of too many ideas or exceptions being communicated). Equally, syllable scores do not necessarily reflect word complexity or topic complexity. Some words may have complex definitions that are not factored in to the overall score. Nor does it indicate the unique drafting features of legislation (eg, the use of double negatives or the use of exemptions from exemptions). However, Pau et al, has suggested that the FRE scores do provide an important and comparable measure of the readability of tax materials and should not be ignored. Moreover, Richardson \& Sawyer have suggested that FRE scores should be considered in conjunction with other measures of readability, by way of triangulation of results, to corroborating research findings and recommendations.

It is submitted that the use of alternative readability formulae and other structural measures (eg, instances of defined terms, exceptions, and external references) do provide a degree of triangulation recommended by Richardson \& Sawyer. The variations in FRE scores are to a degree reflective of syllable scores. Substituting syllables for another measure of word complexity might provide more stable comparisons and better reflect complexity.

In this regard, C-Fog and SMOG (which compute only words with 3 or more syllables as complex, rather than compute all syllables) and C-Liau, and ARI (which measure word length in terms of characters, rather than syllables) are good candidates. The aforementioned indexes provide a measure of readability similar to the F-KGL score (eg, years of educational level), so the lower the score the more readable the provision. ${ }^{122}$ As illustrated in Table 4.13 below, the alternative readability indexes to F-KGL, do provide less variability and more compressed scores (although ARI appears to return higher scores than F-KGL).

\footnotetext{
${ }^{122}$ It is acknowledged that these measures suffer the same inability to accommodate the unique drafting features of legislation.
} 
Applying F-KGL G-Fog, and SMOG, the Australian change-in-use provisions return the lower scores (ie, are more readable) than any other jurisdiction. It is equally noticeable that Canada scores comparatively quite high in G-Fog, which would appear to suggest the legislation uses more words comprising three syllables, than any other jurisdiction. However, the difference between the jurisdictions is less pronounced using measures that compute word complexity in terms of character length (ie, C-Liau). In fact it would appear that New Zealand's revised (and new), change-in-use rules use shorter words (measured in character length) than any other jurisdiction. However, while New Zealand's change-in-use rules appear to be heading in the right direction (no doubt due to more recent versions being written), the remainder of the GST Act has not performed so well (see Appendix 1).

Table 4.13: Alternative Readability Scores for Change-in-Use Provisions

\begin{tabular}{|c|c|c|c|c|c|c|c|}
\hline Sections & $F R E$ & $F-K G L$ & G-Fog & SMOG & C-Liau & $A R I$ & $M S F R E$ \\
\hline \multicolumn{8}{|l|}{ Canada } \\
\hline 141 & -15.6 & 37.6 & 42.7 & 22.6 & 11.3 & 44.9 & 0 \\
\hline 141.01 & -8.5 & 34.8 & 38.7 & 20.5 & 11 & 40.9 & 32.8 \\
\hline 169 & -39.6 & 46.8 & 51.1 & 24.2 & 10.4 & 55.9 & 27.7 \\
\hline 196 & -16.5 & 34.2 & 37.7 & 21.8 & 12.3 & 38.5 & 0 \\
\hline 196.1 & -202 & 107.3 & 114.8 & 43.5 & 11.8 & 133.1 & 53.1 \\
\hline 197 & -91.9 & 67.1 & 74.2 & 33.4 & 7.9 & 80 & 0 \\
\hline 199 & -35.4 & 41.3 & 47.5 & 28.4 & 12.7 & 48 & 8.9 \\
\hline 200 & -16.1 & 36 & 41.5 & 24.9 & 11.1 & 41.4 & 20.6 \\
\hline 206 & -72.4 & 57.6 & 63.4 & 30.9 & 11.7 & 69.9 & 41.4 \\
\hline 207 & -180.1 & 97.1 & 103.2 & 41.2 & 11.2 & 118.4 & 42.3 \\
\hline 208 & -87.1 & 59.1 & 64.5 & 34.1 & 12.5 & 69 & 0 \\
\hline \multicolumn{8}{|l|}{ Australia } \\
\hline 129 1 & 46.6 & 13.1 & 14.9 & 10.1 & 11.1 & 12.8 & 42.7 \\
\hline $129 \sim 5$ & 7.7 & 23.2 & 26.3 & 19 & 13.1 & 23.9 & 30.2 \\
\hline $129 \sim 10$ & 19 & 20.3 & 22.8 & 16.3 & 11.6 & 20 & 11.2 \\
\hline $129 \sim 15$ & 24.6 & 18.8 & 21.1 & 16.3 & 12.5 & 19.2 & 9.3 \\
\hline $129 \sim 20$ & -9.2 & 32.7 & 37.8 & 24.2 & 9.4 & 35.3 & 17 \\
\hline $129 \sim 25$ & -4.4 & 32.3 & 37.4 & 22.7 & 9.6 & 36 & 30 \\
\hline $129 \sim 40$ & 41.2 & 13.5 & 17.3 & 13.2 & 12.2 & 13 & 42.8 \\
\hline $129 \sim 45$ & 3.5 & 27.8 & 31.1 & 19.3 & 9.2 & 28.9 & 23.5 \\
\hline $129 \sim 50$ & 37.3 & 17.2 & 19 & 12.9 & 10.1 & 17.6 & 47 \\
\hline
\end{tabular}




\begin{tabular}{|l|c|c|c|c|c|c|c|}
\hline $129 \sim 55$ & 41 & 16.5 & 18.8 & 11.6 & 10 & 17.2 & 60.7 \\
\hline $129 \sim 70$ & -50 & 51.3 & 55.4 & 24.3 & 9.4 & 61.2 & 36.1 \\
\hline $129 \sim 75$ & 49.3 & 50.9 & 55.1 & 24.3 & 9.6 & 60.9 & 36.1 \\
\hline $129 \sim 80$ & 21.3 & 24.4 & 24.9 & 14.1 & 7.3 & 25.6 & 0 \\
\hline $129 \sim 90$ & 35.4 & 13.4 & 18 & 13.5 & 12.6 & 11.6 & 17.9 \\
\hline New Zealand & & & & & & & \\
\hline Old & & & & & & & \\
\hline 21 & -120.7 & 80.1 & 85.5 & 26.7 & 9.6 & 9.6 & 0 \\
\hline Revised & & & & & & & \\
\hline 21 & -29.8 & 45.3 & 47.9 & 19.2 & 8.5 & 54.1 & 31.5 \\
\hline $21 \mathrm{~A}$ & 25.6 & 19 & 21.4 & 14.9 & 13 & 20.5 & 38.6 \\
\hline $21 \mathrm{~B}$ & 20.6 & 24.2 & 28 & 16.3 & 11.2 & 28 & 3.8 \\
\hline $21 \mathrm{C}$ & 36.8 & 18.5 & 22 & 13.8 & 10 & 20.1 & 50.3 \\
\hline $21 \mathrm{CB}$ & -5.2 & 36.1 & 38.3 & 16.3 & 10.3 & 44 & 66.1 \\
\hline $21 \mathrm{D}$ & -12.4 & 37.3 & 40.9 & 19.9 & 10.5 & 44.6 & 31 \\
\hline $21 \mathrm{E}$ & 8.2 & 31.6 & 34.5 & 14.7 & 8.4 & 37.1 & 52.1 \\
\hline $21 \mathrm{~F}$ & 30.5 & 23.4 & 26 & 12.9 & 9.2 & 27.6 & 68.7 \\
\hline $21 \mathrm{G}$ & 38.1 & 18.5 & 22.1 & 13.9 & 9.2 & 19.8 & 42.1 \\
\hline $21 \mathrm{H}$ & 11.2 & 27.1 & 28.8 & 17 & 9.8 & 30.1 & 38 \\
\hline $21 \mathrm{I}$ & 2.7 & 32.2 & 35.4 & 17.2 & 8.7 & 37 & 38 \\
\hline New & & & & & & & \\
\hline 21 & 22.3 & 23.1 & 28.2 & 18 & 10.9 & 26 & 30.8 \\
\hline $21 \mathrm{~A}$ & -7.5 & 32.4 & 37.4 & 22.9 & 11.9 & 37.2 & 35.9 \\
\hline $21 \mathrm{~B}$ & 29.5 & 22.1 & 22.5 & 14.1 & 9 & 24.5 & 57.3 \\
\hline $21 \mathrm{C}$ & -21.8 & 40.9 & 46.9 & 24.3 & 11.4 & 49.8 & 50.6 \\
\hline $21 \mathrm{D}$ & 7.5 & 26.6 & 31.7 & 20.1 & 10.8 & 28.9 & 48.1 \\
\hline $21 \mathrm{E}$ & 26.4 & 21.8 & 24.5 & 14.2 & 9.2 & 23.2 & 46.3 \\
\hline $21 \mathrm{~F}$ & 8.4 & 26.7 & 30.1 & 18.7 & 11.1 & 29.4 & 44.5 \\
\hline $21 \mathrm{G}$ & -0.1 & 31.8 & 36.6 & 20.9 & 10 & 36.5 & 29.9 \\
\hline $21 \mathrm{H}$ & 29.5 & 22.8 & 25.3 & 13.2 & 7.9 & 25 & 38.9 \\
\hline
\end{tabular}

In response to the apparent weakness of the FRE index a series of other measures were captured (see Table 4.14 below), that included: the total number of instances that a defined term, exception, proviso (or exception), paragraph, and external legislative reference, appeared in a provision, together with the total word count of each provision. These measures, together with readability, provide a much clearer picture of the structural complexity of the change-in-use provisions. 
Table 4.14: Structural Complexity for Change-in-Use Provisions

\begin{tabular}{|c|c|c|c|c|c|c|c|}
\hline Sections & Words & Paras & Sentence & WPS & Defins & Proviso & External Refs \\
\hline \multicolumn{8}{|l|}{ Canada } \\
\hline 141 & 447 & 7 & 5 & 89.4 & 50 & 0 & 0 \\
\hline 141.01 & 1145 & 39 & 14 & 81.79 & 114 & 0 & 2 \\
\hline 169 & 1128 & 29 & 10 & 112.8 & 123 & 0 & 14 \\
\hline 196 & 150 & 2 & 2 & 75 & 19 & 0 & 0 \\
\hline 196.1 & 265 & 7 & 1 & 265 & 43 & 0 & 0 \\
\hline 197 & 165 & 6 & 1 & 165 & 19 & 0 & 10 \\
\hline 199 & 466 & 11 & 5 & 93.2 & 63 & 1 & 4 \\
\hline 200 & 660 & 17 & 8 & 82.5 & 97 & 3 & 6 \\
\hline 206 & 690 & 24 & 5 & 138 & 92 & 2 & 1 \\
\hline 207 & 473 & 15 & 2 & 236.5 & 59 & 2 & 2 \\
\hline 208 & 543 & 15 & 4 & 135.75 & 78 & 0 & 0 \\
\hline \multicolumn{8}{|c|}{ New Zealand } \\
\hline Old & & & & 201.38 & & & \\
\hline 21 & 1611 & 27 & 8 & & 149 & 4 & 31 \\
\hline \multicolumn{8}{|l|}{ Revised } \\
\hline 21 & 561 & 15 & 5 & 112.2 & 53 & 3 & 9 \\
\hline $21 \mathrm{~A}$ & 113 & 6 & 3 & 37.67 & 10 & 0 & 0 \\
\hline 21B & 167 & 5 & 3 & 55.67 & 19 & 0 & 2 \\
\hline $21 \mathrm{C}$ & 167 & 7 & 4 & 41.75 & 25 & 0 & 1 \\
\hline $21 \mathrm{CB}$ & 89 & 3 & 1 & 89 & 0 & 0 & 3 \\
\hline 21D & 90 & 3 & 1 & 90 & 16 & 0 & 3 \\
\hline $21 \mathrm{E}$ & 313 & 16 & 4 & 78.25 & 46 & 0 & 9 \\
\hline $21 \mathrm{~F}$ & 116 & 4 & 2 & 58 & 22 & 1 & 2 \\
\hline $21 G$ & 212 & 7 & 5 & 42.4 & 23 & 2 & 5 \\
\hline $21 \mathrm{H}$ & 248 & 13 & 4 & 62 & 23 & 1 & 7 \\
\hline 21I & 388 & 13 & 5 & 7.6 & 25 & 1 & 17 \\
\hline \multicolumn{8}{|l|}{ New } \\
\hline 21 & 261 & 10 & 5 & 52.2 & 24 & 1 & 17 \\
\hline $21 \mathrm{~A}$ & 73 & 4 & 1 & 73 & 11 & 0 & 1 \\
\hline 21B & 209 & 12 & 4 & 52.25 & 23 & 1 & 5 \\
\hline $21 \mathrm{C}$ & 99 & 5 & 1 & 99 & 16 & 0 & 1 \\
\hline 21D & 174 & 8 & 3 & 58 & 16 & 0 & 3 \\
\hline $21 \mathrm{E}$ & 444 & 18 & 9 & 49.33 & 32 & 1 & 2 \\
\hline $21 \mathrm{~F}$ & 176 & 10 & 3 & 58.67 & 14 & 0 & 1 \\
\hline $21 \mathrm{G}$ & 671 & 27 & 9 & 74.56 & 66 & 2 & 24 \\
\hline
\end{tabular}




\begin{tabular}{|c|c|c|c|c|c|c|c|}
\hline $21 \mathrm{H}$ & 220 & 6 & 4 & 55 & 15 & 1 & 7 \\
\hline \multicolumn{8}{|c|}{ Australia } \\
\hline 129 1 & 51 & 1 & 2 & 25.5 & 0 & 0 & 1 \\
\hline $129 \sim 5$ & 89 & 8 & 2 & 44.5 & 8 & 1 & 0 \\
\hline $129 \sim 10$ & 117 & 5 & 3 & 39 & 5 & 0 & 2 \\
\hline $129 \sim 15$ & 36 & 1 & 1 & 36 & 1 & 0 & 1 \\
\hline $129 \sim 20$ & 366 & 15 & 5 & 73.2 & 2 & & 4 \\
\hline $129 \sim 25$ & 223 & 15 & 3 & 74.33 & 4 & 2 & 4 \\
\hline $129 \sim 40$ & 338 & 15 & 14 & 24.14 & 23 & 0 & 2 \\
\hline $129 \sim 45$ & 182 & 7 & 3 & 60.67 & 7 & 2 & 2 \\
\hline $129 \sim 50$ & 110 & 5 & 3 & 36.67 & 10 & 1 & 0 \\
\hline $129 \sim 55$ & 36 & 4 & 1 & 36 & 0 & 0 & 0 \\
\hline $129 \sim 70$ & 125 & 5 & 1 & 125 & 5 & 0 & 3 \\
\hline $129 \sim 75$ & 124 & 5 & 1 & 124 & 5 & 0 & 4 \\
\hline $129 \sim 80$ & 57 & 1 & 1 & 57 & 1 & 0 & 6 \\
\hline 129 90 & 41 & 2 & 1 & 20.5 & 2 & 0 & 1 \\
\hline
\end{tabular}

Immediately evident is the striking similarity in structure between the Canadian provisions (s 169) and original New Zealand provision (s 21) - both the worst provisions in terms of highest total words, words-per-sentence, number of paragraphs, instances of defined terms, and external references, to other provisions. Yet surprisingly, the Canadian provision advocates an apportionment approach and the New Zealand provision a threshold adjustment approach. However, it is noticeable how much the New Zealand provision has improved after revision in 2000. It is also striking to see the similarity between the Canadian and New Zealand drafting style in terms of the usage of definitions, which add another layer of complexity to understanding the meaning of a provision. In contrast, the Australian provisions (which adopt an apportionment approach) have low definition and external reference scores.

It is also noticeable that New Zealand's revised adjustment rules are much longer than Australia's apportionment rules. From the discussion above, shorter simpler rules are preferred from a complexity and compliance perspective. However, in comparison to Australia, New Zealand's former rules (and especially the measurement rules) are more detailed, run over several sections, and comprise many more words. It would appear that comparatively, New Zealand's revised adjustment 
rules are from a legislative perspective, much more complex than Australia's apportionment rules.

\section{G. Conclusion}

It would appear from the empirical evidence that any technical or structural complexity in the change-in-use provisions does not explain the different outcomes in the respective jurisdictions. Canada received very poor readability scores and appears to have poorly structured provisions, yet its litigation activity is similar to Australia, whose readability scores are markedly better. Only New Zealand's original change-in-use provisions received readability scores that would appear to indicate a significant correlation between poor readability and high compliance costs (eg, high litigation activity) — although the New Zealand experience could equally be attributable to the underlying policy (ie, the use of a threshold adjustment approach, rather than apportionment). This later observation is even more perplexing when one considers that the worst performing Canadian provision advocates an apportionment approach, and the New Zealand provision, a threshold adjustment approach. Yet, it is the New Zealand provision that has significantly more litigation activity in relation to change-in-use.

One is left to conclude that tax complexity may not have a significant correlation to legislative complexity for the change-in-use provisions, which would appear to suggest that tax complexity and consequential compliance costs might be more related to the underlying policy (ie, apportionment versus threshold adjustment approach). If this is the case, then the empirical data would appear to suggest that those jurisdictions that have used an apportionment approach tend to have lower litigation activity and therefore lower compliance costs, than those jurisdictions that have not.

The evidence also suggests that the expression of New Zealand's revised adjustment rules are longer and more complex than Australia's (and New Zealand's new) apportionment rules, which are shorter and easier to understand. The fact that the threshold adjustment policy approach requires lengthy expression in both in New Zealand and Canadian legislation suggests that from a certainty and compliance cost perspective, the apportionment rules should be preferred. 
While the introduction of the new apportionment rules may improve compliance costs for small and medium businesses, there remains a concern that the new provisions need to be further simplified to avoid any erosion of compliance cost gains. Submissions on the Taxation (GST and Remedial Matters) Bill 2010 (proposing the introduction of the apportionment rules) observed that "a number of new provisions are overly complex with ambiguity surrounding key terms and formulae. The legislative drafting, in our view, needs to be further simplified."

The empirical research of this study confirms the view that little has changed in terms of legislative complexity (and readability) between the New Zealand revised adjustment rules and the new apportionment rules. While, there has been a substantial improvement since the enactment of the original change-in-use provision, there is still room for substantial improvement, in both the change-in-use rules and in the wider GST Act.

Finally, this study provides empirical evidence that generally, New Zealand's GST provisions are overly complex in comparison to New Zealand's own income tax legislation and in comparison to Australia's GST Act. As the evidence illustrates, New Zealand's GST legislation (like the former New Zealand Income Tax Act 1976), is far from simple. The length of some provisions suggests a higher level of complexity than the readability scores might suggest. Many GST provisions are long, complex, and difficult to read. This conclusion is not dissimilar to that reached by the Valabh Committee (1992) when recommending that New Zealand's income tax legislation should be rewritten.

On the basis of the empirical evidence of this study the New Zealand GST Act would appear to fulfil the Valabh Committee's criteria for rewriting. Furthermore, the recent observations about the quality of drafting in the GST Act by Blanchard J

\footnotetext{
${ }^{123}$ KPMG Submissions on the Taxation (GST and Remedial Matters) Bill (9 September 2010) 2. Document available at $<$ www.parliament.nz/enNZ/PB/SC/Documents/Evidence/?Custom=00DBHOH_BILL10121_1> (viewed 20 March 2011).
} 
in his extra-judicial writing ${ }^{124}$ and in the Contract Pacific case in the New Zealand Supreme Court must also add weight to a general call to rewrite the GST Act.

${ }^{124}$ P Blanchard "Some Basic Concepts of New Zealand GST" in R Krever and D White (eds) GST in Retrospect and Prospect (Brookers Ltd, Wellington, 2007) 91 at 92. 


\section{CONCLUSIONS}

"Our tax system, like that of many other countries, depends essentially on the central strategy of voluntary compliance. Accordingly it is necessary to consider and balance the objectives of certainty, economic efficiency, and acceptability." Sir Ivor Richardson ${ }^{1}$

\section{A. Evaluating the Performance of the New Zealand Adjustment Approach}

It is clear from the empirical evidence that the former New Zealand adjustment rules have failed the tests of good tax design. Generally, the adjustment rules have provided a high degree of uncertainty (before and after Lundy), which has manifested itself in a high degree of litigation. The former New Zealand adjustment rules were inefficient and did not measure accurately non-taxable use or reduce compliance costs by actively reducing further adjustments.

\section{Administrative Simplicity}

A tax rule should be simple and inexpensive for taxpayers to comply with and for the revenue authority to administer and enforce. This has not been the case with the former New Zealand adjustment rules, which have resulted in high litigation activity over a prolonged period of time. The adjustment rules have inherently high compliance costs by requiring subsequent adjustments to occur to correct the overpayment of full initial input tax credits where purposes were initially mixed. In contrast, the apportionment rules provide mechanisms to reduce compliance cost in not only reducing the need for subsequent adjustments, but also in reducing the number of adjustments that have to be tracked. Furthermore, New Zealand's adoption of an alternative EUL method in the application of apportionment rules appears to have responded to concerns raised by larger organisations that greater alignment with income tax reporting methods would aid in further reducing existing compliance costs.

1 ILM Richardson "Launch of Journals by Sir Ivor Richardson” (1995) 1 New Zealand Journal of Taxation Law and Policy 196 at 197. 


\section{Coherence}

Prior to the Court of Appeal decision in Lundy, New Zealand's former adjustment rules were disconnected from the underlying policy intent of the legislation and allowed adjustments to exceed the initial input tax credits when using periodic taxable periods to account for adjustments. The disconnection between the initial supply and subsequent adjustments also illustrated that the supply rules were unable to provide the policy outcomes that they were being put under strain to achieve. These factors demonstrate that the adjustment rules provide poor coherence.

On a broader level, the apportionment approach offers greater symmetry and consistency with income tax law than the former adjustment approach. The new apportionment approach has removed a complicated layer of rules (eg "principal purpose" and a deemed supply mechanism) that does not exist in income tax law, and aligns business and accounting practices (eg, the availability of EUL) with income tax rules.

\section{Efficiency}

An adjustment approach does not reflect actual non-taxable use until after a deemed adjustment has been made. In contrast, an apportionment approach provides the opportunity for more accurate accounting of non-taxable use, thus minimising the economic distortions of the change-in-use rules. The former New Zealand adjustment rules have also required extensive investment in litigation activity. In contrast, the apportionment approach has widely experienced minimal litigation activity, with most cases dealing with questions of fact, rather than law.

New Zealand's former adjustment rules were unique and their model of operation has not been adopted in any other jurisdiction. This seriously limits the ability to learn from and possibly follow legal precedents from other jurisdictions. In contrast, the apportionment approach is simpler and more widely understood and will allow for greater harmonisation of rules with New Zealand's major trading partners. 


\section{Equity and Fairness}

New Zealand's former adjustment rules were not transparent, were poorly understood, and consequently resulted in a high level of litigation over a prolonged period of time. Judicial confusion in the interpretation of the rules also resulted in subsequent cases returning different outcomes for participants over an extended period of time (as the interpretation of the rules has evolved) and on appeal. The disconnection between the initial acquisition and subsequent adjustments, as well as the indefinite nature of adjustments, also resulted in taxpayers potentially remitting more tax than initially claimed. In contrast, the apportionment rules tend to experience lower levels of litigation activity and more accurately measure (in a more timely fashion) non-taxable supplies.

\section{Predictability}

The former New Zealand adjustment rules have not been certain or predictable. The judiciary has struggled to agree on how the rules operate or how adjustments should be calculated. Key elements of the rules have gradually changed over time (eg the principal purpose test shifting from a "more than half" to a "less than half" test). Equally, the courts (and taxpayers) have had to resort to "rough and ready" methodologies to provide statutorily required outcomes. In contrast, the Australian and Canadian apportionment rules provide easily measurable outcomes that can be more readily predicted. For this reason, these apportionment rules have not required the amount of litigation activity that has haunted the former New Zealand adjustment rules.

\section{Revenue Integrity}

While officials have regularly stated that the reform proposals are revenue neutral, the New Zealand adjustment rules provided a full input tax credit up-front that only took account of non-taxable activity in the subsequent period. This timing difference provided taxpayers an initial financial windfall and corresponding revenue gap. In contrast, the apportionment rules more accurately account for non-taxable activity and more effectively protect the tax base from over-payment of input tax credits. 
The New Zealand former adjustment rules have not been understood by taxpayers, tax advisors, or the courts, and have been considered complex and confusing. Revenue authority guidance has been minimal or lacking in sufficient detail. There has been judicial disagreement arising early in the consideration of the New Zealand rules. Furthermore, the guidance that has been provided has gradually degraded from binding rulings to just interpretation statements and has diminished taxpayer certainty in interpreting and applying the adjustment rules. The readability of the original adjustment rules was also poor and while readability has improved in subsequent revisions, it is still well below the readability of the New Zealand Income Tax Act 2007 or the equivalent provisions in the Australian GST Act.

\section{B. The Adjustment Approach Experience}

\section{Lessons from New Zealand}

If there is one central lesson from the New Zealand experience it is that the mechanics of the former adjustment rules were not clearly articulated by tax policymakers, leaving it to taxpayers, tax advisers, and the judiciary to struggle to formulate a workable model from the statutory language. Clearly, the underlying policy intent was to ensure that the GST Act provided a mechanism of adjustments that ensured the taxpayer paid no more or no less than they were obliged to (allowing for the obvious timing issues that the GST Act is premised upon). The New Zealand approach did utilise existing supply rules by creating a deemed supply, but, this created inherent problems. The existing supply rules had never contemplated the repetitive nature of a deemed supply which was required for change-in-use purposes, and the inevitable and indefinite recalculation of the same fictional supply. Protracted litigation was inevitable.

Assuming that a decision to use an adjustment approach is optimal, the change-inuse rules should have maintained a more than half approach that allowed for only one purpose (that being the principal purpose). Such an approach would have removed the opportunity for repetitive supplies and instead have provided a one-off adjustment process that merely asked the question whether the principal purpose had been abandoned or not. Effectively, the one-purpose model approach applied in 
Canada - a model that appears to produce far less litigation activity than in New Zealand.

Unfortunately, the New Zealand courts (in the absence of adequate guidance from tax policymakers and the tax administration) over a course of time embarked on a journey that would create an adjustment mechanism that was not only unique in the world, but disconnected adjustments from the initial (real) supply. The judges thus created an adjustment mechanism that could not have been contemplated by Parliament. It took 19 years before the New Zealand Court of Appeal in Lundy had an opportunity to attempt to fix the downstream effects of the judiciary's interpretation of the adjustment rules and to contain the potential for indefinite adjustments that would out-strip the original input tax credit.

However, while the Court of Appeal was able to resolve this problem and cap the number of adjustments, ${ }^{2}$ the New Zealand GST was still exposed to apportionment problems arising from the concurrent purpose model the courts had developed, and which it could only resolve from applying a "rough and ready" approach to apportionment. The fact that remedial legislation was enacted to plaster over the inherent problems of a concurrent purpose model, by statutorily allowing one-off adjustments, acknowledged the strain that the existing rules were under.

It has been suggested, that New Zealand did not have to abandon the adjustment approach (or principal purpose test), and that what was required to address the disconnection between the initial input tax credit and adjustments was the introduction of the adjustment capping mechanism applied in the Australian apportionment rules. ${ }^{3}$ There are several problems with this suggestion. First, the Australian adjustment mechanism would not necessarily have prevented the possibility of adjustments still exceeding initial input tax credits (especially in circumstances where assets substantial increase in value over short durations).

2 One-off adjustments were statutorily provided for in the 2000 reforms. Effectively, this merely codified what the Courts had already allowed.

3 PricewaterhouseCoopers Submissions on the Taxation (GST and Remedial Matters) Bill 2010 (undated, considered on 15 September 2010). Document available at <www.parliament.nz/NR/rdonlyres/65E97BA6-4B22-409D-ADF70F26C2ABE70C/159164/49SCFE_EVI_00DBHOH_BILL10121_1_A67947_Pricewaterho.pdf> (viewed 20 March 2011). 
Second, the suggestion also overlooks the fact that the GST supply mechanism (via deeming) was being asked to do something that it was not designed to do (and as the evidence suggests, failed to do very well). The fact the Court of Appeal were called upon to correct, not only the disconnection between the initial acquisition and adjustment, but also the disconnection between the underlying policy and the statutory rules themselves, suggests that further manipulation at the fringes would only invite further litigation. It would not have addressed the inherent problems that the New Zealand adjustment approach had. It is also evident that not everyone was convinced by the Court of Appeals reasoning $\mathrm{n} L u n d y .{ }^{4}$ Taking a long term perspective, it seems eminently more sensible to look towards a more stable set of rules (that also provides opportunities for harmonisation with the rules in Australia and elsewhere), than continuing on with an approach that was still open to dispute and on-going maintenance.

The empirical evidence shows that the New Zealand adjustment rules were complex and confusing. This view has been expressed by commentators, who made repeated submissions on the GST Act in its infancy and during subsequent reviews and reform initiatives. There has been substantial judicial consideration of the rules over a very long time. In some instances, the New Zealand judges have developed divergent interpretations, or have attempted to distinguish their interpretations from earlier interpretations, ${ }^{5}$ leading to difficult problems for appeal courts. The volume of New Zealand litigation was also quite high as a proportion of GST cases that appeared before the New Zealand courts, and compared to Australia and Canada.

The empirical data has also suggested that those jurisdictions that have used an apportionment approach tend to have lower litigation activity and therefore lower compliance costs than New Zealand had with its former adjustment rules.

\footnotetext{
4 Based on anecdotal conversations with officials and commentators.

5 Judge Willy's attempt in Case U49 (2000) 19 NZTC 9,429 (TRA), and successfully appealed in CIR v Carswell Investments Ltd (2001) 20 NZTC 17,149 (HC), could well be described as judicial dissention and a flawed attempt to distinguish itself from binding precedent.
} 


\section{Lessons from Canada}

As noted above, Canada appears to have adopted a different approach to adjustments than the rules applied in New Zealand. While the Canadian rules are more prescriptive than New Zealand's former adjustment rules, they are also far more liberal. For example, Canada's de minimis tests are not financially capped. However, this might also be due to the lower rate of GST (ie, less revenue at risk).

An inherent problem of the Canadian adjustment approach (ie, a one-purpose model) is the amount of revenue applied for non-taxable purposes that is not immediately accounted for. Essentially, this is a timing issue. In Canada, the GST rate is much lower, so the revenue gap is relatively smaller. However, New Zealand's rate of GST is much higher and exposure to this potential revenue risk appears to have been reduced by adopting a "less than half" approach to principal purpose so that subsequent adjustments would be larger and clawed back earlier (ie, before the 50 per cent threshold is met). Furthermore, while the GST Act ensures that the revenue will eventually be recaptured at some later time, there is always the possibility that in the absence of appropriate avoidance measures, that the revenue for non-taxable supplies will never be returned (eg, through phoenix entities). However, recent reforms in New Zealand have addressed some of these concerns. ${ }^{6}$

While New Zealand policy makers and revenue authority officials might emphasise that their major concerns have been compliance, it is equally apparent that the rules have also developed in response to revenue concerns. This is evident not only in the Crown's arguments made to the New Zealand courts (that appear to focus on clawing back non-taxable use as soon as possible), but also in the design choices made in the new apportionment rules (that sometimes adopt Crown positions argued in court) and in a general refusal to provide more liberal de minimis rules during recent reform discussions.

The empirical evidence shows that the Canadian adjustment rules are easier to understand and comply with. The amount of litigation is very low in comparison to

\footnotetext{
6 Taxation (GST and Remedial Matters) Act 2010 has introduced new rules intended to address phoenix entity in relation to land transacitons. For a recent outline of key features see Tax Information Bulletin Vol 23:1 (February 2011) 33-42.
} 
both the apportionment approach used in Canada and Australia, and also compared to the total amount of GST litigation in Canada. This is more surprising when the poor readability of the Canadian adjustment provisions is taken into account. One possible explanation for such low levels of Canadian litigation is lower levels of GST audit activity, but the evidence appears to suggest that audit activity is just as vigorous in Canada as in New Zealand.

\section{Assessment}

Overall the Canadian adjustment rules appear to have better administrative simplicity, visibility, predictability, coherence, and efficiency than New Zealand's adjustment rules, but have poorer revenue adequacy and revenue integrity. If revenue considerations were not as important as compliance (which is what the New Zealand reform proposals have constantly emphasised), then New Zealand might have been expected to look towards Canada's apportionment rules. The fact New Zealand has instead looked towards the Australian rules, would suggest revenue has been a much larger consideration in determining the New Zealand reform strategy, unless harmonisation of rules with Australia has been a major factor in the thinking of officials.

\section{The Apportionment Approach Experience}

\section{Lessons from Australia}

The Australian apportionment model comprises two important elements: a use test (providing immediate up-front apportionment), and a statutory mechanism for capping the number of adjustments. In contrast, the former New Zealand adjustment rules comprised a principal purpose test (the gateway into the system) and a deemed supply mechanism. In both systems an apportionment is undertaken between the taxable and non-taxable part of the supply.

How the apportionment is determined and how it is valued will determine the complexity of the system. There are two models. The first is a value parity (or "usedup") model that will only allow adjustments to be made until the total value of the adjustments equals the total value of the initial input tax claim. The second model is a disparate value model that disconnects the total value of the adjustment from the 
total value of the initial input tax claim. This disconnect in total values allows the total value of adjustments to exceed the total value of the initial acquisition.

Disparate models have no inherent mechanism to end the number of adjustments. The effect of the disparate model is accentuated when valuation methods are also disparate (eg initial acquisition is valued according to cost, but the adjustment values are derived from market value). The differences between the two models can also be described on the basis of the broader holistic approach of a "used-up" model that focuses on the initial acquisition, compared to a "disparate model" that is focused only on the adjustments.

The Australian apportionment rules adopt a parity $\operatorname{model}^{7}$ that also caps the number of adjustments based on the value of the transaction, rather than the assets EUL (as done in the UK). ${ }^{8}$ In the UK, the revenue authority has declared that adjustments will not exceed the value of the initial tax credits, regardless how adjustments are valued. However, it also appears to have provided an additional cap on the number of adjustment that can be made, based on EUL. ${ }^{9}$

Significantly, New Zealand has provided taxpayers the choice of either approach (ie, transaction value or EUL), but has excluded land from any additional capping mechanism. New Zealand has also not provided any additional differences in treatment in terms of the type of adjustment (eg, private or exempt) or type of entity (eg, financial or non-financial).

In terms of safe harbour thresholds and de minimis rules, all three jurisdictions have adopted different approaches in their respective apportionment rules (see Table 5.1). While the Canadian approach appears to provide a very simple rule, it fails to accommodate low value changes and is therefore high in compliance costs for low

7 The model is embodied in the statutory calculation methodology that takes into consideration the initial input tax credit. An explanation of the calculation methodology is provided in GST Ruling 2000/24. At present, there are no equivalent New Zealand rulings providing guidance.

${ }^{8}$ In contrast, the former New Zealand adjustment rules (pre-Lundy) were a disparate model. However, post-Lundy, they were a parity model.

9 For example, if an asset has a 20 year EUL it means adjustments cannot go beyond this point in time, even if the value of the adjustments at the end of 20 years does not yet exceed the initial input tax claim. 
value assets. In contrast, the Australian and New Zealand approaches have more complex rules that have low compliance costs for low value assets, but higher compliance cost for higher value assets.

Table 5.1: Comparison of De Minimis Rules in Australia, Canada and New Zealand

\begin{tabular}{|r|c|c|c|}
\hline & New Zealand & Australia & Canada \\
\hline Safe Harbour & $\$ 5,000$ & $\$ 1,000$ & Nil \\
\hline De minimis & & & $10 \%$ \\
\hline Single supply & $10 \%(\mathrm{NZ} \$ 1,000$ cap) & & $10 \%$ \\
\hline Annual & $5 \%(\mathrm{NZ} \$ 50,000$ cap)* & $5 \%($ AU $\$ 90,000$ cap) & \\
\hline
\end{tabular}

* Proposal to increase to $10 \%$.

New Zealand appears to have closely followed the current Australian adjustment thresholds (see Table 5.2). However, it would appear that New Zealand's apportionment rules have lower compliance costs than Australia for low value assets (eg, by adopting a higher safe harbour of $\$ 5,000$ and a limited 10 per cent de minimis rule).

Table 5.2: Comparison of Adjustment Thresholds in Australia and New Zealand

\begin{tabular}{|c|c|c|c|c|c|}
\hline \multicolumn{4}{|l|}{ Australia } & \multicolumn{2}{|l|}{ New Zealand } \\
\hline \multicolumn{2}{|l|}{ Current Rules } & \multicolumn{2}{|l|}{ Proposed Rules } & \multicolumn{2}{|l|}{ From 1 April 2011} \\
\hline Threshold & Periods & Threshold & Periods & Threshold & Periods \\
\hline Non Business Finance & & Private Use & & & \\
\hline$\$ 0-\$ 1,000$ & 0 & $\$ 0-\$ 1,999$ & 0 & $\$ 0-\$ 5,000$ & 0 \\
\hline$\$ 1,001-\$ 5,000 *$ & 2 & $\$ 2,000-\$ 14,999$ & 2 & $\$ 5,001-\$ 10,000$ & 2 \\
\hline$\$ 5,001-\$ 499,999$ & 5 & $\$ 15,000+$ & 5 & $\$ 10,001-\$ 500,000$ & 5 \\
\hline \multirow[t]{2}{*}{$\$ 500,000+$} & 10 & & & $\$ 500,001+$ & 10 \\
\hline & & $\$ 1,000,000+* *$ & 10 & & \\
\hline Business Finance & & Exempt Use & & & \\
\hline$\$ 0-\$ 10,000$ & 0 & $\$ 0-\$ 19,999$ & 0 & & \\
\hline$\$ 10,001-\$ 50,000 *$ & 2 & $\$ 20,000$ - $\$ 499,999$ & 2 & & \\
\hline$\$ 50,001-\$ 499,999$ & 5 & $\$ 500,000+$ & 5 & & \\
\hline \multirow[t]{2}{*}{$\$ 500,000+$} & 10 & & & & \\
\hline & & $\$ 5,000,000+* *$ & 10 & & \\
\hline \multicolumn{2}{|c|}{ * GST exclusive amounts. } & \multicolumn{2}{|c|}{ ** Applies to real property only. } & & \\
\hline
\end{tabular}


Whether Australia adopts a dual EUL and transaction threshold approach is hard to judge given they have already gone down a two-streamed approach. Given submissions on the Australian reforms have already suggested adoption of EUL, and revised reform proposals have not accommodated them, it would appear unlikely. No doubt Australia will be watching New Zealand with interest if an EUL approach outperforms a two streamed reduced adjustment period approach in terms of compliance costs and efficiency.

\section{Lessons from Canada}

Canada has adopted a "used-up" model of adjustments that calculates adjustments based on cost, not market value. The Canadian model has not sought to further constrain the number of adjustments by using an adjustment period mechanism that restricts the number of adjustments based on either transaction value or EUL. Rather, it has mitigated costs through the adoption of an uncapped 10 per cent de minimis rule. In all other aspects, the rules are similar to "use" based apportionment rules in other jurisdictions.

In relation to the apportionment methodology, all jurisdictions appear to recognise direct and indirect methods of apportionment. The New Zealand and Australian rules require a "fair and reasonable" estimate of use and also allow taxpayers to select a fair and reasonable method of adjustment (subject to the Commissioner's prior approval and provided it has regard to the tenor of the calculation methodology provided in the apportionment rules). In Canada, the courts have chosen not to interfere in the adoption of a "fair and reasonable" method of apportionment, thus avoiding the need to pick the best method. This is a sound approach that reduces room for litigation or judicial inquiry, which is both efficient and reduces compliance costs. In Australia, the courts have to date focused on the scope of elements in an apportionment method, rather than the method itself, and this would appear to be consistent with the approach in Canada.

\section{Assessment}

Generally the Canadian rules are very simple to understand in mechanical terms (although the readability of legislative provisions has room for improvement). However, Australia's apportionment rules appear to provide greater revenue 
adequacy and revenue integrity than Canada. The Australian rules also enable more flexible valuation approaches which could be considered more efficient. However, at present, it would appear that New Zealand's rules are the most efficient of all three jurisdictions and are more geared towards maximising existing accounting and income tax practices and therefore minimising compliance costs for businesses.

\section{Legislative Drafting}

Finally, consideration must be given to the drafting of the rules and Sir Kenneth Keith's observations on the need to rewrite tax legislation: ${ }^{10}$

\footnotetext{
"The four matters that I have mentioned, like the whole emphasis on plain drafting, are motivated by a number of considerations. One is simple efficiency. Time and money can be saved if legislation is written in a way which makes for ease of comprehension and, often as a consequence, a greater likelihood of compliance. Compliance costs are also reduced if the legislation does not have to be amended to take account of problems that were not appreciated because of the failure in any of the four respects."
}

The empirical evidence of this thesis and the observations from the Court of Appeal about the quality of drafting in the GST Act suggests that the New Zealand GST Act should be rewritten in plain language.

\section{E. Mapping Comparative Complexity}

A generalised picture (or matrix) of the three jurisdictions that compares policy and complexity (illustrated in Figure 5.1) can now be developed. The matrix uses litigation activity as a proxy for measuring policy complexity (horizontal axis) and FRE scores for measuring readability complexity (vertical axis). ${ }^{11}$ The left-hand side of the vertical axis are adjustment approaches, and the right-hand side of the axis are apportionment approaches. Those policy approaches closer to the centre are considered less complex than those further away.

\footnotetext{
${ }^{10}$ K Keith "The Need to Rewrite Tax Legislation" (1997) 3 New Zealand Journal of Taxation Law and Policy 96 at 98.

11 The New Zealand approaches (old and revised) are based on the same number of cases (46) as the revised rules merely codified earlier policy (see Chapter 1). The Canadian approaches are based on 58 adjustment cases and 39 apportionment cases (see Chapter 3). The Australian apportionment approach is based on one Division 129 case (see Chapter 2).
} 
Figure 5.1: Complexity Matrix

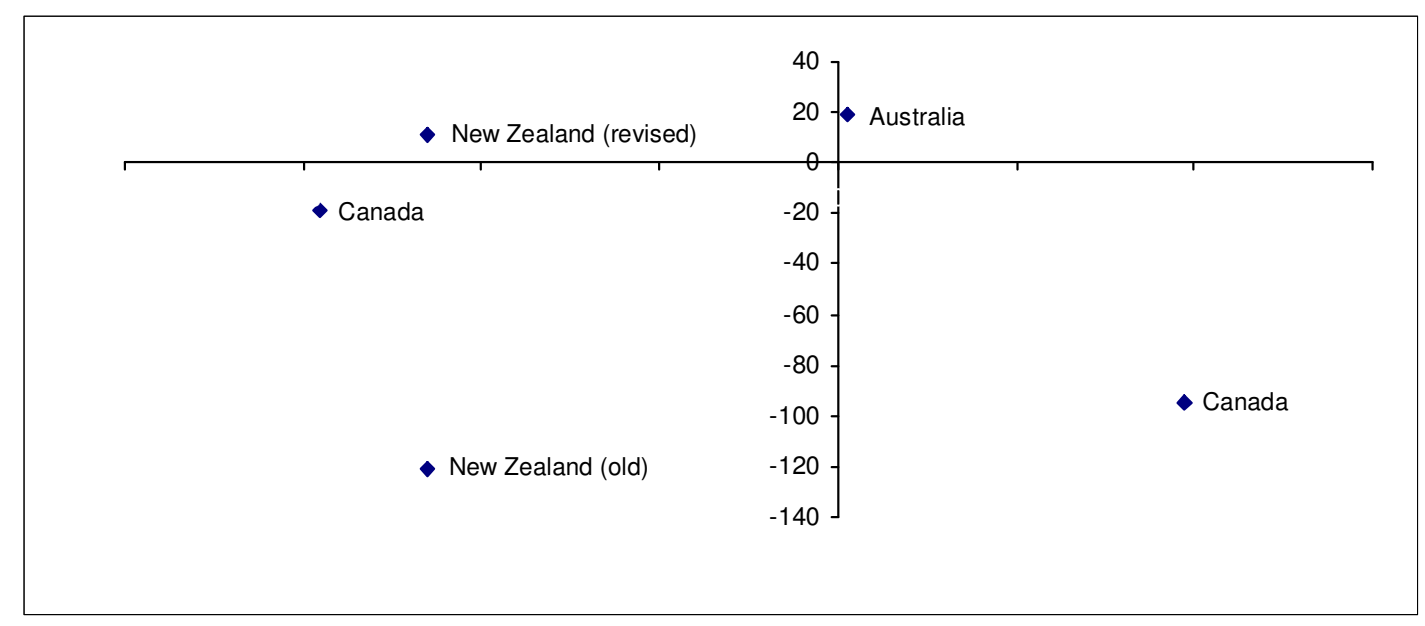

\section{F. Conclusion}

Overall, an evaluation of the performance of the New Zealand's change-in-use rules against tax policy criteria weighs heavily in favour of New Zealand adopting an apportionment approach in place of its former adjustment approach. During the course of the research undertaken on this thesis, the New Zealand Government finally decided to change to an apportionment approach. The comparative research undertaken in this thesis suggests that it has made the right policy choice. However, the empirical evidence in this thesis suggests that high priority should be given to rewriting the New Zealand change-in-use provisions, and indeed the GST Act as a whole, in plain language. 


\section{BIBLIOGRAPHY}

\section{A. Dissertations}

Davis H The New Zealand Goods and Services Tax 1985: An Interpretation, Comparison and Evaluation (VUW, LLM Thesis, 1986).

\section{B. Journal Articles}

Alley C and Bentley D “A Remodelling of Adam Smith's Tax Design Principles” (2005) 20 Australian Tax Forum 579.

Anderson W and Sawyer A "Legislative Complexity - The Need for Appropriate Variables and Some Likely Candidates" (1997) 3 New Zealand Journal of Taxation Law and Policy 3.

Arnold BJ “The April 27, 1989 Federal Budget” (1989) 1 International Tax Notes 41.

AW Schinnour “GST Tips \& Traps” (Spring 1994) Vol 7(1) Canadian Petroleum Tax Journal 1.

Bullot A "GST Update" NZICA 2007 Tax Conference (New Zealand Institute of Chartered Accountants, Auckland 26-27 October 2007).

Choi E "Principles of creditable purpose following HP Mercantile" (2006) 6 Australian GST Journal 117.

Coleman J "GST - The Principal Purpose Test” (2009) 23 Taxation Today 6.

Cooper GS "Legislating Principles as a Remedy for Tax Complexity" (2010) British Tax Review 334.

Cooper GS “Themes and Issues in Tax Simplification” (1993) 10 Australian Tax Forum 417.

Cooper GS and Vann R “Implementing the Goods and Services Tax” (1999) 21 Sydney Law Review 337. 
Dabner J and Burton $\mathrm{M}$ “The Relationship Between Tax Administrators and Tax Practitioners: The Australasian Environment" (2008) 14 New Zealand Journal of Taxation Law and Policy 31.

Dirkis M “Accidents of History - Australia's Residency Rules for Individuals” 3 New Zealand Journal of Taxation Law and Policy (1997) 108.

Dixon A "Risk-Free Return Method - Out of the Frying Pan and Into the Fire" (2003) 9 New Zealand Journal of Taxation Law and Policy 329.

Evans L, Grimes A, Wilkinson B and Teece D "Economic Reform in New Zealand 1984-95: The Pursuit of Efficiency" (1996) 34 Journal of Economic Literature 1,856 .

Greenbaum A "A Goods and Services Tax for Australia : What Can Be Learned from the Canadian Experience?” (1993) 3 Revenue Law Journal 152.

Greenbaum A "The Canadian GST Treatment of Financial Services - What Lessons Are There For Australia" (2000) 10 Revenue Law Journal 24.

Harley GJ, "Dilemmas for GST Tax Policy Designers - Land Transactions" (2007) 13 New Zealand Journal of Taxation Law and Policy 281.

Jackson B and Milliron V "Tax Compliance Research: Findings, Problems and Prospects" 5 Journal of Accounting Literature (1986) 125.

James C, Jeffrey I and Miller H “Apportionment Principles: Part I” (2004) 4(1) Australian GST Journal 24.

James C, Jeffrey I and Miller H “Apportionment Principles: Part II” (2004) 4(2) Australian GST Journal 10.

James J and Cumberland B “Tax Update” (2004) New Zealand Law Journal 247.

James S "VAT/GST: The UK Experience Revisited" (2000) 10 Revenue Law Journal 72. Document available at <http://www.austlii.edu.au/au/journals/RevenueLawJ1/2000/4.pdf> (viewed 20 March 2011). 
James $\mathrm{S}$ and Wallshutzky I "Tax Law Improvement $\mathrm{n}$ Australia and the UK: The Need for a Strategy for Simplification" (1997) 18 Fiscal Studies 445.

James S, Sawyer A and Wallschutzky I "The Complexities of Tax Simplification: Progress in Australia, New Zealand and the United Kingdom" (1998) 14 Australian Tax Forum 29.

Kaplow L "How Tax Complexity and Enforcement Affect the Equity and Efficiency of the Income Tax" (1996) 49 National Tax Journal 135.

Keating M “A Unified Theory of Tax Avoidance” (2007) 4 New Zealand Tax Planning Report 1.

Keating M “Calculation GST Adjustments - The Way Forward?" (2006) 2 New Zealand Tax Planning Report 9.

Keating M “GST Pitfalls for Mortgagee Sales” (2002) 3 New Zealand Tax Planning Report 20.

Keating M "The Principal Purpose Test for the GST Input Tax: Is a Wide Interpretation Justified?" (2010) 16 New Zealand Journal of Taxation Law and Policy 85.

Keith K “The Need to Rewrite Tax Legislation” (1997) 3 New Zealand Journal of Taxation Law and Policy 96.

Ketterman B "VAT? A Look Inside Canada's Experience with Goods and Services Tax” (2006) 8 San Diego International Law Journal 259.

Kraal D “GST Apportionment and Industry Superannuation Funds” (2008) 8 Australian GST Journal 265 at 271. Document available at $<$ www.taxboard.gov.au/content/reviews_and_consultations/legal_framework_for_ad ministration_of_gst/submissions/Kraal\%20submission.pdf> (viewed 20 March 2011).

Krever R "Taming Complexity in Australian Income Tax" (2003) 25(4) Sydney Law Review 467. 
Krever R "Tax Reviews in Australia: Before and After Henry" (2009) British Tax Review 339.

Krongold S "Writing Laws: Making The Easier to Understand" (1992) 24 Ottawa Law Review 495.

Maples AJ "GST Under the Spotlight: The First Comprehensive Review of the Goods and Services Tax Act” (2001) 7 New Zealand Journal of Taxation Law and Policy 42.

Millar R "Cross-Border Services: A Survey of the Issues" (2007) 13 New Zealand Journal of Taxation Law and Policy 302.

Milliron VC "A Behavioural Study of the Meaning and Influence of Tax Complexity" (1985) 23 Journal of Accounting Research 794.

Pallot M "GST and Financial Services - Rating Zero-Rating” (2007) 13 New Zealand Journal of Taxation Law and Policy 267.

Pallot M and Fenwick H "Recent GST Reforms and Proposals in New Zealand" (2000) 10 Revenue Law Journal 88.

Pau C, Sawyer A and Maples A "Complexity of the New Zealand Tax Laws: An Empirical Study" (2007) 22 Australian Tax Forum 59.

Prebble J “Can Income Tax Law be Simplified?" (1996) 2 New Zealand Journal of Taxation Law and Policy 187.

Prebble J "Should Tax Legislation be Written from a Principles and Purpose Point of View or a Precise and Detailed Point of View?" (1998) British Tax Review 112; updated in (2001) 7 New Zealand Journal of Taxation Law and Policy 235.

Prebble J "Why is Tax Law Incomprehensible?” (1994) British Tax Review 380.

Redish J and J Selzer "The Place of Readability Formulas in Technical Communication" (1985) 32 Technical Communication 46.

Richardson G and Smith D "The Readability of Australia's Goods and Services Tax Legislation: An Empirical Investigation” (2002) 30 Federal Law Review 475. 
Richardson ILM “Appellate Court Responsibilities and Tax Avoidance” (1986) 3 Australian Tax Forum 3.

Richardson ILM "Launch of Journals by Sir Ivor Richardson” (1995) 1 New Zealand Journal of Taxation Law and Policy 196.

Richardson ILM “The Concept of Income and Tax Policy" (1990) 4 Canterbury Law Review 187.

Richardson M and Sawyer AJ "A Taxonomy of the Tax Compliance Literature: Further Findings, Problems and Prospects" (2001) 16 Australian Tax Forum 137.

Richardson M and Sawyer AJ "Complexity in the Expression of New Zealand's Tax Laws: An Empirical Analysis" (1998) 14 Australian Tax Forum 325.

RM Bird "The Cost and Complexity of Canada's VAT: The GST in International Perspective" (1994) 8 Tax Notes International 37.

Saw K and Sawyer A "Complexity of New Zealand Income Tax Legislation: The Final Instalment” (2010) 25 Australian Tax Forum 213.

Sawyer A "New Zealand's Tax Rewrite Program - In Pursuit of the (Elusive) Goal of Simplicity" (2007) British Tax Review 405.

Sawyer A "Regulatory Impact Statements and Accountability: Recent Australasian Experience"(2008) 11 Journal of Australian Taxation 42.

Sawyer AJ "Enhancing Compliance Through Improved Readability: Evidence from New Zealand's Rewrite 'Experiment'” (2011) IRS Research Bulletin 225.

Sawyer AJ "RAP(ping) in Taxation: A Review of New Zealand's Rewrite Advisory Panel and its Potential for Adaptation to Other Jurisdictions" (2008) 37 Australian Tax Review 148.

Sawyer AJ "Why Are Taxes So Complex and Who Benefits (1996) Tax Notes International 1,337.

Schinnour AW “GST Tips \& Traps” (Spring 1994) 7(1) Canadian Petroleum Tax Journals 1 . 
Smith D and Richardson G “The Readability of Australia's Taxation Laws and Supplementary Materials: An Empirical Investigation” (1999) 20 Fiscal Studies 321.

Smith M and Taffler R "Readability and Understandability: Different measures of the textual Complexity of Accounting Narrative" (1992) 5 Accounting, Auditing and Accountability Journal 84.

Smyth R and Wilkinson T “Apportionment of GST Supplies” (2002) 5 New Zealand Tax Planning Report 39.

Stevens KC, Stevens KT and Stevens WP “A Response to 'Measuring Readability:

A Comparison of Accounting Textbooks"” (1993) 11 Journal of Accounting

Education 287.

Strader J and Fogiliasso CE “An Investigation of Some Factors Affecting Taxpayer Non-Compliance" (1989) 20 Accounting and Business Research 39.

Tan LM and Sawyer A "A Synopsis of Taxpayer Compliance Studies: Overseas VisVis New Zealand" (2003) 9 New Zealand Journal of Taxation Law and Policy 431.

Tan LM and Tower G "The Readability of Tax Laws: An Empirical Study in New Zealand" (1992) 9 Australian Tax Forum 355.

Terra B "European Proposals for New VAT Rules Regarding the Place of Supply of Services" (2007) 13 New Zealand Journal of Taxation Law and Policy 329.

Thornton G "Drafters, the Nature of Drafting, and the Complexity of Tax Drafting" (1997) 3 New Zealand Journal of Taxation Law and Policy 148.

Tran-Nam B “Tax Compliance Research: An Economic Perspective” (2003) 9 New Zealand Journal of Taxation Law and Policy 455.

Trombitas E "Tax Reform Issue - No Need for a General Anti-Avoidance Provision in the Income Tax Act 1994" (1999) 5 New Zealand Journal of Taxation Law and Policy 121.

Trombitas E "The Role for a General Anti-Avoidance Rule in a GST” (2007) 13 New Zealand Journal of Taxation Law and Policy 396. 
Warren N "The UK Experience with VAT” (1993) 3 Revenue Law Journal 75.

White D “Appellate interpretation of NZ's GST Legislation: An Initial Survey: 1986-2005” (2005) 5 Australian GST Journal 205.

White D "The Serious Research Gap on VAT/GST: A New Zealand Perspective after 20 years of GST" (2007) 18 International VAT Monitor 343.

White D "Twenty Years of GST: The Best Path Forward" (2007) 13 New Zealand Journal of Taxation Law and Policy 357.

White MJ "Why are Taxes so Complex and Who Benefits" (1990) Tax Notes International 341.

Woellner R, Coleman C, McKerchar M, Walpole M and Zetler J "Can Simplified Legal Drafting Reduce the Psychological Costs of Tax Compliance? An Australian Perspective" (2007) British Tax Review 717.

\section{Monographs and Books}

Alley C, et al New Zealand Taxation 2009 (Brookers Ltd, Wellington, 2009).

Bibbey C, O'Neil G and Trombitas E GST: Practical Advice on Getting it Right (Zealand Law Society Seminar, May 2007).

Bird RM and Gendron PP "Sales Tax in Canada: The GST- QST-PST System" (2009) 63 Tax Law Review 517.

Bird RM and Gendron PP The VAT in Developing and Transitional Countries (Cambridge University Press, Cambridge, 2007).

Bird RM Where Do We Go From Here? Alternatives to the GST (KPMG Centre for Government, Toronto, 1994).

Blanchard P "Some Basic Concepts of New Zealand GST" in Krever R and White D (eds) GST in Retrospect and Prospect (Brookers Ltd, Wellington, 2007) 91.

Boadway RW and Kitchen H Canadian Tax Policy (3d ed, Canadian Tax Papers Series No 103, Canadian Tax Foundation, Toronto, 1999). 
Brooks N "An Overview of the Role of the VAT, Fundamental Tax Reform, and a Defence of the Income Tax" in Krever R and White D (eds) GST in Retrospect and Prospect (Brookers Ltd, Wellington, 2007) 597.

Buckle B, et al A Tax System for New Zealand's Future: Report of the VUW Tax Working Group (Centre for Accounting, Governance and Taxation Research, VUW, Wellington, January 2010).

CCH New Zealand Master Tax Guide (CCH New Zealand Ltd, Auckland, 2010).

D’Ascenzo M “The Australian Approach to GST Administration” in Krever R and White D (eds) GST in Retrospect and Prospect (Brookers Ltd, Wellington, 2007) 389.

D'Arcy SK Non-Residents, Cross-Border Transactions, and the GST (CCH Canadian Ltd, Toronto, 2005).

Deloitte NZSA Educational Tax Course - GST (Continuing Education Paper, March 1994).

Dickson I "The New Zealand GST Policy Choice: An Historical and Policy Perspective" in Krever R and White D (eds) GST in Retrospect and Prospect (Brookers Ltd, Wellington, 2007) 45.

Dickson I and White D "Value-Added Tax and Excises: Commentary" in Mirrlees J (ed) Dimensions of Tax Design: The Mirrlees Review (Institute for Fiscal Studies, Oxford University Press, Oxford, 2010). Document available at <www.ifs.org.uk/mirrleesreview/dimensions/ch4.pdf> (viewed 20 March 2011).

Domingue R and Soucy J The Goods and Services Tax: 10 Years Later (Economics Division, 15 June 2000). Document available at $<\mathrm{http}: / / \mathrm{dsp}-$ psd.pwgsc.gc.ca/Collection-R/LoPBdP/BP/prb0003-e.htm> (viewed 20 March 2011).

Douglas R “The New Zealand GST Policy Choice and its Political Implications" in Krever R and White D (eds) GST in Retrospect and Prospect (Brookers Ltd, Wellington, 2007) 3. 
Evans C, Pope J and Hasseldine J (eds) Tax Compliance Costs: A Festschrift for Cedric Sandford (Prospect Media Pty Ltd, Sydney, 2001).

Evans M "The Value Added Tax Treatment of Real Property - An Antipodean Context" in Krever R and White D (eds) GST in Retrospect and Prospect (Brookers Ltd, Wellington, 2007) 243.

Flesch R How to Write Plain English (Harper and Row, New York, 1979).

Green R “Consulting the Public in Developing a GST” in Krever R and White D (eds) GST in Retrospect and Prospect (Brookers Ltd, Wellington, 2007) 13.

Harris G and Mapp W Goods and Services Tax: The Application of the Act (Butterworths Ltd, Wellington, 1986).

Harley GJ "Dilemmas for GST Tax Policy Designers - Land Transactins" in Krever $\mathrm{R}$ and White D (eds) GST in Retrospect and Prospect (Brookers Ltd, Wellington, 2007) 213.

Hayek F Rules and Order: Legislation and Liberty (University of Chicago Press, 1973) vol 1.

Head JG (ed) Australian Tax Reform in Retrospect and Prospect (Australian Tax Research Foundation, 1989).

Hill PR, et al Australian GST Handbook (Law Book Company, 2009).

Institute for Fiscal Studies (eds) Dimensions of Tax Design: The Mirrlees Review (Institute for Fiscal Studies, Oxford University Press, Oxford, 2010). Document available at <www.ifs.org.uk/mirrleesreview/dimensions/ch4.pdf> (viewed 20 March 2011).

Institute for Fiscal Studies and Mirrlees J, et al (eds) Tax by Design: The Mirrlees Review vol 2, ch 2 (draft). Document available at $<w w w . i f s . o r g . u k / m i r r l e e s R e v i e w / d e s i g n>$ (viewed 20 March 2011). Final publication expected in Spring 2011 by Oxford University Press.

Kay JA and King MA The British Tax System ( $5^{\text {th }}$ ed, Clarendon Press, 1990). 
KPMG Australia GST - 5 Years On (2005) 6. Document available at <www.kpmg.com.au/Portals/0/GST-5yearson.pdf> (viewed 20 March 2011).

Krever R and White D (eds) GST in Retrospect and Prospect (Brookers Ltd, Wellington, 2007).

Lamb M, et al Taxation: An Interdisciplinary Approach to Research (Oxford University Press, 2005).

Mayne E Issues Paper (The Board of Taxation, Canberra, 18 July 2008). Document available at

<www.taxboard.gov.au/content/reviews_and_consultations/legal_framework_for_ad ministration_of_gst/issues_paper/downloads/legal_framework_for_administration_o f_gst_issues_paper.pdf> (viewed 20 March 2011).

Mayne E Review of the Legal Framework for the Administration of the Goods and Services Tax: A Report to the Assistant Treasurer and Minister for Competition Policy and Consumer Affairs (The Board of Taxation, Canberra, December 2008). Document available at <www.taxboard.gov.au/content/reviews_and_consultations/legal_framework_for_ad ministration_of_gst/report/downloads/legal_framework_for_administration_of_gst_r eport.pdf> (viewed 20 March 2011).

McKenzie A GST: A Practical Guide (8th ed, CCH Ltd, Auckland, 2008).

McKenzie A New Zealand Goods and Services Tax Guide (looseleaf ed, CCH Ltd, Auckland, 2010).

McKerchar M Complexity, Fairness and Compliance: A Study of Personal Income Taxpayers in Australia (Australian Tax Research Foundation, Sydney, 2003).

McKerchar M The Impact of Complexity Upon Tax Compliance: A Study of Australian Personal Taxpayers (Australian Tax Research Foundation, Sydney, 2003).

Meade JE The Structure and Reform of Direct Taxation: Report of a Committee chaired by Prof JE Meade (The Institute for Fiscal Studies, George Allen \& Unwin, 
London, 1978). Document available from <www.ifs.org.uk/docs/meade.pdf> (viewed 20 March 2011).

Morse G and Williams D Davies: Principles of Tax Law $\left(6^{\text {th }}\right.$ ed, Sweet \& Maxwell Ltd, London 2008).

PWC GST Direct Newsletter (August 2010).

Reimann M and Zimmerman R The Oxford Handbook of Comparative Law (Oxford University Press, 2006).

Robinson AJ Retail Sales Tax in Canada (Canadian Tax Papers Series No 77, Canadian Tax Foundation, Toronto, 1986).

Ross S and Burgess P Income Tax: A Critical Analysis (2nd ed, Law Book Company, Sydney, 1996).

Ryan ULC Value Added Taxation in Canada: GST, HST and QST ( $3^{\text {rd }}$ ed, CCH Canada Ltd, Toronto, 2009).

Sandford C and Hasseldine J The Compliance Costs of Business Taxes in New Zealand (Institute of Policy Studies, Wellington, 1992).

Sandford CT (ed), Tax Compliance Costs Measurement and Policy (Fiscal Publications, Bath, 1995).

Schenk A and Oldman O Value Added Tax: A Comparative Approach (Cambridge University Press, 2007).

Scott C and Davis H The Gist of GST: A Briefing on the Goods and Services Tax (VUW Press, Wellington, 1985).

Sherbaniuk DJ “Tax Simplification - Can Anything Be Done About It?” in 1988 Conference Report: Report of the Proceedings of the $40^{\text {th }}$ Tax Conference (Canadian Tax Foundation, Toronto, 1988) 13.

Sherman D TaxNetPro GST Commentary (looseleaf ed, Carswell Ltd, 2001). 
Smith A An Inquiry into the Nature and Causes of the Wealth of Nations (Methuen \& Co Ltd, London, 1776). Document available at <www.econlib.org/library/Smith/smWN.html> (viewed 20 March 2011).

Smith M "GST and Real Property Transactions in New Zealand: Some Interpretative Issues" in Krever R and White D (eds) GST in Retrospect and Prospect (Brookers Ltd, Wellington, 2007) 277.

Stephens C All about Readability (2000). Document available at: $<$ http://plainlanguage.com/newreadability.html> (viewed 20 March 2011).

Stephens R "Economic and Equity Effects of GST in New Zealand" in Krever R and White D (eds) GST in Retrospect and Prospect (Thomson Reuters, Wellington, 2007) 65 .

Teixeira A, Scott C and Devlin M Inside GST: The Development of Goods and Services Tax (VUW Press, Wellington, 1986).

Tolley's Value Added Tax 2007 ( $1^{\text {st }}$ ed, Lexis Nexis Ltd, London, 2007).

Value Added Tax 2006-07 (Tottel Publishing Ltd, London, 2006).

Veal J, et al Staples Tax Guide (Brookers Ltd, Wellington, 2010).

Victoria University of Wellington Tax Working Group A Tax System for New Zealand's Future: Report of the VUW Tax Working Group (Centre for Accounting, Governance and Taxation Research, VUW, Wellington, January 2010).

Whalley J and Fretz D The Economics of the Goods and Services Tax (Canadian Tax Papers Series No 88, Canadian Tax Foundation, Toronto, 1990).

White D and Dickson I Tax Design Insights from the New Zealand Goods and Services Tax (GST) Model (Centre for Accounting, Governance and Taxation Research, VUW, Wellington, April 2008) Working Paper No 60.

White D and Trombitas E "New Zealand" in Ecker T, Lang M and Lejeune I (eds) The Future of Indirect Taxation: Recent Trends in VAT and GST Systems Around the World - A Global Comparison (2011) forthcoming publication. 


\section{Parliamentary and Departmental Material}

Australia

ATO Annual Report, Section 2.4 (2009) 44. Document available at <www.ato.gov.au/content/downloads/cor00216293AR0809Part02.pdf> (viewed 20 March 2011).

Australian Bankers Association Submission on the Implementation of the Recommendations of the Board of Taxation's Review of the Legal Framework for the Administration of the Goods and Services Tax (22 June 2009) 2. Document available at <www.treasury.gov.au/documents/1578/PDF/Australian_Bankers_Association. pdf> (viewed 20 September 2010).

GST minutes (ATO, March 2010). Document available at $<$ http://ato.gov.au/taxprofessionals/content.asp?doc=/content/00239910.htm\&page= $31 \&$ H31> (viewed 20 October 2010).

Review of Business Taxation A Strong Foundation (23 November 1998). Document available at: <www.rbt.treasury.gov.au/publications/paper1/index.htm> (viewed 20 March 2011).

Treasury Implementation of the Recommendations of the Board of Taxation's Review of the Legal Framework for the Administration of the GST: Treasury Discussion Paper (Commonwealth of Australia, Canberra, July 2009). Document available at <www.treasury.gov.au/documents/1525/PDF/Review_of_the_legal_framework_3. pdf> (viewed 20 March 2011).

Treasury Implementation of the Recommendations of the Board of Taxation's Review of the Legal Framework for the Administration of the GST: Second Consultation Paper (Commonwealth of Australia, September 2009). Document available at <www.treasury.gov.au/documents/1613/PDF/Discussion_Paper_20090911.pdf> (viewed 20 September 2010).

Treasury, Reform of the Australian Tax System: Draft White Paper (AGPS, Canberra, 1985). 


\section{Canada}

Canada Revenue Agency Annual Report (2007-08).

Canada Revenue Agency Annual Report (2008-09).

Canada Revenue Agency Annual Report (2009-10).

Canada Revenue Agency GST Memoranda (New Series) ch 3.1.

Canada Revenue Agency GST Memorandum (New Series) ch 8.1.

Canada Revenue Agency GST Memorandum (New Series) ch 8.2.

Canada Revenue Agency GST Memoranda (New Series) ch 19.1.

Canada Revenue Agency GST Memoranda (New Series) ch 19.4.

Canada Revenue Agency GST Memoranda (New Series) ch 19.4.2.

Canada Revenue Agency GST Memorandum (Old Series) ch 400

Canada Revenue Agency GST Memorandum (Old Series) ch 700.

Department of Finance The Fiscal Monitor (March 2010) 2. Document available at <www.fin.gc.ca/fiscmon-revfin/pdf/2010-03-eng.pdf> (viewed 20 November 2010).

New Zealand

Birch B and Creech W Core Provisions: Rewriting the Income Tax Act (IRD, Wellington, 1985).

Birch B and Creech W Rewriting the Income Tax Act 1994 - Objectives, Process, Guidelines: A Discussion Document (IRD, Wellington, December 1994).

Birch B and English B GST: A Review - A Government Discussion Document (Policy Advice Division, IRD, Wellington, March 1999). Document available at <http://taxpolicy.ird.govt.nz/publications/1999-dd-gst-review/overview> (viewed 20 March 2011). 
Brash D Report of the Advisory Panel on the Goods and Services Tax (Wellington, June 1985).

Caygill D Consultative Document on Tax Simplification (IRD, Wellington, December 1989).

Caygill D GST Legislative Audit - Miscellaneous Issues (IRD, Wellington, September 1990).

Caygill D Tax Simplification: Final Report of the Consultative Committee (IRD, Wellington, September 1990).

Caygill D Tax Simplification: Interim Report of the Consultative Committee (IRD, Wellington, March 1990).

Caygill D The Goods and Services Tax Act 1985: Legislative Audit (IRD, Wellington, February 1989).

Corporate Taxpayers Group Submissions on the Taxation (GST and Remedial Matters) Bill (9 September 2010) at [4.6]. Document available at $<$ www.parliament.nz/NR/rdonlyres/9792EC07-61 A5-4E8E-9022D7816E51CB91/159146/49SCFE_EVI_00DBHOH_BILL10121_1_A67981_Corpor ateTax.pdf> (viewed 20 March 2011).

Cullen M Rewriting The Income Tax Act 1994 (IRD, Wellington, 2001).

De Cleene TA Goods and Services Tax Bill - Finance and Expenditure Committee Report of 5 December 1985 (2 August 1985 to 12 December 1985) XI Appendix to the Journals I.24.

Douglas R “Goods and Services Tax Bill - Introduction” (1985) 465 NZPD 6,558.

Douglas R “Goods and Services Tax Bill - Second Reading” (1985) 468 NZPD 8,412 .

Douglas R “Goods and Services Tax Bill - Third Reading” (1985) 468 NZPD 8,463. Douglas R Proposals for the Administration of the Goods and Services Tax (Wellington, March 1985). 
Dunne P "Taxation (GST and Remedial Matters) Bill - First Reading” (19 August 2010) 665 NZPD 13,277. Document available at <www.parliament.nz/enNZ/PB/Debates/Debates/6/5/e/49HansD_20100818_00001365-Taxation-GST-andRemedial-Matters-Bill-First.htm> (viewed 20 March 2011).

Dunne P "Taxation (GST and Remedial Matters) Bill - Second Reading” (24 November 2010) 669 NZPD 15,769. Document available at $<$ www.parliament.nz/enNZ/PB/Debates/Debates/1/1/0/49HansD_20101124_00001004-Taxation-GST-andRemedial-Matters-Bill-Second.htm> (viewed 20 March 2011).

Dunne P GST: A Review (IRD, Wellington, March 1999).

Dunne P GST: Accounting for Land and Other High-Value Assets - A Government Discussion Document (IRD, Wellington, November 2009). Document available at $<$ http://taxpolicy.ird.govt.nz/publications/2009-dd-gst/overview> (viewed 20 March 2011).

Dunne P Taxation (GST and Remedial Matters) Bill: Commentary on the Bill (IRD, Wellington, August 2010). Document available at <http://taxpolicy.ird.govt.nz/sites/default/files/2010-commentary-gstrm.pdf> (viewed 20 March 2011).

Goods and Services Tax Bill 1985 Second Report on Goods and Services Tax Bill to the Finance and Expenditure Committee (IRD, Wellington, 17 November 1985) (HO433).

Graham D Legislative Change: Guidelines on Process and Content (revised edition, Legislation Advisory Committee, Wellington, December 1991).

Inland Revenue Department Rewriting the Income Tax Act: Exposure Draft: General Commentary (Policy Advice Division, Wellington, 2001).

Inland Revenue Department Tax Policy Report, PAD 2010/255 (7 October 2010).

KPMG New Zealand Submissions on the Taxation (GST and Remedial Matters) Bill (9 September 2010) 2. Document available at <www.parliament.nz/en- 
NZ/PB/SC/Documents/Evidence/?Custom=00DBHOH_BILL10121_1> (viewed 20 March 2011).

Latham C Regulatory Impact Statement - Taxation (GST and Remedial Matters) Bill (IRD, Wellington, 21 June 2010). Document available at <http://taxpolicy.ird.govt.nz/sites/default/files/2010-ris-gstrm-bill-1-gst.pdf> (viewed 20 March 2011).

Law Commission Legislation Manual: Structure and Style (NZLC R35, May 1996). Law Commission The Format of Legislation (NZLC R27, December 1993).

McLeod R Tax Review - Final Report (IRD, Wellington, October 2001).

McLeod R Tax Review - Issues Paper (IRD, Wellington, June 2001).

NZICA Submissions on the Taxation (GST and Remedial Matters) Bill (10

September 2010) 5. Document available at

<www.parliament.nz/NR/rdonlyres/85113B1E-46F9-40E1-84B4-

97B8FA15C81F/159160/49SCFE_EVI_00DBHOH_BILL10121_1_A68095_NewZ ealandIn.pdf $>$ (viewed on 20 March 2011).

Pallot M Cabinet Paper: GST Issues for the July 1010 Bill PAD 2010/137 (21 June 2010).Obtained under Official Information Act 1982. Request made to Manager, Policy Advice Division, Inland Revenue Department.

Pallot M Tax Policy Report to Minister of Revenue, PAD2009/192 (8 October 2009). Obtained under Official Information Act 1982. Request made to Manager, Policy Advice Division, Inland Revenue Department.

Pallot M Tax Policy Report to Minister of Revenue, PAD2009/202 (20 October 2009). Obtained under Official Information Act 1982. Request made to Manager, Policy Advice Division, Inland Revenue Department.

Peat Marwick Submissions on the Goods and Services Tax Bill 1985 (25 September 1985) (Finance and Expenditure Committee file number FE/85/307, 262W). 
Policy Advice Division and Treasury Options for Strengthening GST Neutrality in Business-to-Business Transactions: An Officials' Issues Paper (IRD, Wellington, June 2008). Document available at <http://taxpolicy.ird.govt.nz/publications/2008ip-gst-b2b-neutrality/overview> (viewed 20 March 2011).

PricewaterhouseCoopers Submissions on the Taxation (GST and Remedial Matters) Bill 2010 (undated, considered on 15 September 2010). Document available at <www.parliament.nz/NR/rdonlyres/65E97BA6-4B22-409D-ADF70F26C2ABE70C/159164/49SCFE_EVI_00DBHOH_BILL10121_1_A67947_Price waterho.pdf> (viewed 20 March 2011).

Taxation (GST and Remedial Matters) Bill 2010 (182-2) Officials' Report to the Finance and Expenditure Committee on Submissions on the Taxation (GST and Remedial Matters) Bill (IRD, Wellington, October 2010). Document available at $<$ http://taxpolicy.ird.govt.nz/sites/default/files/2010-or-grm.pdf> (viewed 20 March 2011).

Waugh J Tax Simplification: Final Report of the Consultative Committee (IRD, Wellington, 1990).

Working Party on the Reorganisation of the Income Tax Act 1976 Second Report of the Working Party (Wellington, September 1993). 
APPENDIX

A. Goods and Services Tax Act Readability Table 

Table: Readability of New Zealand GST Act 1985 (as at 19 December 2010)*

\begin{tabular}{|c|c|c|c|c|c|c|c|c|c|c|c|c|c|c|c|c|c|}
\hline & Sections & Words & Paras & Sentence & WPS & Syllables & SyPS & $F R E$ & $F-K G L$ & $G-F o g$ & C-Liau & SMOG & Auto & $\begin{array}{c}M S \\
F R E \\
\end{array}$ & $\begin{array}{c}M S \\
F-K G L \\
\end{array}$ & $\begin{array}{c}M S \\
\text { Words }\end{array}$ & $\begin{array}{c}M S \\
W P S\end{array}$ \\
\hline & 1 & 60 & 3 & 3 & 20 & 78 & 1.3 & 76.6 & 7.6 & 8.7 & 5.2 & 6 & 5.4 & 55.4 & 10.5 & 60 & 20 \\
\hline \multirow[t]{9}{*}{ Part 1} & 2 & & & & & & & & & & & & & & & & \\
\hline & $2 \mathrm{~A}$ & 741 & 38 & 7 & 105.86 & 1162 & 1.57 & -33.3 & 44.2 & 48 & 8.4 & 22.6 & 50.8 & 53.5 & 12.6 & 734 & 27.7 \\
\hline & 3 & 1245 & 47 & 8 & 155.63 & 2159 & 1.73 & -97.8 & 65.6 & 69.7 & 11.9 & 32 & 78.6 & 33.2 & 17 & 1241 & 34 \\
\hline & $3 \mathrm{~A}$ & 652 & 34 & 6 & 108.67 & 968 & 1.48 & -29.1 & 44.3 & 47.4 & 8.4 & 18.7 & 52.2 & 53.6 & 12.2 & 649 & 26.1 \\
\hline & 4 & 342 & 7 & 5 & 68.4 & 551 & 1.61 & 1.1 & 30.1 & 32.4 & 12.4 & 17.2 & 35.3 & 13.4 & 25.1 & 341 & 55.4 \\
\hline & 5 & 3233 & 92 & 42 & 76.98 & 4865 & 1.5 & 1.4 & 32.2 & 35 & 9.5 & 17.5 & 37.3 & 28 & 20.6 & 3223 & 45.3 \\
\hline & $5 \mathrm{~B}$ & 72 & 1 & 1 & 72 & 98 & 1.36 & 18.6 & 28.6 & 32.1 & 3.4 & 14.1 & 29.9 & 8.8 & 29.4 & 70 & 70 \\
\hline & 6 & 380 & 15 & 3 & 126.67 & 679 & 1.79 & -72.9 & 54.9 & 57.7 & 11.7 & 31 & 63.9 & 26 & 15.4 & 376 & 23.3 \\
\hline & 7 & 6 & 1 & 1 & 6 & 6 & 1 & 116.1 & -1.4 & 2.4 & 7.7 & 1.8 & 0.4 & 100 & 0 & 6 & 6 \\
\hline \multirow[t]{11}{*}{ Part 2} & 8 & 699 & 23 & 11 & 63.55 & 1059 & 1.52 & 14.2 & 27.1 & 30.5 & 10 & 16.6 & 31 & 27.5 & 19.5 & 698 & 40.7 \\
\hline & $8 \mathrm{~A}$ & 145 & 4 & 4 & 36.25 & 242 & 1.67 & 28.8 & 18.2 & 20.6 & 13 & 13.8 & 19.7 & 26.7 & 18.4 & 143 & 35.7 \\
\hline & 9 & 1212 & 33 & 8 & 151.5 & 1783 & 1.47 & -71.4 & 60.9 & 65.3 & 9.9 & 24.8 & 74.9 & 44.3 & 16.8 & 1211 & 29.5 \\
\hline & 10 & 2245 & 72 & 31 & 72.42 & 3332 & 1.48 & 7.8 & 30.2 & 32.7 & 8.8 & 15.5 & 34.4 & 37.7 & 17.3 & 2235 & 37.6 \\
\hline & 11 & 1805 & 73 & 11 & 164.09 & 2686 & 1.49 & -85.6 & 66 & 70.1 & 9 & 25.8 & 80.4 & 44.1 & 16.7 & 1801 & 38.8 \\
\hline & $11 \mathrm{~A}$ & 1540 & 58 & 6 & 256.67 & 2324 & 1.51 & -181.4 & 102.3 & 107.8 & 10.4 & 33.7 & 127.8 & 45.9 & 14.4 & 1531 & 30.5 \\
\hline & $11 \mathrm{AB}$ & 76 & 3 & 1 & 76 & 140 & 1.84 & -26.1 & 35.8 & 37.8 & 14.5 & 21.5 & 40.8 & 3.4 & 20.4 & 75 & 31 \\
\hline & 11B & 197 & 6 & 4 & 49.25 & 317 & 1.61 & 20.7 & 22.6 & 25.4 & 9.8 & 16 & 23.7 & 25.1 & 20.6 & 197 & 43.7 \\
\hline & $11 \mathrm{C}$ & 338 & 12 & 7 & 48.29 & 537 & 1.59 & 23.4 & 22 & 25.3 & 10.7 & 15.5 & 23.9 & 36.5 & 16.8 & 337 & 34.8 \\
\hline & 12 & 1033 & 34 & 8 & 129.13 & 1538 & 1.49 & -50.2 & 52.3 & 55.5 & 8.7 & 21.7 & 62.7 & 41.3 & 15 & 1032 & 30.5 \\
\hline & 14 & 565 & 27 & 4 & 141.25 & 869 & 1.54 & -66.7 & 57.6 & 61.7 & 9.3 & 25 & 69.3 & 40.8 & 17 & 562 & 38.2 \\
\hline \multirow[t]{9}{*}{ Part 3} & 15 & 279 & 16 & 5 & 55.8 & 426 & 1.53 & 21 & 24.2 & 28.8 & 6.7 & 18 & 24.5 & 49 & 11.5 & 275 & 20.8 \\
\hline & $15 \mathrm{~B}$ & 328 & 13 & 6 & 54.67 & 499 & 1.52 & 22.6 & 23.7 & 26.5 & 9.1 & 15.2 & 25.8 & 41.6 & 14.9 & 327 & 30.1 \\
\hline & $15 \mathrm{C}$ & 292 & 13 & 7 & 41.71 & 462 & 1.58 & 30.6 & 19.3 & 2.2 & 8.1 & 15.4 & 18.5 & 43.8 & 14.2 & 292 & 28.7 \\
\hline & $15 \mathrm{D}$ & 151 & 6 & 4 & 37.75 & 230 & 1.52 & 39.7 & 17.1 & 20.1 & 8.8 & 13.2 & 17.1 & 42.4 & 14.5 & 150 & 29 \\
\hline & $15 \mathrm{E}$ & 130 & 6 & 4 & 32.5 & 199 & 1.53 & 44.3 & 15.1 & 18.5 & 7.8 & 12.9 & 13.7 & 49.9 & 12.6 & 130 & 25.5 \\
\hline & 16 & 254 & 12 & 6 & 42.33 & 380 & 1.5 & 37.3 & 18.6 & 22.8 & 7.1 & 15.4 & 18.1 & 50.4 & 12.2 & 253 & 24.1 \\
\hline & 17 & 355 & 17 & 4 & 88.75 & 490 & 1.38 & 0 & 35.3 & 38.1 & 8.5 & 15.5 & 42.4 & 58 & 13.1 & 355 & 32 \\
\hline & 18 & 62 & 1 & 1 & 62 & 96 & 1.55 & 12.9 & 26.9 & 26.7 & 11 & 14.1 & 31 & 6 & 27.8 & 62 & 62 \\
\hline & 19 & 299 & 12 & 4 & 74.75 & 495 & 1.66 & -9.1 & 33.1 & 35.9 & 11.3 & 21.1 & 37.7 & 46.4 & 11.1 & 299 & 17.5 \\
\hline
\end{tabular}




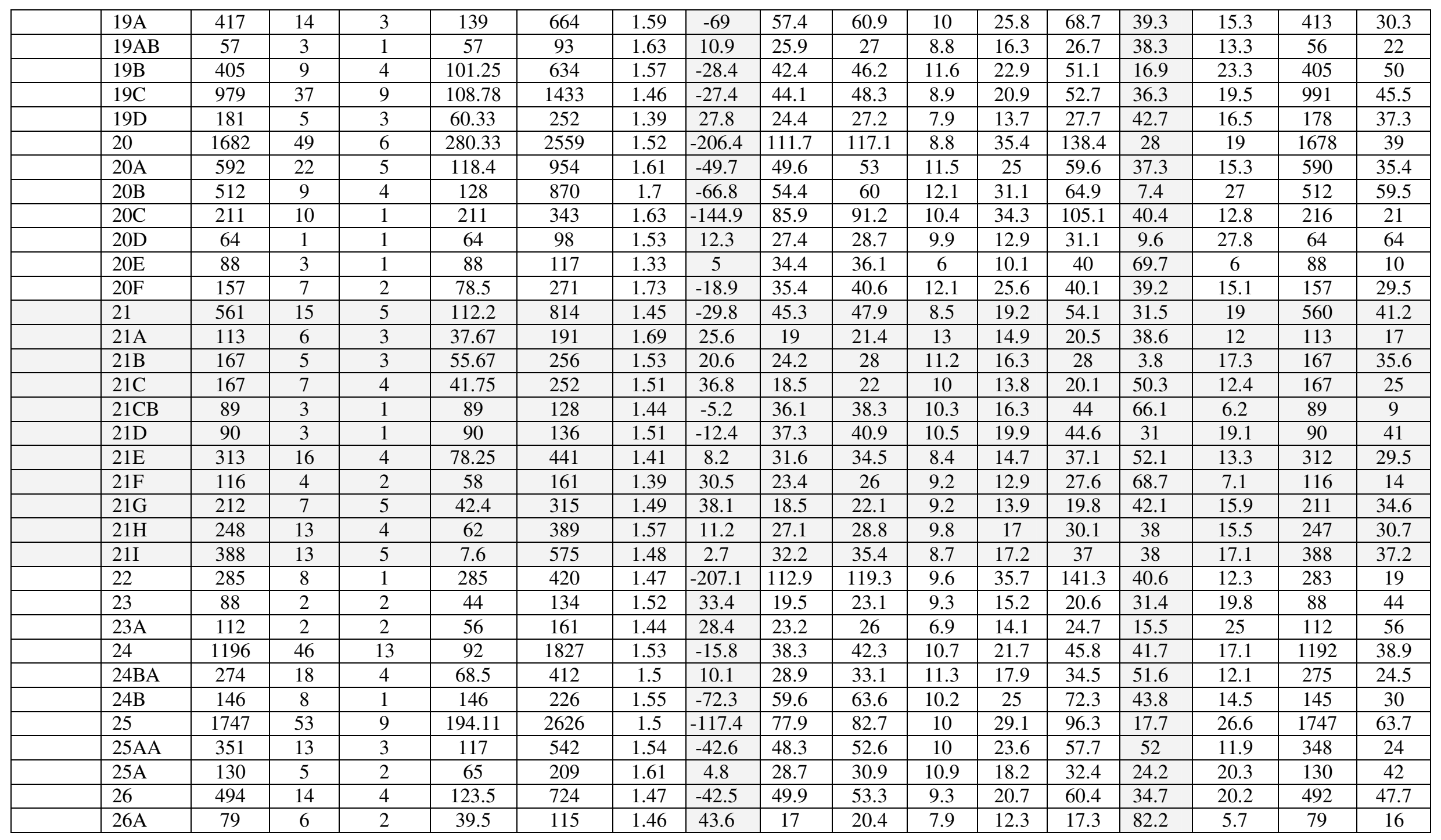




\begin{tabular}{|c|c|c|c|c|c|c|c|c|c|c|c|c|c|c|c|c|c|}
\hline Part 6 & 42 & 604 & 15 & 5 & 120.8 & 1020 & 1.69 & -58.6 & 51.4 & 54.3 & 11.3 & 26.4 & 60.7 & 24.3 & 16.7 & 604 & 27.6 \\
\hline & 43 & 1574 & 43 & 11 & 143.09 & 2394 & 1.52 & -67.1 & 58.2 & 62 & 9.8 & 24.9 & 70.6 & 23.9 & 22.2 & 1574 & 54.3 \\
\hline \multirow[t]{4}{*}{ Part 7} & 45 & 355 & 16 & 4 & 88.75 & 528 & 1.49 & -9.1 & 36.6 & 39.4 & 8.1 & 19.5 & 42.1 & 58 & 11.4 & 355 & 25.2 \\
\hline & 46 & 530 & 27 & 7 & 75.71 & 888 & 1.68 & -11.8 & 33.7 & 35.3 & 11.3 & 20.9 & 38.1 & 36.6 & 11.9 & 530 & 15.1 \\
\hline & 47 & 160 & 4 & 1 & 160 & 286 & 1.79 & -106.8 & 67.9 & 72.3 & 12.3 & 35.3 & 81 & 0 & 32.6 & 160 & 69 \\
\hline & $48 \mathrm{~A}$ & 265 & 15 & 3 & 88.33 & 404 & 1.52 & -11.8 & 36.8 & 40.3 & 9 & 19.6 & 42.5 & 43.8 & 15.6 & 265 & 34.3 \\
\hline \multirow[t]{5}{*}{ Part 8} & 51 & 847 & 20 & 7 & 121 & 1368 & 1.62 & -52.6 & 50.7 & 54.2 & 11.2 & 26.3 & 60.7 & 9 & 26.1 & 839 & 56.8 \\
\hline & 51B & 206 & 8 & 3 & 68.67 & 319 & 1.55 & 6.1 & 29.5 & 32.1 & 9.7 & 17.5 & 33.3 & 43.4 & 14.8 & 206 & 31 \\
\hline & 52 & 506 & 10 & 7 & 72.29 & 841 & 1.66 & -7.1 & 32.2 & 35.7 & 11.9 & 22.3 & 36.8 & 8.8 & 25.7 & 505 & 55.2 \\
\hline & 53 & 278 & 11 & 2 & 139 & 36 & 1.57 & -66.9 & 57.1 & 61.4 & 10.2 & 26.9 & 68.9 & 62.1 & 10.3 & 278 & 23 \\
\hline & 54 & 61 & 1 & 1 & 61 & 99 & 1.62 & 7.6 & 27.4 & 30.3 & 11.9 & 18.2 & 31.2 & 7.6 & 27.3 & 61 & 61 \\
\hline \multirow[t]{9}{*}{ Part 9} & 55 & 1190 & 44 & 10 & 119 & 1805 & 1.52 & -42.3 & 48.7 & 53.1 & 9.4 & 24.2 & 58.2 & 38.7 & 17 & 1189 & 37.2 \\
\hline & 56 & 410 & 6 & 6 & 68.33 & 679 & 1.66 & -2.6 & 30.6 & 35 & 12.6 & 21.6 & 35.5 & 0 & 30.6 & 410 & 68.3 \\
\hline & $56 \mathrm{~B}$ & 145 & 8 & 4 & 36.25 & 216 & 1.49 & 44 & 16.1 & 19.2 & 8.7 & 11.9 & 16.3 & 61.4 & 9.8 & 143 & 20.7 \\
\hline & 57 & 613 & 16 & 7 & 87.57 & 944 & 1.54 & -12.3 & 36.7 & 40.1 & 9.5 & 19.8 & 42.6 & 35.8 & 17.5 & 613 & 37.5 \\
\hline & 58 & 488 & 12 & 7 & 69.71 & 878 & 1.8 & -16.1 & 32.8 & 36.9 & 11.9 & 23.2 & 35.6 & 0 & 26.5 & 488 & 53.5 \\
\hline & 59 & 186 & 5 & 2 & 93 & 290 & 1.56 & -19.5 & 39.1 & 42.6 & 9 & 21.5 & 44.9 & 13.3 & 26.2 & 186 & 60 \\
\hline & 60 & 769 & 20 & 7 & 109.86 & 1140 & 1.48 & -30.1 & 44.7 & 48.8 & 9.6 & 21.6 & 53.8 & 39.8 & 17.2 & 767 & 38.4 \\
\hline & 61 & 32 & 1 & 1 & 32 & 45 & 1.41 & 55.4 & 13.5 & 15.3 & 8.7 & 8.3 & 14.1 & 42.1 & 15.3 & 32 & 32 \\
\hline & $61 \mathrm{~A}$ & 483 & 30 & 6 & 80.5 & 836 & 1.73 & -21.3 & 36.2 & 39.9 & 11.6 & 22.9 & 40.8 & 29 & 16.8 & 483 & 30.6 \\
\hline \multirow[t]{12}{*}{ Part 11} & 75 & 495 & 13 & 5 & 99 & 814 & 1.64 & -32.8 & 42.4 & 45.8 & 12.7 & 24.2 & 50.9 & 25.4 & 18.6 & 495 & 35.8 \\
\hline & 76 & 594 & 25 & 8 & 74.25 & 971 & 1.63 & -6.8 & 32.7 & 35.7 & 10.1 & 20.1 & 36.4 & 28.6 & 18.9 & 594 & 39 \\
\hline & 77 & 56 & 1 & 1 & 56 & 78 & 1.39 & 32.2 & 22.7 & 24.5 & 9 & 10.1 & 26.4 & 30.6 & 22.8 & 56 & 56 \\
\hline & 78 & 811 & 16 & 6 & 135.17 & 1220 & 1.5 & -57.6 & 54.9 & 58.7 & 10.2 & 23.6 & 66.9 & 27.2 & 20.3 & 810 & 43.8 \\
\hline & $78 \mathrm{AA}$ & 1308 & 58 & 14 & 93.43 & 1896 & 1.45 & -10.6 & 38 & 41.3 & 0.1 & 17.8 & 45.2 & 51 & 13.2 & 1306 & 28.7 \\
\hline & $78 \mathrm{~A}$ & 491 & 12 & 5 & 98.2 & 717 & 1.46 & -16.4 & 39.9 & 43.8 & 9.4 & 20.5 & 47.9 & 47.1 & 16.9 & 491 & 41.2 \\
\hline & $78 \mathrm{~B}$ & 1678 & 60 & 10 & 167.8 & 2477 & 1.48 & -88.4 & 67.3 & 71.2 & 9.1 & 24.4 & 82.4 & 43.3 & 15.2 & 1678 & 32.4 \\
\hline & $78 \mathrm{BA}$ & 501 & 22 & 5 & 100.2 & 756 & 1.51 & -22.5 & 41.3 & 44.7 & 9.8 & 19.7 & 49.1 & 39.7 & 15.3 & 501 & 30.6 \\
\hline & $78 \mathrm{C}$ & 548 & 15 & 2 & 292 & 866 & 1.48 & -215 & 115.8 & 120.7 & 8.7 & 31.6 & 144.2 & 0 & 3.1 & 584 & 79.5 \\
\hline & $78 \mathrm{D}$ & 165 & 3 & 1 & 165 & 282 & 1.71 & -105.2 & 68.9 & 75 & 11.9 & 34.8 & 83.2 & 0 & 30.7 & 165 & 67 \\
\hline & $78 \mathrm{E}$ & 163 & 5 & 1 & 163 & 246 & 1.51 & -86.3 & 65.8 & 70.1 & 9.5 & 25.6 & 80.3 & 24.9 & 19.9 & 162 & 41 \\
\hline & 79 & 140 & 7 & 2 & 70 & 240 & 1.71 & -9.2 & 31.9 & 35.4 & 13.7 & 2.2 & 37.2 & 37.8 & 15.3 & 139 & 29.5 \\
\hline \multirow[t]{2}{*}{ Part 12} & 84 & 1164 & 29 & 6 & 194 & 1699 & 1.46 & -113.6 & 77.3 & 81.7 & 8.8 & 27.8 & 95.2 & 29 & 21.3 & 1162 & 48.8 \\
\hline & $84 \mathrm{~B}$ & 335 & 10 & 4 & 83.75 & 471 & 1.41 & 2.9 & 33.7 & 34.8 & 7.2 & 15 & 38.8 & 28 & 21.4 & 330 & 48.7 \\
\hline
\end{tabular}




\begin{tabular}{|c|c|c|c|c|c|c|c|c|c|c|c|c|c|c|c|c|c|}
\hline & 85 & 382 & 10 & 3 & 127.33 & 489 & 1.54 & -52.9 & 52.3 & 55.5 & 10.6 & 22.4 & 63.3 & 32 & 19.7 & 379 & 44 \\
\hline & 86 & 681 & 7 & 2 & 340.5 & 1016 & 1.49 & -265 & 134.8 & 140.2 & 9 & 36.2 & 168.7 & 0 & 38.2 & 678 & 91.5 \\
\hline Average & & 511.73 & 17.37 & 5.13 & 99.53 & 780.46 & 1.54 & -25.08 & 41.66 & 44.87 & 9.71 & 20.24 & 49.16 & 34.91 & 17.39 & 510.93 & 37.58 \\
\hline Median & & 338 & 12 & 4 & 87.57 & 495 & 1.52 & -11.8 & 35.8 & 38.3 & 9.7 & 19.8 & 40.8 & 37.8 & 16.8 & 337 & 35.4 \\
\hline Std Dev & & 541.72 & 17.96 & 5.42 & 61.09 & 817.85 & 0.12 & 62.88 & 23.71 & 24.71 & 2.02 & 7.03 & 30.34 & 18.66 & 6.37 & 540.54 & 15.78 \\
\hline
\end{tabular}

* Prior to assent of Taxation (GST and Remedial Matters) Act 2010. 
